$\leadsto$ Editora Poisson

\title{
Tópicos em Gestão da Produção
}

$\overrightarrow{0}$

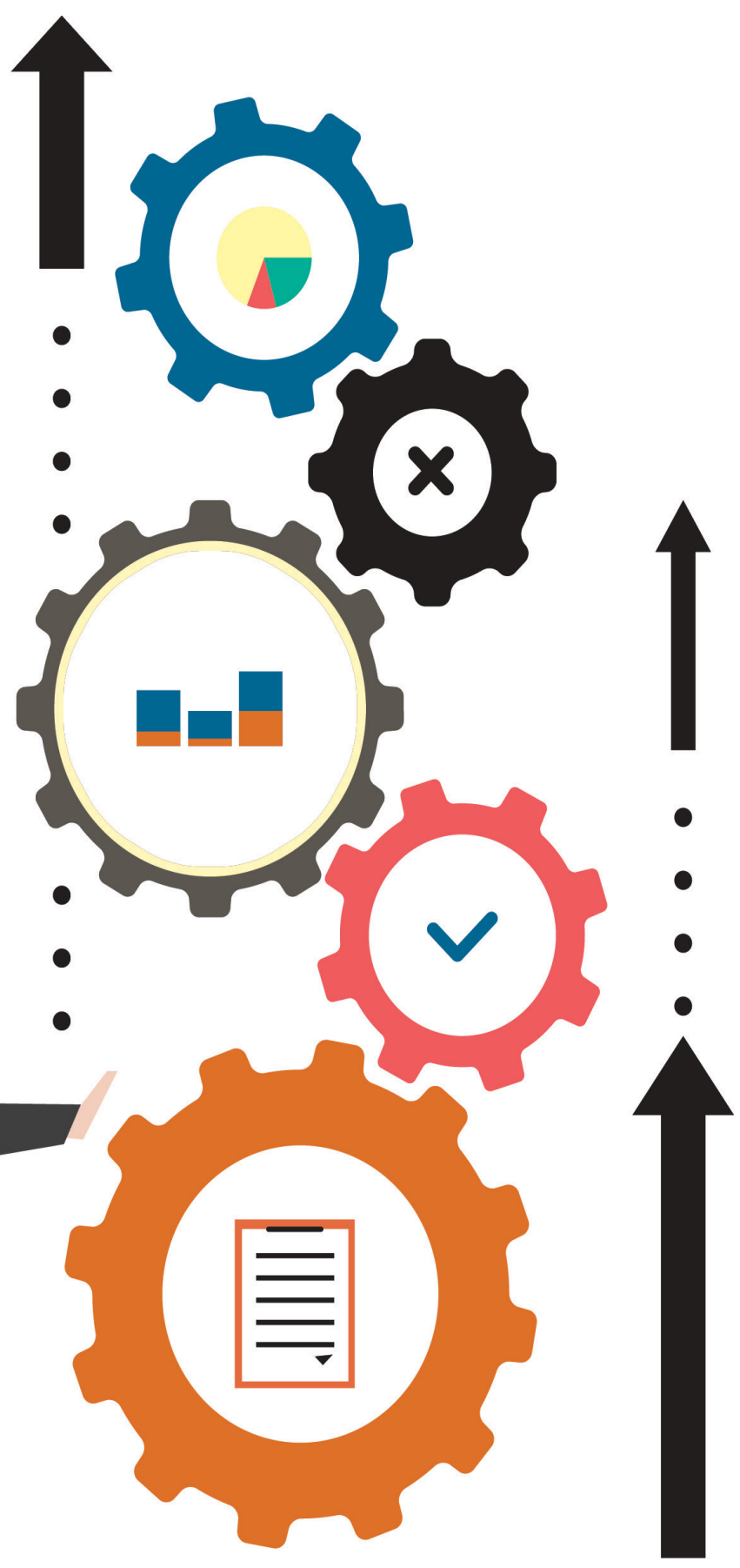

Marcelo Ruy

(Organizador) 
Marcelo Ruy

(organizador)

\section{Tópicos em Gestão da Produção Volume I}

1a Edição

Belo Horizonte

Poisson

2017 


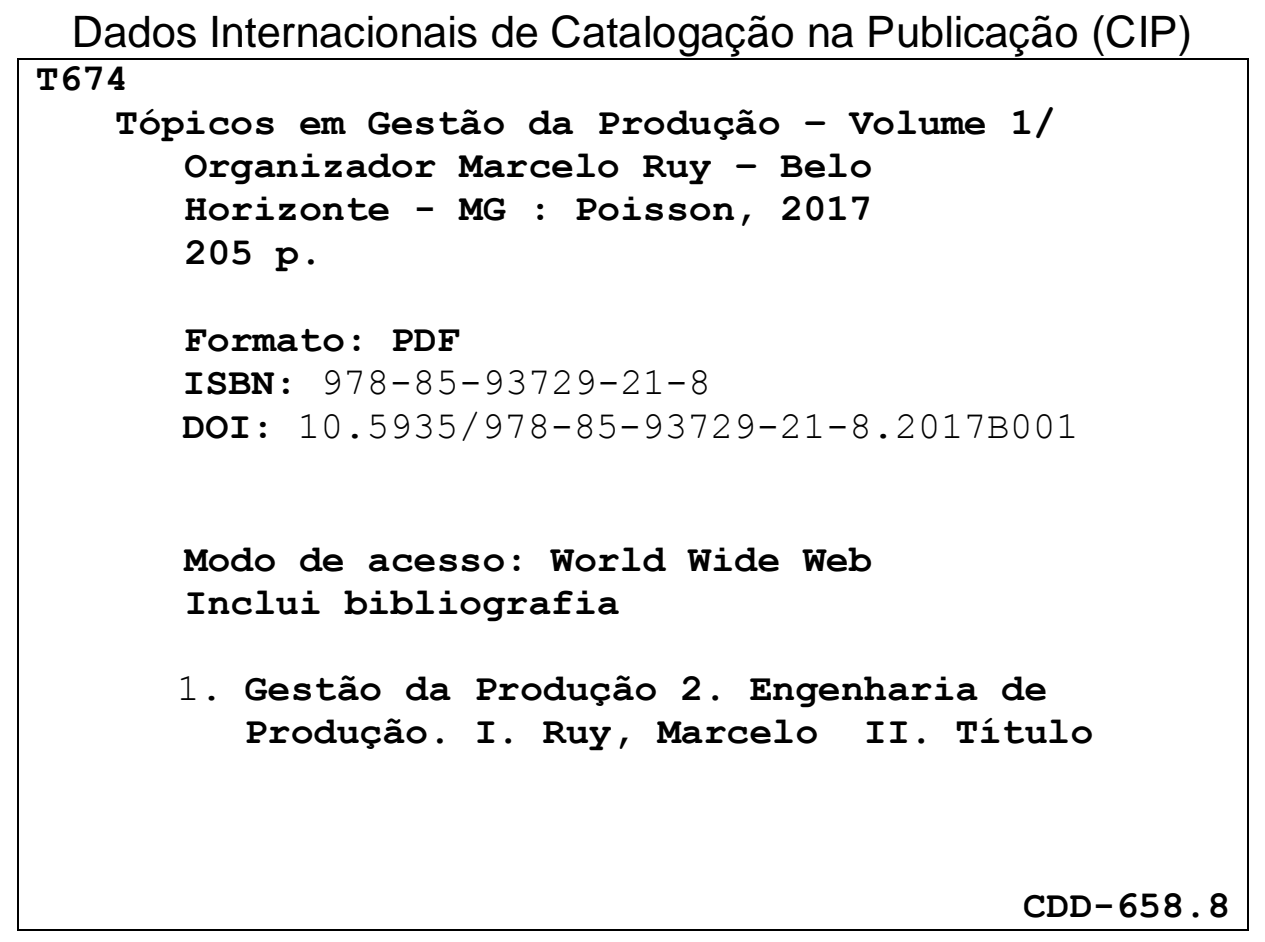

O conteúdo dos artigos e seus dados em sua forma, correção e confiabilidade são de responsabilidade exclusiva dos seus respectivos autores.

www.poisson.com.br

contato@poisson.com.br 


\section{Apresentação}

A Administração da Produção é responsável por gerenciar os recursos que criam e entregam produtos e serviços aos clientes, sendo, por consequência, de importância central a qualquer organização. Ela engloba o projeto, a operação e o controle dos sistemas responsáveis pelo uso de matérias primas, informações, recursos humanos, equipamentos e instalações. Tal definição evidencia de maneira inequívoca a variedade e amplitude de temas abordados pela Administração da Produção.

Dessa forma, a coletânea de artigos constante neste volume apresenta uma série de estudos que cobre uma gama de áreas da Administração da Produção, incluindo Simulação de Processos Produtivos, Gestão Econômica, Tecnologia da Informação, Serviços Logísticos e Planejamento e Controle da Produção. A Pesquisa Operacional está representada por dois estudos de seleção de fornecedores por métodos quantitativos e um trabalho de Programação Linear. Por fim, a Engenharia do Trabalho se faz presente por meio dos temas Higiene e Segurança no Trabalho, Análise e Prevenção de Riscos, Ergonomia, Motivação e Qualidade de Vida no Trabalho.

Com abordagem objetiva, o livro se mostra relevante para estudantes de graduação, pós-graduação, profissionais atuantes no mercado e professores, por apresentar temáticas e metodologias diversas, bem como situações brasileiras reais.

Aos autores, agradecemos pela confiança e cordial parceria. E uma ótima leitura a todos!

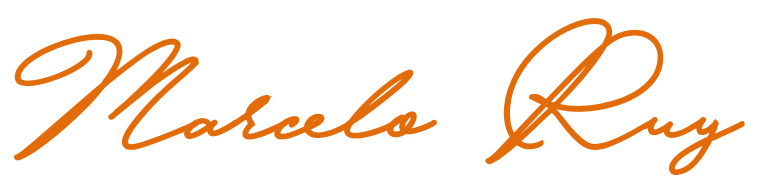




\section{SUMÁRIO}

Capítulo 1 - Jogo educacional aplicável à Engenharia de Produção: desenvolvimento e percepções do público alvo

(Alessandra Lopes Carvalho, Marcelo de Souza Nery)

Capítulo 2 - Análise das práticas de gestão de segurança e saúde no

trabalho em uma micro empresa do setor industrial

(Horrany Leite de Carvalho, Luis Felipe Cândido)

Capítulo 3 - Análise do processo de trabalho na lapidação de cristais e

rochas ornamentais do Município de Corinto/MG

(Mário Eugênio de Paula Alves Bezerra, Natália Luísa Felício Macedo)

Capítulo 4 - Aplicação do modelo de Hackman \& Oldham para avaliar a qualidade de vida no trabalho na empresa júnior de engenharia de produção da UTFPR - Ponta Grossa.

(Rodrigo Salvador, Bruno Alexandre Oliveira, Bruna Zuccolotto Guedes, Fernanda Gomes Andrade,

Letícia Pavan Silva, Antonio Carlos de Francisco)

Capítulo 5 - Avaliação da atividade do operador de torno semiautomático para peças seriadas - Um estudo ergonômico

(Roger Poglia da Luz, Ademar Alves de Meira, Tassiana Cristina Dala Costa, Sergio Luiz Ribas Pessa,

Dalila G. Pagnoncelli Laperuta)

Capítulo 6 - Proposta de redimensionamento de posto de trabalho: O caso da atividade de montagem de janelas de venezianas em indústria de esquadrias de alumínio

(Lívia Pinto Neri, Priscila Pereira Suzart de Carvalho, André de Mendonça Santos, Thiago Francisco de Souza, Indara Santos de Souza)

Capítulo 7 - Uma revisão dos métodos de avaliação ergonômica e suas aplicações (Ariel Orlei Michaloski, Jaciara Dias Trzaskos)

Capítulo 8 - Avaliação dos riscos ocupacionais em áreas de mineração subterrânea (Bismark Soares Matos Santos, Luciano José Minette,Denise Ransolin Soranso)

Capítulo 9 - Análise do sistema de gestão de riscos no setor de rebobinadeiras em uma indústria de autoadesivos.

(Jordana Dorca dos Santos, Luci Mercedes De Mori, Celise Roder, Luani Back, Jean Carlos B. de Almeida)

Capítulo 10 - Proposta de avaliação do comportamento tridimensional dos trabalhadores e sua relação com o aumento da produtividade na empresa. 
Capítulo 11 - Mensurando os índices de concentração: A indústria do Estado do Espírito Santo sob análise

(Fabrício Alves de Almeida, Antônio Suerlilton Barbosa da Silva)

Capítulo 12 - Gestão estratégica e organizacional em empresas comerciais de micro, pequeno e médio porte do Município de Irati - PR

(Andréia Gura, Mauricio João Atamanczuk, Everaldo Veres Zahaikevitch, Antônio Cecílio Silvério, Flávio Fuhr)

Capítulo 13 - Potencialidades do marketing portuário: um estudo de caso do Porto de Imbituba Santa Catarina

(Ibaldo Gonçalves Pedra Júnior, Maria Helena de Souza, Natália Martins Gonçalves)

Capítulo 14 - Uma proposta da estrutura organizacional do setor de engenharia numa Instituição Pública Federal de Ensino.

(Kazuo Khatakeyama, Rommel Souza da Silva, Mehran Misaghi)

Capítulo 15 - Modelo de apoio à tomada de decisão para seleção de fornecedores por meio do Aanalytic Hierarchy Process (AHP).

(Wellington Gonçalves, Rodrigo Randow de Freitas)

Capítulo 16 - Modelo de aquisição de equipamentos de informática para empresa de médio porte.

(Diego Ricardo Krohl, Guilherme Constantini, Maikon Bridi, Thiago Crestani, Ana Paula de Carli Bertaioli)

Capítulo 17 - Avaliação de desempenho e seleção de fornecedores por meio da Análise Envoltória de Dados (DEA)...

(Nilton Fabiano Ribeiro, Rogério Martins de Azevedo, Paulo Rotela Junior)

Capítulo 18 - Técnica de pesquisa operacional aplicada no estufamento de contêineres:

Um estudo de caso para a empresa TLE

(Márcia Jussara Hepp Rehfeldt, Gabriel Machado Braido)

Capítulo 19 - Um estudo teórico sobre planejamento agregado de produção (PAP). 181 (Denislaine Regina Cordeiro, Diullya Carolina Cordeiro, Edimar Nunes Dias, Márcia de Fátima Morais, Rony Peterson da Rocha) 


\title{
CAPÍTULO 1
}

\section{JOGO EDUCAGIONAL APLICÁVEL À ENGENHARIA DE PRODUÇÃO: DESENVOLVIMENTO E PERCEPÇÕES DO PÚBLICO ALVO}

\author{
Alessandra Lopes Carvalho \\ Marcelo de Souza Nery
}

Resumo: Este trabalho tem por objetivo apresentar o desenvolvimento um jogo digital com fins educacionais envolvendo conceitos relacionados à Engenharia de Produção. Pretende-se simular de forma simplificada e lúdica um processo produtivo, sendo o público alvo constituído por alunos ingressantes. O tema para o jogo foi escolhido buscando fácil entendimento para leigos. Sendo assim, o tema Fast Food foi selecionado por ser um tema presente no dia a dia da população em geral e por proporcionar a identificação de forma simples e dinâmica de várias áreas da Engenharia de Produção. A equipe de trabalho identificou como áreas a serem abordadas: Gestão da Qualidade, Gestão de Estoques, Logística, Gestão de Pessoas, Engenharia de Sustentabilidade, Planejamento e Controle da Produção. Os resultados obtidos sugerem um melhor entendimento por parte dos alunos iniciantes com relação às atribuiçốes, responsabilidades e campo de ação de um engenheiro de produção.

Palavras Chave: Engenharia de Produção, Ensino 


\section{Introdução}

Segundo Neto e Leite (2010), a Engenharia de Produção está inserida em um contexto no qual os problemas caracterizam-se pela complexidade. Assim, para serem resolvidos, esses problemas demandam conhecimentos que vão além da matemática e da física, como ocorre nas engenharias clássicas. Como consequência deste fato, a solução de problemas deriva de uma abordagem que permite o acesso ao conhecimento de várias disciplinas simultaneamente, ou seja, através de uma abordagem interdisciplinar. Por disciplina entende-se um conjunto de conhecimentos especializados e focados em um domínio científico específico e homogêneo. A Figura 1 apresenta graficamente as várias abordagens disciplinares para se observar a realidade.

Figura1- As várias abordagens disciplinares para se observar a realidade

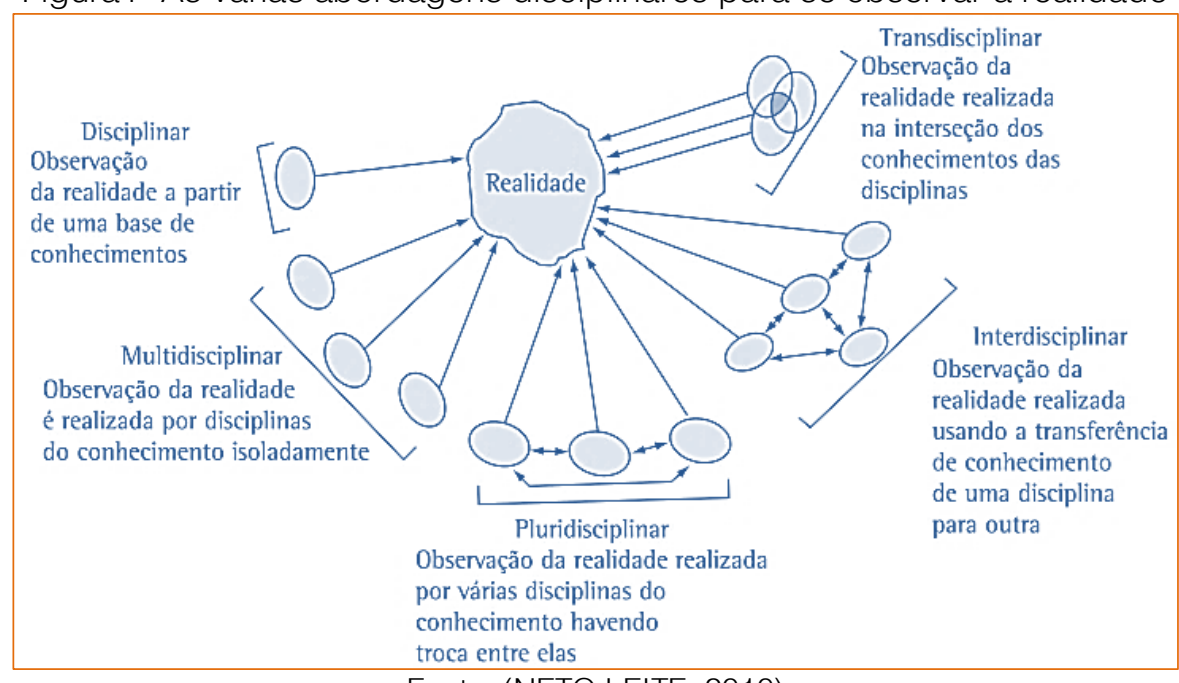

Fonte: (NETO;LEITE, 2010)

A multidisciplinaridade é caracterizada pela intervenção de várias disciplinas para estudar um mesmo fenômeno de forma sequencial ou paralela sem que haja cooperação entre elas. Dessa forma, o sistema produtivo será analisado do ponto de vista da otimização dos fluxos de materiais pela matemática, como um sistema de agregação de valor do ponto de vista da economia e como um sistema social do ponto de vista da sociologia.

Considerando a pluridisciplinaridade um fenômeno qualquer também pode ser estudado por meio da ótica de várias disciplinas de forma independente. Entretanto, há troca de conhecimentos entre as disciplinas a partir da cooperação entre elas, de forma a enriquecer o conhecimento sobre $\mathrm{o}$ fenômeno.

Segundo Jantsch e Bianchetti (1999) citado por Neto e Leite (2010), a abordagem baseada na interdisciplinaridade implica em um intercâmbio de conceitos, conhecimentos e métodos entre as disciplinas. Nesta abordagem há uma interação participativa de um grupo de disciplinas conexas, cujas relações são definidas a partir de um nível hierárquico superior.

De acordo com Pombo (2006) citado por Neto e Leite (2010), na transdisciplinaridade existe uma integração das disciplinas, conduzida pela necessidade de observação da realidade em vários níveis de complexidade, para cobrir o extenso espectro de objetivos necessários para estudar a realidade de uma forma mais ampla. $\mathrm{Na}$ abordagem transdisciplinar ocorre uma fusão do conhecimento das diversas disciplinas que tende à criação de um campo de saber totalmente novo e com autonomia teórica.

Finalmente, ainda segundo Neto e Leite (2010), os problemas da área de Engenharia de Produção demandam abordagens que transitam entre a pluri, a inter e a transdisciplinaridade. A necessidade dessas abordagens é resultado da diversidade de variáveis que envolvem as áreas do conhecimento relacionadas aos problemas da Engenharia de Produção. Por exemplo, a pesquisa sobre o funcionamento de um processo produtivo necessita "observar" o processo do ponto de vista: do seu arranjo físico, dos fluxos de materiais, dos fluxos de informação, das relações sociais que se estabelecem entre os envolvidos, do conhecimento e capacidade de aprendizagem dos indivíduos, dos fatores ambientais que incidem na operação do processo, das condições de trabalho, das relações formais e informais, entre outros. É possível abordar apenas um desses aspectos, mas deve-se ter consciência de que essa abordagem será parcial e irá limitar a análise do problema. 
Considerando a complexidade, a abrangência e as características pluri, inter e transdisciplinares inerentes à Engenharia de Produção, compete aos educadores lidarem constantemente com os desafios naturalmente impostos pelo processo ensino/aprendizagem. Diante deste contexto é imperativa a busca de ferramentas que auxiliem a compreensão e a assimilação de conceitos por parte do corpo discente.

Sabe-se que a aprendizagem de qualquer conceito ocorre com maior efetividade se, associadas à transmissão de conceitos teóricos, for possível realizar uma aplicação prática que facilite o processo de ensino/aprendizagem. Uma forma de possibilitar a aplicação pratica de conceitos teóricos é a utilização de jogos que simulem, com o significado necessário, situações similares ao contexto da vida real onde aqueles conceitos poderiam ser aplicados (PANTALEÃO; OLIVEIRA; ANTUNES JÚNIOR, 2003; BATISTA, OLIVEIRA, NASCIMENTO 2011)

O surgimento de novas tecnologias de informação e comunicação alteraram os meios de disseminação do conhecimento. Observa-se que a adoção de métodos participativos tem permitido aos alunos vivenciem experiências que estimulam sua criatividade $e$ autonomia e, consequentemente, contribuem para o seu desenvolvimento acadêmico e profissional. ( CHIROLI, SAMED E DE PAULA, 2014)

O uso de jogos como ferramentas de aprendizado é uma prática tão antiga quanto o ensino. Os jogos tem sido usados com uma considerável variedade de formatos visando alcançar objetivos muito diversos (QUEIROZ; LUCERO, 2000). A década de 50 registrou, nos Estados Unidos, grande utilização de jogos simulados como instrumento de aprendizagem. A ideia da utilização dos jogos para a aprendizagem no Brasil passou a ser consolidada na década de 80 (GRAMIGNA, 1993 citado por PANTALEÃO; OLIVEIRA; ANTUNES JÚNIOR, 2003)

Observa-se que, atualmente, os jogos digitais e outras mídias interativas tem se tornado veículos de expressão da cultura popular. Observa-se, inclusive, que esta tem se transformado radicalmente com o surgimento e democratização das novas formas digitais de comunicação e expressão. Os exemplos mais conhecidos de jogos digitais são os chamados vídeo games que utilizam dispositivos de vídeo e simulação em tempo real para interação com o usuário

A indústria de jogos digitais vem crescendo em importância econômica no cenário mundial. O que teria sido considerado apenas como um nicho de mercado nos anos 90 evoluiu para um mercado bilionário. Os jogos digitais representam atualmente um mercado que amplia as fronteiras da tecnologia e alimenta diversos campos de pesquisa como inteligência artificial e computação gráfica (CORREA, 2010)

Especificamente no Brasil, o mercado de jogos ainda é jovem e caracterizado por problemas estruturais, tais como: baixa renda da população, exclusão digital e pirataria. Apesar de embrionário, o mercado doméstico de jogos engloba uma nascente indústria criativa, cujo potencial mundial de crescimento supera outros setores criativos tradicionais como indústria fonográfica, cinema e esportes. O apelo econômico vem encorajando iniciativas (inclusive por parte do governo brasileiro) como programas de fomento à pesquisa, desenvolvimento tecnológico e formação de mão de obra qualificada para empreendimentos de base tecnológica e inovadora (PERUSIA; BALESTRIN; VERSCHOORE, 2011)

Atualmente, com o desenvolvimento acelerado de tecnologias de suporte à criação de jogos digitais as Game Engines ( plataformas de criação e edição de ambientes virtuais) apresentam características de visualização e interação que vão além das ferramentas computacionais tradicionais. (MOURA e BRITO, 2016).

Observa-se com frequência a utilização de jogos para simulação em Engenharia de Produção.

Segundo Prado (2014) simulação é a técnica de solução de problemas pela análise de um modelo que descreva o comportamento do sistema estudado utilizando métodos computacionais. A utilização dos jogos, enquanto simulação empresarial na educação se contrapõem a metodologia tradicional de ensino, pois se trata de um exercício seqüencial de tomada decisão, estruturados dentro de um modelo de conhecimento empresarial, em que os participantes se envolvem. (BATISTA, OLIVEIRA, NASCIMENTO 2011)

Exemplos de modelagem e simulação de sistemas no ambiente industrial abrangem as áreas de produção, logística, controle de qualidade, análise de riscos e segurança, análise de vulnerabilidade e análise de confiabilidade. Considerando negócios, finanças e economia industrial podem ser citados exemplos de simulação aplicados à modelagem de fluxos de negócios, análise financeira e planejamento estratégico.

Aplicações da simulação em engenharia de produção incluem a emulação do arranjo físico de fábrica, do fluxo de processo, dos sistemas de manuseio de material, do planejamento da capacidade produtiva, da utilização de mão-de-obra, entre outras.

Segundo Gramigna (1993) citado por Pantaleão, Oliveira e Antunes Júnior (2003), o chamado Jogo Simulado, é uma atividade planejada previamente pelo facilitador, na qual os jogadores são convidados a enfrentar desafios que reproduzem a realidade de 
seu dia-a dia. Segundo os autores, no jogo simulado pode-se identificar todas as características do jogo real: regras definidas, presença do espírito competitivo, possibilidades de identificar vencedores e perdedores, ludicidade, fascinação e tensão. Por sua vez, o Jogo de Empresa tem a mesma estrutura do jogo simulado, porém retrata situações específicas da área empresarial. Nos Jogos de Processo, as equipes passam por processos simulados nos quais devem executar atividades como: planejar e estabelecer metas, negociar, administrar tempo e recursos, estabelecer métodos de trabalho, organizar processos de produção e tomar decisões acerca deste processo.

Objetiva-se, através deste trabalho, desenvolver um jogo digital com fins educacionais envolvendo conceitos relacionados à Engenharia de Produção caracterizado como um "Jogo de Processo".

Objetiva-se mais especificamente simular (emular) de forma simplificada e lúdica o ambiente industrial, sendo o público alvo constituído por estudantes dos primeiros períodos. Os benefícios esperados compreendem um melhor entendimento por parte dos alunos com relação às atribuições, responsabilidades e campo de ação de um engenheiro de produção.

\section{Referencial teórico}

\subsection{Conceito e classificações de jogos digitais}

Afinal, surge a pergunta: o que é um jogo? Um jogo é uma atividade espontânea, realizada por uma ou mais pessoas, regida por regras (onde estão incluídas o tempo de duração, o que é permitido e proibido, valores das jogadas e indicadores sobre como terminar a partida) que determinam quem o vencerá.

Vários autores salientam o papel psicopedagógico dos jogos definindo-os como instrumentos que permitem a construção de conhecimentos e a superação de erros. Existe também uma valiosa oportunidade para a resolução de incapacidades e aquisição de autoconfiança. Cabe ainda ressaltar as características socializadoras dos jogos, ao entendêlos como espaço para a transmissão de costumes por meio de trocas interindividuais e arranjos coletivos (CAIADO; ROSSETTI, 2009)

O jogo digital, elemento da chamada "indústria cultural" constitui-se como um instrumento de lazer e entretenimento, cujo alcance é cada vez mais amplo nas brincadeiras infantis. Isso significa que o conteúdo desses jogos e a identificação com seus personagens são vetores importantes de referência para analisar a constituição da identidade infantil e a emergência de valores na sociedade atual (ZANOLLA, 2007).Segundo Hoff e Wechsler (2002), a dinâmica de jogos resgata o contexto de interações diretas no qual o computador deixa de ser oponente para colocar-se como mediador de interações humanas.

Schell (2014) enumera várias sensações potencialmente vivenciadas através dos jogos como por exemplo a possibilidade de se imaginar como um personagem inserido em um mundo hipotético. O mesmo autor cita ainda os sentimentos de companheirismo, amizade e cooperação.

Existem vários tipos de jogos. A classificação proposta por Wolf (2010) considerada aventura, vida artificial, jogos de tabuleiro, combate, corrida, educacional e simulação de gerência.

Existem outras formas de classificação dos jogos digitais com relação à tecnologia gráfica utilizada. Considerando jogos digitais projetados em ambientes gráficos em duas dimensões (2D), a movimentação dos personagens é realizada apenas horizontalmente e verticalmente. Nos jogos projetados em ambientes em três dimensões (3D) existe a possibilidade de introdução de elementos mais realistas.

Normalmente, os softwares utilizados para desenvolvimento de jogos possibilitam a simulação de fenômenos físicos tais como colisão, interação entre corpos rígidos, dinâmica de fluidos, gravidade, atrito, entre outros (ERICSON , 2005; GREGORY, 2014). O comportamento de personagens autônomos é usualmente definido através de lógicas de programação baseada em inteligência computacional (BOURG.; SEEMANN, 2004).

\subsection{Aplicações de jogos digitais educacionais}

A potencialidade educacional de jogos digitais é apontada internacionalmente. Destacam-se as habilidades relacionadas à coordenação de variáveis dinâmicas em interação simultânea como antecipação, planejamento e elaboração de estratégias ( HOFF; WECHSLER,2002)

Existe a possibilidade de desenvolvimento e utilização de jogos digitais independente do público alvo considerando. Caiado e Rossetti (2009) realizaram um estudo sobre a inserção de jogos de regras na escola primaria como estratégia facilitadora do desenvolvimento de relações cooperativas. A literatura reporta também estudos envolvendo jogos voltados para ciências sociais. Por exemplo, Hoff e Wechsler (2002) conduziram um estudo com caráter exploratório tendo como objetivo averiguar os hábitos de adolescentes brasileiros na sua prática de jogos computadorizados.

No processo de transferência tecnológica de conceitos de Engenharia de Produção, a utilização de jogos pode ser muito produtiva no sentido de imprimir, sob o ponto de vista do participante, 
significado aos conceitos. Exemplos de modelagem e simulação de sistemas no ambiente industrial abrangem as áreas de produção, logística, controle de qualidade, análise de riscos e segurança, análise de vulnerabilidade e análise de confiabilidade. Considerando negócios, finanças e economia industrial podem ser citados exemplos de simulação aplicados à modelagem de fluxos de negócios, análise financeira e planejamento estratégico

De acordo com o estudo bibliométrico desenvolvido por Chiroli, Samed e de Paula (2014) sobre aplicação de jogos a Engenharia de Produção, pode-se afirmar que o maior número de publicações trata de Jogos de Empresas e Simulação.

Queiroz e Lucero (2000) reportam a experiência que se originou do projeto e implementação de uma fábrica virtual no âmbito do Departamento de Engenharia Mecânica da UFSC. O Jogo emula situações reais de produção com vários produtos de fluxo longo (processos encadeados) e configurações de produto complexas. O jogador é um Engenheiro Trainee passando por um Departamento de Planejamento da Produção para assumir todo o planejamento e programação de uma unidade fabril que está em plena atividade. Nos níveis mais básicos do jogo, por razões pedagógicas, evitou-se colocar o aluno diante de estados transientes na fabricação, já que o nível de decisão deste estado é bem mais complexo na manufatura de lotes. Quando inserido na produção em regime permanente, há uma vantagem para o aprendizado que é a oportunidade de examinar as programações anteriores, os níveis de estoque, as interrupções e atrasos de produção, os índices de refugo e as flutuações de pedidos. Nos níveis mais avançados o aluno é exposto à situações mais realísticas de clientes que cancelam pedidos, de máquinas que quebram e de novos produtos que são introduzidos na produção. Para jogar exige-se que $\mathrm{o}$ aluno tenha conhecimentos básicos de Gerência de Produção, noções de MRP (Manufacturing Resource Planning) e JIT (Just in Time) devido ao uso de extenso vocabulário próprio destas tecnologias.

Pantaleão, Oliveira e Antunes Júnior (2003) apresentam um exemplo de aplicação de um jogo simples - o 'Jogo do Barco' - como ferramenta de aprendizagem dos conceitos de Engenharia de Produção. São especialmente utilizados os conceitos ligados ao STP (Sistema Toyota de Produção ) e à TOC (Theory of Constraints - Teoria das Restrições). Resultados expressivos de efetividade da aprendizagem obtidos pelos autores em inúmeras aplicações do "Jogo do Barco" ao longo do tempo permitem afirmar que ele constitui-se em um instrumento de grande utilidade no processo de ensino e aprendizagem dos modernos conceitos associados a Engenharia e a Administração da Produção.

Sauaia e Zerrenner (2009) contribuem, por meio de análise empírica de comportamentos em jogos de empresas, para a discussão das teorias clássicas da tomada de decisão. Outro exemplo de jogo de empresas pode ser encontrado no trabalho de Rosas e Sauaia (2009) que apresentaram o desenvolvimento de um modelo conceitual que reúne as principais decisões de um empreendedor no estágio de criação de um negócio. Pode ser citado ainda o trabalho de Machado e Campos (2016) apresenta uma proposta para utilização conjunta de um simulador computacional e um jogo na área de gestão da produção.

Considerando as diversas áreas que podem se beneficiar utilizando técnicas de simulação destacase a gestão da produção. Podem ser citados, entretanto, trabalhos desenvolvidos em outras áreas como a dinâmica apresentada por Martins et al ( 2016) que simula a atuação dos participantes em um processo de montagem de peças $L E G O \circledast$ explorando conceitos da manufatura enxuta. Bertazzo, Leiras e Yoshizaki (2014) desenvolveram um modelo conceitual de simulador e uma proposição de jogo humanitário de logística, com o intuito de permitir o treinamento para tomada de decisão de gestores humanitários. O trabalho de Mattos( 2015) apresenta uma abordagem do Learnig by Doing no contexto dos sistemas de informação.

Observa-se, finalmente, que diversos temas tem sido associados de forma positiva aos jogos: comportamento negocial, planejamento estratégico, processo decisório, estilos de liderança, dentre tantos outros.

\section{Desenvolvimento}

Esse trabalho está inserido em um contexto amplo que envolve o projeto de um jogo digital concebido em conjunto por profissionais vinculados aos cursos de Engenharia de Produção e Tecnologia em Jogos Digitais. Espera-se, desta forma, recriar o ambiente de cooperação interpessoal necessário para a realização de um projeto típico.

O tema para o jogo foi escolhido buscando fácil entendimento para leigos. Sendo assim o tema Fast Food foi selecionado por ser um tema presente no dia a dia da população em geral e por proporcionar a identificação de forma simples e dinâmica de várias áreas da Engenharia de Produção. A equipe de trabalho identificou como áreas da engenharia de produção a serem abordadas: Gestão da Qualidade, Ergonomia e Higiene e Segurança do Trabalho, Gestão de Estoques, Logística, Gestão de Pessoas, Engenharia de Sustentabilidade, Planejamento e 
Controle da Produção. Apresenta-se na figura 2 a tela inicial do jogo.

Figura 2 - Tela inicial do jogo

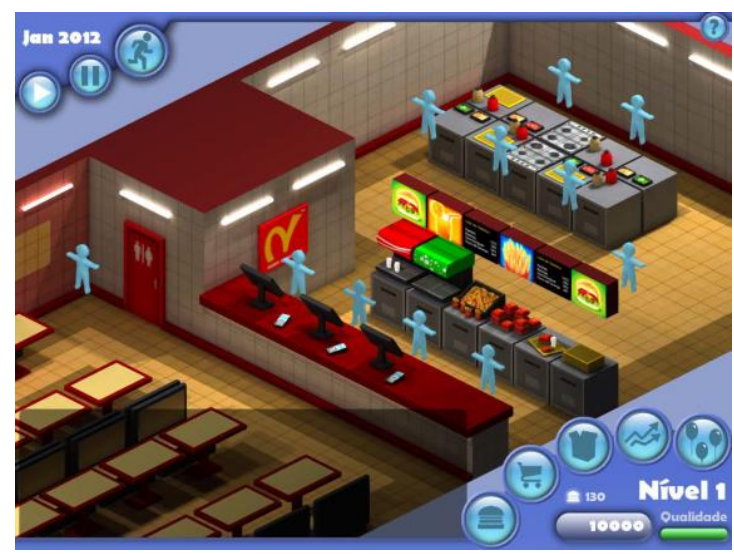

Fonte: Elaborado pelos autores

O jogador tem a oportunidade de contratar quatro tipos de funcionários da lanchonete: caixa, entregador de pedidos, cozinheiro e faxineiro. Apresenta-se na figura $3 \mathrm{um}$ detalhe do projeto gráfico do jogo apresentando um cozinheiro.

É importante registrar que a satisfação de todas as partes interessadas cai continuamente à medida que o tempo passa. Para os clientes, isso decorre do atraso na entrega do pedido, que tem ligação direta com a quantidade de funcionários trabalhando e a velocidade de cada funcionário. Para os funcionários, a satisfação cai a cada pedido feito, na proporção inversa ao volume de trabalho. Existe um indicador de qualidade que é exibido por uma barra verde na tela inicial. Caso este indicador atinja um nível muito baixo o jogo é finalizado.
Durante o jogo é possível perceber que os funcionários e os clientes podem se irritar por algum motivo. Se um funcionário estiver insatisfeito, ele trabalhará mais lentamente e se sua satisfação chegar à zero, ele se demitirá na primeira oportunidade. No caso dos clientes, sua satisfação decai muito rapidamente, uma vez que esperam que a comida seja entregue o mais rápido possível.

São apresentadas para o jogador as possibilidades de jogar, pausar o jogo, sair e salvar a situação atual ou solicitar ajuda. Apresenta-se no quadro1 a relação de botões presentes na tela inicial do jogo e seu significado.

Figura 3 - Detalhe gráfico

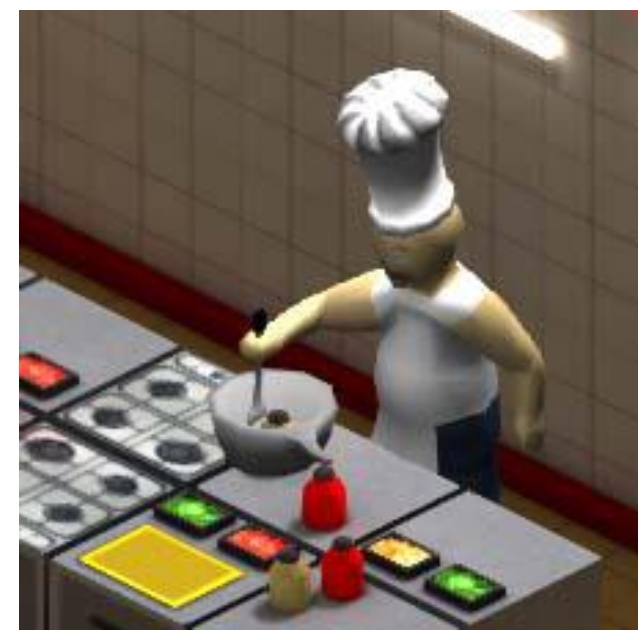

Fonte: Elaborado pelos autores

Quadro 1 - Relação botões iniciais / significado

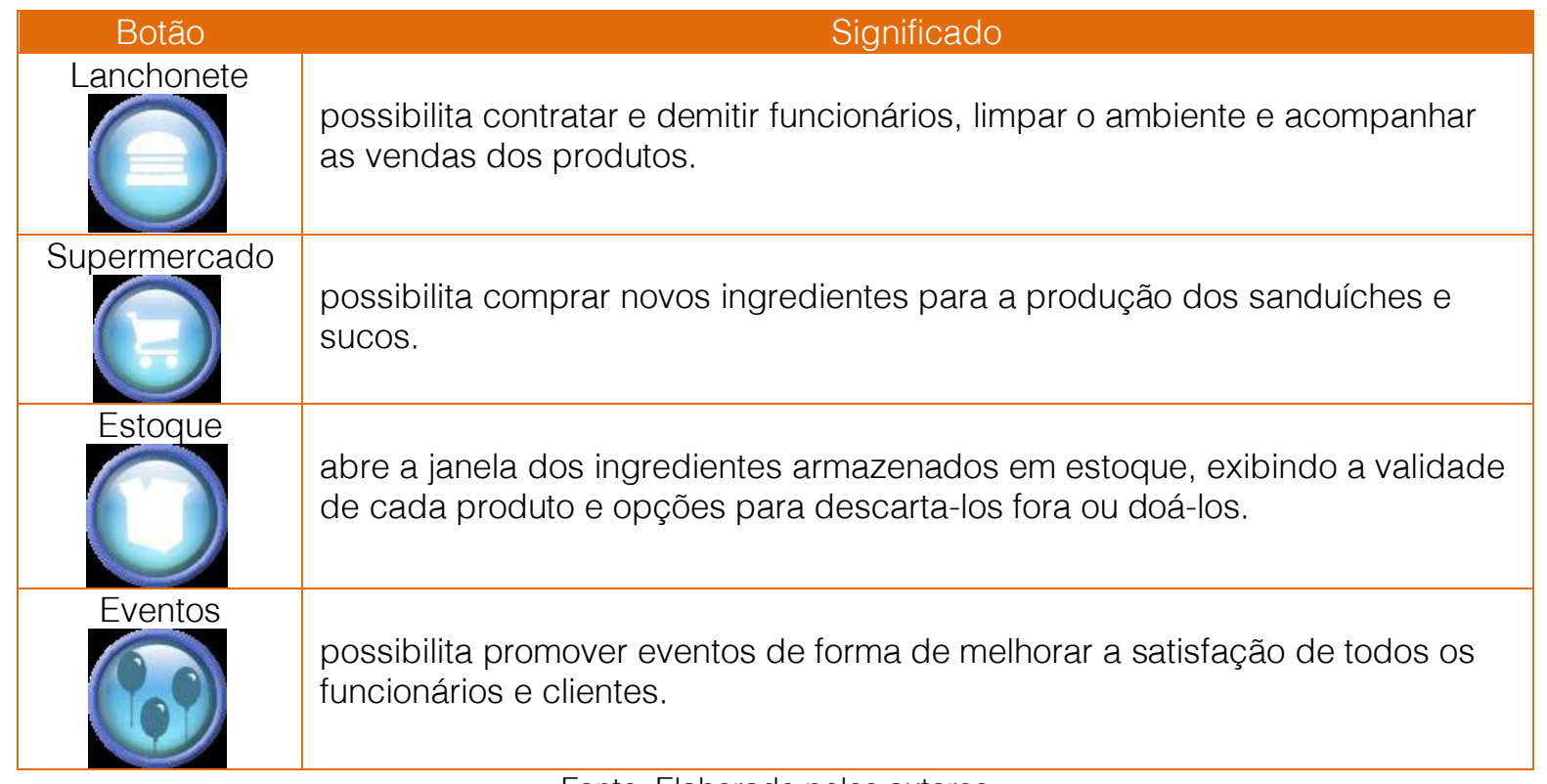


Existem 4 tipos de funcionários: caixa, entregador de pedidos, cozinheiro e faxineiro. Para que um produto seja entregue é necessário pelo menos 1 funcionário caixa, 1 entregador de pedidos e 1 cozinheiro. $O$ faxineiro só é necessário quando sua loja estiver sendo usada e a sujeira começar a aparecer. Os locais onde os funcionários irão atuar já estão prédefinidos no jogo. Existe a possibilidade de contratação de 2 funcionários para o caixa, 2 funcionários entregadores de pedidos, 5 cozinheiros e 2 faxineiros.
É possível contratar todos os funcionários de uma vez ou contratar à medida que seu lucro for aumentando. Para contratar, basta clicar sobre um dos bonecos azuis. Estão disponíveis as opções contratar, desistir ou descartar o currículo. Neste caso um novo currículo estará disponível apenas em um tempo simulado equivalente a 2 meses. Após a contratação de um funcionário existem quatro possibilidades de ação representadas por botões na tela inicial do jogo e detalhadas no quadro 2.

Quadro 2 - Relação botões recursos humanos / significado

\begin{tabular}{|l|l|}
\hline & $\begin{array}{l}\text { Sotãonificado } \\
\text { Pemitir } \\
\text { funcionário poderá ocorrer a partir de 2 meses da demissão. A demissão tem } \\
\text { um custo igual a 2 vezes o salário do funcionário, simulando assim o } \\
\text { pagamento de FGTS e outros benefícios. }\end{array}$ \\
\hline Pratificar & $\begin{array}{l}\text { Permiti pagar ao funcionário (imediatamente) um salário extra no mês. Isso } \\
\text { atua diretamente em sua satisfação e consequentemente na sua velocidade } \\
\text { de trabalho. }\end{array}$ \\
\hline & $\begin{array}{l}\text { Adverte um funcionário que esteja trabalhando mal, aumentando sua } \\
\text { velocidade de trabalho momentaneamente, mas, como consequência, reduz } \\
\text { sua satisfação. }\end{array}$ \\
\hline
\end{tabular}

Fonte: Elaborado pelos autores

Existem vários tipos de sanduíches disponíveis na lanchonete que são liberados à medida que o jogo evolui. Para cada sanduíche listado, são apresentados os ingredientes necessários. Caso o estoque ( Figura 4) indique falta com algum produto, é necessário fazer compras clicando no ícone carrinho de supermercado. São necessários ao todo 18 ingredientes, divididos por categoria: pães, queijos, carnes, frutas, legumes/verduras e ovos. Cada ingrediente possui um custo fixo no jogo.

Figura 4 - Gestão de estoque

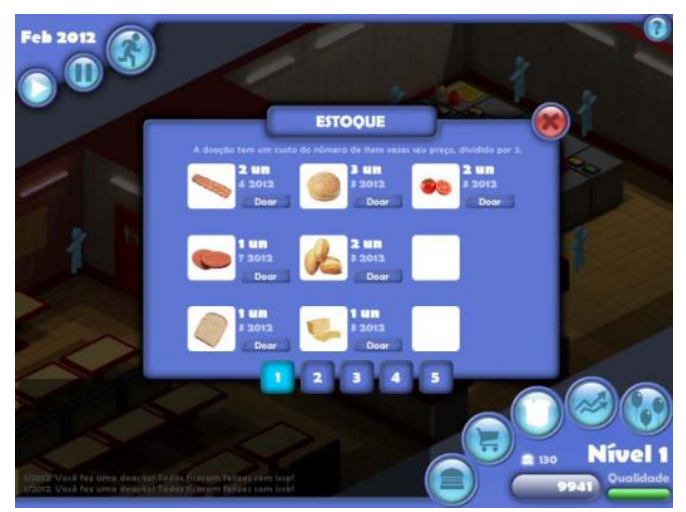

Fonte: Elaborado pelos autores
É importante ressaltar que o estoque possui uma quantidade de espaço limitado, sendo ao todo 45 espaços disponíveis. Os produtos são listados na ordem que foram comprados. Caso o produto tenha ultrapassado o prazo de validade, ele automaticamente será descartado do estoque e seu espaço de armazenamento será liberado para ocupar com outro produto.

Há ainda a opção de doar os produtos que possuir no estoque. Uma doação tem o custo do produto vezes a quantidade em estoque, dividido por 2. Contudo, ao doar, ocorre aumento da qualidade a partir da sugestão de responsabilidade social corporativa.

\section{Análise de resultados e conclusões}

Considerando a complexidade, a abrangência e as características pluri, inter e transdisciplinares inerentes à Engenharia de Produção, compete aos educadores lidarem constantemente com o desafios naturalmente impostos pelo processo ensino/aprendizagem. Diante deste contexto é imperativa a busca de ferramentas que auxiliem a compreensão e a assimilação de conceitos por parte 
do corpo discente. O jogo desenvolvido cumpre este papel.

A metodologia de avaliação do jogo foi baseada na coleta de impressões e críticas de uma amostra do público alvo. O jogo foi instalado em laboratórios de informática em dois campi diferentes da universidade foco do estudo. Foi organizado um evento em forma de aula prática e foi solicitado aos alunos que o jogo fosse experimentado durante o tempo de uma hora e quarenta minutos. Foi fornecido um computador com o jogo instalado para cada aluno. Como atividade extra classe um texto livre e aberto deveria ser entregue como relatório da experiência.

Cabe ressaltar que não foi providenciado nenhum treinamento prévio ou manual de instruções para o jogo pois, em se tratando de uma experiência lúdica e interativa, uma preparação deste tipo poderia influenciar a avaliação pessoal dos jogadores. No entanto, foi permitida e incentivada a interação entre os participantes.

Durante o experimento foi realizada uma avaliação qualitativa em relação as percepções dos jogadores. As avaliações assim obtidas foram analisadas objetivando-se interpretar as impressões, em termos do gameplay (experiência de jogo) e do tema proposto pelo aplicativo.

As observações qualitativas obtidas durante 0 experimento revelaram bons resultados em termos de satisfação e engajamento dos participantes durante 0 jogo. Um indicador importante deste fato, é que a maioria dos participantes decidiu continuar o jogo mesmo depois de excedido o tempo reservado ao experimento. Além disso, foi observado um alto nível de descontração dos participantes, com grande quantidade de interações entre os mesmos. Embora o ambiente do laboratório tenha se tornado informal e ruidoso, observa-se que o contexto das conversas e comentários se mantiveram focadas no contexto

\section{REFERÊNCIAS}

[1] BATISTA, Carla Sena, OLIVEIRA, Fabiana Lucena NASCIMENTO, Enily Vieira. Proposta de um Jogo Didático de Gestão da Produção. In: ENCONTRO NACIONAL DE ENGENHARIA DE PRÓDUÇÃO, XXXI, 2011, Belo Horizonte. Anais... ABEPRO, 2011.

[2] BERTAZZO, Tabata Rejane, LEIRAS, Adriana; YOSHIZAKI, Hugo Tsugunobu Yoshida

[3] Modelo Conceitual de Simulador e de Jogo de Empresas para Análise dos Mecanismos de Coordenação em Logística Humanitária. In: ENCONTRO NACIONAL DE ENGENHARIA DE PRODUÇÃO, XXXIV ,2014, Curitiba. Anais... ABEPRO, 2014.

[4] BOURG, David M.; SEEMANN, Glenn. Al for Game Developers. Creating Intelligent Behavior in Games. $1^{\text {a }}$ ed. Sebastopol: O'Reilly Media, 2014. 392 p. oferecido pelo jogo, o que demonstra o engajamento da turma com o tema.

Em relação aos relatórios coletados, observou-se uma certa recorrência na maioria das impressões o que possibilitou organiza-las em quatro tópicos distintos: GESTÃO DE ESTOQUES, GESTÃO DE PESSOAS, ADMINSTRAÇÃO FINANCEIRA e GERÊNCIA. Os tópicos identificados na compilação demonstram claramente a aderência com o tema abordado no jogo

A análise dos relatos e críticas demonstraram que a reflexão sobre o conteúdo didático do jogo se deu em dois níveis. Todos os jogadores conseguiram traçar um paralelo entre a realidade de um verdadeiro negócio, e a simulação oferecida pelo jogo. Por exemplo, no seguinte comentário: Os funcionários se sentem motivados a trabalhar somente com gratificação em dinheiro, excluindo outros possíveis meios(...). O jogador reconhece que, no mundo real, as empresas usam variadas estratégias motivacionais.

Além deste paralelo, uma parcela considerável dos alunos foram capazes de identificar dificuldades na administração da empresa simulada e oferecer sugestões de modificações que podem melhorar o desempenho do jogador. Por exemplo, um jogador sugere: "Inserir estatísticas de vendas de produtos". Neste tipo de comentário, o jogador demonstra alto nível de engajamento no gameplay. Observa-se ainda que este tipo de abstração é um exercício útil também para a vida real.

Foram coletadas ainda críticas à qualidade de design e produção do jogo que serão importantes para trabalhos futuros. Finalmente conclui-se que o objetivo principal do projeto, simular de forma simplificada e lúdica um processo produtivo, foi plenamente alcançado.

[5] CAIADO, Ana Paula Sthel e ROSSETTI, Claudia Broetto. Jogos de regras e relações cooperativas na escola: uma análise psicogenética. Revista Semestral da Associação Brasileira de Psicologia Escolar e Educacional (ABRAPEE), vol.13, n.1, p. 87-95, 2009.

[6] CHIROLI , Daiane Maria De Genaro; SAMED, Marcia Marcondes Altimari ; DE PAULA, Thais Rocha. Estudo Bibliométrico: Identificação de Tendências, Desafios e Oportunidades em Engenharia de Produção. In: ENCONTRO NACIONAL DE ENGENHARIA DE PRODUÇÃO, XXXIV ,2014, Curitiba. Anais... ABEPRO, 2014. [7] CORRÊA, Artur. Prototipagem para Criação de Jogos Digitais: Um Estudo de Caso. 2010. 55f. Monografia (Conclusão do curso de Especialização em Desing e Modelagem de Jogos Digitais) - Pontifícia Universidade 
Católica de Minas Gerais, Instituto de Educação Continuada, Belo Horizonte.

[8] GREGORY, Jason. Game Engine Architecture. $2^{2}$ ed. Boca Raton: CRC Press. Taylor \&Francis Group, 2014 $1052 p$

[9] HOFF, Miriam Schifferli e WECHSLER, Solange Muglia. A prática de jogos computadorizados em um grupo de adolescentes. Revista Estudos de Psicologia, vol.19, n.2, p. 59-77, 2002

[10] MACHADO, Heitor Bezerra Coelho ; CAMPOS , Renato. Proposta de Procedimento para Utilização Conjunta de um Simulador Computacional e um Jogo na Area de Gestão da Produção. In: ENCONTRO NACIONAL DE ENGENHARIA DE PRODUÇÃO, XXXVI, 2016, João Pessoa. Anais... ABEPRO, 2016.

[11] MATTOS , Claudia Aparecida. Integração da Tecnologia da Informação no Ensino: Aplicando a Abordagem do Learnig by Doing Através de Jogos de Simulação no Contexto dos Sistemas de Informações ( ERP). In: ENCONTRO NACIONAL DE ENGENHARIA DE PRODUÇÃO, XXXV ,2015, Fortaleza. Anais... ABEPRO, 2015.

[12] MARTINS, Paula Carneiro; LEAL, Fabiano; MONTEVECHI, Jose Arnaldo Barra; QUEIROZ, Jose Antonio; REIS, Cintia Martins de Oliveira. Mensuração da Reação e do Aprendizado em uma Dinâmica de Ensino com peças LEGO Aplicada em uma Empresa. In: ENCONTRO NACIONAL DE ENGENHARIA DE PRODUÇÃO, XXXVI ,2016, João Pessoa. Anais... ABEPRO, 2016.

[13] MOURA, Daniel Braatz Antunes de Almeida; BRITO, Esdras Paravizo. Aplicação de Game Engine na Engenharia de Produção: Análise do Potencial e partir de uma taxomia de Simulação de Sistemas de Produção. In: ENCONTRO NACIONAL DE ENGENHARIA DE PRODUÇÃO, XXXVI ,2016, João Pessoa. Anais... ABEPRO, 2016.

[14] NETO, Alfredo larozinski.; LEITE, Maria Silene. A abordagem sistêmica na pesquisa em Engenharia de Produção. Revista Produção, v.20, n. 1, p.1- 14, 2010.

[15] PANTALEÃO, Luiz Henrique; OLIVEIRA, Rafael Mello; ANTUNES JÚNIOR, José Antonio Valle. Utilização de um jogo de produção como ferramenta de aprendizagem de conceitos de Engenharia de Produção: o Jogo do Barco. In: ENCONTRO NACIONAL DE ENGENHARIA DE
PRODUÇÃO, XXIII ,2003, Ouro Preto. Anais... Ouro Preto: ABEPRO, 2003.

[16] PERUSIA, Alexandre; BALESTRIN, Alsones; VERSCHOORE, Jorge. Coordenação das atividades produtivas na indústria brasileira de jogos eletrônicos: hierarquia, mercado ou aliança? Revista Produção .v21, n1, pp. 64-75, 2011.

[17] PRADO, D. Teoria das Filas a da Simulação. $5^{\mathrm{a}}$ ed . Belo Horizonte: Editora Falconi, 2014. 158p.

[18] QUEIROZ, Abelardo A. de ; LUCERO, Adrián G. Jogos, uma alternativa para complementar o ensino da administração da produção. In: ENCONTRO DE EDUCAÇÃO EM ENGENHARIA, VI, 2000, Petrópolis. Anais... Petrópolis: UFRJ, 2000. Disponível em <www. dee.ufrj.br/VIIEEE/VIEEE/artigos/40/40.doc. >. Acesso em: 7 mar 2017.

[19] ROSAS, André Rosenfeld e SAUAIA, Antonio Carlos Aidar. Modelo conceitual de decisões no estágio de criação de um negócio: base para construção de um simulador para jogos de empresas. Revista Administração Contemporânea, vol.13, n.4, p. 663-682, 2009. Disponível em

http://www.anpad.org.br/periodicos/content/frame_base.ph p?revista=1 > Acesso em: 7 mar 2017.

[20] SAUAIA, Antonio Carlos Aidar e ZERRENNER, Sabrina Arruda. Jogos de empresas e economia experimental: um estudo da racionalidade organizacional na tomada de decisão. Revista Administração Contemporânea, vol.13, n.2, p. 189-209, 2009. Disponível em < http://www.anpad.org.br/rac > Acesso em: 7 mar 2017.

[21]

SCHELL, Jesse. The Art of Game Design. A Book of Lenses. $2^{a}$ ed. Burlington: Elsevier, 2014. 600 p.

[22] WOLF, Mark J.P The Medium of the Vídeo Game. $1^{\mathrm{a}}$ ed. University of Texas Press, 2010. 224 p.

[23] ZANOLLA, Silvia Rosa Silva. Indústria cultural e infância: estudo sobre formação de valores em crianças no universo do jogo eletrônico. Revista Educação \& Sociedade, vol.28, n.101, p. 1329-1350, 2007. Disponível em: < http://www.cedes.unicamp.br >. Acesso em: 7 mar 2017. 


\title{
CAPÍTULO 2
}

\section{ANÁliSe dAS PRÁTICAS DE GESTÃo DE SEGURANÇA E SAÚDE NO TRABALHO EM UMA MICRO EMPRESA DO SETOR INDUSTRIAL}

\author{
Horrany Leite de Carvalho \\ Luis Felipe Cândido
}

Resumo: A gestão da Segurança e Saúde no Trabalho (SST) quando bem exercida pode reduzir riscos de acidentes, promover a saúde e a satisfação dos trabalhadores, melhorar os resultados operacionais e a imagem das organizações. Porém, construir ações relacionadas à saúde e segurança em Micro e Pequenas Empresas (MPE) não é uma tarefa fácil, uma vez que essas empresas normalmente são abertas sem nenhum planejamento prévio ou aquisição de conhecimentos técnicos pertinentes ao ramo ao qual se destinará, além de grande informalidade gerencial, baixo volume de capital empregado e escassez de créditos o que limita diversos investimentos, dentre os quais aqueles relativos à SST. Assim, este estudo tem por objetivo analisar as práticas de SST em uma microempresa especializada na fabricação de vassouras, rodos e escovas e reciclagem de materiais. Foi possível identificar os riscos presentes no processo produtivo, indicar boas práticas de SST e perceber o quanto a elaboração de ações a partir das necessidades e limitações de cada empresa pode facilitar a gestão e promover uma melhora das condições de saúde e segurança nas MPE.

Palavras Chave: Sistemas de gestão, Prevenção de acidentes, MPE. 


\section{INTRODUÇÃO}

A competição em escala mundial em levado às empresas a buscarem continuamente por melhorias nos seus sistemas produtivos por meio do uso de novos mecanismos de gestão. A implantação destas ferramentas de gestão tem por objetivo aumentar a qualidade dos produtos, aumentar os lucros e melhorar relação empresa-sociedade, a fim de conquistarem uma posição de destaque no gosto do cliente (OLIVEIRA et al., 2010).

A Segurança e Saúde no Trabalho (SST) é um desses mecanismos e, nos últimos anos, ela tem se tornado decisivo para a construção da imagem de qualquer empresa, uma vez que trata da prevenção de acidentes e de doenças profissionais, bem como da proteção e promoção da saúde dos trabalhadores, melhorando as condições e o ambiente de trabalho (OIT, 2011). Além disso, SST é condição básica e fundamental par qualquer empresa que deseja atingir qualidade e produtividade (MONTEIRO et al., 2005 apud RIBEIRO; AMARAL, 2011).

A satisfação dos colaborados aliada a um ambiente seguro pode se desdobrar em uma melhora dos resultados operacionais, além de melhorar a imagem da empresa no mercado gerando, inclusive, novas oportunidades de crescimento (OLIVEIRA et al., 2010). Esta satisfação está relacionada com o bemestar e está vinculado a aspectos mais latentes a sua remuneração, tais como autodeterminação individual e coletiva, envolvimento com os valores da empresa e compartilhamento de sua visão (SEN, 1993; RYAN; DECl, 2000).

A gestão de SST pode proporcionar Qualidade de Vida no Trabalho (QVT) proporcionando um ambiente juridicamente correto, socialmente encorajador e individualmente desafiador. Além disso, pode evocar o sentimento individual ou coletivo de querer estar naquele local, se sentir em casa e encontrar o apoio necessário para desenvolver-se (SENNET, 2009, 2012).

Porém, a gestão de SST nem sempre é praticada por todas as empresas, dentre os quais pode-se destacar as Micro e Pequenas empresas (MPE). As MPEs possuem importante papel na inclusão econômica e social, destacando-se pela participação no acesso às oportunidades de emprego e no desenvolvimento econômico do país (MENDONÇA, 2011).

Devido às MPEs serem importante instrumento de inclusão econômica e social, nos últimos anos o governo lançou programas de concessão de crédito para a abertura de micro e pequenas empresas (MPE) (BNDES, 2014) o propiciou um significativo crescimento do número de empresas abertas, chegando a 13.885.170 em 2015 (INSTITUTO BRASILEIRO DE PLANEJAMENTO E TRIBUTAÇÃO, 2015).

Mesmo com este cenário de investimento nas MPME, as políticas de saúde e segurança são dificilmente vistas em empresas de pequeno porte. A dificuldade de implantação destas políticas é resultado, principalmente, do pouco recurso financeiro e da falta de informação dos donos das empresas (COSTA; MENEGON, 2008).Quando há a implantação do sistema, nem sempre é possível perceber os resultados, já que o investimento em segurança não repercute diretamente nos lucros.

Assim, devido a estas características estruturais, culturais e de gestão, Costa e Menegon (2008) afirmam que algumas normas e leis referentes à SST deveriam ser adaptadas a realidade das MPEs, facilitando a utilização das mesmas pelas organizações e é neste contexto que a presente pesquisa foi desenvolvida. Soma-se a isso incipiência de estudos focados neste tipo de organizações, pois a maioria dos estudos se focam em organizações de grande porte (MOORE; PARAHOO; FLEMING, 2010 apud MENDONÇA, 2011).

Assim, o objetivo deste trabalho é analisar as práticas de SST em uma microempresa especializada na fabricação de vassouras, rodos e escovas e reciclagem de materiais do interior do Estado do Ceará. Foram identificados os riscos presentes e as principais dificuldades relacionadas à gestão de saúde e segurança do trabalho no processo produtivo, apresentando-se recomendações para sanar os riscos e indicando algumas boas práticas para auxiliar na melhoria gestão da SST.

Para tal, este artigo foi dividido em cinco seções, incluindo esta introdução. A seguir, é apresentado o 
referencial teórico acerca da questão da Segurança e Saúde do Trabalho nas MPEs e das dificuldades e motivações para gestão da SST. Na sequência, é apresentado o método de pesquisa, seguido da caracterização do estudo de caso realizado. Por fim, são apresentados os resultados divididos em (i) levantamento dos riscos e recomendações e (ii) boas práticas que podem ser adotadas para gestão da SST em empresas deste porte.

\section{ESPECIFICIDADES DAS MICRO E PEQUENAS EMPRESAS E SUA RELAÇÃO COM A SEGURANÇA E SAÚDE DO TRABALHO}

As diferenças entre pequenas, médias e grandes empresas demandam atividades desenvolvidas de acordo com o seus tamanhos as características de cada local de trabalho. O sistema de gerenciamento de ações em saúde e segurança deveria se adaptar ao tamanho, às necessidades, aos processos operados, especificidades e limitações de cada MPE. (BRADSHAW et al., 2001 apud COSTA; MENEGON, 2008).

O Brasil possui diversas medidas de manutenção de saúde e segurança, tais como as Normas Regulamentadoras do Trabalho (NR), a Consolidação das Leis do Trabalho (CLT), além de eventuais programas em saúde e segurança (COSTA; MENEGON, 2008).

A CLT estabelece critérios para um ambiente de trabalho seguro e saudável. Ela determina que o órgão de âmbito nacional competente deve estabelecer normas e controlar a fiscalização; que as empresas devem cumprir as normas relacionadas à saúde e segurança, instruindo seus empregados quanto aos procedimentos de segurança e manutenção da saúde, e estes devem cumpri-las juntamente com a empresa (COSTA; MENEGON, 2008).

Dependendo do número de funcionários e da periculosidade das atividades desenvolvidas, a empresa também deverá constituir uma Comissão Interna de Prevenção de Acidentes (CIPA), composta por representantes do empregador e dos empregados, e manter Serviços Especializados em Engenharia de Segurança e em Medicina do Trabalho (SESMT) (CAMPANHOLE; CAMPANHOLE, 1993 apud COSTA; MENEGON, 2008).

Porém, o que se observa é que as mesmas leis que regem as grandes organizações são impostas às micro e pequenas, sem levar em consideração as condicionantes estruturais e ambientais que limitam ou impulsionam as empresas as quais são apresentadas no quadro 1.

Quadro 1- Principais características das MPEs brasileiras.

\begin{tabular}{|c|c|c|}
\hline $\begin{array}{l}\text { Especificidades } \\
\text { Organizacionais }\end{array}$ & $\begin{array}{c}\text { Especificidades } \\
\text { Decisionais }\end{array}$ & $\begin{array}{l}\text { Especificidades } \\
\text { Individuais }\end{array}$ \\
\hline $\begin{array}{l}\text { pobreza de } \\
\text { recursos } \\
\text { gestão } \\
\text { centralizadora } \\
\text { situação extra- } \\
\text { organizacional } \\
\text { incontrolável } \\
\text { fraca maturidade } \\
\text { organizacional } \\
\text { fraqueza das partes } \\
\text { no mercado } \\
\text { estrutura simples } \\
\text { e leve } \\
\text { ausência de } \\
\text { planejamento } \\
\text { fraca especialização } \\
\text { estratégia intuitiva } \\
\text { sistema de } \\
\text { informações simples }\end{array}$ & $\begin{array}{l}\text { tomada de decisão } \\
\text { intuitiva } \\
\text { horizonte temporal } \\
\text { de curto } \\
\text { prazo } \\
\text { inexistência de } \\
\text { dados } \\
\text { quantitativos } \\
\text { alto grau de } \\
\text { autonomia decisória } \\
\text { racionalidade } \\
\text { econômica, política } \\
\text { e familiar }\end{array}$ & $\begin{array}{l}\text { onipotência do } \\
\text { proprietário/ } \\
\text { dirigente } \\
\text { identidade entre } \\
\text { pessoa física e } \\
\text { jurídica } \\
\text { dependência } \\
\text { perante certos } \\
\text { funcionários } \\
\text { influência pessoal } \\
\text { do proprietário / } \\
\text { dirigente } \\
\text { simbiose entre } \\
\text { patrimônio social e } \\
\text { pessoal } \\
\text { propriedade dos } \\
\text { capitais } \\
\text { propensão a riscos } \\
\text { calculados }\end{array}$ \\
\hline
\end{tabular}

Fonte: elaborado a partir de Leone (1999)

Estas características per se são desafios à gestão que se refletem na aplicação de recursos para a SST, o que conduz naturalmente a deficiências quanto ao cumprimento das normas regulamentadoras. É comum que firmas menores não conseguirem seguir as regras estabelecidas pelas normas de saúde e segurança (COSTA; MENEGON, 2008).

Segundo o Ministério da Previdência e Assistência Social, a incidência de acidentes e doenças relacionadas às condições de trabalho nas micro e pequenas empresas chegam a ser quatro vezes maior que naquelas classificadas como grandes(MPAS, 2003 apud MENDONÇA, 2011).

Esta realidade pode estar vinculada a estratégia e as 
tomadas de decisões intuitivas, conforme apontado por Leone (1999, p. 92): "para o dirigente, é preferível agir só e guiado mais pela sua sensibilidade do que pelos meios técnicos de administração [...]". Some-se a isto a falta de planejamento e conhecimentos técnicos suficientes para identificar os resultados positivos da aplicação de recursos para a gestão da SST.

Os Sistemas de Gestão de Saúde e Segurança no Trabalho (SGSSTs) são ferramentas gerenciais que contribuem para a melhoria do desempenho das empresas com relação às questões de segurança e saúde, visando atendimento às legislações, aumento da produtividade, diminuição de acidentes e credibilidade perante a opinião pública (OLIVEIRA et al., 2010).

As micro e pequenas empresas devem adotar SGSSTs de forma a conseguir a "melhoria na imagem, aumento da competitividade, chance de reduzir os custos com gestão, novas oportunidades de mercado, produtividade mais alta e melhorias nos produtos." (SALAMONE, 2008 apud OLIVEIRA et al., 2010).

Oliveira et al. (2010) observaram várias motivações e obstáculos para o investimento em SST, conforme o Quadro 2.

Quadro 2- Principais motivações e os obstáculos para implantação de SGSSTs

\begin{tabular}{|l|l|}
\hline Motivações & Obstáculos \\
\hline Melhoria contínua & Dificuldades no gerenciamento \\
Melhoria na imagem & Custos muito alto \\
Maior competitividade & Falta de recursos humanos \\
Novas oportunidades no & competentes \\
mercado & Falta de informação \\
Melhoria na produtividade & Falta de clareza de padrões \\
Melhorias no produto & \\
Pressões governamentais & \\
Pressão da comunidade local & \\
Pressão dos clientes & \\
\hline
\end{tabular}

Fonte: Oliveria et al. (2010).

Observa-se que, apesar do número de motivações ser superior ao de obstáculos, a gestão de SGSSTs em Micro e Pequenas Empresas esbarra nos custos provenientes desta busca, pois os gestores de MPEs possuem visão de curto prazo e focam em investimentos com retorno rápido, retornos estes dificilmente relacionados à SST .

\section{METODOLOGIA}

A estratégia aplicada nesta pesquisa foi o estudo de caso. Quanto aos objetivos da pesquisa, este trabalho caracteriza-se como pesquisa exploratória com dados qualitativos com resultados aplicados, visando à evidenciação de boas práticas a partir do caso analisado (COLLIS; HUSSEY, 2005).

O presente estudo classifica-se como qualitativo com objetivos descritivos(COLLIS; HUSSEY, 2005). Como estratégia de pesquisa utilizou-se o estudo de caso (YIN, 2010) cujas fontes de evidencia foram utilizadas entrevistas semiestruturadas, documentos (RICHARDSON, 2011) e observação não-participante (FERREIRA; TORRECILHA; MACHADO, 2012). Para análise dos dados utilizou-se a análise de conteúdo (KRIPPENDORFF, 2004).

Yin (2010) define o estudo de caso como uma investigação empírica que permite analisar um fenômeno contemporâneo em seu contexto de vida realproporcionando um grande alcance do objeto estudado, pois envolve um estudo profundo e exaustivo que permite o amplo e detalhado conhecimento sobre o objeto estudo (ROESCH, 2006; GIL, 2008; YIN, 2010). Este estudo foi realizado entre janeiro de 2015 e maio de 2015.Foram quatro visitas a unidade fabril quando da oportunidade foram realizadas as entrevistas, bem como foram colhidas as documentações como, por exemplo, instruções de trabalho relacionados à SST.

A empresa estudada, aqui denominada ficticiamente de Empresa Alfa, tem 15 anos de atuação e é especializada na fabricação de vassouras, rodos e escovas e reciclagem de materiais. Ela possui 12 funcionários, com faixa etária entre 18 e 50 anos, e maquinários de grande porte como extrusoras, tufadeiras e resfriadores. É classificada, de acordo com a NR 4, como grau de risco 3 e não precisa de SESMT e/ou CIPA. Além disso, a empresa não possui técnicos em segurança do trabalho. 


\section{RESULTADOS}

A seguir os resultados são apresentados em duas seções: (i) Levantamento dos Riscos e Recomendações; e (ii) Boas práticas para gestão de SST.

\subsection{LEVANTAMENTO DOS RISCOS RECOMENDAÇÕES}

O processo de levantamento dos riscos se deu por toda empresa identificando os riscos do processo produtivo, analisando e avaliando as condições de iluminação, ventilação, ruído, pisos, deslocamento dos materiais, uso dos EPIs, proteção de máquinas, eletricidade, arranjo físico, histórico de acidentes, entre outros, cujos resultados encontram-se no Quadro 3.

Quadro 3- Riscos e recomendações levantadas para a Empresa Alfa.

\begin{tabular}{|c|c|c|c|}
\hline \multirow[t]{2}{*}{ Tipo } & \multicolumn{2}{|r|}{ Fonte Geradora } & $\begin{array}{l}\text { Recomendações } \\
\text { (atendendo as normas regulamentadoras) }\end{array}$ \\
\hline & Ruído & $\begin{array}{l}\text { Injetoras, aglutinador, grampeador, } \\
\text { tufadeiras, floradeira }\end{array}$ & Uso de protetor auditivo circum-auricular simples. \\
\hline Riscos Físicos & Calor/Vapores & $\begin{array}{l}\text { Injetoras, plastificadora de cabos, } \\
\text { aglutinador }\end{array}$ & $\begin{array}{l}\text { - Uso de ventiladores e umidificadores; } \\
\text { - Uso de luvas de proteção contra agentes térmicos; } \\
\text { - Vestimentas para proteção do tronco contra riscos de } \\
\text { origem térmica; } \\
\text { - Ingestão de líquidos. }\end{array}$ \\
\hline \multirow{2}{*}{$\begin{array}{l}\text { Riscos } \\
\text { Químicos }\end{array}$} & Poeira & $\begin{array}{l}\text { Sacos de armazenagem da } \\
\text { matéria prima, serragem, pó do } \\
\text { acabamento }\end{array}$ & $\begin{array}{l}\text { - Uso de máscara respiratória PFF1para proteção das vias } \\
\text { respiratórias contra poeiras. } \\
\text { - Óculos para proteção dos olhos contra impactos de } \\
\text { partículas volantes. }\end{array}$ \\
\hline & $\begin{array}{l}\text { Substâncias } \\
\text { Químicas }\end{array}$ & $\begin{array}{l}\text { Adição de pigmentos e aditivos, } \\
\text { fundição e resfriamento rápido do } \\
\text { plástico. }\end{array}$ & $\begin{array}{l}\text { - Uso de máscara respiratória semifacial PFF3para proteção } \\
\text { das vias respiratórias contra poeiras e fumos. } \\
\text { - Óculos para proteção dos olhos contra impactos de } \\
\text { partículas volantes. }\end{array}$ \\
\hline \multirow[t]{2}{*}{$\begin{array}{l}\text { Riscos } \\
\text { Biológicos }\end{array}$} & $\begin{array}{l}\text { Vírus, bactérias, } \\
\text { protozoários, fungos } \\
\text { e parasitas. }\end{array}$ & Matéria-prima contaminada & $\begin{array}{l}\text { - Uso de luvas, máscaras e óculos; } \\
\text {-Práticas de higiene. }\end{array}$ \\
\hline & Postura repetitiva & $\begin{array}{l}\text { Longos períodos de trabalho em pé } \\
\text { nas injetoras, tufadeiras, floradeiras } \\
\text { e na produção de rodo. }\end{array}$ & $\begin{array}{l}\text { - Revezamento de posto. } \\
\text { - Intervalos para descanço. } \\
\text { - Adaptação do posto de trabalho para esta posição. }\end{array}$ \\
\hline \multirow[t]{4}{*}{$\begin{array}{l}\text { Riscos } \\
\text { Ergonômicos }\end{array}$} & $\begin{array}{l}\text { Movimentos } \\
\text { repetitivos }\end{array}$ & $\begin{array}{l}\text { Abastecimento das extrusoras, } \\
\text { separação de material, } \\
\text { encaixotamento dos produtos. }\end{array}$ & $\begin{array}{l}\text { - Revezamento de posto. } \\
\text { - Intervalos para descanço. } \\
\text { - Adaptação do posto de trabalho às condições } \\
\text { psicofisiológicas do funcionário. }\end{array}$ \\
\hline & $\begin{array}{l}\text { Trabalho físico } \\
\text { pesado }\end{array}$ & $\begin{array}{l}\text { Carga e descarga de sacos de } \\
\text { matéria prima, cabos e mercadorias } \\
\text { prontas. }\end{array}$ & $\begin{array}{l}\text { - Revezamento de posto. } \\
\text { - Intervalos para descanço. } \\
\text { - Uso de meios técnicos apropriados para facilitar o } \\
\text { transporte da carga. }\end{array}$ \\
\hline & $\begin{array}{l}\text { Arranjo físico } \\
\text { deficiente }\end{array}$ & Piso com variações, má iluminação & $\begin{array}{l}\text { - Conserto. } \\
\text { - Instalação de placas de aviso. }\end{array}$ \\
\hline & Choques & Fiação exposta e improvisada & Isolar toda a fiação de acordo com as normas de segurança. \\
\hline \multirow[t]{3}{*}{$\begin{array}{l}\text { Riscos } \\
\text { Mecânicos }\end{array}$} & $\begin{array}{l}\text { Objetos perfuro } \\
\text { cortantes }\end{array}$ & $\begin{array}{l}\text { Grampeador de cabos, facas, } \\
\text { pregos, agulhas e hélices }\end{array}$ & Uso de luvas de raspa de couro. \\
\hline & Incêndio & Matéria prima inflamável & $\begin{array}{l}\text { Possuir equipamentos de combate a incêndio: extintores, } \\
\text { sensores de fumaça, hidrantes. }\end{array}$ \\
\hline & Queimadura & Injetoras, aglutinador & Uso de luvas e mangote de couro. \\
\hline
\end{tabular}

Fonte: Elaborada pelos autores em conformidade com as NRs 12, 15, 17. 
As Figuras 1, 2 e 3 apresentam o setor de produção da empresa analisada, podendo-se verificar a falta de Equipamentos de Proteção Individual (EPI) e Equipamentos de Proteção Coletiva (EPC). Assim, é importante destacar que os funcionários também devem usar calçados e calças para proteção contra impactos de quedas de objetos cortantes e perfurantes, contra

Figura 1 - Setor da produção onde estão as injetoras

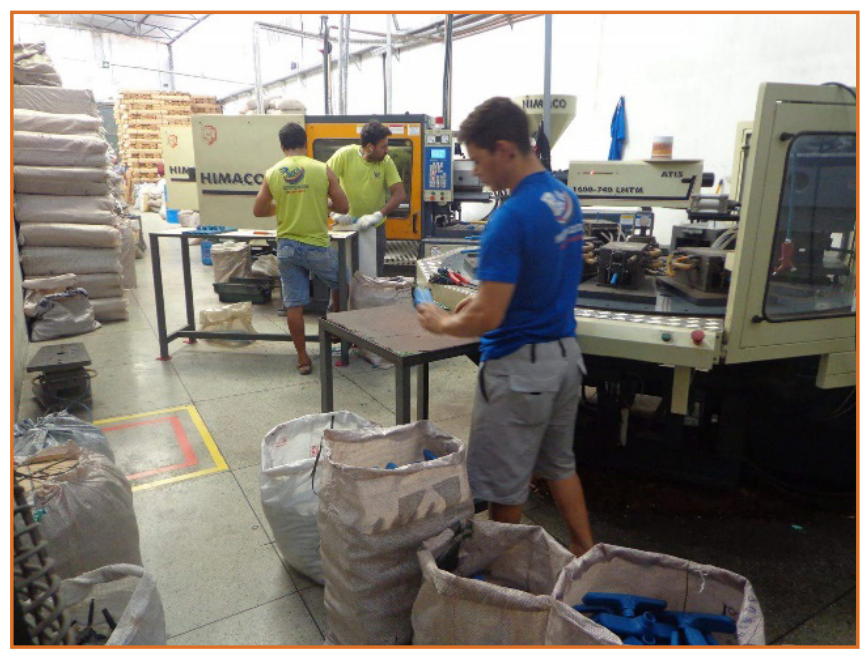

Figura 3 - Estoque de ativos (primeiro plano) e máquinas tufadeiras (ao fundo).

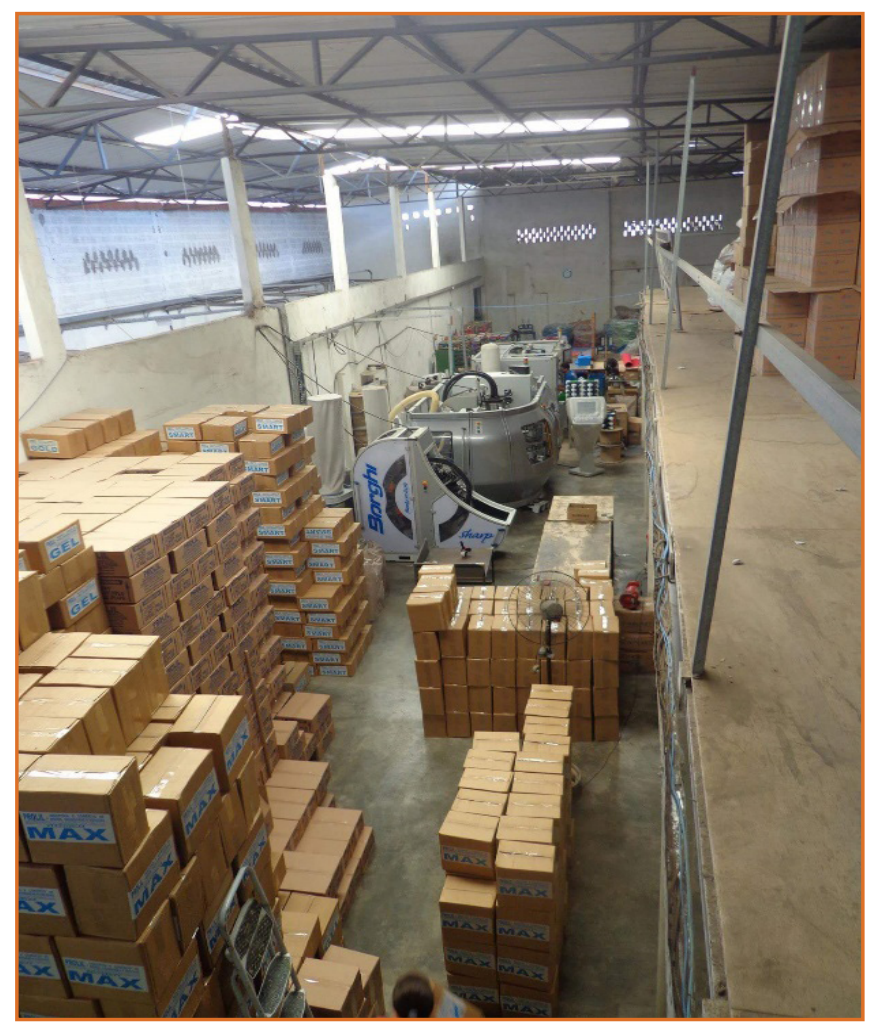

Durante os seus 15 anos deatuação, a empresaregistrou quatro acidentes de trabalho. No primeiro acidente, agentes abrasivos e escoriantes; e contra respingos de produtos químicos. Além do fornecimento, como forma de propiciar melhoria das condições de trabalho mediante a prevenção de acidentes deve-se realizar treinamentos e a sensibilização para o seu uso, uma vez que o grau de escolaridade dos funcionários é baixo.

Figura 2 - Setor onde os cabos recebem o acabamento final

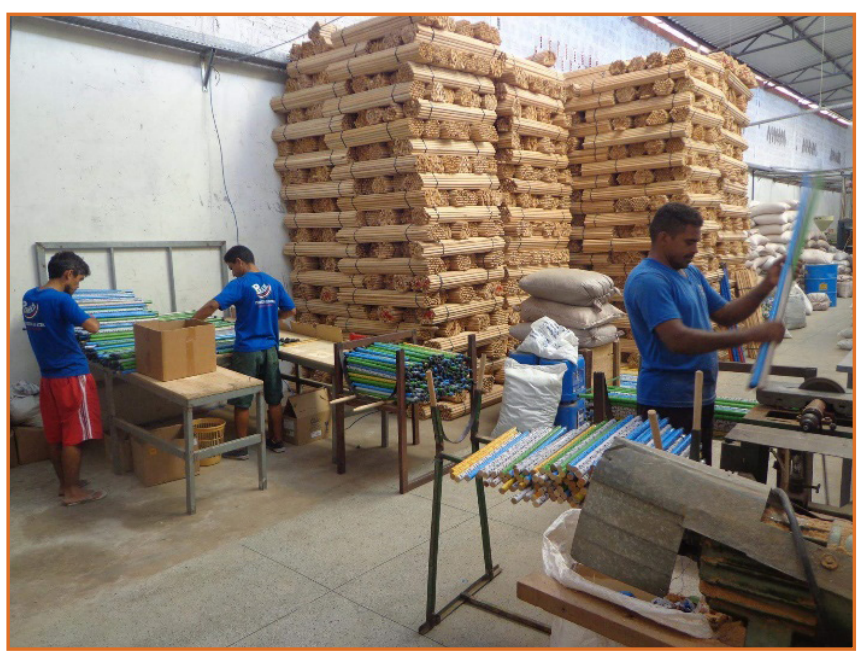

um corte causado por material perfurocortante, o funcionário recebeu atestado médico e ficou afastado por um dia. O custo médio gerado para a empresa foi de $R \$ 150,00$, relacionado ao atendimento em um ambulatório hospitalar e um dia sem o funcionário na linha de produção.

No segundo acidente, também um corte causado por material perfurocortante, o funcionário recebou um atestado médico de cinco dias. O custo médio gerado para a empresa foi de $R \$ 270,00$, relacionado ao atendimento em um ambulatório hospitalar e os dias sem o funcionário na linha de produção.

O terceiro e o quarto acidente ocorreram com funiconários que trabalhavam na preparação de misturas da matérias-primas com aditivos químicos. Um foi acometido de problemas respiratórios e o outro desenvolveu alergia cutânea nos braços. Ambos estão sob licença há dois anos e recebem auxílio doença da Previdência Social até os dias atuais. Com isso, a empresa teve um custo médio de $\mathrm{R}$ \$572,00/ funcionário gerado pelos primeiros 15 dias de afastamento. Após esse período, o pagamento do auxílio-doença passou 
a ser feito pelo INSS.

A empresa Alfa não soube informar de quanto foi a queda na produção em cada um dos casos e se isso atrasou as vendas e a entrega de mercadorias.

Com esses quatro acidentes a empresa teve um custo total de $R \$ 1564,00$ sem levar em consideração a queda na produção pelos dias de afastamento. Apesar de o valor ser pequeno, em termos econômicos para a empresa, o prejuízo à saúde dos operários afastados pelo INSS é grave, podendo-se desdobrar em aposentadoria por invalidez repercutindo negativamente sobre a motivação dos funcionários remanescentes à empresa.

\subsection{BOAS PRÁTICAS PARA GESTÃO DE SST}

Com base na literatura, na experiência dos autores e no estudo realizado, foi possível identificar algumas boas práticas para a gestão de sistemas de segurança e saúde no trabalho que podem ser adotadas na empresa Alfa:

- Comprometimento da direção: o real comprometimento da direção comoSGSST estimula os funcionários a participarem das iniciativas propostas pela organização e contribuírem com a melhoria do ambiente de trabalho;

- Minimização da resistência às mudanças: conflitos, incertezas e falta de informação podem gerar resistência às mudanças sugeridas e interferir negativamente na implantação do SGSST. Incentivar a participação dos colaboradores no sistema, valorizar as opiniões, capacitar e disponibilizar informações e recursos aliviam essa resistência;

- Capacitação técnica e gerencial dos profissionais: investir em treinamentos técnicos e comportamentais pode ser um meio eficaz para desenvolver competências específicas nos funcionários e mostrar os benefícios individuais e coletivos da prevenção de acidentes colaboradores;

- Desenvolver um mapa de riscos: o mapa de riscos tende a ser melhor aceito pelos empregados por resultar em maior conhecimento e proximidade entre o trabalhador e o local com possível risco de gerar acidente. O mapa é mais específico e de fácil leitura;

- Definir indicadores de desempenho em SST e realimentar o sistema: indicadores com a taxa de gravidade, custos dos acidentes de trabalho global e por colaborador, números de dias sem acidente de trabalho, número de queixas e ações judiciais, custos com multas, valor investido mensalmente em segurança do trabalho dentre outrospermitem a visualização do status do desempenho do SGSST, e a partir disto, a realização de uma autoavaliação e o estabelecimento de planos de ação para eventuais correções dos objetivos e metas estabelecidos.

- Colaboração na cadeia produtiva local: um conjunto de microempresas poderiam se unir e ratear o salário de um técnico de segurança que desenvolveria mapas de riscos e indicaria quais equipamentos são necessários para evitar acidentes de trabalho no processo produtivo dessas microempresas.

\section{CONCLUSÕES}

A avaliação e controle dos riscos são indispensáveis para a garantia do ambiente de trabalho seguro. A sistematização da identificação, quantificação e qualificação dos riscos permite aos gestores condições para agir e minimizar as causas de acidentes ou de riscos proeminentes.

O simples ato de instruir quanto à segurança não garante que tudo correrá bem. Organizar o trabalho é essencial para que a mudança seja de fato eficaz e para eliminar fatores de risco no trabalho, tanto em questão de segurança, quanto de saúde, não só contribuindo para diminuição de acidentes, mas também para a prevenção destes e de doenças relacionadas ao trabalho.

Com o exposto foi possível identificar algumas boas práticas e as principais dificuldades relacionadas à implantação de Sistemas de Gestão de Saúde e Segurança no Trabalho em micro e pequenas empresas. 
Esse conhecimento possibilita o direcionamento de investimentos em programas e sistemas na área de segurança do trabalho, impulsionando a melhoria das condições de vida do trabalhador, que levam a minimizar as condições de riscos existentes nos ambientes de trabalho.

Os micro e pequenos empresários devem estar cientes de que promover a segurança do trabalho é economicamente vantajosa. Além da obrigação legal, é dever moral, devido aos aspectos sociais envolvidos, causando danos a todos os segmentos: empresas, trabalhadores e sociedade; resultando para todos, custo econômico e humano.

Conclui-se que a gestão de SST na microempresa analisada é uma questão crítica tendo em vista os diversos riscos identificados. Porém, tais riscos podem ser mitigados com pequenas ações e de custos inexpressíveis o que indica a falta de informações dos gestores, obstáculo mencionado na literatura e característica marcante das MPEs. Esta constatação, embora proveniente de um único estudo de caso, pode indicar um sintoma presente em várias MPEs ora não exploradas.

Por fim, aponta-se que os órgãos que regulamentam as questões de SST não possuem ações em caráter orientativo e de parceria com as MPEs que dispõem de pouco capital. Seria oportuno, neste sentido que ao invés de fiscalizações com caráter punitivo o governo investisse em ações colaborativas aos empresários.

\section{REFERÊNCIAS}

[1] Banco Nacional de Desenvolvimento Econômico e Social (BNDES). Cartilha de Apoio às Micro, Pequenas e Médias Empresas. 2014.

[2] COLLIS, J; HUSSEY, R. Pesquisa em administração: um guia prático para alunos de graduação e pós-graduação. 2ed. Porto Alegre, RS: Bookman, 2005.

[3] COSTA, C. D.; MENEGON, N. L. Condução de ações em saúde e segurança do trabalho em pequenas e médias empresas: análise de três casos. Revista Brasileira de Saúde Ocupacional, vol. 33, Brasil, 2008.
[4] FERREIRA, L. B.; TORRECILHA, N.; MACHADO, S. H. S.A técnica de observação em estudos de administração. In: ENCONTRO NACIONAL DOS PROGRAMAS DE PÓSGRADUAÇÃO E PESQUISA EM ADMINISTRAÇÃO, 36., 2012, Rio de Janeiro. Anais... Rio de Janeiro, RJ: ANPAD, 2012.

[5] GIL, A. C.Métodos e Técnicas de Pesquisa Social. 6 ed. São Paulo: Atlas S. A, 2008.

[6] JÚNIOR, B. B., VÉRAS, J. C., LAGO, E. M. G., RABBANI, E. R. K. Indicadores de segurança do trabalho para direcionamento do sistema de gestão de segurança e saúde no trabalho. In: XXVI Encontro Nacional de Engenharia de Produção, 2006.

[7] KRIPPENDORFF, K. Content analysis: an introduction to its methodology. 2 ed. London, UK: Sage Publications, 2004.

[8] LEONE, N. M. C. P. G. As especificidades das pequenas e médias empresas. Revista de Administração, v. 34, n. 2, p. 91-94, 1999. Disponível em: <http://www.spell.org.br/ documentos/ver/18123/as-especificidades-das-pequenase-medias-empresas> Acesso em: 18 ago. 2015.

[9] MONTEIRO, L. F.; LIMA, H. L. M.; SOUZA, M. J. P.A Importância da Saúde e Segurança no Trabalho nos Processos Logísticos.XII SIMPEP, Bauru, 2005.

[10] OLIVEIRA,O. J. de, OLIVEIRA, A. B. de, ALMEIDA, R. A. de. Gestão da segurança e saúde no trabalho em empresas produtoras de baterias automotivas: um estudo para identificar boas práticas. RevistaProdução, v. 20, n. 3, p. 481-490, jul./set. 2010.

[11] ORGANIZAÇÃO INTERNACIONAL DO TRABALHO. Sistema de Gestão da Segurança e Saúde no Trabalho : Um instrumento para uma melhoria contínua. 2011.

[12] RIBEIRO, C. T.; AMARAL, F. G.Proposta de implementação de um sistema de gestão de saúde e segurança no trabalho com base na OHSAS 18001: um estudo de caso. Monografia - Universidade Federal do Rio Grande do Sul. Escola de Engenharia, 2011.

[13] RICHARDSON, R. J. Pesquisa Social: Métodos e Técnicas. 3 ed. São Paulo, SP: Atlas, 2011.

[14] ROESCH, S. A.Projetos de estágio e de pesquisa em administração: guia para estágios, trabalhos de conclusão, dissertações e estudos de caso. 3 ed. São Paulo, SP: Atlas, 2006.

[15] RYAN, R. M. .; DECI, E. L. Self-determination theory and the facilitation of intrinsic motivation, social development, and well-being. American Psychologist, v. 5, n. 1, p. 68-78, 2000. SEN, A. Capability and well-being. In M. C. Nussbaum \& A. Sen (Eds.). The quality of life. Oxford: Clarendon Press, 1993. p.30-53

[16] SENNET, R. O Artífice. Rio de Janeiro, RJ: Record, 2009. 
[17] SENNET, R. Juntos: os rituais, os prazeres e a política da cooperação. Rio de Janeiro, RJ: Record, 2012.
[18] YIN, R. K.Estudo de caso: planejamento e métodos. 4 ed. Porto Alegre: Bookman, 2010. 


\title{
CAPÍTULO 3
}

\section{ANÁlise do PROCESSO DE TRABALHO NA LAPIDAÇÃO DE CRISTAIS E ROCHAS ORNAMENTAIS DO MUNICÍPIO DE CORINTO/MG}

\author{
Mário Eugênio de Paula Alves Bezerra \\ Natália Luísa Felício Macedo
}

Resumo: Corinto, município situado em Minas Gerais, é bastante conhecido pela lapidação de cristais de quartzo. Atualmente, grande parte dos lapidários vem sendo diagnosticada com silicose, uma pneumoconiose fibrosante e progressiva, trazendo graves consequências para a saúde dos trabalhadores e para a população nos arredores do ambiente produtivo. Foi estudado o processo de trabalho com vistas a propor medidas de intervenção para amenizar os impactos negativos da atividade sobre os trabalhadores, por meio de observações in loco e entrevistas com informantes chave para a obtenção de detalhes do processo de lapidação e conhecimento das condições de saúde dos lapidários. Verificou-se a necessidade de intervenções imediatas no processo de trabalho para redução de poeira e demais riscos ocupacionais e ambientais, por meio de melhor organização do espaço e eficiência do trabalho, adequação de equipamentos de proteção individual e coletiva, capacitação e sensibilização dos lapidários para a utilização correta e sistemática dos mesmos, umidificação adequada dos processos de trabalho em todas as etapas geradoras de poeiras, com o enclausuramento das máquinas e equipamentos não passíveis de utilização a úmido, monitoramento permanente da qualidade do ar com vistas à identificação, quantificação e qualificação de poeiras e principais fontes geradoras.

Palavras Chave: Lapidação, cristal de quartzo, silicose, doença ocupacional, processo de trabalho. 


\section{INTRODUÇÃO}

A indústria da mineração possui grande relevância na economia brasileira, sendo responsável por 3,8\% do Produto Interno Bruto (PIB) nacional. Além disso, a atividade também apresenta relevância social, uma vez que é responsável pela geração de 2,2 milhões de empregos diretos na cadeia produtiva (SINDIEXTRA, 2011). Segundo o Departamento Nacional de Produção Mineral - DNPM, os principais produtos não metálicos minerados no Brasil são areia (8,2\%), brita (7,6\%) e calcário (3,5\%) (DNPM, 2011).

O cristal de quartzo pode ser obtido na natureza em ocorrências ou jazidas, ou por crescimento hidrotérmico na indústria de cristais cultivados. O Brasil é o país que detém as maiores reservas mundiais de quartzo, situando-se à frente de países como Suíça, Japão e África do Sul. Suas reservas são estimadas em 95\% das reservas mundiais, equivalentes a 78 milhões de toneladas (MINISTÉRIO DAS MINAS E ENERGIA, 2009).

No estado do Pará encontram-se as maiores reservas medidas de quartzo do País, cerca de 64\%, seguido de $17 \%$ em Minas Gerais, $15 \%$ em Santa Catarina e 2\% na Bahia (MINISTÉRIO DAS MINAS E ENERGIA, 2009). No entanto, a real produção brasileira é subestimada, pois como muitas empresas operam no regime de garimpo e de forma muito rudimentar, elas não têm base tecnológica para agregar valor e explorar toda a potencialidade do uso do mineral.

A utilização do quartzo depende de sua qualidade, sendo os melhores cristais destinados à indústria óptica, eletrônica e de instrumentação (considerados os maiores consumidores), e os de qualidade inferior destinados à indústria em geral (abrasivos, cerâmica, metalúrgica). O Brasil, apesar de ser o maior produtor mundial de quartzo, é dependente de produtos de quartzo manufaturado (cristais piezelétricos montados e suas partes, e em menor valor, cristal cultivado bruto e usinado). Os principais setores de consumo são as indústrias de relógios eletrônicos, de automóveis, jogos eletrônicos, equipamento de telecomunicações, computadores e equipamentos médicos (MINISTÉRIO DAS MINAS E ENERGIA, 2009). significativo aumento na década de 1970, com forte declínio na década de 1990. Porém, desde 2004 vem apresentando crescimento, sendo praticamente a totalidade da produção destinada à exportação (MINISTÉRIO DAS MINAS E ENERGIA, 2009). A mecanização da explotação de quartzo é complexa, dada a necessidade de se evitar danos na estrutura do cristal por quebra. Já no caso de extração de lascas, a mecanização pode se estender muito se as jazidas forem contínuas.

A cidade de Corinto, localizada na região central de Minas Gerais, próximo à cidade de Curvelo e a aproximadamente $230 \mathrm{~km}$ ao norte de Belo Horizonte, capital do estado, é uma das principais produtoras de quartzo do estado. A atividade de lapidação artesanal de cristais de quartzo para produção de objetos decorativos constitui uma das principais fontes de renda da população local.

O objetivo do presente estudo é descrever e analisar o processo de trabalho dos lapidários de cristal e rochas ornamentais do município de Corinto, Minas Gerais, e seus possíveis impactos na saúde dos trabalhadores, apontando possíveis soluções.

\section{MÉTODOS}

Foi realizado estudo transversal descritivo, do tipo estudo de caso único, baseado em coleta de dados qualitativos, com objetivo de estabelecer um diagnóstico situacional dos riscos ocupacionais inerentes ao trabalho de lapidação de cristais no município de Corinto/MG e, a partir dele, propor medidas de mitigação dos problemas encontrados. Os estudos transversais, embora se limitem a retratar a realidade em um determinado momento ou recorte de tempo, apresentam vantagens importantes como baixo custo, simplicidade analítica, alto potencial descritivo e rapidez na coleta das informações, além da facilidade na representatividade da população a partir de um número relativamente reduzido de observações (SITTA et al, 2010).

A opção pela realização de um estudo de caso reside no fato de que, segundo Merrian (1988), o conhecimento gerado a partir do estudo de caso

A produção brasileira de quartzo bruto teve 
é diferente do conhecimento gerado a partir de outras pesquisas porque é mais concreto, mais contextualizado, mais voltado para a interpretação do pesquisador e baseado em populações de referência determinadas pelo pesquisador. Por outro lado, o método qualitativo permite a abordagem das questões em amplitude e profundidade, uma vez que consideram as unidades sociais investigadas como totalidades que desafiam o pesquisador, permitindo ao mesmo uma estreita aproximação dos dados, abrindo-se à realidade social para melhor apreendê-la e compreendê-la. Conforme ressalta Martins (2004), "se há uma característica que constitui a marca dos métodos qualitativos ela é a flexibilidade, principalmente quanto às técnicas de coleta de dados, incorporando aquelas mais adequadas à observação que está sendo feita".

Assim, foram realizadas análises de informações constantes em sites de órgãos como IBGE, DNPM, FUNDACENTRO e Ministério de Minas e Energia, observação in loco por meio de visitas de campo a oficinas de lapidários do município de Corinto e entrevistas semiestruturadas com lapidários e técnicos da área, sendo eles Engenheiro de Minas, Médico do Trabalho, Enfermeiro responsável pela vigilância epidemiológica municipal e proprietário/ lapidário de uma das oficinas visitadas (SM Cristais), representativa das demais.

Os dados obtidos foram gravados e posteriormente transcritos para análise. A abordagem foi predominantemente qualitativa, baseada na interpretação dos relatos orais dos entrevistados e nas observações de campo. A partir desses relatos foi elaborada uma sistematização dos resultados com a finalidade de construir uma reinterpretação dos mesmos, visando a apreensão das concepções dos diferentes atores entrevistados sobre o tema estudado. Em seguida, as informações foram utilizadas para elaboração de proposições visando à melhoria das condições de trabalho e de saúde dos lapidários.

\section{RESULTADOS E DISCUSSÃO}

\subsection{OBSERVAÇÕES IN LOCO E ANÁLISES DE INFORMAÇÕES DE SITES}

A população atual de Corinto é estimada em 24.484 habitantes. O município possui 559 empresas atuantes, que empregam 2.042 trabalhadores assalariados, com salário médio mensal de 1,5 salários mínimos (IBGE, 2013). Os ambientes de lapidação geralmente são localizados nas próprias residências, com estruturas precárias, trabalhadores não registrados e ausência de EPIs obrigatórios.

A partir da aquisição da matéria-prima, que pode ocorrer em outros municípios ou estados, o processo produtivo de peças com pontas consiste em utilizar a serra elétrica para moldar o formato desejado (em alguns poucos casos, utiliza-se ácido muriático para retirar as impurezas do material antes de iniciar o processo de lapidação). Após esse corte a peça será "alisada", ou seja, as arestas são reparadas para ficarem pontiagudas e a superfície da peça lisa, em um torno com disco giratório, onde são adicionados água e pó de esmeril.

Em seguida, a peça é lixada de forma que a lixa funcione como uma correia circular para corrigir eventuais defeitos ocasionados pelo alisamento. Por fim, será polida em um cilindro de esmeril, com rotação em seu próprio eixo horizontal.

$\mathrm{Na}$ produção de esculturas em forma de anjos são empregadas serras elétricas diamantadas, lixa (roda expansiva) e pó de Trípoli, usado no polimento, além de pó de esmeril, utilizado no alisamento. Já na produção de peças arredondadas, como esferas e pesos para papéis, tem-se, primeiramente, o corte da matéria prima na serra de disco diamantado. Feito isso, o lapidário utiliza o "rebôlo" para abaular as peças, ou seja, dar forma arredondada para, em seguida, lixar a peça para corrigir eventuais imperfeições. Posteriormente, o produto é polido e o processo é finalizado, obtendo-se o produto final.

Trata-se de ambientes bastante insalubres, onde predominam a desorganização do espaço e de materiais. Assim, dadas as condições de trabalho e o 
ambiente laboral, os trabalhadores estão expostos a riscos de acidentes e doenças ocupacionais, muitos deles passíveis de serem eliminados ou minimizados.

\subsection{ENTREVISTA COM O LAPIDÁRIO}

Foi entrevistado um lapidário de 31 anos, sexo masculino, que possui uma pequena oficina de lapidação de cristais situada no centro urbano de Corinto, representativa das demais existentes no município. A matéria prima utilizada é basicamente o cristal de quartzo, e são produzidas peças como pirâmides, asteroides, cubos, pontas, etc., as quais são consumidas no mercado interno ou exportadas para países como Japão, França, Austrália, Bélgica e Estados Unidos.

Ele relata trabalhar há 8 anos nessa atividade, tendo iniciado sua vida laboral aos 23 anos, já como lapidário. A sua jornada de trabalho, assim como dos outros lapidários locais, é de 10 horas (7 às 17 h) de segunda a quinta feira, e de 9 horas (7 às $16 \mathrm{~h}$ ) nas sextas feiras, com horário para almoço entre 11:00 e 12:00.

A quantidade a ser produzida diariamente depende das metas estabelecidas, que por sua vez são estipuladas em quilos a serem trabalhados pelos seus funcionários, especialmente durante a realização de horas extras. A meta também pode ser estabelecida segundo número de peças por unidade de tempo, e a remuneração dos funcionários está vinculada a essa produção.

O lapidário relata que a matéria-prima é adquirida diretamente de cooperativas de trabalhadores do setor extrativo mineral, provenientes de Corinto ou mesmo dos estados de Tocantins e Bahia. A aquisição da matéria-prima é sazonal, dependendo da qualidade e tipo de quartzo desejado. Relata, ainda, que utiliza em torno de $500 \mathrm{Kg} /$ de quartzo por semana, de diferentes tipos e cores, para produção de peças denominadas "pontas". Para os demais tipos de peças, ele chega a adquirir em torno de $200 \mathrm{Kg} / \mathrm{semana}$.

$\mathrm{Na}$ oficina do entrevistado trabalham cerca de 1 a 2 pessoas por setor, variando de acordo com a demanda de produção, sendo que cada setor corresponde a uma das etapas do processo de trabalho, que envolve corte em serra elétrica, rebôlo, lixamento e polimento. Além dele, trabalham mais quatro funcionários na empresa.

Com relação os impactos do trabalho sobre a saúde dele próprio e de seus funcionários, o entrevistado acredita que existem alguns riscos, dentre os quais as lombalgias, ruídos, cortes mecânicos e doenças respiratórias, mas cita como sua principal preocupação o risco de silicose. Apesar disso, relata que a quantidade de poeira produzida "não é muita", e que a mesma não o incomoda, pois já está "acostumado". Além disso, informa que utiliza EPIs como abafadores de ruído, luvas, óculos e dedeiras, para proteger-se e a seus funcionários de outros riscos de adoecimento e de acidentes. Relata também o risco de choque elétrico, embora afirme que a instalação é "bem feita". Informa que já sofreu pequenos cortes e outros acidentes de trabalho sem maiores consequências, mas, além de apresentar dores constantes nas costas por causa da carga de peso que carrega diariamente, seu maior temor é de contrair a silicose, pois conhece algumas pessoas que trabalham como ele e já têm a doença, sendo alguns em estado grave. O entrevistado afirma que está disposto a promover melhorias no ambiente e no processo de trabalho, pois reconhece que os mesmos trazem riscos graves para a saúde dos que lá trabalham. Dentre eles, pensa em tornar a serra mais silenciosa, e reduzir a quantidade de poeira gerada no processo. Mas alega não ter informação suficiente para saber como fazê-lo, sendo que precisaria de assistência de profissionais capacitados para ajuda-lo nesse processo.

\subsection{ENTREVISTA COM O DIRETOR DO DEPARTAMENTO DE VIGILÂNCIA SANITÁRIA}

O enfermeiro e diretor do departamento de vigilância sanitária e referência técnica em saúde do trabalhador do município de Corinto, disse em sua entrevista que o município ainda possui uma grande dependência da produção de quartzo, apesar da redução do número de trabalhadores, em virtude da ocorrência de silicose e aumento do rigor na fiscalização. 
Segundo o mesmo, a prefeitura possui convênio com o Hospital das Clínicas de Belo Horizonte. Os lapidários são encaminhados para o Hospital para a realização de exames e, se necessário, tratamento, onde têm retorno agendado e o tratamento pré-estabelecido. A prefeitura de Corinto custeia alguns medicamentos mais caros, quando indicados.

Eles são acompanhados regularmente no Serviço Especializado em Saúde do Trabalhador - SEST, órgão vinculado à UFMG por intermédio do Hospital das Clínicas. A responsável pelo acompanhamento desses pacientes é uma médica pneumologista com grande experiência em diagnóstico e tratamento de pneumoconioses. Os pacientes são regularmente transportados em veículos comuns ou ambulâncias que são custeados pela Prefeitura Municipal de Corinto até Belo Horizonte, de acordo com a programação de retorno de cada um deles. Atualmente o SEST/ UFMG acompanha mais de 100 pacientes de Corinto, sendo a maioria considerados casos de silicose, e alguns já em estado bastante avançado da doença.

O entrevistado afirma que a silicose constitui um grave problema de saúde pública local, atingindo principalmente adultos jovens do sexo masculino, - que impacta diretamente as condições socioeconômicas de muitas famílias, pois, detectada a silicose, o indivíduo precisa ser afastado da exposição, o que muitas vezes implica em seu afastamento definitivo da lapidação, reduzindo, assim, a renda da família. Isso também leva a uma introdução precoce dos filhos no processo de trabalho artesanal, pois acabam substituindo seus pais no sustento da família, reproduzindo, assim, o ciclo da exposição e da doença.

\subsection{ENTREVISTA COM O ENGENHEIRO DE MINASE SEGURANÇA DO TRABALHO DA FUNDACENTRO/ MG}

Foi entrevistado um engenheiro da FUNDACENTRO/ MG responsável pela realização de coletas e análises de materiais particulados atmosféricos no município em estudo. Esse profissional possui grande experiência em técnicas de amostragem e amplo conhecimento da área de estudo, onde já desenvolveu diversos outros trabalhos. Segundo ele, os principais riscos para a saúde relacionados à lapidação do quartzo é a geração de poeiras nos ambientes de trabalho à qual estão expostos os lapidários e pessoas que circulam no ambiente. Outros riscos importantes dizem respeito ao excesso de ruído gerado, à inadequação de mobiliários e instalações que apresentam graves problemas ergonômicos, além das instalações elétricas, muitas vezes precárias e situadas em ambientes úmidos.

As etapas mais críticas do processo de trabalho são aquelas desenvolvidas à seco, devido à alta produção de material particulado, além do corte realizado na serra, que engloba elevados riscos, como cortes profundos ou até amputações, podendo ocasionar incapacidade laboral temporária ou permanente.

O entrevistado realizou coleta da poeira ocupacional na localidade, por meio de bombas gravimétricas, utilizando filtros de membrana PVC pré-pesados, preparados e codificados.

A poeira gerada no processo de trabalho ainda não está identificada, conforme salientou. No entanto, acredita que grande quantidade de fração respirável dos particulados, ou seja, partículas menores do que 5,0 $\mu \mathrm{m}$ é produzida na atividade de lapidação, uma vez que existe um número considerável de pessoas com silicose no município.

O entrevistado relata grande dificuldade em promover alterações no processo de trabalho, uma vez que se trata de uma questão cultural e também, em grande parte, pelo próprio desconhecimento por parte da maioria dos trabalhadores dos riscos a que estão submetidos ao inalar as partículas de sílica livre cristalina. Além disso, trata-se de uma atividade de subsistência de inúmeras famílias locais e da própria economia do município, que é altamente dependente da atividade de lapidação. Relata, ainda, que a utilização de equipamentos de proteção individual e coletiva é necessária e pode apresentar resultados satisfatórios. No entanto, as alternativas de intervenção mais eficazes para controle da geração de poeiras são aquelas realizadas em nível do processo de trabalho, como por exemplo a umidificação das etapas em 
que ocorre maior geração de particulado mineral. Outro aspecto salientado por ele diz respeito às instalações elétricas das oficinas locais, muitas vezes inadequadas, desprotegidas, podendo causar graves acidentes laborais. As instalações elétricas precisam ser melhor planejadas e instaladas de forma segura para o trabalhador e para os equipamentos.

A utilização de produtos como pó de Trípoli, ácidos e outros produtos químicos, aumenta, segundo o entrevistado, os riscos de adoecimento na população exposta, devendo os mesmos ser devidamente treinados e capacitados para a utilização segura de tais produtos, bem como o descarte dos resíduos.

Para ele, a FUNDACENTRO tem o importante papel de contribuir para a promoção da saúde e da segurança dos trabalhadores através da elaboração de normas técnicas e também da realização de estudos e pesquisas, cujos resultados devem ser apropriados pelos empregadores e pelos trabalhadores para melhorarem suas condições de trabalho e de vida.

\subsection{ENTREVISTA COM O MÉDICO PNEUMOLOGISTA}

Foi entrevistado um médico pneumologista que faz parte da equipe de pesquisadores que estudam a ocorrência da silicose em Corinto. Segundo ele, a doença pulmonar mais grave que atinge os lapidários é, no momento, a silicose, tanto pela importância da doença em si, que pode levar a limitações importantes, incapacidades e até mesmo à morte, quanto à sua magnitude entre a população exposta. Em Corinto chama a atenção, segundo o médico, a grande quantidade de trabalhadores jovens do sexo masculino já apresentando sinais radiológicos da doença, alguns deles já em situação de grande gravidade.

O impacto dessa doença é preocupante, segundo o entrevistado, porque, além de se tratar de vidas humanas, não são realizadas no momento intervenções significativas no processo de trabalho, de modo a eliminar ou, pelo menos, minimizar a quantidade de poeira de sílica, gerada nos ambientes de trabalho. O impacto da doença ultrapassa a questão da saúde, pois gera também um problema social grave, uma vez que são os provedores de inúmeras famílias os atingidos pela doença.

Para reduzir a magnitude do problema torna-se necessário, segundo ele, intervir diretamente no processo de trabalho, evitando a produção de poeira de sílica. Isso poderia ser conseguido com a utilização de medidas como a umidificação adequada das etapas do processo de trabalho onde ocorre geração de poeira, utilização de sistema de exaustão eficiente e, de imediato, utilização de EPIs eficazes e em bom estado de conservação, com substituição rotineira dos mesmos por exemplares novos, para maior eficiência na retenção de materiais particulados.

Outra medida importante seria o acompanhamento efetivo dos trabalhadores expostos nas unidades de saúde locais, com melhoria da capacidade do município em diagnosticar e tratar minimamente os doentes, e a estruturação de um sistema de vigilância no âmbito da secretaria municipal de saúde para identificar novos casos, notifica-los ao sistema de saúde local e afasta-los imediatamente da fonte da exposição.

\subsection{PROPOSIÇÃO DE INTERVENÇÕES E DISCUSSÃO}

Considerando os problemas relatados pelos atores entrevistados e a gravidade dos riscos a que estão expostos os lapidários de Corinto, propõe-se as seguintes intervenções nos ambientes e processos de trabalho:

- Melhoria do arranjo físico das unidades produtivas, visando melhor organização do espaço e eficiência do trabalho;

- Melhoria das instalações elétricas, hidráulicas e de exaustão, com vistas a reduzir risco de choques elétricos e geração de poeiras e ruídos nos ambientes de trabalho;

- Melhoria das condições ergonômicas de trabalho, especialmente com relação à adequação da postura e promoção de maior conforto do lapidário durante a sua jornada de trabalho;

- Adequação de equipamentos de proteção coletiva 
e individual, com capacitação e sensibilização dos lapidários para a utilização correta e sistemática dos mesmos;

- Umidificação adequada dos processos de trabalho em todas as etapas geradoras de poeiras, com enclausuramento das máquinas e equipamentos não passíveis de utilização a úmido;

- Monitoramento permanente da qualidade do ar, com vistas à identificação e qualificação de poeiras e suas principais fontes geradoras;

- Monitoramento permanente da geração e quantificação de ruídos nos ambientes de trabalho, visando redução máxima possível;

- Desenvolvimento de parcerias com universidades e institutos de pesquisa para capacitação técnica dos trabalhadores e desenvolvimento de novas tecnologias no âmbito da produção sustentável do trabalho;

- Estruturação de um sistema eficaz de vigilância epidemiológica, visando a identificar, monitorar e acompanhar ao longo do tempo todos os trabalhadores expostos, de modo a detectar precocemente qualquer sinal ou sintoma de agravos à saúde desses trabalhadores;

- Melhoria significativa da capacidade do município em estabelecer precocemente diagnósticos de pneumoconioses e outras doenças relacionadas ao trabalho com extração e lapidação de quartzo, em especial a silicose, de modo a reduzir a dependência de serviços de saúde de outros municípios, como Belo Horizonte;

- Identificação e desenvolvimento de formas alternativas de geração de renda no município, de forma segura e sustentável;

- Redução dos riscos de acidente de trabalho, por meio da aplicação de princípios da ergonomia nos ambientes de trabalho;

- Fortalecimento da cooperativa local dos lapidários, visando maior integração entre os mesmos, maior organização, credenciamento de fornecedores e clientes;

- Estabelecimento de política de vendas para melhoria das condições de remuneração dos lapidários;
- Afastamento entre unidades de produção e domicílios, a fim de evitar a exposição ambiental de pessoas não envolvidas no trabalho artesanal;

- Estabelecimento de alternativas de solução para a resolutividade dos impactos ambientais gerados pela atividade, tais como poluição atmosférica, contaminação de cursos d'água com possibilidade de assoreamento e modificação das propriedades do solo nas adjacências dos locais de trabalho;

- Inclusão do município de Corinto no Programa Nacional de Eliminação da Silicose (PNES) para o ano de 2015 e subsequentes, de modo a garantir o apoio institucional governamental para o desenvolvimento das ações aqui sugeridas.

A silicose representa um grave problema de saúde pública no Brasil, que acomete principalmente trabalhadores jovens do sexo masculino. Estudo desenvolvido por Ferreira et al (2008) evidenciou a ocorrência de silicose em 7,1\% de uma amostra de 70 lapidários de cristal uma cidade próxima a Corinto, chamada Joaquim Felício, onde as condições e os processos de trabalho são bastante semelhantes aos observados em Corinto. A doença prevaleceu entre homens jovens, com idade média de 21,5 anos e tempo médio de exposição de 7,1 anos. Outro estudo (Barbosa et al, 2001) envolvendo trabalhadores do setor extrativo de pedras de quartzito também evidenciou a ocorrência da silicose em 24,9\% dos 185 trabalhadores avaliados.

Trata-se de uma pneumoconiose fibrosante grave, que pode se desenvolver na sua forma aguda, acelerada ou crônica dependendo do tempo e da intensidade da exposição (Algranti et al, 2003). Atualmente, um grupo de pesquisadores da Universidade Federal de Ouro Preto - UFOP, Universidade Federal de Minas Gerais - UFMG, Fundação Jorge Duprat Figueiredo de Segurança e Medicina do Trabalho - FUNDACENTRO e Université Lille 2 - Nord de France está investigando a ocorrência de silicose entre os lapidários de Corinto. A prevalência dessa doença no município é elevada, acometendo principalmente indivíduos jovens do sexo masculino, sendo que mais de 100 lapidários são acompanhados rotineiramente no Serviço Especializado em Saúde do Trabalhador - SEST da 
UFMG

O presente estudo evidenciou a precariedade das condições de trabalho dos lapidários. A FUDACENTRO também constatou realidade semelhante em seus estudos, sendo comum encontrar máquinas e ferramentas desprotegidas, com sistemas improvisados. Os trabalhadores usam EPIs eventualmente, sendo que nem todos são adequados ou se encontram na validade. Não há treinamento. Alguns ambientes são abertos, outros não. Não há sistema de ventilação local, bem como exaustores em espaços semiconfinados. Falta manutenção de máquinas e equipamentos. Os assentos são inadequados, obrigando o trabalhador a adotar postura inadequada (FUNDACENTRO, 2014). Diante desse processo, ocorre grande exposição a fatores de risco ocupacional, especialmente à poeira de sílica livre, os quais são passíveis de ocasionar danos graves e irreversíveis à saúde dos artesãos.

\section{CONCLUSÕES}

De acordo com o exposto, constata-se que a situação de trabalho na lapidação de objetos de cristal de quartzo e rochas ornamentais no município de Corinto é preocupante, apresentando diversas situações de risco grave iminente para os trabalhadores expostos e para o meio ambiente, principalmente na cadeia produtiva da lapidação. O processo afeta também as vizinhanças com a poeira de arraste, poluição sonora e ambiental.

A complexidade da situação, por impactar diretamente na saúde das pessoas envolvidas no processo de lapidação e também das que vivem no entorno do ambiente produtivo, exige o envolvimento de todos os atores relacionados, incluindo os lapidários, poder público local, gestores da área de saúde e segurança do trabalho, instituições de pesquisa e toda a sociedade na implementação de soluções capazes de minimizar os riscos para essa população, além dos programas já existentes, como a parceria com o Hospital das Clínicas de Belo Horizonte, onde os pacientes são direcionados para realizarem exames mais detalhados e tratamentos aos quais dificilmente teriam acesso em Corinto. Dentre as soluções propostas, estão a aplicação dos princípios da ergonomia no ambiente produtivo, diminuição dos ruídos produzidos, identificar, monitorar e acompanhar ao longo do tempo todos os trabalhadores expostos, de modo a detectar precocemente qualquer sinal ou sintoma de agravos à saúde desses trabalhadores e separação física das unidades produtivas das moradias, dentre outras apresentadas neste estudo.

Sugere-se que a questão seja abordada publicamente por meio da apresentação dos resultados deste e demais estudos realizados no local, a fim de estabelecer um cronograma de intervenções em curto e médio prazo visando a obtenção de soluções para o problema e o envolvimento da população local na busca dessas soluções.

\section{REFERÊNCIAS}

[1] ALGRANTI, E. et al. Patologia respiratória relacionada com o trabalho. In: MENDES, R. (Org.). Patologia do trabalho. 2. ed. Rio de Janeiro: Atheneu, 2003. p. 1329- 1397.

[2] BARBOSA, M.S.A.; CARNEIRO, A.P.S.; MACIEL, J.G.F.S.; LA ROCCA, E.A.M.P.F.; SANTOS, A.R.M. Silicose em trabalhadores de quartzito da região de São Thomé das Letras - Minas Gerais: dados iniciais indicam um grave problema de saúde pública. Rev. bras. Saúde ocup., São Paulo, 36 (123): 177-184, 2011.

[3] DEPARTAMENTO NACIONAL DE PRODUÇÃO MINERAL. A importância econômica da mineração no Brasil. Disponível em: <www.dnpm.gov.br>. Acessado em: 08/09/2014

[4] FUNDACENTRO. Fundacentro inicia análise de sílica em lapidação de quartzo. Disponível em: < http://www. fundacentro.gov.br/noticias/detalhe-da-noticia/2014/6/ fundacentro-inicia-analise-de-silica-em-lapidacao-dequartzo >. Acessado em: 03/10/2014.

[5] IBGE. Cadastro Central de Empresas 2011. Rio de Janeiro: IBGE, 2013.

[6] MARTINS, E. T. S. Metodologia qualitativa de pesquisa. Disponível em:< www.scielo.br/ scielo. php? pid =S1517-97022004000200007\&script $=$ sci arttext>. Acessado em: 07/12/2014.

[7] MERRIAM, S. Case study research in education: A qualitative approach. San Francisco, CA: Jossey-Bass. 1988.

[8] MINISTÉRIO DAS MINAS E ENERGIA. A Mineração Brasileira. Disponível em:< http://www. mme.gov.br/sgm/galerias/arquivos/plano_duo_decenal/a_ mineracao_brasileira/P27_RT37_Perfil_do_Quartzo.pdf >. Acessado em: 03/10/2014. 
[9] SINDICATO DA INDUSTRIA MINERAL DO ESTADO DE MINAS GERAIS. Mineração: a experiência no Brasil. Disponível em <www.sindiextra.org.br>. Acessado em: 02/02/2014.
[10] SITTA, E. I. et al. A contribuição de estudos transversais na área da linguagem com enfoque em afasia. Disponível em:<www.scielo.br/pdf/rcefac/v12n6/14-10.pdf > . Acessado em: 07/12/2014. 


\section{CAPÍTULO 4}

\section{APLICAÇÃO DO MODELO DE HACKMAN \& OLDHAM PARA AVALIAR A QUALIDADE DE VIDA NO TRABALHO NA EMPRESA JÚNIOR DE ENGENHARIA DE PRODUÇÃO DA UTFPR - PONTA GROSSA}

\section{Rodrigo Salvador}

Bruno Alexandre Oliveira

Bruna Zuccolotto Guedes

Fernanda Gomes Andrade

Letícia Pavan Silva

Antonio Carlos de Francisco

Resumo: Este trabalho objetiva avaliar a qualidade de vida no trabalho da empresa júnior de Engenharia de Produção da Universidade Tecnológica Federal do Paraná (UTFPR), Campus Ponta Grossa, por meio do modelo de Qualidade de Vida no Trabalho de Hackman \& Oldham. Tal modelo caracteriza-se por analisar a necessidade social do funcionário dentro da empresa, se este está satisfeito com o trabalho que realiza. Para atender os objetivos e a metodologia do artigo foi feita a aplicação do modelo na forma de questionário para os funcionários da referida Empresa Júnior da UTFPR Campus Ponta Grossa. A análise e discussão dos resultados obtidos teve como base a teoria previamente pesquisada do modelo, por meio do levantamento de um referencial teórico a respeito de Qualidade de Vida no Trabalho e do modelo em voga. Os resultados encontrados mostraram, de forma geral, uma resposta satisfatória quanto à qualidade de vida no trabalho para os colaboradores da organização estudada.

Palavras Chave: Qualidade de Vida no Trabalho; QVT; Modelo de Hackman \& Oldham; Empresa Júnior. 


\section{INTRODUÇÃO}

Com o desenvolvimento da sociedade, a constante atualização do modo de vida e de trabalho, os conceitos de qualidade de vida (QV) e qualidade de vida no trabalho (QVT) são, também, constantemente atualizados, uma vez que tais conceitos estão ligados à satisfação pessoal dentro de critérios idiossincráticos. A satisfação das necessidades de cada indivíduo é que determina o nível de qualidade de vida do mesmo, sendo este conceito descrito por Freitas et al. (2012, p.1) como a "percepção de bem estar do indivíduo, podendo apresentar diferentes classificações que dependem do ambiente ou da cultura em que o indivíduo está inserido".

Dentro dos parâmetros de qualidade de vida, identificase o trabalho como uma das parcelas relevantes para tal mensuração, visto que o tempo e a dedicação empregados nestas atividades consomem de maneira intensa as capacidades físicas e psicológicas do indivíduo.

Assim, pode-se descrever a qualidade de vida no trabalho, de acordo com Zanetti (2002, p. 39), como "a soma das condições que a organização oferece, permitindo aos trabalhadores um ambiente de trabalho saudável e tranquilo".

Neste contexto, este artigo objetiva avaliar a qualidade de vida no trabalho da empresa júnior de Engenharia de Produção da Universidade Tecnológica Federal do Paraná (UTFPR), Campus Ponta Grossa, por meio do modelo de Qualidade de Vida no Trabalho de Hackman \& Oldham.

A necessidade de um melhor rendimento do indivíduo, bem como a satisfação do trabalhador em seu ambiente de trabalho, levam à discussão de melhores maneiras que objetivam buscar melhores resultados seja da ótica do indivíduo seja para a ótica do empregador (Ali et al., 2013).

Assim, evidencia-se neste estudo a necessidade do indivíduo, tendo como pressuposto que ao atingir suas necessidades essenciais, passíveis de mensuração, o trabalhador, além de ter uma melhora significativa no que diz respeito à qualidade de vida no trabalho, como consequência trará melhores resultados para a empresa.

Sendo assim, verifica-se junto à esta necessidade, que o modelo de Hackman \& Oldham (1974), se mostra o mais eficaz no que diz respeito a obtenção de dados para a verificação proposta, uma vez que o mesmo está voltado para fatores relacionados à motivação do indivíduo no ambiente laboral.

Para tal, a seguir é apresentada a metodologia utilizada para este estudo (2), o contexto da empresa estudada (3), bem como o modelo de Hackman \& Oldham (1974), a aplicação do modelo juntamente com os resultados e a discussão destes (4). Por fim são traçadas as considerações finais (5) acerca do estudo e apresentadas as referências utilizadas.

\section{MÉTODOS}

Esta pesquisa classifica-se quanto à natureza como aplicada, quanto à forma de abordagem do problema, quantitativa, quanto aos objetivos, descritiva e exploratória e, quanto aos procedimentos técnicos, um levantamento de dados.

A população deste estudo delimitou-se aos assessores da Solumax Produção Júnior, empresa júnior do curso de Engenharia de Produção da Universidade Tecnológica Federal do Paraná - Campus Ponta Grossa. A empresa foi selecionada para este estudo devido à acessibilidade da mesma, que se encontra no mesmo campus da Universidade em que o estudo foi desenvolvido.

Foi utilizado para esta pesquisa uma adaptação do questionário de Hackman \& Oldham proposto para avaliação da qualidade de vida no trabalho dentro da empresa abordada.

A coleta de dados foi realizada durante os horários em que os funcionários ficam à disposição da empresa, em um local adequado, onde foi explicado como preencher o questionário (ANEXO 1). Após a coleta de dados, foi realizada a tabulação e em seguida a análise dos dados, de acordo com os passos descritos no Apêndice 1. 


\section{SOLUMAX PRODUÇÃO JÚNIOR}

A Solumax Produção Júnior surgiu em uma roda de conversa entre amigos e um professor no mês de setembro de 2011. Neste período quatro alunos da primeira turma de Engenharia de Produção do câmpus Ponta Grossa da UTFPR participaram do jogo virtual do SEBRAE entre acadêmicos de todo o Brasil, no qual eles chegaram à semifinal nacional, na ocasião entre os melhores do Paraná. Devido ao sucesso, o professor da disciplina de Economia aconselhou os quatro a criarem a Empresa Júnior do curso.

No início tiveram algumas dificuldades devido à burocracia e também para provar que tinham o objetivo de ser uma instituição sem fins lucrativos, além de carregar o nome de uma instituição Federal para o mercado de trabalho. Eles precisavam conseguir um professor responsável, e seguir o regimento da UTFPR. A empresa tem como portfólio prestar serviços de consultoria às micro e pequenas empresas, além de trabalhar de maneira autônoma com a orientação de professores do curso em trabalhos na área de Gestão da Qualidade, Gestão de Custos, e mais recentemente em Gestão Ambiental.

A Empresa Júnior de Engenharia de Produção do Campus Ponta Grossa da Universidade Tecnológica Federal do Paraná é uma instituição sem fins lucrativos, formada e gerida por alunos do curso de Engenharia de Produção.

A Solumax Produção Júnior, como é denominada, foi criada com as seguintes finalidades:

- I. Proporcionar aos seus membros as condições de aplicação prática dos seus conhecimentos relativos à área de formação profissional;

- II. Valorizar o Movimento Empresa Júnior, seguindo o seu Código de Ética, participando de seus órgãos reguladores e respeitando as suas deliberações;

- III. Desenvolver em seus membros habilidades profissionais no âmbito da vivência gerencial, trabalho em equipe, relações interpessoais e análise lógico-analítica de problemas cotidianos empresariais;
- IV. Realizar estudos e projetos sobre assuntos referentes àárea de graduação de seus associados, visando o seu desenvolvimento profissional;

- V. Desenvolver atividades em caráter prático e treinamento, visando à futura inserção no mercado de trabalho, sempre com subordinação profissional competente;

- VI. Fomentar o espírito empreendedor de seus membros;

- VII. Valorizar os alunos e professores da UTFPR - PG no mercado de trabalho e no âmbito acadêmico, bem como a referida instituição;

- VIII. Desenvolver ações que contribuam para o atendimento das finalidades, princípios e objetivos da UTFPR - PG, sempre em observância da indissociabilidade entre ensino, pesquisa e extensão;

\section{MODELO DE HACKMAN \& OLDHAM}

Hackman \& Oldham (1975) propõem que a positividade pessoal e o resultado do trabalho (alta motivação interna, alta satisfação no trabalho, alta qualidade no desempenho e absenteísmo e rotatividade baixos) são obtidos quando os três estados psicológicos - Significação Percebida (SP), Responsabilidade Percebida (RP) e Conhecimento dos Resultados do Trabalho (CR) - estão presentes em um determinado trabalho e apresentam resultado positivo. Esses estados psicológicos críticos são formados pelas seguintes dimensões da tarefa: Variedade de Habilidade (VH), Identidade da Tarefa (IT), Significação da Tarefa (ST), Autonomia (AT), Feedback Extrínseco (FE), Feedback Intrínseco (FI) e Inter-Relacionamento (IR).

A partir da combinação dessas dimensões, é possível, segundo Hackman \& Oldham (1975), chegar-se ao Potencial Motivador da Tarefa (PMT), ou seja, uma medida de análise de determinado trabalho realizado por um indivíduo.

As reações afetivas pessoais que uma pessoa obtém ao desempenhar seu trabalho e gerar resultados com produção de alta qualidade, absenteísmo e rotatividade baixos são incluídas no modelo de Hackman \& Oldham (1975) na dimensão denominada Resultados Pessoais 
e de Trabalho, composta pelas variáveis a seguir: Satisfação Geral (SG) — média global do grau de bemestar do indivíduo no seu trabalho; Motivação Interna para o Trabalho (MIT) - grau de motivação com que o indivíduo experimenta sensações positivas internas, quando desempenha efetivamente suas tarefas, e sensações negativas, quando desempenha de forma inadequada; Produção do Trabalho de Alta Qualidade (PTQ) - grau com que é produzido trabalho de alta qualidade; e Absenteísmo e Rotatividade Baixos (ARB) — nível de ausência e de rotatividade de pessoal.

A partir desta concepção, Hackman \& Oldham (1975) desenvolveram o Job Diagnostic Survey (JDS), que é um instrumento de coleta de dados utilizado e validado para a pesquisa de QVT. Segundo os autores, o JDS permite o diagnóstico dos trabalhos existentes e indica a necessidade e a forma de sua reestruturação para aumentar a produtividade e a motivação do empregado e possibilita também realizar uma avaliação acerca dos impactos das mudanças de trabalho do indivíduo. Considera-se que o modelo de QVT de Hackman \& Oldham (1975) contribui para o estudo da qualidade de vida no trabalho dos funcionários de qualquer área, por avaliar fatores considerados de importância para o desempenho dos cargos relacionados a esta área de atuação, que são: identidade da tarefa, variedade da tarefa e significação da tarefa. Visando isso aplicamos o questionário de Hackman \& Oldham numa empresa que oferece consultoria, para mensurar a qualidade de vida no trabalho desta empresa.

\section{APLICAÇÃO DO MODELO, RESULTADOS E DISCUSSÃO}

Segundo Hackman \& Oldham (1974), para disponibilizar uma ferramenta de qualidade de vida é necessário determinar o nível de motivação ocasionado pelo trabalho no trabalhador. Adaptando o método de Hackman \& Oldham para a cultura brasileira para que possamos melhor interpretar o modelo, foi seguido o modelo por eles proposto.

As questões da Seção 1 foram dispostas na forma interrogativa, possuindo escalas diferenciadas entre si, conforme demonstra a Figura 1.

Figura 1 - Exemplo de questão e escala de respostas da Seção 1

\section{1) Qual é nível de autonomia existente em seu trabalho? Isto é, até que ponto the é permitido decidir a maneira de realizar suas tarefas?}

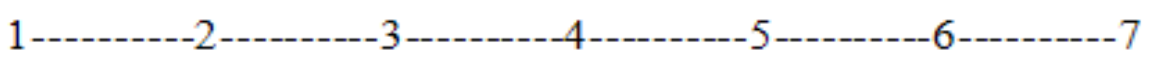

Muito pouca
autonomia; meu
trabalho não me
permite decidir como e
quando realizar as
tarefas.

Muito pouca autonomia; meu trabalho não me permite decidir como e tarefas.

\begin{abstract}
Autonomia moderada; muitos aspectos são padronizados e não estão sob meu controle, mas eu posso tomar algumas decisões.
\end{abstract}

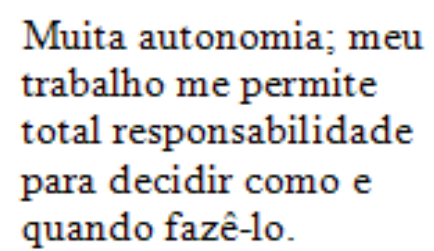
quando fazê-lo.

Fonte: Pedroso et. al. (2010)

A Seção 2 teve suas questões dispostas seguindo o modelo sugerido por Hackman \& Oldham (1974), na forma de afirmações. A escala de respostas é a mesma para todas as questões desta seção, conforme mostrado na Figura 2. 
Figura 2 - Exemplo de questão e escala de respostas da Seção 2

6) Meu trabalho exige que eu utilize diversas habilidades complexas ou de alto-nível.

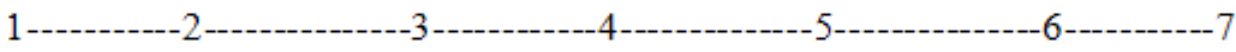

\begin{tabular}{|c|c|c|c|c|c|c|}
\hline $\begin{array}{c}\text { Muito } \\
\text { incorreta }\end{array}$ & $\begin{array}{c}\text { Geralmente } \\
\text { incorreta }\end{array}$ & $\begin{array}{c}\text { Ligeiramente } \\
\text { incorreta }\end{array}$ & Indeciso & $\begin{array}{c}\text { Ligeiramente } \\
\text { correta }\end{array}$ & $\begin{array}{c}\text { Geralmente } \\
\text { correta }\end{array}$ & $\begin{array}{c}\text { Muito } \\
\text { correta }\end{array}$ \\
\hline
\end{tabular}

Fonte: Pedroso et. al. (2010)

As dimensões de trabalho são divididas em: variedade de tarefa (Q3, Q6 e Q9), identidade de tarefa (Q2, Q7 e Q12), significância de tarefa (Q4, Q10 e Q15), autonomia (Q1, Q11 e Q14) e feedback (Q5, Q8 e Q13). O cálculo dos escores das dimensões do trabalho é realizado através da média aritmética simples entre as três questões que compõem cada dimensão.

Após isso calcula-se o Potencial Motivador do Trabalho (PMT) pela seguinte fórmula:

$$
\begin{gathered}
P M T=(\text { var.tarefa }+ \text { ident.tarefa }+ \text { sig.tarefa }) * \text { autonomia } * \text { feedback } \\
P M T=\frac{\left[\left(\frac{Q_{3}+Q_{6}+Q_{9}}{3}\right)+\left(\frac{Q_{2}+Q_{7}+Q_{12}}{3}\right)+\left(\frac{Q_{4}+Q_{10}+Q_{15}}{3}\right)\right]}{3} \times\left(\frac{Q_{1}+Q_{11}+Q_{14}}{3}\right) \times\left(\frac{Q_{5}+Q_{8}+Q_{13}}{3}\right)
\end{gathered}
$$

Os escores foram convertidos em valores centesimais para melhor comparação e são apresentados na Tabela 1.

Tabela 1 - Relação de equivalente entre as escalas

\begin{tabular}{|c|c|c|c|}
\hline \multirow{2}{*}{ Likert } & \multicolumn{3}{|l|}{ PMT } \\
\hline & Escore & Centesimal & Classificação \\
\hline 1 & 1 & 0,00 & \multirow{4}{*}{ Insatisfatório } \\
\hline 2 & 8 & 16,67 & \\
\hline 3 & 27 & 33,33 & \\
\hline 4 & 64 & 50,00 & \\
\hline 5 & 125 & 66,67 & \multirow{3}{*}{ Satisfatório } \\
\hline 6 & 216 & 83,33 & \\
\hline 7 & 343 & 100,00 & \\
\hline
\end{tabular}

Fonte: Pedroso et. al. (2010)

Seguindo esta classificação proposta, o ponto de referência adotado é o valor 125, equivalente a 66,67 na escala centesimal. A partir disso pode-se afirmar que os resultados que apresentem um nível motivacional igual ou superior a $66,67 \%$ são considerados satisfatórios, enquanto os resultados que apresentem um nível motivacional inferior a $66,67 \%$ são considerados insatisfatórios.
Para o cálculo dos escores foi construída uma ferramenta através do software Microsoft Excel que realiza o cálculo dos escores e a estatística descritiva do instrumento desenvolvido no presente estudo, como mostrado na Tabela 2.

Tabela 2 - Valor centesimal para cada assessor respondente

\begin{tabular}{|c|c|}
\hline Assessor & Centesimal \\
\hline 1 & 56,454 \\
2 & 76,261 \\
3 & 86,801 \\
4 & 86,192 \\
5 & 51,163 \\
6 & 68,242 \\
\hline
\end{tabular}

A partir destes dados podemos verificar que quatro dos seis assessores possuem nível motivacional maior que 66,67, sendo assim satisfatórios. E apenas dois possuem níveis motivacionais não satisfatórios. Há 
algumas explicações plausíveis para que apenas dois trabalhadores tenham níveis abaixo do esperado, entre eles está a falta de comunicação, falta de valorização, as pessoas podem ter criado expectativas muito maiores do que a realidade ou falta de entrosamento com os colegas de trabalho.

A partir dos resultados obtidos foi construído o Gráfico 1, mostrando o percentual das dimensões essenciais do trabalho.

Gráfico 1 - Dimensões essenciais do trabalho

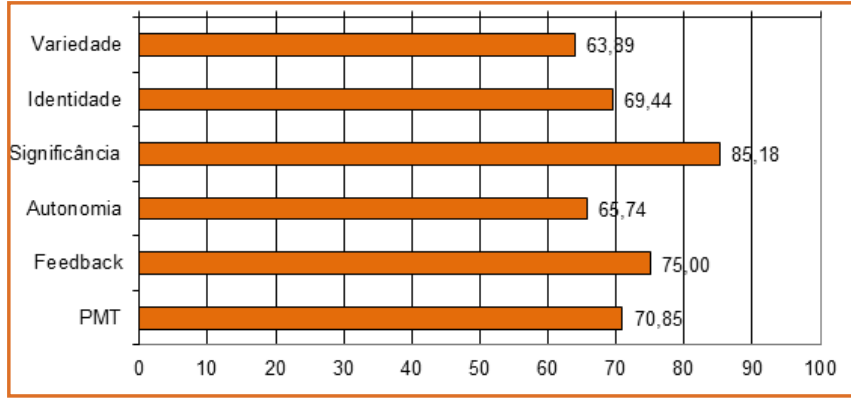

O gráfico mostra que os dados obtidos foram satisfatórios devido aos altos índices de satisfação dos assessores e o alto potencial motivador nos trabalhadores (PMT), resultando em uma satisfatória qualidade de vida no trabalho.

\section{CONSIDERAÇÕES FINAIS}

Com o início da preocupação com qualidade de vida no trabalho, surgiu a necessidade da criação de indicadores para avaliar a Qualidade de Vida no Trabalho, um dos modelos propostos que possuem esses indicadores é o de Hackman \& Oldham (1974). Este modelo apresenta dimensões essenciais do trabalho para assim calcular o Potencial Motivador do Trabalho.

O modelo aplicado na empresa Solumax Produção Júnior obteve resultados satisfatórios, mostrando que a maioria dos assessores estão motivados e felizes com o trabalho que é realizado dentro da empresa júnior.

Os resultados obtidos foram expressos através de uma escala centesimal para facilitar a visualização dos resultados, permitindo assim a inter-relação com outras ferramentas.

\section{REFERÊNCIAS}

[1] ALI, S. A. M.; SAID, N. A.; YUNUS, N. M. ; KADER, S. A. A.; LATIF, D. S. A.; MUNAP, R. Hackman and Oldham's Job Characteristics Model to Job Satisfaction. Social and Behavioral Sciences, v. 129, 2014. P. 46-52.

[2] FREITAS, J. D.; FRANCISCO, A. C.; AQUINO, D. S. DIAGNÓSTICO DA QUALIDADE DE VIDA E QUALIDADE DE VIDA NO TRABALHO DO APL DE VESTUÁRIO DE MARINGÁ/ CIANORTE-PR. In: Seminário de Iniciação Científica e Tecnológica da Universidade Tecnológica Federal do Paraná, SICITE, 17. Anais. Curitiba, Paraná, Brasil. 2012. 8 p. HACKMAN, J. R.; OLDHAM, G, R. DEVELOPMENT OF THE JOB DIAGNOSTIC SURVEY. Journal of Applied Psychology, v. 60 , n. 2, 1975. P. 159-170.

[3] HACKMAN, J. R.; OLDHAM, G. R. The job diagnostic survey: An instrument for the diagnosis of jobs and the evaluation of job redesign projects (Tech. Rep. No. 4). New Haven, Conn.: Yale University, Department of Administrative Sciences, 1974

[4] PEDROSO, B.; PILATTI, L. A.; SANTOS, C. B.; SANTOS JUNIOR, G. POTENCIAL MOTIVADOR DO TRABALHO: TRADUÇÃO E ADAPTAÇÃO CULTURAL DO INSTRUMENTO DE HACKMAN \& OLDHAM. Revista Produção On Line, v. 10, n. 3, set 2010. P. 670-697.

[5] ZANETTI, E. M. S. P. Gerenciamento de recursos humanos: o caso das micro e pequenas indústrias de confecções do município de Colatina-ES. Florianópolis, 2002. 133 f. Dissertação (Mestrado em Engenharia de Produção) Universidade Federal de Santa Catarina. 
APÊNDICE 1 - CÁLCULO DO POTENCIAL MOTIVADOR DO TRABALHO (PMT) A PARTIR DO SCORE

\begin{tabular}{|c|c|c|c|c|c|c|}
\hline 놈ㅇㅎㅎ & 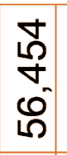 & $\begin{array}{l}\delta \\
\stackrel{0}{ } \\
0 \\
0\end{array}$ & \begin{tabular}{|l|} 
\\
$\infty$ \\
$\infty$ \\
0 \\
0
\end{tabular} & 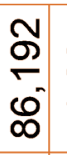 & $\begin{array}{l}\text { જ్ } \\
\text { ద }\end{array}$ & 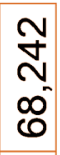 \\
\hline 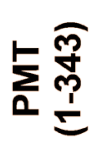 & $\begin{array}{l}\mathbb{Z} \\
\dot{J} \\
\dot{\infty}\end{array}$ & $\begin{array}{l}\stackrel{m}{m} \\
\stackrel{m}{\sim} \\
\stackrel{m}{\sim}\end{array}$ & $\begin{array}{l}\text { న్ } \\
\text { న్ } \\
\text { న్ } \\
\text { N }\end{array}$ & 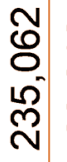 & $\begin{array}{l}\text { N } \\
\text { ○ } \\
\text { ல }\end{array}$ & 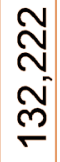 \\
\hline 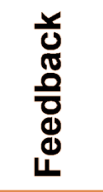 & $\begin{array}{l}8 \\
8 \\
10\end{array}$ & $\begin{array}{l}8 \\
8 \\
10\end{array}$ & $\begin{array}{l}m \\
m \\
m \\
\tilde{\omega}\end{array}$ & $\begin{array}{l}\widehat{\emptyset} \\
\ddot{\bullet} \\
0\end{array}$ & $\begin{array}{l}\text { mె } \\
\text { m} \\
\nabla^{2}\end{array}$ & $\begin{array}{l}\widehat{0} \\
0 \\
10\end{array}$ \\
\hline 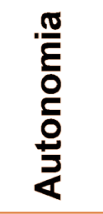 & $\begin{array}{l}8 \\
8 \\
\forall\end{array}$ & $\begin{array}{l}8 \\
8 \\
6\end{array}$ & $\begin{array}{c}\widehat{0} \\
0 \\
10\end{array}$ & $\begin{array}{l}\widehat{0} \\
0 \\
0\end{array}$ & $\begin{array}{l}m \\
m \\
m \\
m\end{array}$ & $\begin{array}{c}8 \\
8 \\
10\end{array}$ \\
\hline 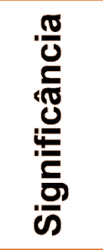 & 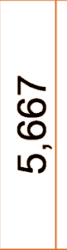 & $\begin{array}{l}8 \\
8 \\
\text { N- }\end{array}$ & $\begin{array}{l}\widehat{0} \\
0 \\
0\end{array}$ & $\begin{array}{l}8 \\
8 \\
N\end{array}$ & $\begin{array}{l}8 \\
8 \\
\end{array}$ & $\begin{array}{l}m \\
m \\
m \\
10\end{array}$ \\
\hline 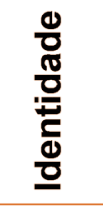 & $\begin{array}{l}8 \\
8 \\
+\end{array}$ & $\begin{array}{l}8 \\
8 \\
10\end{array}$ & $\begin{array}{l}\widehat{\theta} \\
0 \\
0\end{array}$ & $\begin{array}{l}8 \\
8 \\
10\end{array}$ & $\begin{array}{l}\widehat{\emptyset} \\
\varnothing \\
1\end{array}$ & $\begin{array}{l}8 \\
8 \\
10\end{array}$ \\
\hline $\begin{array}{l}\frac{0}{0} \\
\frac{\pi}{0} \\
\frac{0}{\frac{\pi}{2}} \\
\frac{\pi}{\pi}\end{array}$ & $\begin{array}{l}8 \\
8 \\
\text { m. }\end{array}$ & 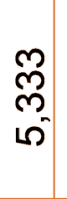 & $\begin{array}{l}\widehat{\Theta} \\
0 \\
0\end{array}$ & $\begin{array}{l}\widehat{\emptyset} \\
\mathscr{0} \\
\widehat{0}\end{array}$ & $\begin{array}{l}\widehat{\Xi} \\
\Xi \\
\text { m. }\end{array}$ & $\begin{array}{l}\hat{0} \\
0 \\
n^{-}\end{array}$ \\
\hline$\stackrel{\circ}{\leftarrow}$ & $\sim$ & \ulcorner & $\sim$ & $r$ & 0 & $\tau$ \\
\hline$\stackrel{\nabla}{ }$ & م & $\wedge$ & $\bullet$ & 0 & $\nabla$ & م \\
\hline$m$ & $m$ & $m$ & $\sim$ & - & 10 & $\sim$ \\
\hline$\stackrel{N}{\sim}$ & in & $\wedge$ & $\lambda$ & $\wedge$ & 0 & $\wedge$ \\
\hline$\mp$ & 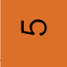 & $m$ & $N$ & $\nabla$ & 0 & $m$ \\
\hline 웅 & 0 & $\wedge$ & $\Lambda$ & $\lambda$ & $\bullet$ & 6 \\
\hline$\sigma$ & 0 & $\nabla$ & $N$ & $\sim$ & $\omega$ & 10 \\
\hline$\infty$ & 10 & $\infty$ & $\Lambda$ & 0 & $\bullet$ & 6 \\
\hline$\Lambda$ & 10 & 10 & $\tau$ & 0 & $N$ & $\checkmark$ \\
\hline 0 & $m$ & $\wedge$ & $\Lambda$ & $\lambda$ & L & م \\
\hline 6 & 10 & 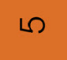 & $\bullet$ & $\lambda$ & $\nabla$ & 10 \\
\hline$\nabla$ & 10 & $\wedge$ & $\Lambda$ & $\Lambda$ & $\Lambda$ & $m$ \\
\hline$m$ & $\nabla$ & Lo & $\Lambda$ & $\Lambda$ & $\nabla$ & m \\
\hline$N$ & $\nabla$ & 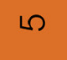 & $\bullet$ & 0 & 0 & $\nabla$ \\
\hline$r$ & $\nabla$ & 0 & L & $\lambda$ & $\checkmark$ & 10 \\
\hline & $r$ & $\mathbf{N}$ & $m$ & O & 10 & 0 \\
\hline
\end{tabular}




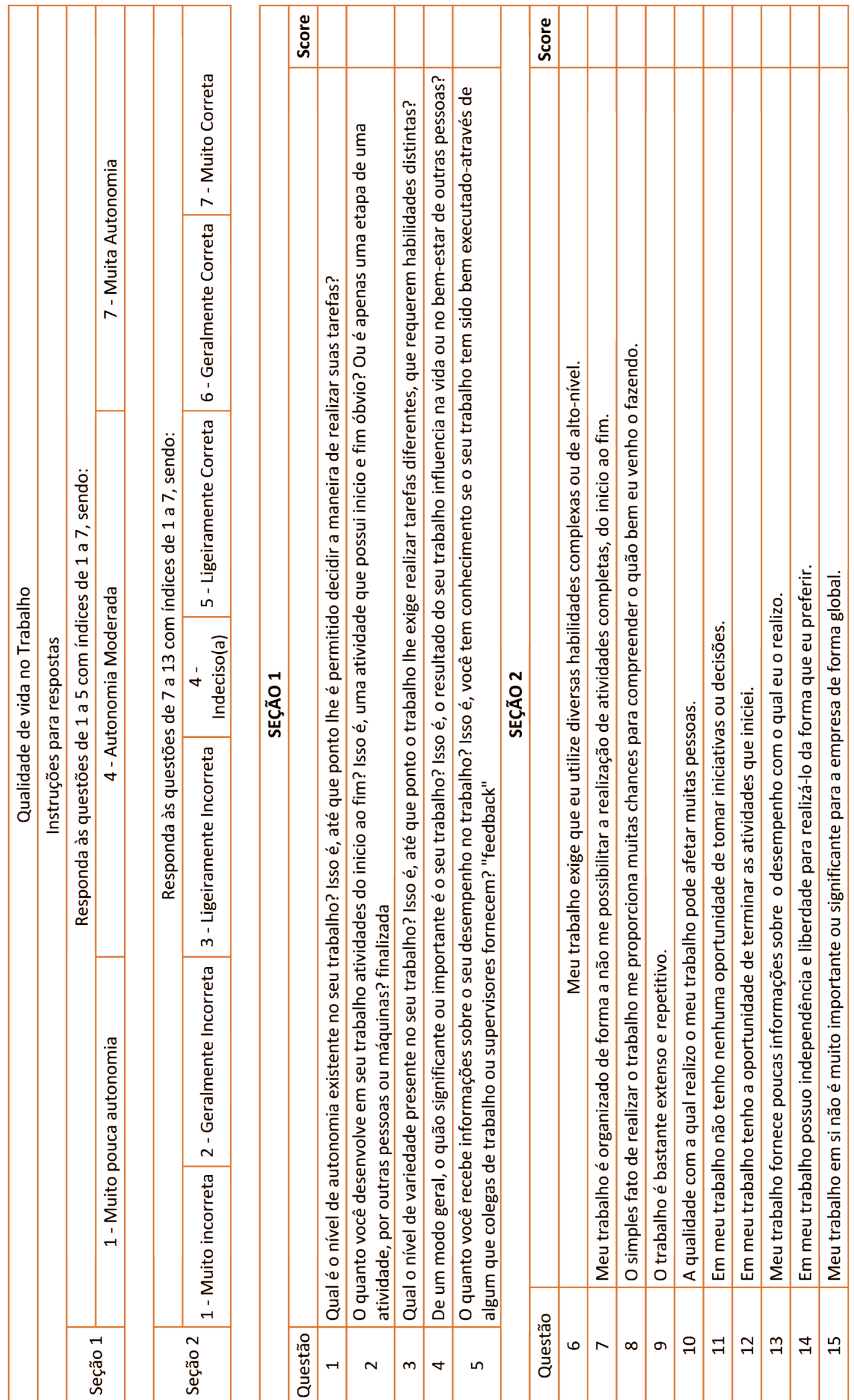




\section{CAPÍTULO 5}

\section{AVALIAÇÃO DA ATIVIDADE DO OPERADOR DE TORNO SEMIAUTOMÁTICO PARA PEÇAS SERIADAS - UM ESTUDO ERGONÔMICO}

Roger Poglia da Luz

Ademar Alves de Meira

Tassiana Cristina Dala Costa

Sergio Luiz Ribas Pessa

Dalila G. Pagnoncelli Laperuta

Resumo: A avaliação ergonômica da atividade do operador de torno semiautomático foi realizada em uma indústria local de conexões, utilizadas na fabricação de acessórios para a linha branca de eletrodomésticos. A pesquisa foi motivada pelo aumento da demanda de ações de segurança e ergonomia, deflagrado com a instalação da Promotoria Pública do Trabalho no município de Pato Branco-PR, no ano de 2013, e também pela presença de processos de usinagem seriada nesta microrregião. Para a consecução dos objetivos do estudo, foram aplicados dois questionários distintos: um deles adaptado do Diagrama das Áreas Dolorosas e o outro do método NASA-TLX, além de uma entrevista semiestruturada, abordando a percepção dos operadores quanto ao seu ambiente de trabalho. Entre os principais resultados, comparando as duas formas de realizar a atividade, foi possivel observar as diferenças existentes e quais os fatores relevantes. Na atividade automatizada a carga mental tem maior relevância, enquanto no processo manual, a carga física e a demanda temporal são mais expressivas. A partir da verificação, foram propostas medidas de melhoria e adequação, como a automatização do abastecimento da matéria prima, inclusão de bancos de apoio semi-sentado, pausas e rodízios, coleta de cavaco automática. Conclui-se, dessa maneira, que a eficácia da ergonomia consiste em promover a ampliação da regulação individual e coletiva da atividade. Mais do que uma ação isolada, precisa fazer parte das políticas organizacionais, estar incorporada como fundamental na cultura empresarial e, mais do que controlar riscos, deve manter a saúde e a qualidade de vida de toda organização.

Palavras Chave: Ergonomia, Posto de trabalho, Operador de torno semiautomático. 


\section{INTRODUÇÃO}

A realidade de trabalho, o seu ambiente físico e social exercem sobre o operador determinados constrangimentos, demandando gasto de energia física, mental, afetiva e emocional, o que evolui, consequentemente, para desgastes e custos ao trabalhador. Este gasto humano é resultante de um processo classificado como carga de trabalho (CARDOSO; GONTIJO, 2012). Assim, a carga de trabalho pode ser conceituada como um termo que representa o custo de realizar os requisitos da função para o operador humano (HART, 2006).

A gestão do capital humano nas organizações tem tido uma longa e bem documentada história, durante a qual ela evoluiu através de uma série de etapas distintas, saindo de uma mera função de manutenção de registros para um olhar de importância estratégica e impacto nos resultados das empresas (FERRIS et al., 2007). Dada a sua importância a partir dessa nova percepção, as condições de trabalho e o bem-estar do trabalhador ganharam lugar de destaque nas agendas de gestão.

Os gestores têm perseguido diferentes estratégias no intuito de obter benefícios a partir dos recursos humanos de sua firma (NEAL et al., 2005). Entre elas, pode-se destacar a utilização de princípios relacionados a Fatores Humanos \& Ergonomia (HF/E) que, num conceito geral, é o estudo da adaptação do trabalho ao homem. Neste caso, o trabalho compreende não somente o que é executado com máquinas e equipamentos, mas também toda ocorrência em que há o relacionamento entre o ser humano e determinada atividade produtiva (IIDA, 2005).

Dessa maneira, juntamente com os avanços tecnológicos, surgiu a diminuição no número de postos de trabalho clássicos, substituídos por novas estações, com exigências cada vez maiores em termos de produtividade e qualificação dos trabalhadores (FERREIRA, 2002). Em resposta ao novo cenário e pensando no capital humano como principal recurso das empresas, percebeu-se necessária a melhoria das condições ergonômicas do trabalho, através da criação ou atualização de normas e leis, além do desenvolvimento de novos métodos ergonômicos de diagnóstico, avaliação e intervenção.
Outra questão relevante é o nítido aumento de doenças osteomusculares e psicológicas relacionadas ao trabalho, que estão ligadas a informatização e aos novos processos industriais, levando as pessoas a permanecerem por longos períodos em posições estáticas, desempenhando tarefas mecânicas e repetitivas que no decorrer do tempo ocasionam desconfortos físicos e, por fim, fadiga física e mental. Considerando a demanda de ações de segurança e ergonomia deflagrada com a instalação da Promotoria Pública do Trabalho no município de Pato BrancoPR, no ano de 2013, além da crescente presença de processos de usinagem seriada nesta microrregião, este estudo tem por objetivo central avaliar a condição ergonômica do posto de trabalho do setor de usinagem de peças, em uma indústria local de conexões de alumínio, latão e chumbaloy (aço SAE 12L14) entre outros materiais, utilizados na fabricação de acessórios para a linha branca de eletrodomésticos, visando proporcionar adequações que resultem em melhoria do processo e da atividade.

\section{REFERENCIAL TEÓRICO}

\subsection{FATORES HUMANOS \& ERGONOMIA}

Fatores Humanos \& Ergonomia (Human Factor \& Ergonomics - HF/E) é um campo de pesquisa científica multidisciplinar - atua em áreas como design industrial, arquitetura, engenharia de manufatura, terapia ocupacional, odontologia, psicologia, entre outras (SOARES, 2006) - que estuda a prática da concepção de produtos, sistemas ou processos levando em conta a interação entre eles e as pessoas que os utilizam, visando otimizar o bem-estar humano assim como o desempenho global do que foi concebido (DUL; NEUMANN, 2007). Com isso, os dois termos, fatores humanos e ergonomia, são essencialmente sinônimos (ABERGO, 2015; HFES, 2015; IEA, 2015).

De forma prática, a ergonomia e seus especialistas contribuem para o projeto e avaliação de tarefas, trabalhos, produtos, ambientes e sistemas, no intuito de torná-los compatíveis com as necessidades, habilidades e limitações das pessoas (THEBERGE; NEUMANN, 2010). Considerando que essa disciplina atualmente se estende a todos os aspectos da atividade humana, de acordo com Wilson (2000), 
faz-se necessária uma compreensão ampla e uma abordagem holística em que fatores físicos, cognitivos, sociais, organizacionais, ambientais e outros relevantes devem ser considerados. Dessa maneira a International Ergonomics Association (2015) define três domínios de especialização da ergonomia: físico, cognitivo e organizacional.

A ergonomia física está preocupada com a anatomia humana, antropometria, fisiologia, características biomecânicas e como elas se relacionam com a atividade física. Alguns tópicos se destacam nesse domínio, tais quais posturas de trabalho, manuseio de materiais, movimentos repetitivos, distúrbios musculoesqueléticos relacionados com o trabalho, layout do local de trabalho, segurança e saúde (BOFF, 2006).

A ergonomia cognitiva, por sua vez, abrange os processos mentais como a percepção, memória, raciocínio e resposta motora, e os efeitos das interações entre o homem e os outros elementos de um sistema. Os principais objetos de estudo envolvendo essa relação incluem a carga mental de trabalho, tomada de decisão, desempenho especializado, interação homem-computador, estresse e treinamento (CORREIA; SILVEIRA, 2009).

A ergonomia organizacional, conforme a Associação Brasileira de Ergonomia (2015), diz respeito à otimização dos sistemas sociotécnicos, incluindo suas estruturas de processos, organizacionais e políticas. Os assuntos relevantes incluem comunicações, gerenciamento de recursos de tripulações, projeto de trabalho, organização temporal do trabalho, trabalho em grupo, projeto participativo, novos paradigmas do trabalho, trabalho cooperativo, cultura organizacional, organizações em rede e gestão da qualidade.

\subsection{AVALIAÇÃO ERGONÔMICA DO POSTO DE TRABALHO}

Os estudos ergonômicos visam realizar mudanças nas condições e no ambiente de trabalho, aperfeiçoamento e adaptação das máquinas e equipamentos utilizados na execução das tarefas, de acordo com as características físicas e condições psicológicas do trabalhador, no intuito de Ihe propiciar segurança, saúde e conforto para, dessa maneira, obter maior eficiência no trabalho executado (DEJOURS, 1992).

Um dos aspectos importantes a serem levados em consideração ao efetuar uma análise do ambiente de trabalho, diz respeito às posturas adotadas pelos trabalhadores durante a sua execução. Segundo Grandjean e Kroemer (2005) é comum nas indústrias a existência de postos de trabalho inadequados à realidade de seus colaboradores. Na maioria dos setores de produção, por exemplo, prevalece a postura em pé, adotada por longos períodos no decorrer da jornada de trabalho. Essa condição não só causa fadiga muscular, como também é responsável por condições adversas do fluxo de retorno venoso. Os autores salientam ainda que, do ponto de vista ortopédico e fisiológico, é recomendável que o operador alterne a postura, evitando assim a sobrecarga, pois enquanto houver carga em determinado grupo muscular, os demais descansam.

Segundo Ferreira (2002) a tendência existente pela eliminação do esforço físico, contrasta com a necessidade do aumento da produção e da eficácia, o que resulta, por consequência, no surgimento da maioria das doenças ocupacionais. Assim, neste universo homem-máquina, a avaliação ergonômica do posto de trabalho se apresenta como uma excelente ferramenta, capaz de proporcionar soluções de adaptação entre os equipamentos, máquinas, ferramentas e as características físicas do homem.

\subsection{NORMA REGULAMENTADORA 17}

Em muitos países, a criação de normas oficiais tem sido a maneira encontrada de reunir conhecimentos oriundos do campo da ergonomia. No Brasil, especificamente, a Norma Regulamentadora 17 (NR-17), entitulada Ergonomia, estabelecida a partir da Portaria $n^{\circ} 3.751$, em 23/11/1990, instituída pelo Ministério do Trabalho e Previdência Social, tem por objetivo principal nortear a adaptação das condições de trabalho às características psicofisiológicas dos trabalhadores, de maneira a proporcionar um máximo de conforto, segurança e desempenho eficiente (ROSA; PILATTI, 2006). 
A partir dessa padronização, pode-se dizer que não há, para as ações relacionadas a essa adaptação, a faculdade ou arbítrio do empregador, mas sua efetiva realização, vinculada à exigência normativa (LIMA, 2004). A não observância da regulamentação implica em sanções aos empresários.

A NR-17 apresenta parâmetros para 0 posto e organização do trabalho. De forma pontual, os principais fatores ergonômicos, de saúde e de segurança, com suas respectivas metas e indicadores são expostos com a seguinte estrutura: levantamento, transporte e descarga individual de materiais; mobiliário dos postos de trabalho; equipamentos dos postos de trabalho; condições ambientais de trabalho; e organização do trabalho. Traz também dois anexos: trabalho dos operadores de checkouts e trabalho em teleatendimento ou telemarketing. A ideia central da norma é a promoção de um ambiente de trabalho seguro e saudável.

\section{METODOLOGIA}

\subsection{CARACTERIZAÇÃO DA PESQUISA}

A pesquisa pode ser classificada, de acordo com os seus objetivos, como exploratória que, de acordo com Gil (2002, p.41) "têm como objetivo proporcionar maior familiaridade com o problema, com vistas a torná-lo mais explícito ou a constituir hipóteses". Por sua vez, de acordo com a sua abordagem, a investigação pode ser considerada qualitativa, uma vez que, essa opção "posiciona o pesquisador de modo a olhar o fenômeno - objeto de análise - a partir e através de um foco consistente que possa estruturar, caracterizar e sustentar a conduta investigativa" (BERTO; NAKANO, 2014, p.226).

De acordo com os procedimentos, a pesquisa é caracterizada como um estudo de caso, definido por Miguel (2007, p.219) como:

[...] um estudo de natureza empírica que investiga um determinado fenômeno, geralmente contemporâneo, dentro de um contexto real de vida, quando as fronteiras entre o fenômeno e o contexto em que ele se insere não são claramente definidas. Trata-se de uma análise aprofundada de um ou mais objetos (casos), para que permita o seu amplo e detalhado conhecimento.

\subsection{CARACTERIZAÇÃO DO LOCAL, POPULAÇÃO E ATIVIDADES}

A avaliação do posto de trabalho ocorreu no setor de usinagem de peças, em uma indústria local de conexões de alumínio, latão e chumbaloy (aço SAE 12L14) entre outros materiais, utilizados na fabricação de conexões e acessórios para a linha branca de eletrodomésticos. Foram aplicados questionários, do método NASA-TLX, com os quatro operadores de torno semiautomático. Destaca-se que todos os trabalhadores envolvidos são do sexo masculino e possuem ensino médio completo. Quanto à experiência e tempo de trabalho na atividade: um trabalhador está na empresa há nove anos; outro, há quatro anos; um terceiro, há um ano e sete meses; e o mais recente, há 5 meses.

As atividades são desenvolvidas em dois tipos de máquinas, as com alimentação automática por magazine de gravidade - e as alimentadas manualmente.

Nos equipamentos do primeiro grupo, a atividade consiste em: programação da máquina no setup; alimentação do magazine de barras, em cada um dos dois tornos, uma vez ao dia; aferição de medidas com paquímetro; retirada do cavaco, de forma contínua; e transferência do cavaco da bandeja, da máquina para o contêiner de reciclagem, em cada um dos dois tornos.

Nos equipamentos de alimentação manual a atividade consiste em: programação da máquina no setup; alimentação manual de barras, a cada 50 minutos, em cada um dos seis tornos sob sua responsabilidade; aferição de medidas com paquímetro; e transferência do cavaco das bandejas, das seis máquinas para o contêiner de reciclagem, a cada 50 minutos.

Uma vez por semana, há o recebimento do material, que é descarregado manualmente do caminhão para a base da balança, localizada no chão e, posteriormente, 
transportado para as prateleiras.

\subsection{PROCEDIMENTOS DE PESQUISA}

Foram aplicados dois questionários distintos: um deles adaptado do Diagrama das Áreas Dolorosas e o outro do método NASA-TLX. Entre um procedimento e outro, realizou-se uma entrevista semiestruturada, abordando a percepção dos operadores quanto ao seu ambiente de trabalho.

\subsubsection{DIAGRAMA DAS ÁREAS DOLOROSAS}

O primeiro instrumento foi elaborado e adaptado a partir do Diagrama das Áreas Dolorosas, de Corlett e Manenica (1980), que divide o corpo humano em 24 segmentos, com o objetivo de facilitar a localização de áreas em que os trabalhadores sentem dores relacionados à atividade laboral.

A aplicação ocorre ao final de um período de trabalho, onde os entrevistados apontam subjetivamente o grau de desconforto que sentem em cada um dos segmentos indicados no diagrama (IIDA, 2005).

A adaptação da ferramenta se deu quando da alteração de algumas áreas do corpo humano a serem apontadas como dolorosas, além dos níveis de desconforto. Onde se tinha graus de 0 a 8 , sendo 0 , sem desconforto, e 8, extremamente desconfortável, passou-se a utilizar três medidas: confortável, leve desconforto e desconfortável.

\subsubsection{NASA-TLX}

O NASA-TLX (Índice Carga Tarefa), desenvolvido por Hart e Staveland (1988) é um procedimento de taxa multidimensional que prevê uma pontuação global da carga de trabalho baseado em uma média ponderada de avaliações em seis subescalas, sendo elas: exigência (demanda) mental, exigência (demanda) física, exigência (demanda) temporal, além do desempenho (performance) próprio - subdividido ainda em níveis de realização, esforço e frustração, conforme Quadro 1.

Quadro 1 - Definição das seis dimensões que classificam o método NASA-TLX

Definições das 6 dimensões do NASA TLX

\begin{tabular}{|l|l|}
\hline MENTAL & $\begin{array}{l}\text { Quantidade da atividade mental e perceptiva que a tarefa necessita (pensar, decidir, } \\
\text { calcular, lembrar, olhar, procurar etc.) }\end{array}$ \\
\hline FÍSICA & Quantidade de atividade que a tarefa necessita (puxar, empurrar, girar, deslizar, etc.) \\
\hline TEMPORAL & Nível de pressão temporal sentida. Razão entre o tempo necessário e o disponível. \\
\hline SATISFAÇÃO/RENDIMENTO & $\begin{array}{l}\text { Até que ponto o indivíduo se sente satisfeito com o nível de rendimento e } \\
\text { desempenho. }\end{array}$ \\
\hline ESFORÇO & $\begin{array}{l}\text { Grau de esforço mental e físico que o sujeito tem que realizar para obter seu nível de } \\
\text { rendimento. }\end{array}$ \\
\hline NÍVEL DE FRUSTAÇÃO & $\begin{array}{l}\text { Até que ponto o sujeito se sente inseguro, estressado, irritado, descontente, durante } \\
\text { a realização da atividade }\end{array}$ \\
\hline
\end{tabular}

\section{RESULTADOS E DISCUSSÃO}

O primeiro questionário fornece respostas contendo as informações quanto aos sintomas de dor, representadas na Tabela 1, que indica o número de operadores que sentem dores em determinada região do corpo humano. 
Tabela 1 - Percepção dos indivíduos quanto às demandas físicas

\begin{tabular}{|c|c|c|c|}
\hline & Confortável & Leve desconforto & Desconfortável \\
\hline Cabeça & 3 & 1 & - \\
\hline Pescoço & 2 & 2 & - \\
\hline Ombro direito & 3 & - & 1 \\
\hline Ombro esquerdo & 3 & - & 1 \\
\hline Cotovelo direito & 3 & 1 & - \\
\hline Cotovelo esquerdo & 3 & 1 & - \\
\hline Punho direito & 3 & 1 & - \\
\hline Punho esquerdo & 3 & 1 & - \\
\hline Mãos e dedos & 2 & 2 & - \\
\hline Coluna superior & 2 & 1 & 1 \\
\hline Coluna inferior & 1 & 2 & 1 \\
\hline Quadril e/ou nádegas & 3 & 1 & - \\
\hline Coxa direita & 2 & 2 & - \\
\hline Coxa esquerda & 2 & 2 & - \\
\hline Joelho direito & 1 & 2 & 1 \\
\hline Joelho esquerdo & 1 & 2 & 1 \\
\hline Tornozelo e/ou pé (D) & 2 & 2 & - \\
\hline Tornozelo e/ou pé (E) & 2 & 2 & - \\
\hline Polegar (D) & 3 & 1 & - \\
\hline Polegar (E) & 3 & 1 & - \\
\hline Demais dedos (D) & 3 & 1 & - \\
\hline Demais dedos (E) & 3 & 1 & - \\
\hline Palma da mão (D) & 4 & - & - \\
\hline Palma da mão (E) & 4 & - & - \\
\hline
\end{tabular}

É possível perceber, a partir das respostas, prevalência de queixas em algumas áreas específicas, como é o caso das regiões 'mãos e dedos' e 'polegar', que pode estar relacionada com a atividade de retirada do cavaco com uso de uma ferramenta rudimentar, ilustrada na Figura 1. O instrumento utilizado para a realização desta atividade não é um produto padronizado, nem possui desenvolvimento de projeto com premissas ergonômicas.
Figura 1 - ferramenta rudimentar para retirada do cavaco

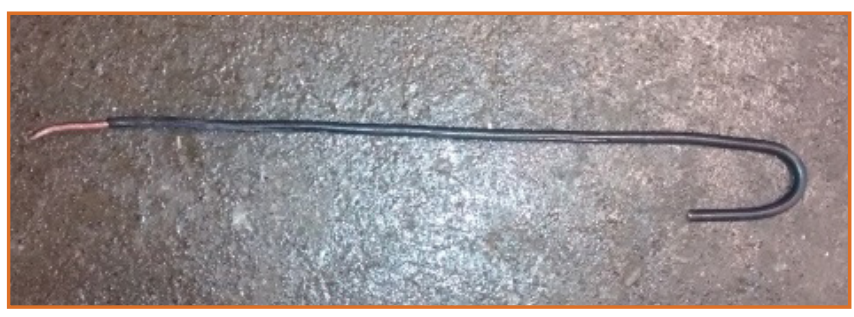

A partir de observação in loco, identificou-se a inadequação na pegada da ferramenta, o que resulta na necessidade de adequar outro sistema para retirada do cavaco. Um dos operadores não apresentou queixa de dores nas mãos e punho, o que motivou uma investigação mais apurada. Nesse caso, foi verificado 
que funcionário opera um conjunto de máquinas que possibilita a retirada do cavaco de forma automática.

Outro fator relevante deve-se às queixas de desconfortos em membros inferiores, como os joelhos e quadris. Durante avaliação das atividades identificouse que o trabalho realizado é predominantemente estático, permanecendo em pé, parado na maior parte da jornada, como ilustrado na Figura 2, realizando pequenos deslocamentos eventuais. Por ser caracterizado como estático, nota-se a demanda de adaptação do posto de trabalho, visando possibilitar a alternância postural, em pé e sentado, o que diminuiria a sobrecarga muscular.

Outro item citado como região de desconforto é a coluna, que também guarda relação com a situação do trabalho estático, já que os músculos posturais são recrutados para a manutenção da posição. É importante destacar que não são adotados mecanismos de regulação para compensar as exigências existentes no trabalho dos operadores, havendo a necessidade de adequação de tal condição.

Figura 2 - Posição de trabalho do operador

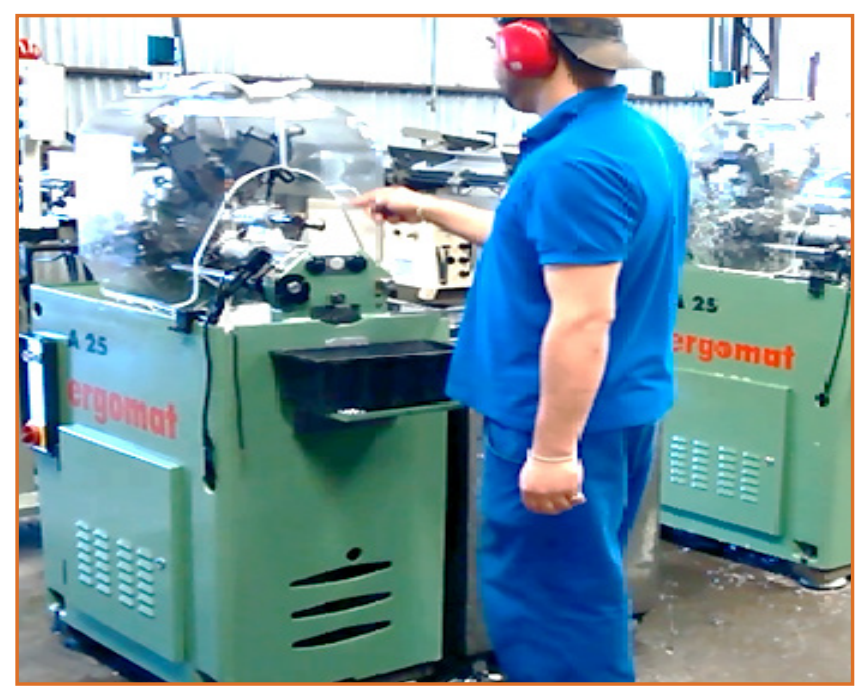

Com relação à entrevista semiestruturada, verificouse que as condições do ambiente interferem na execução das atividades. No caso dos entrevistados, houve relatos de desconforto térmico, apontando que a temperatura do local está elevada e há necessidade de melhorias, como apresentado no Gráfico 1.
Gráfico 1 - Percepção individual quanto ao clima/ temperatura

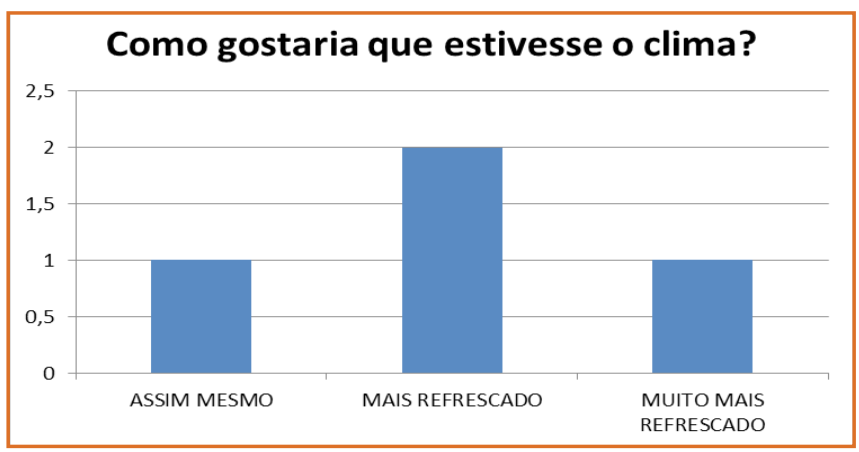

O desconforto acústico também foi diagnosticado a partir das respostas dos operadores, como se observa no Gráfico 2. A respeito deste item, o Programa de Prevenção de Riscos Ambientais (PPRA) da empresa cita que o nível de ruído do local é de 87,5 dB(A), havendo necessidade de uso de abafadores de ruído. Os trabalhadores relataram apresentar dificuldade de compreensão na troca de informações e estresse, associando tais queixas às condições de ruído do seu local de trabalho.

Gráfico 2 - Percepção individual quanto ao ruído

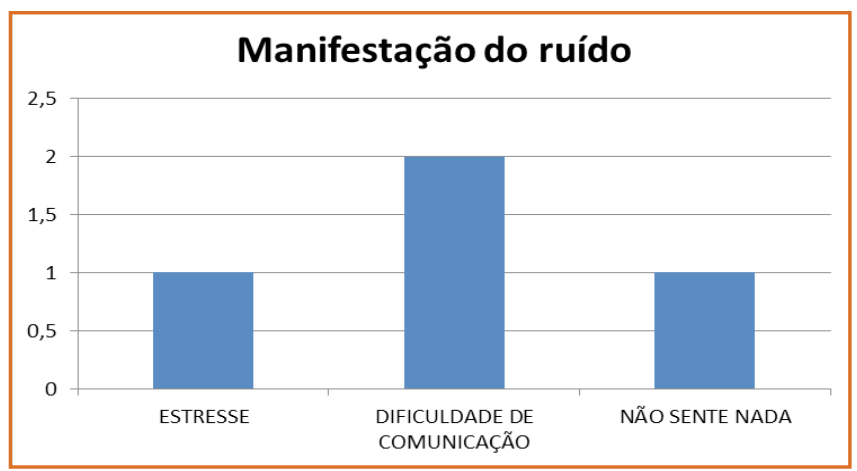

O clima organizacional é um fator importante e possui relação direta com a fadiga no ambiente no trabalho. Referente a este item, a Tabela 02 demonstra as respostas dos entrevistados quanto adequação dos aspectos relacionados ao trabalho. 
Tabela 2 - Percepção da ergonomia organizacional no ambiente de trabalho

\begin{tabular}{|l|l|l|l|}
\multicolumn{5}{c}{ Adequada } & \multicolumn{2}{c|}{ Razoável } & \multicolumn{2}{c|}{ Inadequada } \\
\hline Jornada de trabalho & 3 & 1 & - \\
\hline Turno & 3 & 1 & - \\
\hline Ritmo de trabalho & 2 & 2 & - \\
\hline $\begin{array}{l}\text { Intensidade do } \\
\text { trabalho }\end{array}$ & - & 4 & - \\
\hline Remuneração & 2 & 1 & 1 \\
\hline Benefícios (saúde) & 1 & 1 & 2 \\
\hline $\begin{array}{l}\text { Benefícios } \\
\text { (alimentação) }\end{array}$ & 1 & 1 & 2 \\
\hline Treinamento & 2 & 2 & - \\
\hline $\begin{array}{l}\text { Relação com } \\
\text { supervisores }\end{array}$ & 4 & - & - \\
\hline Relação com colegas & 4 & - & - \\
\hline
\end{tabular}

Pode-se perceber com as respostas, que o ritmo de trabalho dividiu os operadores, indicando que a alimentação de barras e a retirada do cavaco impõem uma atenção e um ritmo acelerado à atividade. Já a intensidade do trabalho foi marcada por todos como razoável, diagnosticando juntamente com o ritmo, que a atividade de aferição de medidas com paquímetro, além da retirada de cavaco e realimentação, intensifica o ritmo de trabalho. O relacionamento com supervisores e colegas, pela avaliação dos entrevistados está adequado, assim como a jornada de trabalho e o turno, de acordo com a maioria. Há divergências de respostas em alguns itens, porém a maioria apresenta insatisfação com a remuneração e os benefícios oferecidos pela empresa, como saúde e alimentação.

No questionário NASA-TLX, a avaliação das demandas foi graduada em escalas de 0 a 10, onde os entrevistados assinalaram em uma linha a sua percepção referente a cada demanda. Os resultados estão demonstrados na Tabela 3.
Tabela 3 - Percepção individual de demandas

\begin{tabular}{|c|c|c|c|c|}
\hline & $\begin{array}{c}\text { Operador } \\
1\end{array}$ & $\begin{array}{c}\text { Operador } \\
2\end{array}$ & $\begin{array}{c}\text { Operador } \\
3\end{array}$ & $\begin{array}{c}\text { Operador } \\
4\end{array}$ \\
\hline $\begin{array}{l}\text { Demanda } \\
\text { mental }\end{array}$ & 5 & 1 & 7,5 & 0,5 \\
\hline $\begin{array}{l}\text { Demanda } \\
\text { física }\end{array}$ & 3 & 1,5 & 7,5 & 4 \\
\hline $\begin{array}{l}\text { Demanda } \\
\text { temporal }\end{array}$ & 5,5 & 1,5 & 5,5 & 8 \\
\hline $\begin{array}{l}\text { Nível de } \\
\text { esforço }\end{array}$ & 1,5 & 1,5 & 6,5 & 4,5 \\
\hline $\begin{array}{l}\text { Nível de } \\
\text { realização }\end{array}$ & 7 & 8 & 8,5 & 6,5 \\
\hline $\begin{array}{l}\text { Nível de } \\
\text { frustração }\end{array}$ & 2 & 7,5 & 2 & 7,5 \\
\hline
\end{tabular}

Verifica-se que as opiniões dos operadores são distintas quanto às demandas mental e física. Um dos operadores cita a demanda mental prevalente sobre a física, já outros dois apontam o contrário, enquanto que um dos entrevistados gradua de forma igual, porém com altos índices. É necessário apontar as situações características que existem nas máquinas operadas. Enquanto alguns equipamentos demandam apenas operações e controles, outros necessitam da intervenção frequente do operador, como é o caso da retirada de cavaco de alguns equipamentos, bem como o abastecimento de materiais, que em algumas máquinas é automático e em outras é alimentada pelo trabalhador.

Outro ponto que chama atenção é referente ao nível de realização e frustração. Todos os operadores apontam que a atividade Ihes proporciona alguma realização, entretanto divergem quanto à frustração, sendo que a metade cita como significativo o nível de frustração. Neste caso o nível de frustração pode estar ligado ao fato de problemas com ajustes dos equipamentos, relatados durante a entrevista pelos trabalhadores.

Realizou-se questionamento comparativo entre demandas para verificar a prevalência segundo a percepção dos operadores, o que pode ser constatado pela Tabela 4.

Classificando as exigências e analisando as suas incidências sobre os quatro trabalhadores, a demanda temporal, que indica a pressão para realizar a tarefa 
sobre a forma de produção puxada, apresentou um escore de 21,67\%; seguido da demanda mental, com o escore de 20\%, o que indica que a atenção continuada sobre o processo com característica multifoco - atenção simultânea sobre mais de uma máquina - causa desconforto no grupo.

A frustração se apresenta com 18,33\%; e a realização com $16,67 \%$. Isto pode ser explicado pela diferença entre os equipamentos, onde o maquinário mais antigo, manual, sobrecarrega os operadores com a atividade de retirada do cavaco. Em contrapartida, os trabalhadores que atuam em máquinas automatizadas, por não necessitarem retirar o cavaco manualmente e a alimentação da matéria-prima ser automatizada, sentem possuir um status mais elevado que os operadores do primeiro grupo. O desconforto se deu por permanecer em pé e de maneira estática, o que foi corroborado pelos escores relativos às demandas físicas e de esforço, que apresentaram percentuais relativamente baixos, $13,33 \%$ e $10 \%$, respectivamente.

Tabela 04 - Comparativo de demandas e níveis percebidos pelos operadores

\begin{tabular}{|c|c|}
\hline Demanda mental & Demanda física \\
\hline 2 & 2 \\
\hline Demanda temporal & Demanda física \\
\hline 4 & 0 \\
\hline Demanda temporal & Nível de frustração \\
\hline 3 & 1 \\
\hline Demanda temporal & Demanda mental \\
\hline 2 & 2 \\
\hline Nível de realização & Demanda física \\
\hline 2 & 2 \\
\hline Demanda temporal & Nível de esforço \\
\hline 2 & 2 \\
\hline Nível de realização & Demanda mental \\
\hline 1 & 3 \\
\hline Nível de frustração & Demanda física \\
\hline 2 & 2 \\
\hline Nível de realização & Nível de frustração \\
\hline 2 & 2 \\
\hline Nível de frustração & Demanda mental \\
\hline 3 & 1 \\
\hline Nível de esforço & Demanda física \\
\hline 2 & 2 \\
\hline Nível de realização & Nível de esforço \\
\hline 3 & 1 \\
\hline Nível de esforço & Demanda mental \\
\hline 0 & 4 \\
\hline Demanda temporal & Nível de realização \\
\hline 2 & 2 \\
\hline Nível de esforço & Nível de frustração \\
\hline 1 & 3 \\
\hline
\end{tabular}


O primeiro é composto pelos retornos dos operadores onde a máquina retira o cavaco automaticamente, enquanto que o segundo grupo diz respeito à retirada manual, conforme podemos observar na tabela 05.

Tabela 05 - Graduação de demandas de acordo com a forma de retirada de cavaco

\begin{tabular}{|l|l|l|}
\multicolumn{2}{c}{ Automática } & Manual \\
\hline Mental & 9 & 3 \\
\hline Física & 3 & 5 \\
\hline Temporal & 3 & 10 \\
\hline Esforço & 5 & 2 \\
\hline Realização & 5 & 4 \\
\hline Frustração & 5 & 6 \\
\hline
\end{tabular}

Ao analisarmos as respostas dos entrevistados separadamente, percebemos que os operadores das máquinas onde a retirada do cavaco é realizada de forma manual, apontaram a demanda temporal como o item de maior relevância, aparecendo com 33,3\%, enquanto que, para os operadores das máquinas automáticas, a demanda de maior graduação foi a mental, com 30\%.

$\mathrm{Na}$ comparação entre as duas formas de realização da atividade, observam-se, pelas graduações, as diferenças existentes entre elas e quais os fatores mais relevantes. Enquanto a processo automatizado requer do operador uma carga mental de maior relevância, o operador da máquina manual percebe a carga física como de maior constrangimento. A demanda temporal, citada pelos operadores da máquina manual, com $33,3 \%$, comparando-se com a demanda de esforço, graduada em $6,6 \%$, pode estar relacionada ao fato de que esta configuração requer permanência e ações contínuas, como é o caso da retirada de cavaco. No equipamento automático, os operadores apontaram a demanda de esforço, com 16,6\%, e a temporal, com $10 \%$. É preciso considerar, no entanto, que apesar de a retirada de cavaco ser automática, as máquinas são alimentadas manualmente e um mesmo trabalhador opera várias máquinas ao mesmo tempo.

Com relação às questões frustração e realização, percebe-se que os operadores da retirada de cavaco manual apontam o nível de frustração de maior relevância, enquanto que, na automática, há um equilíbrio na graduação destas demandas.

\section{CONCLUSÕES}

As demandas do mercado exigem das empresas agilidade nos processos e na entrega dos produtos. Entretanto, o desafio atual das organizações está em atingir esse ideal, considerando o aumento da produção, a qualidade do que é produzido e, ainda, evitando a exposição do trabalhador ao sofrimento na realização da atividade.

Nesse contexto, insere-se a ergonomia, que busca benefícios em comum entre a produção e a saúde dos trabalhadores, com o objetivo de promover a qualidade de vida nas organizações, assim como a avaliação ergonômica do posto de trabalho, que se apresenta como uma excelente ferramenta, capaz de proporcionar soluções de adaptação entre os equipamentos, máquinas, ferramentas e as características físicas do homem.

Percebe-se, após a realização deste estudo, que ao efetuar adaptações em um ambiente laboral, é necessário levar em consideração as condições para tal finalidade, uma vez que a automação em si não indica essencialmente que o trabalho está de acordo. Persiste ainda a necessidade de avaliar a atividade, identificar as demandas existentes e efetuar as melhorias.

No caso em questão, verificou-se que o posto de trabalho do operador de torno exige adequações, sendo que para isso os pesquisadores propõem: i) automatizar o sistema de abastecimento das máquinas; ii) realizar adequações antropométricas, tais quais, nas áreas de alcance, alturas e espaço do posto de trabalho, para proporcionar posicionamento apropriado dos segmentos corporais; iii) adequar um banco semi sentado no posto, já que a atividade é considerada estática; iv) aprimorar a retirada de cavaco, automatizando a atividade; v) implantar mecanismos de regulação como pausas e rodízios, com a criação de um grupo de trabalho, onde os operadores trabalham de forma integrada em todas as máquinas. 
A eficácia da ergonomia consiste em criar um espaço para ampliar a regulação individual e coletiva da atividade. Mais do que uma ação isolada, precisa fazer parte das políticas organizacionais, estar incorporada como fundamental na cultura da empresa e, mais do que controlar riscos, precisa manter a saúde e a qualidade de vida de toda organização.

\section{REFERÊNCIAS}

[1] ASSOCIAÇÃO BRASILEIRA DE ERGONOMIA ABERGO. Disponível em: <http://www.abergo.org.br> Último acesso em: 04 jul. 2015.

[2] BERTO, R.M.V.S; NAKANO, D. Revisiting scholarly output in the records of the Brazilian Meeting of Industrial Engineering. Production, v. 24, n. 1, p. 225-232, mar. 2014.

BOFF, K.R. Revolutions and shifting paradigms in human factors \& ergonomics. Applied Ergonomics, v.37, n.4, p.391399, 2006.

[3] BRASIL. Ministério do Trabalho e Emprego, Norma regulamentadora ㄲo 17 - Ergonomia. Portaria ํo 3.751, de 23 de novembro de 1990

[4] CARDOSO, M.S; GONTIJO, L.A. Avaliação da carga mental de trabalho e do desempenho de medidas de mensuração: NASA-TLX e SWAT. Gestão \& Produção, Vol. 19, n. 4, p. 873-884, 2012.

[5] CORLETT, E.N.; MANENICA, I. The effects and measurement for working postures. Applied Ergonomics, Vol. 11, n. 1, p.7-16, 1980.

[6] CORREIA, S.M.S.; SILVEIRA, C.S. A ergonomia cognitiva, operacional e organizacional e suas interferências na produtividade e satisfação dos colaboradores. XXIX Encontro Nacional de Engenharia de Produção. A engenharia de produção e o desenvolvimento sustentável: integrando tecnologia e gestão. Salvador: 2009. Disponível em: <http:// www.abepro.org.br/publicacoes >. Último acesso em: 06 jul. 2015.

[7] DEJOURS, C. A loucura do trabalho: estudo de psicopatologia do trabalho. 5. ed.. São Paulo: Cortez Oboré, 1992.

[8] DUL, J.; NEUMANN, W.P. The strategic business value of ergonomics. In: PIKAAR, R.N.; KONINGSVELD, E.A.P.; SETTELS, P.J.M. (Eds.), Meeting Diversity in Ergonomics. Amsterdam: Elsevier, 2007

[9] FERREIRA, M.J. Saúde no trabalho: temas básicos para o profissional que cuida da saúde dos trabalhadores. São Paulo: Roca, 2002.

[10] FERRIS, G.R. et al. Human resources reputation and effectiveness. Human Resource Management Review, Vol.17, n.2, p.117-130, 2007.
[11] GIL, A.C. Como elaborar projetos de pesquisa. 4 ed. São Paulo: Atlas, 2002, 175p.

[12] GRANDJEAN, E.; KROEMER, K.H.E. Manual de Ergonomia: adaptando o trabalho ao homem. 5. ed. Porto Alegre: Bookman, 2005.

[13] HART, S.G. NASA-Task Load Index (NASA-TLX); 20 years later. Proceedings of the Human Factors and Ergonomics Society 50th Annual Meeting, 904-908. Santa Monica: HFES, 2006.

[14] HART, S.G.; STAVELAND, L.E. Development of a NASATLX (Task Load Index): Results of empirical and theoretical research. In: Hancock, P.A., Meshkati, N. (Eds.), Human Mental Workload. Elsevier, Amsterdam, 1988.

[15] HUMAN FACTORS AND ERGONOMICS SOCIETY HFES. Disponivel em: <https://www.hfes.org> Último acesso em: 04jul. 2015.

[16] IIDA, I. Ergonomia: projeto e produção. 2. ed. São Paulo: Edgard Blucher, 2005.

[17] INTERNATIONAL ERGONOMICS ASSOCIATION - IEA. Disponivel em: <http://www.iea.cc/whats/index.html> Último acesso em: 04 jul. 2015.

[18] LIMA, J.A.A. Bases Teóricas para uma Metodologia de Análise Ergonômica. In: 4ํㅡㄹ Congresso Internacional de Ergonomia e Usabilidade de Interfaces Humano-Tecnologia: Produtos, Programas, Informação, Ambiente Construído. PUC-Rio. Rio de Janeiro: 2004.

[19] MIGUEL, P.A.C. Estudo de caso na engenharia de produção: estruturação e recomendações para sua condução. Produção, São Paulo, v. 17, n. 1, p. 216-229, 2007.

[20] NEAL, A.; WEST, M.A; PATTERSON, M.G. Do organizational climate and competitive strategy moderate the relationship between human resource management and productivity? Journal of Management, v.31, n.4, p.492-512, 2005.

[21]ROSA, M.A.S.; PILATTI, L.A. Qualidade de vida e legislação pertinente. Lecturas Educación Física y Deportes, Buenos Aires, n.93, 2006.

[22] SOARES, M.M. Ergonomics in Latin America: background, trends and challenges. Applied Ergonomics, v.37, n.4, p.555-561, 2006.

[23] THEBERGE, N; NEUMANN, W.P. Doing 'organizational work': expanding the conception of professional practice in ergonomics. Applied Ergonomics, v.42, n.1, p.76-84, 2010.

[24] WILSON, J.R. Fundamentals of ergonomics in theory and practice. Applied Ergonomics, v.31, n.6, p.557-567, 2000. 


\title{
CAPÍTULO 6
}

\section{PROPOSTA DE REDIMENSIONAMENTO DE POSTO DE TRABALHO: O CASO DA ATIVIDADE DE MONTAGEM DE JANELAS DE VENEZIANAS EM INDÚSTRIA DE ESQUADRIAS DE ALUMÍNIO}

\author{
Lívia Pinto Neri \\ Priscila Pereira Suzart de Carvalho \\ André de Mendonça Santos \\ Thiago Francisco de Souza \\ Indara Santos de Souza
}

Resumo: A competitividade acirrada no mercado atual tem feito com que as empresas busquem alterações nas suas operações para se manter vivente. Assim, algumas fazem uso dos conceitos de Ergonomia para aumentar a sua produtividade, além de proporcionar melhores condições de saúde e segurança aos colaboradores. Este trabalho tem por objetivo apresentar uma proposta de redimensionamento do arranjo físico do posto de trabalho montagem de janelas venezianas em uma indústria de esquadrias de alumínio localizada na cidade de Caculé-BA. Para tanto, utilizou o método Análise Ergonômica do Trabalho com a finalidade de diagnosticar e sugerir tratamentos das principais problemáticas, particularmente aquelas relacionadas à postura. Constatou-se que simples alterações podem não só mitigar fadiga muscular, como também melhorar a produtividade.

Palavras Chave: Ergonomia; Análise Ergonômica do Trabalho; postura; produtividade; esquadrias de alumínio. 


\section{INTRODUÇÃO}

O mundo vem experimentando alterações no conceito de operações. Se o empresário deseja desenvolver sua empresa para maior competitividade, este deve buscar cada vez mais a modernização constante dos seus métodos e processos produtivos (TOMASINI, 2001).

Estas transformações que vêm ocorrendo nas organizações têm também levado-as a voltar sua atenção para a Ergonomia, uma vez que esta tem se destacado nas discussões empresariais por proporcionar ganhos não só relacionados à segurança, saúde e satisfação do trabalhador, mas também de produtividade.

Na indústria de esquadrias de alumínio, as mudanças situacionais não são diferentes. Segundo a Associação Nacional de Fabricantes de Esquadrias de Alumínio (AFEAL) (2014), nas últimas três décadas, o setor vem conquistando o mercado nacional, desde os especificadores até o consumidor final, representando cerca de $20 \%$ do volume total de caixilhos produzidos no país. Isto está relacionado, principalmente, às características do material: comportamento estrutural, longevidade, durabilidade e isolamento acústico e térmico.

Uma fábrica de esquadrias de alumínio tem as suas operações de produção basicamente dividida em 05 (cinco) setores: armazenagem, corte, usinagem, colocação de acessórios e montagem. Este último é um dos de maior fluxo, pois praticamente passam todas as peças que compõem a esquadria, interferindo diretamente na produtividade de todo o processo produtivo.

Em decorrência disso, este trabalho apresentará uma proposta de redimensionamento do arranjo físico do posto de trabalho montagem de janelas venezianas em uma indústria de esquadrias de alumínio localizada na cidade de Caculé-BA. Foi identificado na referida empresa que a postura inadequada dos operadores tem contribuído para a ineficiência do setor, o que permite pressupor que alterações no projeto do posto possibilitarão melhoria do desempenho e redução da fadiga.

\section{REVISÃO DA LITERATURA \\ 2.1 ERGONOMIA: DEFINIÇÃO, OBJETIVOS, VANTAGENS E DOMÍNIOS}

A atual competitividade e a necessidade de um bom posicionamento no mercado têm levado as organizações a investirem em tecnologia e colaboradores qualificados. O conhecimento ergonômico e sua filosofia para adaptar o trabalho ao homem têm originado grandes benefícios não só aos funcionários, mas também às organizações (PRATES, 2007).

A palavra Ergonomia deriva do grego Ergon [trabalho] e nomos [normas, regras, leis].

A Associação Internacional de Ergonomia (IEA) e a Associação Brasileira de Ergonomia (ABERGO) ambos adotam a definição de Ergonomia como sendo uma disciplina científica relacionada ao entendimento das interações entre os seres humanos e outros elementos ou sistemas, e à aplicação de teorias, princípios, dados e métodos a projetos a fim de otimizar o bem estar humano e o desempenho global do sistema.

Os objetivos principais da Ergonomia são: manter a saúde do trabalhador livre de estresse e de doenças ocupacionais; segurança para evitar riscos e acidentes; satisfação e bem-estar do trabalhador; e eficiência. Considera-se que trabalhadores adotando comportamentos mais seguros e tornam-se mais produtivos (IIDA, 2005).

Ainda de acordo lida (2005), a Ergonomia, assim como qualquer outra atividade do setor produtivo, só será implantada se apresentar uma relação custo/ benefício favorável.

O benefício econômico do projeto ou redesign ergonômico pode ser mensurado pelo seu impacto em valor das ações da empresa, vendas, produtividade ou redução de acidentes (HENDRICK, 2003).

Para Mafra (2006), os caminhos para demonstrar as vantagens econômicas da Ergonomia variam desde o uso de simples planilhas a desenvolvimento de um modelo de caso de negócio. Porém, todos 
os caminhos confirmam que as intervenções de Ergonomia oferecem benefícios consideráveis para a organização em questão, gerando resultados financeiros quantificáveis.

A Ergonomia ainda pode ser caracterizada como física, cognitiva e organizacional. A Ergonomia física está relacionada com as características antropométricas, fisiológicas e biomecânicas relacionadas ao trabalho. A Ergonomia cognitiva relaciona-se às solicitações cognitivas exigidas pela tarefa e suas repercussões sobre a saúde e o desempenho da população estudada. Já a Ergonomia organizacional relaciona-se à otimização do sistema sociotécnico, incluindo suas estruturas organizacionais, políticas e processos (IEA, 2014; TOSETTO, 2009).

Com base nas classificações citadas, este trabalho aborda a Ergonomia física, fazendo uso de medições antropométricas para desenvolvimento de um posto de trabalho adequado aos seus usuários e discutindo elementos a cerca do tópico biomecânica ocupacional, em específico, postura.

\subsection{POSTURA}

A Ergonomia estuda as relações existentes entre algumas variáveis, como a postura em que o operador realiza a atividade e os movimentos corporais que ele realiza ao longo do dia; fatores ambientais como barulhos, iluminação, clima; informação (informações captadas pela visão, audição e outros sentidos), além de cargos e tarefas. Uma boa relação desses fatores permite projetar ambientes seguros, saudáveis, confortáveis e eficientes, tanto no trabalho quanto na vida cotidiana (MOTTA, 2009).

Dul \& Weerdmeester (2004) e Motta (2009) afirmam que a postura é frequentemente determinada pela natureza da tarefa ou do posto de trabalho. Projetos inadequados de máquinas, assentos ou bancadas de trabalho, obrigam o trabalhador a assumir posturas inadequadas. Com o passar do tempo, podem gerar doenças no conjunto de músculos que estava sendo sobrecarregados, bem como nas articulações.
Assim, a postura é o estudo do posicionamento relativo de partes do corpo, como cabeça, tronco e membros, no espaço. A boa postura é importante para a realização do trabalho sem desconforto e estresse. Existe certo tipo de postura que pode ser considerado mais adequado para cada tipo de tarefa (IIDA, 2005). Esta questão deve ser levada em consideração quando se está projetando ambientes de trabalho e/ ou novos produtos.

\subsection{PROJETO DE POSTO DE TRABALHO}

Há dois tipos de enfoques para avaliar o posto de trabalho: o taylorista e o ergonômico. Segundo lida (2005), o enfoque taylorista é fundamentado nos princípios de economia dos movimentos e o enfoque ergonômico é baseado principalmente na análise biomecânica da postura e nas interações entre o homem, sistema e ambiente.

Um dos pontos que merece destaque quando se fala em projeto de posto de trabalho consiste na definição da altura da área de trabalho. Para o uso de bancadas, o trabalho pode ser realizado predominantemente sentado ou predominantemente em pé. Um espaço suficiente deve ser mantido sob a bancada para acomodar as pernas e pés, permitindo que o operador se aproxime do trabalho, sem necessidade de curvar o tronco além, também mudanças frequentes de postura (SILVA, 2003; DUL, WEERDMEESTER, 2004).

Além disso, os materiais necessários que serão utilizados na realização das tarefas devem estar acessíveis e/ou facilmente encontrados. Para tanto, o ideal é dispor todos os elementos dentro da zona de alcance do usuário.

De acordo com Grandjean (1998), a bancada de trabalho deve ser regulável ou possuir a altura mais adequada para seu usuário, pois aquelas muito altas faz com que o operador fique com os ombros ou a lateral dos braços levantados, levando-os a sentir dores musculares. Do mesmo jeito, se a superfície estiver muito baixa, as costas ficarão sobrecarregadas o que pode resultar em dores nas costas. 


\section{METODOLOGIA}

O estudo foi realizado em uma empresa que atua no setor de fabricação de esquadrias de alumínio e está no mercado há 8 anos. De acordo ao Banco Nacional de Desenvolvimento (BNDES), a empresa se classifica como pequeno porte com relação a sua receita operacional bruta anual.

A referida empresa tem como principal atividade a fabricação de portas, janelas, venezianas e basculantes de alumínio e conta com um quadro de 39 funcionários. Está localizada na cidade de Caculé, no sudoeste baiano, distante cerca de 780 quilômetros de Salvador.

A motivação da escolha foi a constatação de que era possível propor um posto de trabalho para a montagem de janelas venezianas com maior adequação, de forma a evitar distúrbios relacionados a má postura, consequentemente aumentar a produtividade. De acordo com a Organização PanAmericana da Saúde (OPAS), a saúde ocupacional é uma importante estratégia tanto para garantir a saúde dos trabalhadores, como para contribuir positivamente para a produtividade, qualidade dos produtos, motivação e satisfação do trabalho.

Para tanto, foi utilizado o método Análise Ergonômica do Trabalho (AET) com a finalidade de analisar, diagnosticar e corrigir o posto de trabalho montagem de janelas venezianas no que se trata das diferentes posturas do pescoço, tronco e membros superiores e inferiores adotadas pelos trabalhadores. Desta forma, foi realizado o seguinte procedimento:

a. Primeira etapa: apresentação e análise da demanda, ou seja, da situação problemática;

b. Segunda etapa: análise da tarefa, de forma a conhecer os operários que realizam a atividade, a quais circunstâncias estão expostos e onde está localizado o posto em estudo;

c. Terceira etapa: descrição das ações, onde se encontram dispostas todas as atividades que são realizadas pelos operadores e identificação dos membros que são utilizados para realização dessas tarefas;

d. Quarta etapa: formulação do diagnóstico, por meio do confronto entre as técnicas observação direta e questionário de auto-preenchimento;

e. Quinta etapa: proposta acompanhada de desenhos com detalhamentos das modificações do arranjo físico do posto de trabalho elaborados no software SOLIDWORKS 2012.

O questionário utilizado consiste no Diagrama das Áreas Dolosas, proposto por Corlett e Manenica (1980). A escolha deste questionário está relacionada à sua fácil aplicação, fácil entendimento e os resultados obtidos são imediatos. Ele é dividido em 24 segmentos, no qual o trabalhador ao final do período de trabalho irá apontar as regiões onde sentem dores, dentre "sem desconforto" até "extremamente desconfortável".

É importante salientar que para a realização do redimensionamento do posto de trabalho será utilizado a tabela antropométrica de medição da população brasileira proposto pelo Instituto Nacional de Tecnologia (1988). A escolha em utilizar a medida da população e não fazer a medição dos funcionários na empresa foi porque a empresa apresenta alta rotatividade de funcionários, turnover, o que faz com que não seja indicado o uso de medições dos funcionários da empresa.

\section{RESULTADOS E DISCUSSÃO 4.1 ANÁLISE DA DEMANDA}

Ao desenvolverem suas atividades, os operadores realizam grandes esforços físicos em algumas situações, como ficar com o ombro suspenso por alguns minutos (FIGURA 1a), abaixar na bancada várias vezes para apanhar os perfis necessários para montagem (FIGURA 1b), colocar a janela veneziana no chão e se agachar para alinhar o produto (FIGURA 1c), entre outros. Estas situações quando realizadas por diversas vezes ao longo do dia pode levar a doenças ocupacionais no futuro. 
Figura1- Esforços físicos realizados pelos operadores

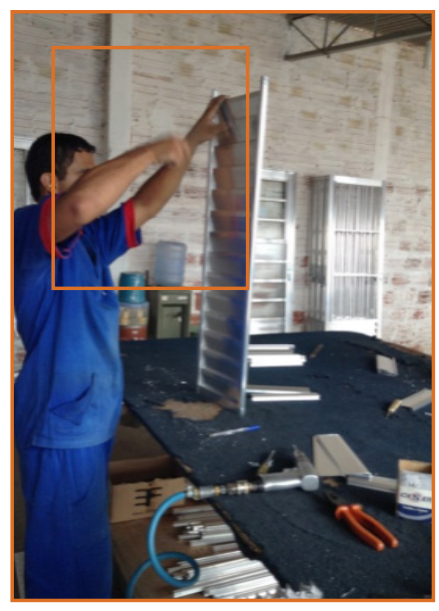

(a)

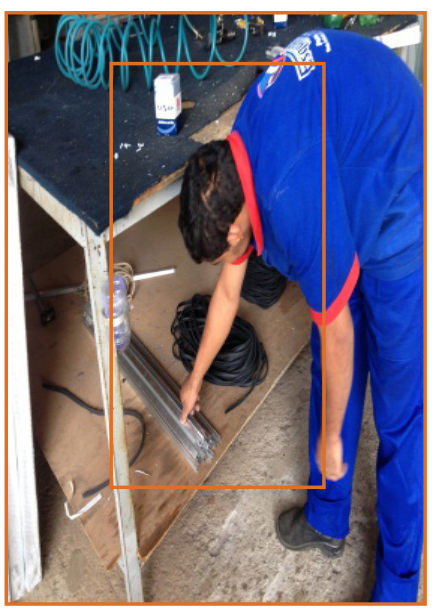

(b)

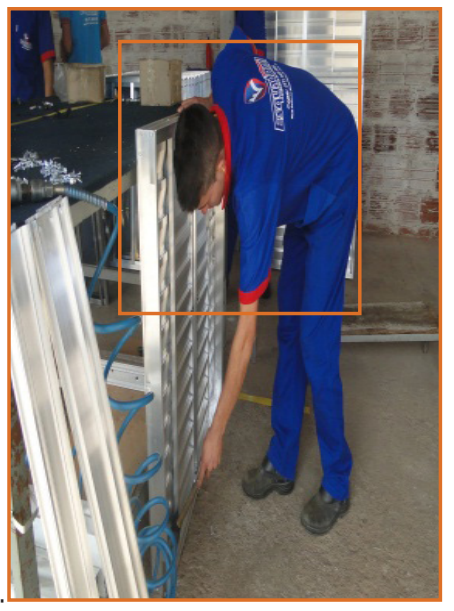

(c)

\subsection{ANÁLISE DA TAREFA}

O posto em análise consta com 2 operários, do sexo masculino, com idades de 21 e 25 anos. Possuem a estatura de $1,70 \mathrm{~m}$ e $1,81 \mathrm{~m}$, peso de $71 \mathrm{~kg}$ e $70 \mathrm{~kg}$. O nível de instrução escolar é ensino médio completo para ambos e desenvolvem a atividade há 3,5 e 3 anos. Eles possuem jornada de trabalho diurna com 8 horas de trabalho por dia, havendo duas pausas de 15 minutos pela manhã e tarde para o intervalo e 1,5 horas para o almoço.
As máquinas e ferramentas necessárias para realização da atividade são parafusadeira, rebitadeira, tesoura, marreta de borracha, esmerilhadeira, chave de fenda e faca; e os materiais envolvidos são perfis de alumínio e óleo lubrificante. Os materiais chegam até o posto através do alimentador que, transporta os materiais, em sua maioria, nos braços (FIGURA 2a), usando apenas um carrinho para transportar as paletas de venezianas (FIGURA 2b).

Figura 2- Alimentação feita com as mãos (a) e com auxílio do carrinho (b)

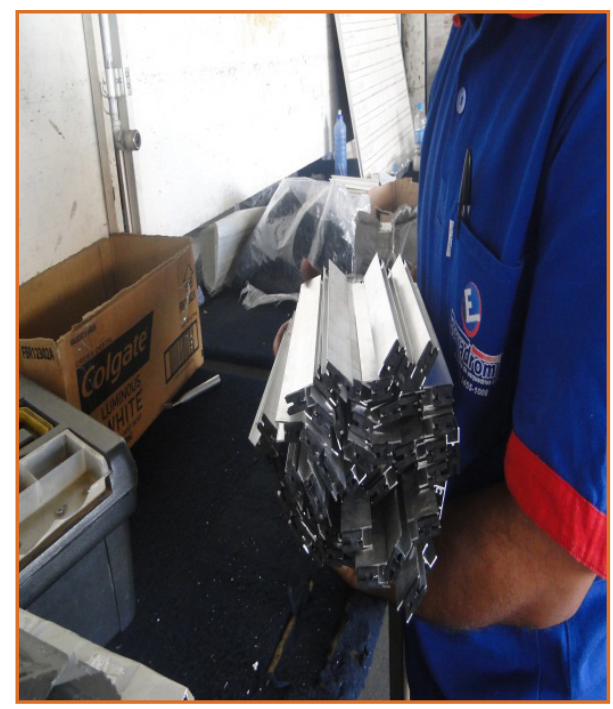

(a)

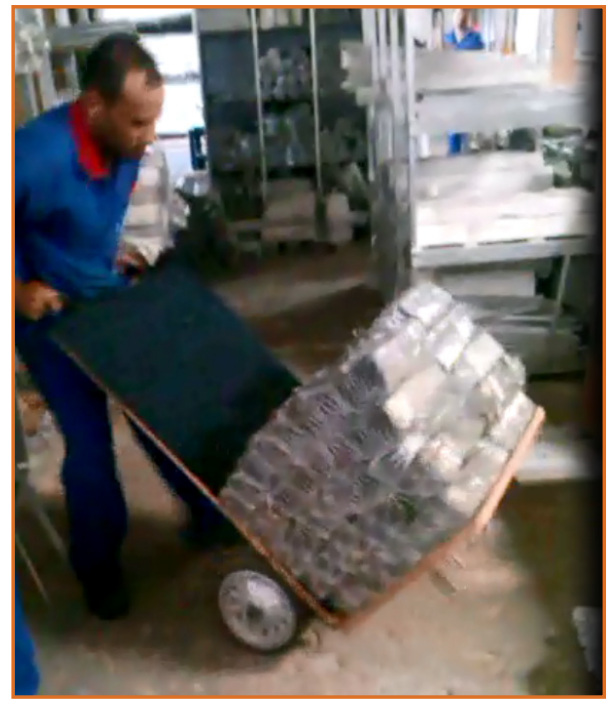

(b) 
produtos acabados. Devido a essa aproximação com o posto de inspeção, o próprio operador transporta manualmente a veneziana até a inspeção, após a finalização.

As atividades desenvolvidas pelos operadores são realizadas em pé e os membros solicitados durante a realização destas são os superiores e inferiores, sendo as mãos, braços e pernas os mais utilizados.

Os Equipamentos de Proteção Individual (EPI's) que são utilizados pelos operadores são os protetores auriculares e a bota com bico de plástico. Luvas são disponibilizadas pela empresa, porém na maioria dos postos, não são usados pelos operários que alegam não ter pega quando usam a luva, o que acaba gerando riscos aos próprios funcionários.

Com relação às condições ambientais na área de produção, pode-se observar que apesar do galpão de produção ser aberto, permitindo uma ventilação, - local ainda é quente. Entende-se que alguns dos fatores geradores dessa temperatura elevada são:o próprio clima da cidade que possui temperatura média 22,9 C(CLIMATE-DATA, 2014) e também a ausência de ventiladores na produção.

A iluminação é natural, pois mesmo tendo lâmpadas não são utilizadas para não aumentar o calor, o que resulta em locais bastante escuros e de difícil condição de realizar a atividade. Além disso, constatase a presença de ruídos advindo das parafusadeiras, esmerilhaderias, usinagens, serragem dos perfis, martelete rebarbador pneumático e outros. $\mathrm{Na}$ utilização da máquina parafusadeira é possível observar que esta transmite sua vibração para o operador resultando em desconforto e até perda de eficiência.

Vale ressaltar que estes fatores ambientais supracitados não foram mensurados no desenvolvimento do estudo, sendo análises intuitivas.

\subsection{DESCRIÇÃO DAS AÇÕES}

As atividades realizadas pelos operadores são: a. Segurar os perfis fixos e parafusar para formar um "L";

b. Encaixar a outra lateral e parafusar na estrutura para formar uma nova estrutura fixa em forma de "U";

c. Encaixar a roldana em um perfil móvel;

d. Segurar os perfis e parafusar para formar um "L";

e. Encaixar a outra lateral e parafusar na estrutura para formar uma nova estrutura móvel em forma de "U";

f. Encaixar as 13 folhas de veneziana em todas as estruturas em $U$ fixas e móveis;

g. Medir a última folha de veneziana e em seguida, cortar com o auxílio da tesoura;

h. Parafusar a largura superior das folhas fixas e móveis;

i. Emborrachar as folhas móveis;

j. Perfurar as folhas móveis e fixas e em seguida, rebitá-las.

\subsection{PROPOSTA DE REDIMENSIONAMENTO DO POSTO DE TRABALHO}

Um posto de trabalho quando mal dimensionado provoca uma postura inadequada que futuramente, vai provocar um desconforto e consequentemente, uma doença ocupacional nos operadores. Verificou-se com base nas observações e na aplicação do questionário Diagrama das Áreas Dolosas, proposto por Corlett e Manenica (1980) que, no operador 1as partes do corpo que mais apresentam dor são as mãos e as pernas, e no operador 2 são os ombros, as mãos e as pernas.

Sendo assim, como as mãos e as pernas são partes críticas em ambos, foi proposto um redimensionamento no posto de trabalho visando melhores condições de trabalho para os operários, com base nos conhecimentos disponibilizados na literatura a respeito do tema e na utilização das medidas antropométricas da população brasileira disponibilizada pelo Instituto Nacional de Tecnologia (1988).

Segundo Dul \& Weerdmeester (2004), não se recomenda passar o dia todo na posição em pé, pois isso provoca fadiga nas costas e pernas. Um estresse adicional pode aparecer quando o tronco fica inclinado, provocando dores no pescoço e nas costas. 
Além disso, trabalhar com os braços para cima, sem apoio, provoca dores dos ombros.

As atividades desenvolvidas pelos operadores são todas na posição em pé. Além disso, durante a realização das atividades de encaixe das paletas de veneziana o operador fica com os braços suspensos para fazer o encaixe, provocando desconforto dos ombros.

Baseado ainda em Dul \& Weerdmeester (2004), uma possível solução para o problema de realizar todas as atividades em pé seria a adoção do "selim" para apoiar o corpo na posição em pé. Este tipo de banco com apoio tripé deve ser utilizado para apoio das nádegas quando se está na posição em pé.

O selim é um pequeno assento, com altura ajustável e é inclinado para frente possibilitando uma postura semiapoiada, aliviando a tensão nas pernas (FIGURA 3). Não deve ser utilizado por períodos prolongados. Só é adequado para trabalhos em pé e que não necessitam de grandes esforços.

Para evitar dores nos ombros e mãos Kroemer \& Grandjean (2005) propõe que para as atividades manuais realizadas de pé, as alturas recomendadas são de 5 a10 cm abaixo da altura dos cotovelos. Se houver muita exigência de empregar-se força, o que requer ajuda da parte superior do tronco, então a altura da superfície de trabalho deve ser mais baixa: a altura deve ficar entre 14 e $40 \mathrm{~cm}$ abaixo da altura do cotovelo.

Como proposta, a altura da superfície de mesa estará a $10 \mathrm{~cm}$ abaixo da altura dos cotovelos, que é de 104,5 $\mathrm{cm}$ para um percentil de 50\%, atendendo tanto aos funcionários altos como os mais baixos, resultando numa altura de 94,5 cm (FIGURA 3).

Uma proposta para melhorar a atividade de encaixe das paletas e evitar que o operador fique com os ombros suspensos por muito tempo seria o desenvolvimento de uma mesa de suporte semelhante a uma mesa de teclado que ficaria em um nível mais baixo do que a superfície da bancada, para que o operador pudesse

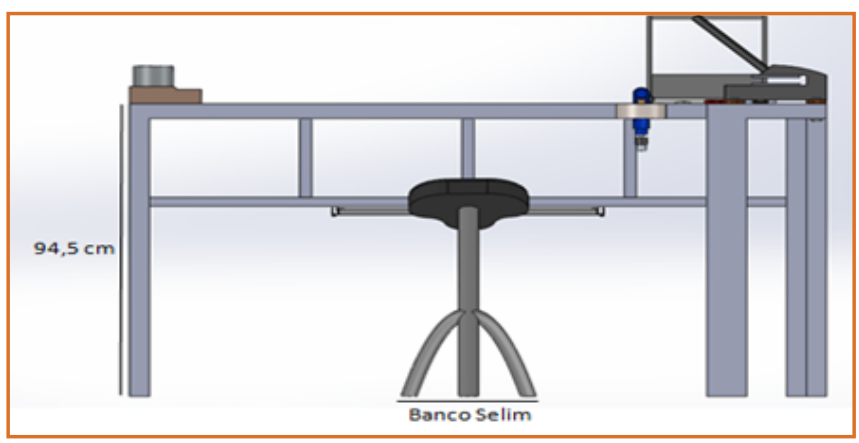

apoiar a estrutura de alumínio e fazer o encaixe das paletas sem a necessidade de suspender os ombros (FIGURA 4).

Figura 3 - Altura ideal e banco selim

Figura 4 - Suporte para encaixe das paletas de venezianas Para evitar as dores nas pernas, estas devem ser acomodadas dentro de um espaço sob a superfície de trabalho de forma que fique confortável para o usuário

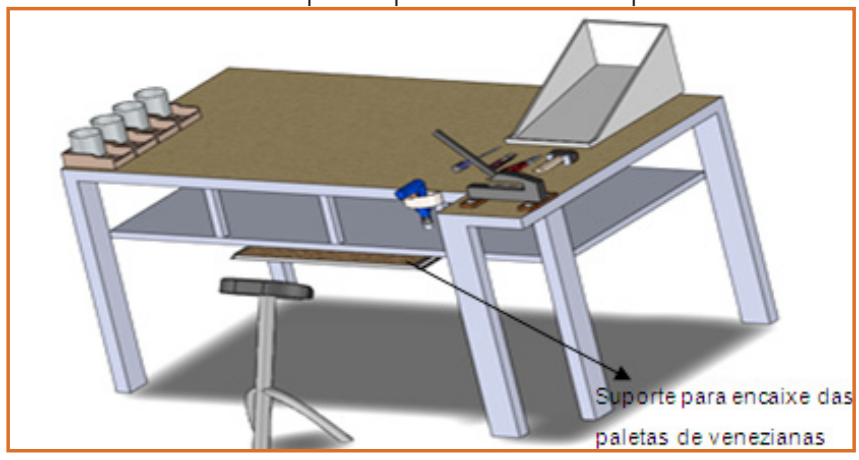

e permita uma postura correta. Isso permite que 0 usuário se aproxime do trabalho sem a necessidade de curvar o tronco, além de permitir mudanças de postura, movimentando as pernas e pés (DUL; WEERDMEESTER, 2004).

No posto em análise será proposto a existência de um espaço de $28 \mathrm{~cm}$ de acordo com o percentil de $95 \%$ para atender a um maior número de pessoas, com base na tabela antropométrica para que haja uma maior mobilidade e conforto para o operador (FIGURA $5)$.

O alcance com os braços, para frente e para o lado, deve ser limitado para evitar a inclinação ou rotação do corpo. Para isso, as ferramentas, peças e controles de uso mais frequentes devem situar-se em frente e perto do corpo (DUL; WEERDMEESTER, 2004). 
Na empresa estudada, os materiais e ferramentas não ficam localizados na área de alcance do operador. Geralmente, estes se encontram distantes do operador que, em algumas situações, acaba se debruçando sobre a mesa para apanhar alguma ferramenta. Os perfis de alumínio ficam dispostos na parte inferior da bancada, isso faz com que o operador se agache para pegá-los.

Para o novo projeto, será proposto que as ferramentas fiquem dispostas dentro da área de alcance máximo do operador ou próximo a ela, de forma que o mesmo não faça movimentos desnecessários durante a realização do seu trabalho nem cause danos para a sua saúde (FIGURA 5). Sendo assim, para a determinação da zona de alcance ótima do usuário foi adotado o raio de alcance como o comprimento interarticular do cotovelo- pulso, com base na tabela antropométrica com percentil de $5 \%$, pois assim atenderá a uma maior parcela de usuários. Logo, o valor do raio da zona ótima será de 22,9cm.

Para a determinação do raio da área máxima foi feito a medição do ângulo formado pelos braços estendidos e levemente caídos tocando numa superfície que estava a $94,5 \mathrm{~cm}$ de altura do chão. Para isso, foi utilizado um usuário de altura de $1,74 \mathrm{~cm}$. Em seguida, o mesmo ficou com seus braços estendidos, de forma que, não fosse necessário inclinar o tronco para alcançar a superfície e feito então à medição do ângulo utilizando um transferidor.

Com a definição do valor do ângulo $\left(29,59^{\circ}\right)$ e com o valor do comprimento do braço de $33,5 \mathrm{~cm}$ de acordo a tabela antropométrica com o percentil de $5 \%$, a fim

de atender a uma maior quantidade de operadores, pode-se calcular o valor do raio de alcance máximo com

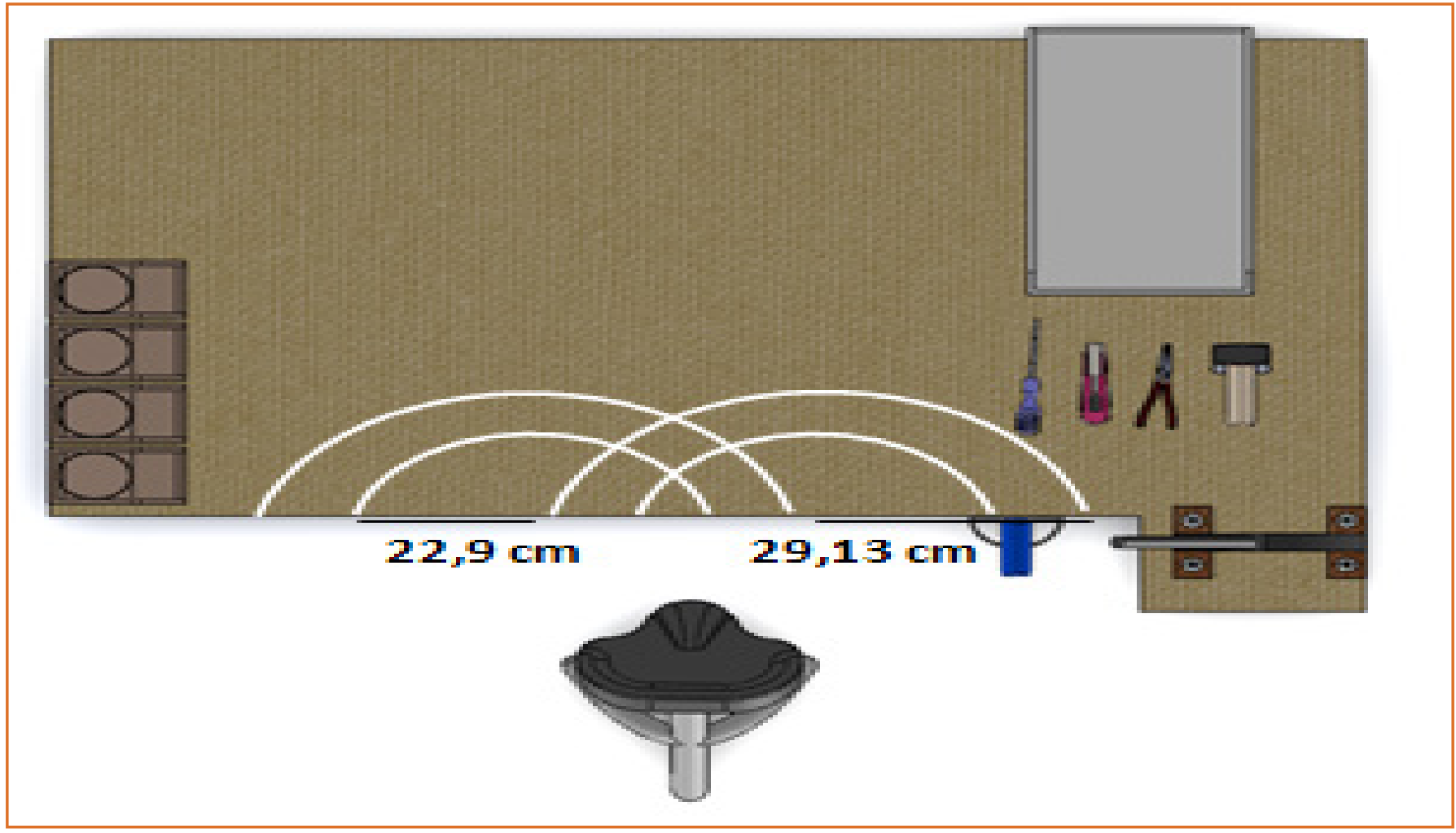

base nas relações trigonométricas que foi de $29,13 \mathrm{~cm}$ (FIGURA 5).

As ferramentas ficam dispostas sobre a mesa sem

Figura 5 - área de alcance máximo e ótimo nenhum local específico, apenas os parafusos que possui um local definido. Todos os outros ficam sobre a mesa sem local demarcado. Como proposta, 
na bancada haverá locais destinados especificamente para cada material e ferramenta evitando assim, a

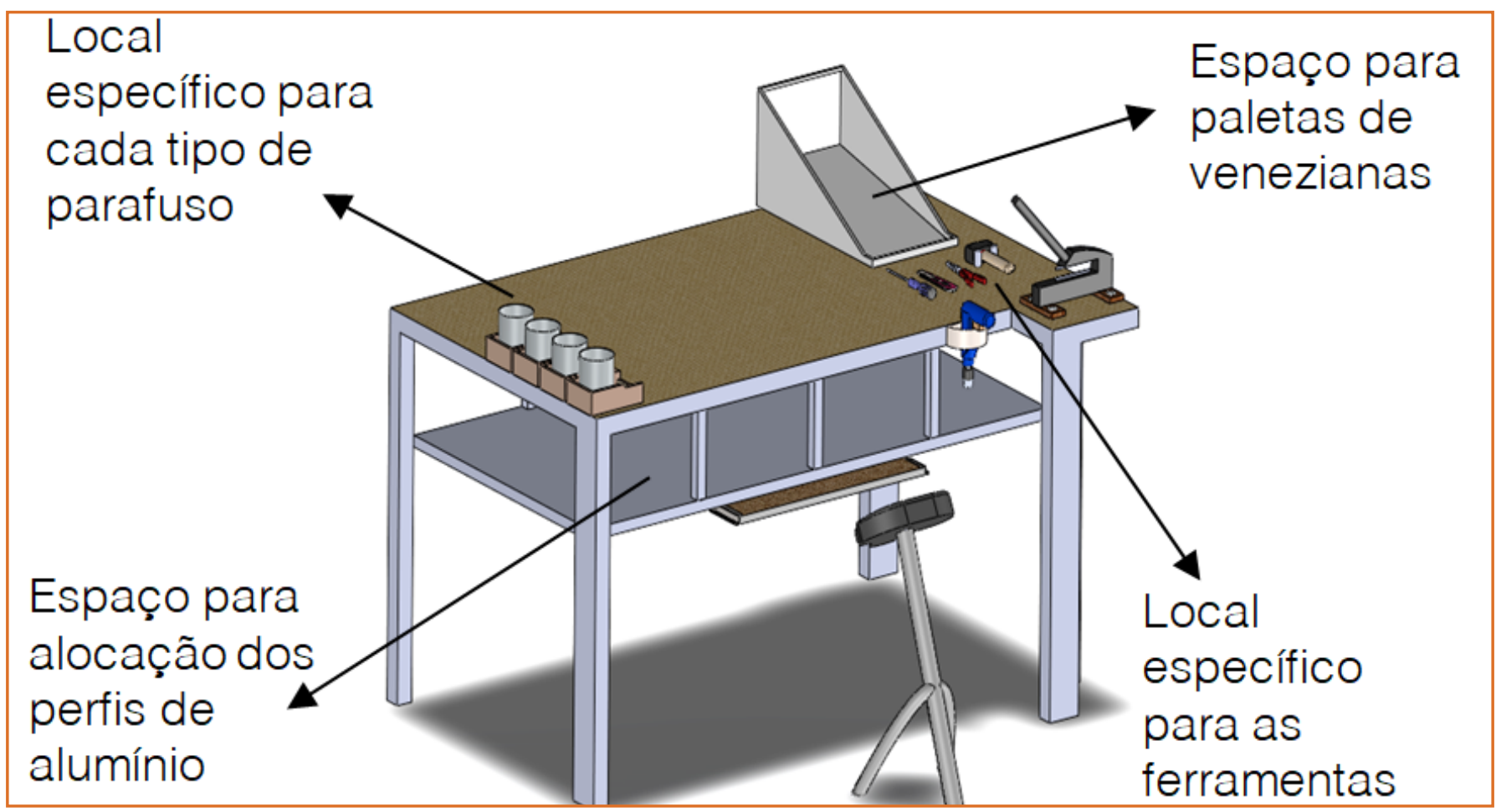

desorganização do posto de trabalho (FIGURA 6).

Figura 6- Disposição dos materiais e ferramentas

\section{CONSIDERAÇÕES FINAIS}

Uma postura inadequada resulta em prejuízos não só para o operador, mas também para a empresa. Tais problemas podem ser evitados através da projeção de postos de trabalhos mais adequados às necessidades do operador.

O trabalho atingiu o objetivo de fazer uma proposta de redimensionamento do posto de trabalho de montagem de veneziana, de forma a atender aos seus usuários proporcionando-Ihes uma postura mais correta para a realização da atividade. Tendo em vista os benefícios que são gerados tanto para a empresa quanto para os operadores, espera-se que o projeto proposto venha a ser implantado, resultando em colaboradores mais satisfeitos com as suas atividades e consequente, ganho em produtividade.

Uma sugestão para a empresa seria o desenvolvimento de projetos de bancadas para todas as linhas de produção, não só a da montagem de veneziana, além de aplicação de conceitos de Ergonomia para outros problemas encontrados na empresa, como os movimentos corporais (principalmente o levantamento de cargas) e fatores ambientais (ruídos, vibrações, iluminação, clima).

\section{REFERÊNCIAS}

[1] ABDEL-AAL, R.E.; AL-GARNI, Z. Forecasting Monthly Electric Energy Consumption in eastern Saudi Arabia using Univariate Time-Series Analysis. Energy Vol. 22, n.11, p.10591069, 1997.

[2] ASSOCIAÇÃO BRASILEIRA DE ERGONOMIA (ABERGO). O que é Ergnonomia. Disponível em <http:// www.abergo.org.br/>. Acesso em: jun. 2014.

[3] ASSOCIAÇÃO NACIONAL DE FABRICANTES DE ESQUADRIAS DE ALUMÍNIO (AFEAL). Esquadrias de Alumínio. Disponível em <http://www.afeal.com.br/portal/ pagina . php?id=299> Acesso em: mai. 2014.

[4] CLIMATE-DATA. Clima: Calculé. Disponível em:<http:// pt.climate-data.org/location/43251/>. Acesso: nov. 2014.

[5] DUL, J.; WEERDMEESTER, B. Ergonomia prática. São Paulo: Edgard Blücher, 2004.

[6] GRANDJEAN, E. Manual de Ergonomia: adaptando o trabalho ao homem. Porto Alegre: Bookman, 1998.

[7] IIDA, I. Ergonomia: projeto e produção. São Paulo: Edgard Blücher, 2005.

[8] INSTITUTO NACIONAL DE TECNOLOGIA. Disponível 
em < https://www.int.gov.br/>. Acesso em: ago 2015.

[9] INTERNATIONAL ERGONOMICS ASSOCIATION (IEA). What is Ergonomics. Disponível em < http://www.iea.cc/ > Acesso em: ago 2015

[10] KROEMER, K.H.E.; GRANDJEAN, E. Manual de ergonomia: adaptando o trabalho ao homem. Porto Alegre: Bookman; 2005.

[11] MAFRA, J. R. D. Metodologia de Custeio para a Ergonomia. Revista Contabilidade Financeira, n. 42,p. 77-91, 2006.

[12] MOTTA, F. V. Avaliação ergonômica de postos de trabalho no setor de pré- impressão de uma indústria gráfica. Monografia (Trabalho de Conclusão de Curso) Universidade Federal de Juiz de Fora, 2009.
[13] ORGANIZAÇÃO PAN-AMERICANA DA SAÚDE BRASIL (OPAS). Saúde do trabalhador. Disponível em: <http://www.paho.org/bra/index.php?option=com_ content\&view $=$ article\&id=378\& $\mid$ temid $=1>$. Acesso: mai. 2014.

[14] PRATES, G. A. Reflexão sobre o uso da ergonomia aliado à tecnologia: propulsores do aumento da produtividade e da qualidade de vida no trabalho. Revista de Administração, v. 07, n. 11, 2007.

[15] SILVA, S. A. Análise ergonômica do trabalho do soldador: contribuição para projetação ergonômica. Dissertação (Mestrado) - Universidade Federal do Rio Grande do Sul, Porto Alegre, 2003.

[16] SOLIDWORKS. Disponível em < http://www.solidworks. com/>. Acesso em: ago 2015.

[17] TOMASINI, A. Desenvolvimento e aplicação de modelo de gestão ergonômica para uma empresa da indústria metalúrgica. Dissertação (Mestrado) - Universidade Federal do Rio Grande do Sul, Porto Alegre, 2001. 


\title{
CAPÍTULO 7
}

\section{UMA REVISÃO DOS MÉTODOS DE AVALIAÇÃo ERGONÔMICA E SUAS APLICAÇÕES}

\author{
Ariel Orlei Michaloski \\ Jaciara Dias Trzaskos
}

Resumo: Este artigo tem como objetivo identificar os métodos existentes para avaliações ergonômicas através de artigos já existentes com estudos de caso, identificando os autores, comentando os métodos e suas pesquisas. Isto ajudará a uma melhor escolha dos métodos existentes e um maior conhecimento para a correta avaliação ergonômica para diferentes postos de trabalho e áreas do conhecimento. Identificar programas computacionais que disponibilizam acesso a ferramentas ergonômicas, disponibilizar um número de informações em que se possa fazer um uso adequados das ferramentas em diferentes situações de uso, exemplificando através da pesquisa, a melhor metodologia utilizada para uma avaliação de qualidade e extraindo o melhor de cada método. Os estudos de caso nos trazem pesquisas aprofundadas com alto teor de informações de campo, assim métodos como Niosh, Owas, Rula, Reba, Tor Tom serão abordados, visto que são utilizados mundialmente, podendo assim extrair um rápido comparativo entre esses métodos ou até mesmo obtendo um melhoramento de resultados com a interação entre eles. Métodos como o Owas pode complementar o método da Niosh, assim os mecanismos de gestão do conhecimento na seleção dos métodos de avaliação ergonômica estarão expostos em diferentes áreas do conhecimento, desde a medicina até a trabalhadores da indústria.

Palavras Chave: Usabilidade, Ferramentas Ergonômicas, Análise. 


\section{INTRODUÇÃO}

Em agosto de 2000, a IEA - Associação Internacional de Ergonomia adotou a definição oficial para ergonomia: "A Ergonomia (ou Fatores Humanos) é uma disciplina científica relacionada ao entendimento das interações entre os seres humanos e outros elementos ou sistemas, e à aplicação de teorias, princípios, dados e métodos a projetos a fim de otimizar o bem estar humano e 0 desempenho global do sistema". (IEA, 2000).

\begin{abstract}
A Análise Ergonômica do Trabalho (AET) vem evoluindo com o passar dos anos, a preocupação no Brasil iniciou-se quando na década de 1980, os digitadores sofriam com a tenossinovite devido a jornadas de trabalho exaustivas, premiação devido a produtividade e jornadas de trabalho sem pausas, assim o Sindicato dos Empregados em Empresa de Processamento de Dados no Estado de São Paulo fez contato com a DRT do mesmo estado buscando soluções e recursos para prevenir lesões nestes trabalhadores, anos passaram e na década de 1990, mesmo sem um estudo ergonômico sistemático, porém com algumas soluções para o caso dos digitadores e também do setor produtivo.
\end{abstract}

De acordo com a Médica, doutora em Ergonomia Leda Leal Ferreira, "a decisão de fazer uma análise do trabalho no momento em que ele está sendo feito, a chamada análise do trabalho "real", exigia a elaboração e utilização de um conjunto especial de técnicas que pudessem ser usadas sem atrapalhar a atividade de quem estava trabalhando, nem alterar (muito) a situação que se queria compreender. Escolheu-se a observação do ergonomista como técnica principal. Mas o que deveria ser observado? Logicamente, apenas o que era observável, por exemplo, as posturas corporais ou de segmentos corporais que os trabalhadores adotam em uma determinada situação; as comunicações que trocam entre si; os produtos ou instrumentos que manipulam ou utilizam; o modo como o fazem; os caminhos que percorrem; os percursos que realizam; os documentos que usam; os controles que fazem ou aos quais estão submetidos etc." (LEDA LEAL FERREIRA,2015)

Os métodos ergonômicos foram criados para facilitar essa observação, com isso surgiu o gradativo melhoramento e qualidade da análise, assim os métodos foram ficando mais abrangentes e com condições de melhor avaliar as atividades laborais.

Um dos grandes problemas encontrados hoje no sistema produtivo é o levantamento de carga de trabalho juntamente com a posição do trabalhador em relação ao posto de trabalho, isso tornou-se um dos principais requisitos para o desenvolvimento de métodos para a avaliação e tentativa de correção dos arranjos corporais, a maioria dos métodos atribuem códigos indicativos para uma categoria de carga. A posição corporal indica os diferentes graus de especificidade dependendo do método utilizado.

Neste artigo será abordado alguns métodos existentes como o método que a Niosh (NATIONAL INSTITUTE FOR OCUPATIONAL SAFETY AND HEALTH, 1980) formulou para a verificação e quantificação da carga limite recomendada para a atividade do trabalhador, analisando a posição de trabalho e o limite de carga admissivel para o trabalho, como a Niosh verificou apenas a o peso da carga a ser levantada e os aspectos desse levantamento, verificou-se que faltava um índice ou uma forma de verificar a posição corporal desse trabalhador em relação a sua postura, posição de braços e pernas.

Assim em 1977 os autores Osmo Karhu Pekka Kansi e Likka Kuorinka propuseram um estudo dos trabalhadores na indústria do aço onde chamou-se Owas (Working postura Sistema de Análise Ovako), nele verifica-se o posicionamento dos braços, costas e pernas, Owas identifica as posturas mais comuns de trabalho para as costas (4 posturas), braços (3 posturas) e pernas (7 posturas), e o peso da carga movimentada (3 categorias). Postura de todo o corpo é descrita por estas partes do corpo com um código de quatro dígitos. As 252 posturas foram classificadas para quatro ações de categorias que indicam a necessidades de mudanças ergonômicas, as observações são feitas instantaneamente, com intervalos de tempo constantes.

Analogamente encontramos o método Rula desenvolvido por Dr. Lynn McAtamney e Professor E. Nigel Corlett, ergonomistas da Universidade de Nottingham, na Inglaterra, Rula é um método de 
segmentação postural para estimar os riscos de distúrbios dos membros superiores relacionadas com o trabalho.

Uma avaliação Rula (Rapid Upper Limb Assessment) apresenta uma rápida avaliação e sistemática dos riscos posturais a um trabalhador. A análise pode ser realizada antes e depois de uma intervenção para demonstrar que a intervenção tem trabalhado para reduzir o risco de lesões.

O método Reba (Rapid Entire Body Assessment) foi proposto no ano de 2000 por Sue Hignett y Lynn McAtamney e publicado pela revista especializada em ergonomia aplicada, é um trabalho em conjunto de ergomistas, fisioterapeutas, terapeutas ocupacionais e enfermeiros, que através de 600 posições de posturas analisaram um conjunto das posições adotadas para membros superiores.

O método Tor-Tom foi proposto pelo Prof. Dr. Hudson de Araújo Couto, o qual estabeleceu uma relação entre a Taxa de Ocupação Real do trabalhador em sua atividade laboral ao longo de sua jornada e a Taxa de Ocupação Máxima, este índice estabelece limites de tolerância na avaliação ergonômica, com isso obtémse um auxilio no gerenciamento das tarefas e soluções para eventuais problemas ergonômicos observados no trabalho.

\section{REFERENCIAL TEÓRICO}

Foram consultados diversos artigos relacionados aos métodos de avaliação ergonômica, com estudos de caso, discussões sobre o melhor método para avaliação de uma determinada posição ou até mesmo para uma determinada função.

A observação e a experiência de um ergonomista experiente faz com que os dados e as técnicas sejam melhores aplicados e assim cada vez mais os resultados são mais confiáveis. Leda Leal Ferreira traz a tona uma discussão muito importante, relatando o que dizia Duraffourg "A situação de trabalho não é um laboratório"(JACQUES DURAFFOURG, 1977), "com isso, estava destacando que a análise ergonômica do trabalho que eles estavam então sistematizando se diferenciava daquela praticada em laboratório, no qual se simulava a situação de trabalho, ou mais geralmente um aspecto dela, onde se podia manipular variáveis e onde os sujeitos eram, em geral, estudantes. Mas se diferenciava também daquela praticada pelas empresas, a famosa "análise de tarefas" de inspiração taylorista na qual, em última instância, nem era preciso observar os trabalhadores em atividade, uma vez que a sua tarefa poderia ser estabelecida em escritórios de engenharia". (LEDA LEAL FERREIRA, 2015), imprescindível é observar a realidade laboral do trabalhador para transmitir às técnicas de observação e ferramentas ergonômicas dados mais confiáveis possíveis.

Segundo Joanna Bartnicka (2014) em seu artigo "Knowledge-based ergonomic assessment of working conditionsin surgical ward - A case study" (Avaliação ergonômica baseada no conhecimento das condições de trabalho em enfermaria cirúrgica - Um estudo de caso) propõe um estudo para uma avaliação mais abrangente.

Em conjunto com vários métodos ela analisa e integra esses resultados com diferentes métodos em busca de um resultado que leve a melhor qualidade em centros cirúrgicos da Polônia. A autora escolheu a atividade realizada pelo profissional médico que realiza cirurgias ortopédicas, no qual existem inúmeros problemas ergonômicos devido a carga excessiva do sistema musculo esquelético durante a cirurgia.

A avaliação contou com os seguintes métodos para a avaliação, Niosh, Owas, Rula e Reba, a autora conseguiu um sinergismo entre os métodos e resultados excelentes na avaliação. Todos os métodos utilizados possuem implementações na forma de programas de computador, tais como ErgoLAB (Owas), ErgoFellow (Owas, Rula, REBA), WinOwas (Owas), aqui no Brasil é utilizado o Ergolandia, o qual contempla todos os métodos citados.

Um estudo feito por Diana De Las Mercedes Cevallos Ortega(2015), para obtenção do título de mestre em segurança industrial e saúde ocupacional, cujo o título é "Evaluación de riesgos ergonómicos Biomecánicos en Técnicos mecánicos de vehículos pesados, de la 
agencia Hino en Quito. Propuesta de un programa para diminuir los Trastornos musculoesqueléticos" (Avaliação biomecânica de riscos ergonômicos em técnicos mecânicos de veículos pesados agência Hino em Quito. Proposta de um programa para reduzir distúrbios musculoesqueléticos).

Um estudo de caso onde a autora avaliou um grupo de 25 trabalhadores mecânicos utilizando os métodos de análise Owas avaliação biomecânica, Reba e Mac. Além do questionário Nórdico. O principal objetivo do estudo da autora foi de estabelecer fatores de risco ergonômicos e tempo de exposição biomecânica, para propor um programa de prevenção distúrbios musculoesqueléticos, para aumentar a produtividade e melhorar a saúde do trabalhador. Com a utilização dos métodos, e a integração dos resultados, conseguiu uma boa avaliação e um diagnóstico para o melhoramento das condições de trabalho.

Um estudo muito importante foi publicado no Canadá em um dos jornais mais importantes para a ergonomia, o International Journal of Industrial Ergonomicsno no ano de 2007, por T.Jones, S.Kumar com o título de Comparison of ergonomic risk assessments in a repetitive high-risk sawmill occupation: Sawfiler (Comparação de avaliações de riscos ergonômicos em uma serraria ocupação de alto risco repetitivo: Saw-Filer).

Os estudos pretendem comparar os pontos de avaliação de risco de vários métodos e são necessários para avaliar a concordância entre os métodos e ganhar uma compreensão da variabilidade entre sujeitos. Compreender a variabilidade é necessário para determinar quantos trabalhadores devem ser avaliados para obter pontuação representativos de avaliação de risco para esse local ou instalação ( T.JONES, S.KUMAR, 2007), além do que diz T.Jones, S.Kumar, a confiabilidade dos resultados trabalhados estatisticamente com os diferentes métodos também é um fator importante para a realização destes trabalhos comparativos, apesar de serem muitos escassos, devido a dificuldades de coleta de dados, e profissionais que consigam fazer uma coleta de informações confiáveis e padronizadas, pois a observação é inerente a cada pessoa.
Levando em consideração a repetição de movimentos e o mais importante do estudo é a comparação dos 5 métodos aplicados na pesquisa, os quais são Rula, Reba, a versão quantificada da Conferência Americana de Higienistas Industriais Governamentais Valor Limite para o trabalho de mão mono-tarefa (ACGIH TLV), o Índice de deformação (SI), e o índice de exposição concisa (Ocra). Os resultados foram satisfatórios, todas as metodologias de avaliação dos riscos concordam que o nível de risco está associado com o desempenho do trabalho na serra-filer, encontrando uma exceção no método da ACGIH TLV.

A tecnologia avança a cada dia, temos vários métodos utilizados que possuem implementações na forma de programas de computador, tais como ErgoLAB (Owas), ErgoFellow (Owas, Rula, Reba), WinOWAS (Owas), aqui no Brasil é utilizado o Ergolandia, o qual contempla 20 ferramentas ergonômicas para avaliação e melhoria dos postos de trabalho, os quais são: Método Niosh (Equação de levantamento de carga), Owas, Rula, Reba, Método Suzanne Rodgers, Moore e Garg (Strain lindex), Questionário Bibolar, Método Lehmann, Check List de Couto, Método QEC, Análise de Imagem, Análise de Vídeo, Antropometria, Cálculo de Força, Uso de EPI (NR 6), Avaliação de Calor (NR 15), Avaliação de Ruído (NR 15), Avaliação de Digitação (NR 17), Avaliação de Iluminação (NBR 8995), Check List para Escritório.

Um avanço tecnológico na avaliação ergonômica foi publicado em 2013 no International Journal of Industrial Ergonomics pelos autores Giovanni De Magistris, Alain Micaelli, Paul Evrard, Claude Andriot, Jonathan Savin, Clarisse Gaudez, Jacques Marsot, onde foi estudado em laboratório a possibilidade de uso de realidade virtual para analises de postura, riscos físicos e estudo aprofundado das forças aplicadas durante o trabalho. Nesta publicação os autores citaram vários pacotes de softwares relacionados com programas digitais para a ergonomia como: digitais modelo humano (DHM), como o Pro / ENGINEER Manikin, JACK, RAMSIS ou CATIA-DELMIA Humano. Porem todos vislumbravam algum problema, foi o que levou os pesquisadores a levantar uma nova dinâmica autônoma DHM (modelo humano digital), que foi usada para descrever em laboratório uma aplicação nas tarefas de uma 
montagem industrial.

Esse novo DHM requer o mínimo de informações, com isso mudando a antropometria e a simulação não é necessário novos ajustes adicionais, isto se torna uma vantagem para a indústria.

Esta nova técnica desenvolveu um novo modelo humano digital baseado em robótica e simulação física. Os experimentos foram avaliados com base em uma avaliação real pelo Ocra ergonômico. Esse novo modelo trouxe inúmeras vantagens, entre elas o mínimo de informações para a simulação, assim diminuindo erros de avaliação, a simulação do torque de flexão do cotovelo, porem sempre observando valores menores dos que os admissíveis para as partes do corpo estudadas

\section{METODOLOGIA}

A busca por parâmetros que forneçam informações suficientes para um melhoramento da qualidade na análise ergonômica e escolha dos melhores métodos para a avaliação dos inúmeros postos de trabalho existentes, fez com que se buscasse uma pesquisa qualitativa dentro de artigos publicados nos melhores locais, onde a preocupação com a qualidade da informação fosse absorvida da melhor forma possível e a transmissão deste conhecimento possa ser disseminado de forma a ser de fácil entendimento para os leitores.

Os artigos consultados em sua maioria tiveram a sua publicação internacional, assim buscando uma informação de qualidade, a fonte nacional para uma rica pesquisa é a Revista Brasileira de Saúde Ocupacional da Fundacentro. Portanto a pesquisa se dá de forma bibliográfica, buscando informações relevantes aos métodos de avaliação ergonômica, assim como a qualidade e a melhor usabilidade dessas ferramentas dentro do conceito de que a ergonomia juntamente com as inúmeras ferramentas abordadas está voltada para a qualidade da saúde e melhoramento do ambiente de trabalho do indivíduo.

\section{DESENVOLVIMENTO}

A ergonomia procura aprimorar a relação homem $x$ trabalho, fazendo com que não haja prejuízos a nenhum dos lados, assim a análise do trabalho tem a importância de estabelecer limites para que o trabalho não seja prejudicial ao homem e nem o homem leve prejuízos ao trabalho, assim as ferramentas ergonômicas auxiliam e dão o apoio necessário para parâmetros que levem a qualidade de vida para o trabalhador, visto que a ergonomia é uma ciência que leva em consideração o homem como prioridade, assim os estudos foram se aperfeiçoando e surgindo numerosas ferramentas, as quais pode-se afirmar que uma complementa a outra, auxiliando em uma análise muito mais abrangente e completa.

A avaliação surge da decorrência das más condições de trabalho, onde a preocupação principal é analisar e corrigir as atividades do trabalho que determinam o comportamento do homem frente ao seu posto de trabalho, visando os aspectos físicos e cognitivos. Identificando essas técnicas e ferramentas, descreveremos a seguir as abordadas neste trabalho.

\section{1. $\mathrm{NIOSH}$}

Com uma evolução natural, foram surgindo estudos, maneiras de se aplicar não só qualitativamente a ergonomia, mas quantitativamente, tendo assim parâmetros para adequações das atividades, sendo que em 1980 nos Estados Unidos, o National Institute for Ocupational Safety and Health - NIOSH teve a iniciativa de desenvolver um método, que é difundido amplamente pelo mundo e oferece os parâmetros para o limite de peso recomendado.

Ele permite analisar postos de trabalho, fazer pericias ocupacionais, priorizar riscos entre os diversos postos, simular projetos de melhorias, e o ponto mais forte deste método é agir precisamente no item do posto de trabalho mais crítico ou até mesmo determinar a interrupção da atividade até que a melhoria seja feita, oferecendo a possibilidade de adequação do posto de trabalho. 
uma ferramenta que identifique os riscos de lombalgia associada a carga física a que estava submetido o trabalhador, recomendar um limite de peso adequado para cada tarefa em questão.

Então foi estabelecido critérios para o levantamento manual de cargas, que para uma situação qualquer de trabalho existe um limite de peso recomendado (LPR), uma vez calculado compara-se com o peso real levantado, com isso obtém-se o índice de levantamento (IL), assim estipula-se que se o valor de IL seja menor que 1,0 o risco de existir lesão na atividade é mínimo. No Brasil o atraso ainda é grande, a CLT Consolidação das Leias do Trabalho, art. 198/199, e Convenção OIT n.127, determinam um limite de $60 \mathrm{~kg}$ para homens e $25 \mathrm{~kg}$ para mulheres.

\subsection{OWAS}

Como a avaliação NIOSH oferece apenas a avaliação do peso da carga para levantamento manual, temos então que avaliar a postura desse trabalhador em relação a este levantamento, o método simplista mas muito difundido no mundo é o OWAS.

O método OWAS (Ovako Working Posture Analysis System), foi proposto pelos autores Osmo Karhu Pekka Kansi e Likka Kuorinka em 1977 com o título: Correção das posições de trabalho na indústria: um método prático para análise, e publicado na revista especializada -Ergonomia Aplicada-, a colaboração de engenheiros dedicados ao estudo do trabalho no setor do aço e um grupo de ergonomia, permitiu a autores tirar conclusões válidas e extrapolou a análise, sendo que estas conclusões refletiram-se no método proposto OWAS.

O método avalia 3 segmentos corporais, os braços, costas e pernas, o tempo da posição também é considerado na observação, porém não oferece a informação de grau de nocividade que o trabalhador está submetido, isso está definido e desenvolvido para todas as combinações posturais.

$\begin{array}{lrrrr}\text { Um grande } & \text { número de profissionais } \\ \text { estudam os resultados fornecidos pelo }\end{array}$

método, em diversas áreas profissionais como a medicina, indústria em geral ou mesmo a agricultura. O método por sua simplicidade pode ser aplicado a quase todas as atividades e fornece bons resultados, melhorando as posições de conforto e aumentando a qualidade de produção e de saúde dos trabalhadores. Com os objetivos deste método podemos destacar a observação da tarefa e se ela deve ser dividida em etapas, a definição do período da tarefa, duração dos intervalos, a identificação durante o trabalho da postura do trabalhador, visando a posição dos braços, pernas e costas. Ele nos oferece a porcentagem da posição dos membros, assim determinamos o quão critico é aquela postura, seu resultado orienta se é necessário um estudo mais aprofundado da posição de trabalho. Assim fornecendo mudanças na posição e readequação do posto de trabalho.

Observando a postura, o método oferece para cada postura um código identificador, estabelecendo uma relação entre esse código e a postura, assim é numerado crescentemente conforme o grau de desconforto para o trabalhador, sendo que 1 é o menor desconforto e o 4 é a pior situação, para cada categoria existe uma proposta de ação. Observando as possíveis combinações das diferentes posturas tomadas pelo trabalhador, o método oferece pontualmente a possibilidade de melhoramento da postura mais inadequada para cada parte do corpo (braços, costas e pernas).

Por ser um método muito simplista, apresenta limitações, sendo que não é possível o estudo detalhado e a gravidade de cada posição.

\subsection{TOR-TOM}

Foi desenvolvido pelo Prof. Dr. Hudson de Araújo Couto, que também propôs um Cheque list, este índice estabelece limites de tolerância na avaliação ergonômica e ajuda no gerenciamento de soluções em atividades repetitivas. Significa a relação entre Taxa de Ocupação Real do trabalhador em determinada atividade durante a sua jornada e a Taxa de Ocupação Máxima que deveria haver na atividade, segundo as características daquele trabalho. Taxa de Ocupação Real, gira em torno de $85 \%$ a $95 \%$. 
A Taxa de Ocupação Máxima é dependente de vários fatores, como, repetitividade, intensidade da força exercida, peso da carga, postura ao executar a tarefa, calor do ambiente, uso energético para a realização da tarefa, enfim, uma série de fatores que também são chamados de fatores de recuperação de fadiga e são aspectos que reduzem a taxa de ocupação máxima. (Ergoltda, disponível em < http://ergoltda.com.br/ dicas/dicas_03_03.html> acesso em 18 de set. de 2015).

Neste método procurou-se desenvolver um índice que estude esses fatores detalhadamente, assim possibilitando ao trabalhador exercer sua função sem sobrecarga e sem lesões. Observamos a quantificação da exposição do trabalhador em atividades repetitivas, ao final dos cálculos, tem-se um resultado numérico que quantifica a exposição do trabalhador a fatores que levam a problemas de saúde, isso oferece uma ideia clara das condições de trabalho, caso necessário a intervenção para o melhoramento do posto, isto levando em conta critérios científicos para tanto. Toda avaliação leva em conta estatisticamente uma inferência de 95\%.

\subsection{REBA}

O método REBA (Rapid Entire Body Assessment) foi proposto por Lynn e Sue Hignett McAtamney e publicado pela revista Ergonomia Aplicada no ano de 2000. O método identificou cerca de 600 posições, o qual analisadas em conjunto, cujas posições de membros superiores braço, ante-braço, punho, tronco, pescoço e pernas definem fatores decisivos para avaliação da postura, porem outros fatores também são levando em consideração como a postura, carga, tipo de pega e tipo de atividade muscular desenvolvida para a realização do trabalho.

As atividades estáticas e dinâmicas também são avaliadas, este método é muito utilizado na avaliação em serviços médicos, os quais verificam-se as mudanças bruscas na postura. Neste método foi incluído um novo fator que determina a posição dos membros superiores, se está a favor ou contra a gravidade, assim acentua-se ou atenua-se o risco conforme a posição. Contou-se com o auxílio de várias metodologias, para obter a confiança no método, como exemplo foi utilizado a NIOSH (método Waters et al.1993), a Escala de Estresse Percebido (Borg, 1985), OWAS (Karhu et al., 1994), BPD (Corlett e Bishop, 1976) e método RULA (McAtamney e Corlett,1993).

Existe uma grande semelhança entre os métodos RULA e REBA, o motivo é que o RULA ajudou na elaboração dos parâmetros que o REBA codifica. A análise é feita em atividades que desenvolvem mudanças inesperadas na postura, como o manuseio de cargas instáveis, a sua aplicação é dada na prevenção de lesões na postura tipo musculoesquelético, indicando medidas corretivas em cada caso, hoje é um dos principais estudos para análise posturais de carregamento de carga.

\subsection{RULA}

Ruala (Rapid Upper Limb Assessment) desenvolvido por Dr. Lynn McAtamney e Professor E. Nigel Corlett, ergonomistas da Universidade de Nottingham, na Inglaterra. Avalia posições especificas, ele segmenta a postura para proporcionar uma avaliação dos riscos de problemas para os membros superiores, riscos esses relacionados ao trabalho como a força excessiva, esforços repetitivos e posturas extremas levando o indivíduo a riscos de disfunções.

Inicia-se a observação da atividade e as posições mais significativas durante o ciclo de trabalho, verifica-se principalmente os ângulos formados pelos membros estudados, existe uma distinção entre os membros, deve-se aplicar o método do lado direito e esquerdo separadamente, este método divide o corpo em dois grupos A e B, o A inclui os membros superiores e o B o pescoço, pernas e tronco, tem o objetivo de ser um método de avaliação rápido das forças exercidas, a postura e a musculatura.

Os critérios para de escore para a classificação de risco variam de 1 a 7 , onde os valores mais próximos de 7 indicam alto risco e mais próximos a 1 o trabalhador está livre de cargas de trabalho, por se tratar de um método que foca esforços repetitivos e a postura, geralmente emprega-se em escritórios. 


\section{RESULTADOS E DISCUSSÕES}

Considerando que todas as pesquisas descritas conseguiram introduzir um amplo e novo conhecimento dentro da ciência ergonômica, acarretando em novos pensamentos e renovações, isto provoca um engrandecimento no conhecimento.

Visto que as publicações são atuais, e todas chegaram ao seu objetivo, o qual era verificar, aplicar e reunir resultados dentro dos mais diversos métodos de análise ergonômica, em diferentes áreas do conhecimento, visto que uma mesma ferramenta de análise foi utilizada dentro de um centro cirúrgico e em uma serraria com esforços repetitivos dos trabalhadores, o objetivo principal é a descoberta da interação entre os métodos e a usabilidade dentro das diferentes áreas do conhecimento, seja na medicina, na indústria ou tecnologia.

Foi possível observar que os métodos se entrelaçam e nem sempre um método concorda com o resultado de outro, independentemente dos resultados, caso exista alguma discordância entre eles, deveremos sempre seguir a pior situação, verificar um estudo mais profundo no ponto onde não se obteve uma resposta satisfatória para a saúde e a segurança do trabalhador no seu ambiente de trabalho.

\section{REFERENCIAS}

[1] BARTNICKA, Joanna. Knowledge-based ergonomic assessment of working conditionsin surgical ward - A case study. Safety Science, Zabrze, Poland, p.178-188, 10 de set. 2014.

[2] CARDOSO JUNIOR, Moacyr M., Avaliação ergonômica: revisão dos métodos para avaliação postural. Revista Produção On-Line, Florianópolis, v. 6, n. 3, dez. 2006. Disponível em: http://www.producaoonline.org.br/rpo/article/ view/630/668. Acesso em 18 de set. de 2015
[3] Ergoltda, Assessoria e consultoria em saúde ocupacional. Disponível em < http://ergoltda.com.br/dicas/ dicas_03_03.html> acesso em 18 de set. de 2015).

[4] Ergoltda, Assessoria e consultoria em saúde ocupacional. Disponível em < http://ergoltda.co m.br/dicas/ dicas_03_03.html> acesso em 18 de set. de 2015).

[5] FERREIRA, Leda L. Sobre a Análise Ergonômica do Trabalho ou AET. Rev. bras. saúde ocup., São Paulo ,v. 40, n. 131, p. 8-11, jun. 2015. Disponível em: <http: // www.scielo.br/scielo.php? script=sci_arttext\&pid=S0303 $76572015000100008 \&$ lng $=p t \& n r m=i s o>$. acessos em 8 set. 2015

[6] JONES,T;KUMAR, S. Comparison of ergonomic risk assessments in a repetitive high-risk Sawmill occupation: Saw- $\square$ ler. International Jornal of Industrial Ergonomics, Cience Direct, Edmonton, Alberta, Canada, p.744-753, 26 jun. 2007.

[7] MAGISTRIS, Giovanni De; et al. Dynamic control of DHM for ergonomic assessments, International. Jornal of Industrial Ergonomics, Vandoeuvre-lès-Nancy, França, p.170-180, 31 jan. 2013.

[8] ORTEGA,Diana de Las M. C. Evaluación de riesgos ergonómicos biomecánicos en técnicos mecánicos de vehículos pesados, de la agencia Hino en Quito. Propuesta de un programa para disminuir los trastornos musculoesqueléticos. 2015. 184 f. Trabalho de conclusão de curso (Magíster En Seguridad Industrial Y Salud Ocupacional) - Facultad De Ciencias Del Trabajo Y Del Comportamiento Humano, Universidad Internacional Sek, Quito, Equador. 2015

[9] Portal IEA, International Ergonomics Association. Disponível em: <http://www.iea.cc/> Acesso em 05 de set. 2015

[10] SHIDA, Georgia Jully; BENTO, Paulo Eduardo G. Métodos e ferramentas ergonômicas que auxiliam na análise de situações de trabalho. In: VIII Congresso Nacional de Excelência em Gestão, 2012, Rio de Janeiro/ RJ, Brasil. 8 e 9 de junho de 2012.

[11] TIRADO, Rocio De Los A. B. Identificación, medición, evaluación y propuestas de medidas de control a los factores de riesgo ergonómico para los trabajadores de una micro - empresa extractora de fruta. 2015. $61 \mathrm{f}$. Trabalho de conclusão de curso (Ingeniera En Seguridad Y Salud Ocupacional) - Facultad De Ciencias Del Trabajo Y Del Comportamiento Humano, Universidad Internacional Sek, Quito, Equador. 2015. 


\title{
CAPÍTULO 8
}

\section{AVALIAÇÃO DOS RISCOS OCUPACIONAIS EM ÁREAS DE MINERAÇÃ̃o SUBTERRÂNEA}

\author{
Bismark Soares Matos Santos \\ Luciano José Minette \\ Denise Ransolin Soranso
}

Resumo: Atividades na área de mineração subterrânea estão sujeitas a riscos e isso mostra a necessidade da determinação de regras e condições a serem observadas tanto na organização como no ambiente de trabalho. Neste artigo é proposto uma análise dos principais riscos inerentes ao trabalhador em atividades de extração mineral, e tem o objetivo de demonstrar qualitativamente os riscos ambientais intrínsecos na mineração subterrânea. Um levantamento bibliográfico foi necessário para a realização desse estudo, bem como a realização de entrevistas a profissionais que atuam em ambientes de mineração subterrânea. A partir dos dados coletados, foi integrada a matriz GUT (Gravidade, Urgência e Tendência) que possibilitou uma análise quantitativa dos riscos inerentes nesse cenário. Com a matriz GUT quantificada, foi factível uma priorização em relação aos grupos de riscos, podendo ser físicos, químicos, biológicos, ergonômicos e de acidentes. Os riscos de acidentes representaram o grupo com maior prioridade em minas subterrâneas. Com os resultados obtidos, é possível uma proposição de medidas de controle para elaboração do Programa de Gerenciamento de Riscos (PGR). Assim, instituições que atuam no setor de mineração serão capazes de agirem de modo preventivo, assegurando a saúde e segurança dos trabalhadores.

Palavras Chave: Mineração, riscos, segurança, saúde ocupacional. 


\section{INTRODUÇÃO}

A mineração cumpre importante papel no setor econômico brasileiro, e tem uma expressiva participação na qualidade de vida das pessoas. Esse setor envolve a exploração de combustíveis, minerais metálicos e não metálicos. A utilização abrangente dessas matérias primas da natureza compreende o propósito da produção de energia elétrica, asfalto, produtos industriais, aço, materiais de construção, entre outros. Em contrapartida aos benefícios que as atividades de mineração trazem para a economia, os trabalhadores mineiros tem contato com diferentes fontes de perigos no local de trabalho, expondo-os a riscos como ruído excessivo, exposição direta à radiação solar, sobrecarga térmica, exposição à poeira e microrganismos, queda de fragmentos de rochas, explosões, entre outros. Por isso, ao longo da história a mineração sempre foi considerada como uma das atividades mais perigosas.

Condições inseguras e atos inseguros podem ser considerados as principais causas para a ocorrência de acidentes. As condições inseguras ocorrem quando os termos do projeto de mina são insuficientes ou falhos e a infra estrutura do local de trabalho é precária. Já os atos inseguros aparecem em decorrência a comportamentos inadequados dos trabalhadores, que podem ser associados a falta de informação (Battacherjee, 1991).

Atualmente há uma maior conscientização por parte dos empregadores e empregados quanto à importância da segurança do trabalho, sendo que o cenário desse aspecto no Brasil tem mudado. O que era considerado custo em melhorias na saúde ocupacional, hoje é considerado investimento. Está cada vez mais intrínseca a realidade de que um acidente pode representar um custo muito maior do que um investimento para uma medida que poderia ter sido feita para preveni-lo. Juntamente com isso, a legislação referente à segurança do trabalho vem constantemente se atualizando, e a fiscalização nos cenários de mineração está cada vez mais rigorosa. Isso contribui para uma significativa melhoria na saúde ocupacional dos trabalhadores, dando-lhes higiene e segurança no setor. Mas ainda há muito para melhorar nesse quesito, pois o número de acidentes e sua gravidade ainda são elevados, se as atividades de mineração forem comparadas com outros tipos de atividades. Por isso é essencial a implantação de uma política de prevenção da saúde e segurança dos trabalhadores, com uma estratégia e gestão adequada.

Uma política de Saúde e Segurança do Trabalho (SST) é necessária para a efetivação das alterações e melhorias propostas, já que promove um maior comprometimento da gerência da empresa (LIMA, 2002). A Norma Regulamentadora 22 (NR-22: Segurança e Saúde Ocupacional na Mineração) determina a elaboração do Programa de Gerenciamento de Risco (PGR), obrigando as empresas do setor de mineração a agirem de modo preventivo, garantindo, assim, a saúde e a segurança dos trabalhadores (Barreiros, 2002).

O presente estudo analisa os principais riscos inerentes ao trabalhador em atividades de extração mineral, e objetiva indicar qualitativamente os riscos ambientais, possibilitando uma proposição de medidas de controle para a elaboração do Programa de Gerenciamento de Riscos (PGR).

\section{MATERIAIS E MÉTODOS}

Para a execução do trabalho foi necessário um levantamento bibliográfico acerca do assunto, sendo empregadas como fonte de pesquisa variadas publicações, como também entrevistas aos profissionais que exercem atividades de extração mineral no setor de mineração subterrânea. As normas existentes referentes à Segurança do Trabalho na mineração serviram como suporte para a análise dos riscos existentes no setor.

Como área de estudo, para a realização das entrevistas aos profissionais que exercem atividades de extração mineral, foi escolhida a região do Município de Mariana - MG, na qual existem diversas Mineradoras. O município de Mariana tem coordenadas 20²2'40" S, e 4324'57" W, e se localiza a 110 km da capital de Minas Gerais, Belo Horizonte. Possui área de 1194,208km², população estimada de 59343 habitantes, densidade de 45,4 hab/km² (IBGE, 2017). 
Com os estudos feitos e análise dos resultados obtidos em entrevista aos profissionais, foi viável examinar quais os principais riscos inerentes na mineração, para que sejam tiradas conclusões e sugestões que reduzam os problemas atuais no setor. Chegou-se ao melhor entendimento das operações e, desse modo, foi obtida a matriz GUT (Gravidade, Urgência, Tendência). Segundo Klassmann (2011), o método de GUT deve ser utilizado para indicar preferências na exclusão de problemas, principalmente se forem inúmeros e vinculados entre si.

Os principais riscos na mineração foram identificados, baseando-se no trabalho de diversos autores, quantificados a partir do diagnóstico das atividades de mineração e incorporados conforme a especificação definida pela NR 9, que se refere ao Programa de Prevenção de Riscos Ambientais. Foram utilizadas a NR 22 e NR 33 para padronizar o ambiente de trabalho de maneira a deixa-lo propenso a desenvolver o trabalho de mineração, respaldando a saúde e segurança dos trabalhadores. A NR 22 se refere à Segurança e Saúde Ocupacional na Mineração, e a NR 33 diz respeito à Segurança e Saúde nos Trabalhos em Espaços Confinados.
Nesta matriz são consideradas as questões gravidade, urgência e tendência de cada problema, sendo possível que os riscos sejam analisados por classe: Gravidade (G), classificado segundo o abalo ocasionado nas pessoas, assim como as consequências; Urgência $(U)$ é examinada de acordo com o tempo que o trabalhador está exposto ao risco em sua jornada de trabalho; Tendência $(T)$ que faz a análise da gravidade do prejuízo, lesão ou risco nas pessoas. A Priorização de Riscos demonstra o parecer a ser feito na prevenção, eliminação, ou minimização do risco, segundo a sua prioridade. A proporção é evidenciada em um modelo que indica que quanto maior o resultado, mais alta será a prioridade: $G \times U \times T=P R I O R I Z A C ̧ A ̃ O$, sendo possível a classificação dos riscos existentes nas operações envolvidas em mineração. A tabela 1 indica a interpretação dos riscos partindo de cada tipo representado, atribuindo critérios de níveis qualitativos e quantitativos.

É importante destacar que os resultados obtidos são qualitativos, e foram arrumados com base na experiência adquirida na metodologia desse estudo. De acordo com a análise realizada para o preenchimento dos dados, a ordem de prioridades alcançada é a que se demonstra como a mais próxima da realidade.

Tabela 1 - Pontuação atribuída à matriz GUT

\begin{tabular}{|l|l|l|l|}
\hline Pontos & \multicolumn{2}{l}{ Gravidade } & \multicolumn{2}{l|}{ Tendência } \\
\hline 5 & $\begin{array}{l}\text { Os prejuízos ou dificuldades } \\
\text { são extremamente graves }\end{array}$ & $\begin{array}{l}\text { É necessário uma ação } \\
\text { imediata }\end{array}$ & $\begin{array}{l}\text { Se nada for feito, o } \\
\text { agravamento será imediato }\end{array}$ \\
\hline 4 & Muito graves & Com alguma urgência & Vai piorar a curto prazo \\
\hline 3 & Graves & O mais cedo possível & Vai piorar \\
\hline 2 & Pouco graves & Pode esperar um pouco & Vai piorar \\
\hline 1 & Sem gravidade & Não tem pressa & $\begin{array}{l}\text { Não vai piorar ou pode até } \\
\text { melhorar }\end{array}$ \\
\hline
\end{tabular}

(Fonte: Adaptado de Klassmann, 2011).

Para o preenchimento da Matriz G.U.T. foram associados os principais riscos inerentes em atividades de extração mineral, e classificados em 5 tipos: Físicos, Químicos, Biológicos, Ergonômicos e de Acidentes.

\section{RESULTADOS}

Os riscos mais propensos identificados em atividades minerárias foram:

- Ruído Excessivo - A exposição a níveis elevados sem devida proteção pode causar perdas auditivas 
irreversíveis (Shrage, 2005).

- Alta umidade-Operações realizadas em ambientes com umidade podem causar problemas de pele e fuga de calor do organismo. A umidade está presente em ambientes alagados ou encharcados (Neverton; Leandro, 2012).

- Sobrecarga térmica - Quando um trabalhador é obrigado a suportar altas temperaturas, seu rendimento cai significativamente. A velocidade do trabalho diminui, as pausas se tornam maiores, a propensão a acidentes aumenta, e concentração diminui (Lida, 2000).

- Exposição à poeira - pode provocar a silicose, principal doença pulmonar e uma das maiores preocupações ocupacionais (Gruenzner, 2006; Gabas, 2008).

- Exposição à gases - a presença de gases provenientes de explosivos em ambientes de espaço confinado constituem duas situações de risco: a explosão/incêndio e a exposição do trabalhador a concentrações perigosas (Edson, s.d.).

- Presença de micro organismos - é causada pela decomposição da matéria orgânica. Muitas doenças originadas por micro organismos, que podem ser bactérias, vírus, protozoários, são contraídas caso as regras básicas de proteção não sejam respeitadas. Locais com alta umidade são favoráveis na multiplicação de micro organismos.

- Postura inadequada - provoca vários problemas para a saúde, que podem ser dores musculares e de cabeça, falta de concentração e até má digestão. Isso provoca desgaste psicológico e físico para o trabalhador.

- Uso de ferramentas em mal estado de conservação - ferramentas obsoletas ou em mal estado podem atrasar a produção, desgastar os trabalhadores que estão manuseando e até causar acidentes.

- Desagregação dos minerais com ferramentas manuais - existem técnicas de produção rudimentares no setor de mineração subterrânea, que exige esforço físico excessivo do trabalhador, como é o caso do uso de picaretas para extração de minérios.
- Esforços por sobrecarga - podem causar graves problemas no trabalhador, tendo potencial para acarretar lesões no seu corpo, sendo nos músculos ou nos ossos, resultando até em uma possível invalidez.

- Esforço físico excessivo - é um dos causadores das Doenças Osteomusculares Relacionadas ao Trabalho (DORT). Pode ser proveniente da necessidade do trabalhador se submeter a grande sobrecarga física carregando materiais pesados dentro da mineração. Isso expõe a lesões que podem ser desde inflamações no tendão do músculo (tendinite) a uma compressão do nervo (lesão compressiva).

- Manuseio de explosivos - pode ser um dos maiores riscos presentes na mineração subterrânea, visto que envolve todo o ambiente e toda a equipe de trabalho presente no local, e um erro grave pode resultar em consequências catastróficas.

- Explosão - Pode ser causada pelo manuseio incorreto de explosivos, ou concentrações altas de gases inflamáveis no local. Esse risco se enquadra dentre os riscos de maior gravidade, sendo que pode comprometer seriamente a integridade de toda a equipe de trabalho.

- Queda de fragmentos de rochas - na mineração subterrânea existe a possibilidade de quedas de fragmentos e desmoronamentos, visto que o ambiente é subterrâneo, e se tiver em condições precárias pode ocorrer esse tipo de acidente, submetendo o trabalhador do local a riscos de ser atingido, ocasionando sérios danos a sua integridade física.

- Tropeções em rochas - são riscos comuns em ambientes de mineração, pois geralmente são locais com estrutura irregular. Um tropeção em locais de mineração pode acarretar em ferimentos e contusões que comprometem o trabalhador.

As matrizes GUT compostas das tabelas 2 a 6 apresentam o diagnóstico, identificação e priorização dos riscos encontrados na mineração subterrânea, para cada classe de risco. 
Tabela 2 - Matriz G.U.T. preenchida pela associação conforme os riscos físicos.

\begin{tabular}{|l|l|l|l|l|l|}
\hline Matriz GUT & G & U & T & \multicolumn{2}{l|}{ Total } \\
\hline Ruído excessivo & 2 & 3 & 4 & 24 & Sétima \\
\hline Alta umidade & 3 & 2 & 3 & 18 & Oitava \\
\hline Sobrecarga Térmica & 4 & 4 & 5 & 80 & Terceira \\
\hline
\end{tabular}

(Fonte: Adaptado de Klassmann, 2011).

Tabela 3 - Matriz G.UT. preenchida pela associação conforme os riscos químicos

\begin{tabular}{|l|l|l|l|l|l|}
\hline Matriz GUT & G & 3 & 3 & 4 & 36 \\
\hline $\begin{array}{l}\text { Poeira proveniente da } \\
\text { perfuração de rochas }\end{array}$ & 3 & 4 & 4 & 48 & Sexta \\
\hline Gases provenientes de material explosivo & 3 & 4 & Quinta \\
\hline
\end{tabular}

(Fonte: Adaptado de Klassmann, 2011).

Tabela 4 - Matriz G.U.T. preenchida pela associação conforme os riscos biológicos.

\begin{tabular}{|l|l|l|l|l|l|}
\hline Matriz GUT & G & U & 3 & 12 & Notal \\
\hline Presença de Microorganismos & 2 & 2 & 3 & \\
\hline
\end{tabular}

(Fonte: Adaptado de Klassmann, 2011).

Tabela 5 - Matriz G.U.T. preenchida pela associação conforme os riscos ergonômicos.

\begin{tabular}{|c|c|c|c|c|c|}
\hline Matriz GUT & G & $\mathbf{U}$ & $\mathbf{T}$ & Total & Prioridade \\
\hline Postura inadequada & 3 & 2 & 4 & 24 & Sétima \\
\hline $\begin{array}{l}\text { Uso de ferramentas em mal estado de } \\
\text { conservação }\end{array}$ & 4 & 5 & 4 & 80 & Terceira \\
\hline $\begin{array}{l}\text { Desagregação dos minerais com } \\
\text { ferramentas manuais }\end{array}$ & 4 & 5 & 4 & 80 & Terceira \\
\hline Esforços por sobrecarga & 3 & 5 & 4 & 60 & Quarta \\
\hline Esforço físico excessivo & 3 & 5 & 4 & 60 & Quarta \\
\hline
\end{tabular}

(Fonte: Adaptado de Klassmann, 2011).

Tabela 6 - Matriz G.U.T. preenchida pela associação conforme os riscos de acidentes

\begin{tabular}{|l|l|l|l|l|l|}
\hline Matriz GUT & G & U & T & Total & Prioridade \\
\hline Manuseio de explosivos & 5 & 4 & 5 & 100 & Segunda \\
\hline Explosão & 5 & 5 & 5 & 125 & Primeira \\
\hline Queda de fragmentos de rocha & 5 & 5 & 5 & 125 & Primeira \\
\hline Tropeções em rochas & 5 & 5 & 5 & 125 & Primeira \\
\hline
\end{tabular}

(Fonte: Adaptado de Klassmann, 2011).

Em ambientes de mineração subterrânea é possível localizar os riscos ambientais que são citados na NR 9. O risco de acidentes é o que constitui maior predomínio, caracterizando as prioridades primeira e segunda. É um risco presente em qualquer atividade dentro das minas. As circunstâncias do trabalho e a estrutura do local são condições indispensáveis para a mitigação dos riscos de acidentes. 
Os riscos ergonômicos vêm em segundo, visto que apresentaram prioridades terceira, quarta e sétima. Estes riscos são gerados do ambiente de mineração subterrânea, que podem exigir grande esforço físico e posturas inadequadas. Isso pode ocasionar desgaste psicológico ou fisiológico ao trabalhador.

Os riscos químicos apresentam as prioridades quinta e sexta, visto que na mineração subterrânea pode haver grande quantidade de poeira dispersa no ar proveniente da perfuração de rochas, assim como a presença de gases provenientes de material explosivo. Normalmente minerações subterrâneas se encontram em ambientes fechados, o que agrava a situação de presença de substâncias no ar.

Os riscos físicos na mineração são advindos de ruídos excessivos de perfuratriz, e ao tempo que o trabalhador está exposto a estes ruídos, que em locais fechados podem gerar maior efeito, devido à reflexão do som gerado. A sobrecarga térmica e a alta umidade são outros tipos de riscos físicos presentes em mineração subterrânea, o que pode provocar problemas sérios ao trabalhador que não estiver utilizando os EPI's adequados, e ultrapassar o limite de tempo tolerável nesse ambiente insalubre. Estes riscos se enquadram nas prioridades terceira, sétima e oitava.

Os riscos biológicos, que apresentaram prioridade nona demonstram menos gravidade comparando com os demais riscos, apesar de que em um ambiente de mineração subterrânea é provável que haja presença de microorganismos, devido ao ambiente do local.

\section{CONCLUSÃO}

Os resultados obtidos são indispensáveis para a elaboração do Programa de Gerenciamento de Riscos - PGR, de acordo com a NR 22, que se refere à segurança e saúde ocupacional da mineração. A partir das prioridades adquiridas através do método de avaliação, é viável o planejamento e execução de medidas que eliminem ou minimizem os riscos à saúde ocupacional do trabalhador na mineração subterrânea. Deve-se atentar a diversos critérios para a escolha do processo na extração mineral a ser utilizado, tais como:
- Condições de higiene e segurança são importantes para assegurar a integridade física e psicológica dos trabalhadores que irão atuar durante toda a vida útil da mina subterrânea.

- Os equipamentos a serem utilizados devem ser avaliados em relação às entradas da mina para que a produtividade seja otimizada, reduzindo os custos.

- A solidez política e econômica do país e empresa deve ser analisada, pois as atividades de extração mineral demandam muitos recursos.

- Características ambientais são essenciais, visto que os trabalhos em mineração subterrânea causam diversos impactos ambientais.

Como ações mitigadoras em trabalhos de extração mineral, o trabalhador deve realizar o trabalho de forma ágil e atento a possíveis rupturas de barramentos, estar apropriadamente equipado com os Equipamentos de Proteção Individual, como também ficar atento a taludes que expõem riscos, locar os depósitos de explosivos em áreas isoladas e de pouca movimentação, e evitar a repetitividade e monotonia.

É essencial o seguimento das normas para a execução dos trabalhos de extração mineral, visto que nesses ambientes o trabalhador está sujeito a riscos que podem comprometer sua saúde ocupacional, tanto como qualidade do trabalho. Por isso, é necessário grande ênfase na metodologia de execução dos serviços de mineração subterrânea. É indispensável ações de fiscalização para verificação do cumprimento das normas técnicas de segurança do trabalho voltadas para empresas de pequeno, médio e grande porte.

A matriz GUT apresentada é qualitativa, e isso implica que pode expor diferentes interpretações, de acordo com diversas experiências adquiridas.

É recomendada a realização de um estudo de viabilidade e as diretrizes que estão no Novo Código de Mineração, se as atividades do trabalhador em minas subterrâneas são passíveis de serem desenvolvidas de forma segura. 


\section{REFERÊNCIAS}

[1] BATTACHERJEE, A. Mine safety managemnet: An aplication of risk analyses, forecasting techniques, and Markov process to injury experience data. The Pennsilvania State University, 1991. 301 p. (Doctoral Thesis).

[2] BRASIL. Portaria no 3.214 de 08 de junho de 1978 Normas Regulamentadoras. In: SEGURANÇA E MEDICINA DO TRABALHO. 29. ed. São Paulo: Atlas, 1995. 489 p. (Manuais de legislação, 16).

[3] LIMA, C. Q. B. Implantação de modelos de gestão para a segurança e saúde no trabalho: estudo de casos no setor mineral. São Paulo: Escola Politécnica da Universidade de São Paulo, 2002. 139p. (Dissertação de Mestrado).

[4] BARREIROS, D. Gestão da segurança e saúde no trabalho: estudo de um modelo sistêmico para as organizações do setor mineral.São Paulo: Escola Politécnica da Universidade de São Paulo, 2002. 317p. (Tese de Doutorado).

[5] KLASSMANN, A. B.; BREHM, F. A.; MORAES, C. A. Percepção dos funcionários dos riscos e perigos nas operações realizadas no setor de fundição. R. Est. Tecnológicos. v. 7, n. 2:142-162 (mai/dez 2011).

[6] SCHRAGE, M. W. Mapa de ruído como ferramenta de diagnóstico do conforto acústico da comunidade. São Paulo: Escola Politécnica da Universidade de São Paulo, 2005. 101p. (Dissertação de Mestrado).
[7] MORAN, D. S., PANDOLF, K. B., VITALIS, A., HELED, Y., PARKER, R., GONZALEZ, R. R. The role of solar and UV radiation in environmental stress assessment. Journal of Thermal Biology, v. 29, p. 529-533, 2004.

[8] LIDA, I. Ergonomia-projeto e produção. São Paulo: Edgard Blücher, 2000 (6ª reimpressão).

[9] GRUENZNER, G. Avaliação da poeira de sílica: um estudo de caso em uma pedreira na região metropolitana de São Paulo. São Paulo: Escola Politécnica da Universidade de São Paulo, 2006. 93p. (Dissertação de Mestrado).

[10] GABAS, G. C. C. Análise crítica dos critérios de seleção de respiradores para particulados em ambientes de mineração. São Paulo: Escola Politécnica da Universidade de São Paulo, 2008. 124p. (Dissertação de Mestrado).

[11] Haddad, E. Riscos associados aos produtos perigosos. Sem data. Disponível em http://www.bvsde.paho.org/ cursode/p/modulos/modulo_1.6.pdf Acesso em 20/02/2017.

[12] PEIXOTO, N. H., FERREIRA, L. S., Higiene Ocupacional I. Rede e-Tec. Santa Maria - RS. Colégio Técnico Industrial. UFSM. 2012. P. 58.

[13] BRASIL. INSTITUTO BRASILEIRO DE GEOGRAFIA E ESTATÍSTICA - IBGE I v4.1.14. 2017. Disponível em < https:// cidades.ibge.gov.br/v4/brasil/mg/mariana/panorama> 


\section{CAPÍTULO 9}

\section{ANÁliSE DO SISTEMA DE GESTÃo DE RISCOS NO SETOR DE REBOBINADEIRAS EM UMA INDÚSTRIA DE AUTOADESIVOS}

Jordana Dorca dos Santos

Luci Mercedes De Mori

Celise Roder

Luani Back

Jean Carlos B. de Almeida

Resumo: O gerenciamento de riscos é uma ferramenta capaz de identificar, qualificar, prevenir ou eliminar os riscos no ambiente de trabalho. Este trabalho tem por objetivo analisar a gestão de riscos no setor com maior incidência de acidentes de trabalho em uma indústria de autoadesivos e propor medidas de melhoria. A identificação dos perigos foi realizada através do levantamento do processo produtivo, aplicaçao de check list de inspeção de segurança do trabalho e consulta a documentação. Para avaliação e qualificação dos riscos foi utilizada a metodologia proposta por Rego (2005), baseada nas normas ISO 14001, OHSAS 18001, BS 8800 e AS/NZS 4360, pela qual se obteve o índice de risco do setor (IRS). Constatou-se que o setor com maior índice de acidentes foi o de rebobinadeira onde os ribbons de papel são cortados em diferentes padrões de tamanho e rebobinados com auxílio de equipamento específico. A situação da gestão de riscos encontrada foi apenas relativa à legislação vigente, não caracterizando um sistema de gestão de risco. O aspecto que apresentou maior risco foi de cortes/lesões das mãos na operação de acerto das metragens da rebobinadeira, contribuindo com $36,4 \%$ no IRS, e o índice geral do setor foi de 60,4\%. Este índice representa o quão vulnerável/perigoso é um processo em relação a segurança do trabalho para os colaboradores envolvidos nas atividades produtivas. Para implantação do sistema de gestão de risco é necessário o estudo de todos os setores da indústria de forma integrada, com a contribuição dos colaboradores, encarregados e gestores da organização.

Palavras Chave: segurança do trabalho, prevenção de risco, gestão do risco ocupacional. 


\section{INTRODUÇÃO}

De acordo com os dados do último Anuário Estatístico de Acidentes do Trabalho, realizado pelo Instituto Nacional do Seguro Social - INSS - as notificações de acidentes de trabalho diminuíram em 2010, de 701.496, ante 733.365 no ano anterior. Contudo, o número de mortes cresceu $11,4 \%$ de um ano para o outro, saltando de 2.650 para 2.712 (SINAIT, 2012).

O mercado de rotulagem tem forte potencial de crescimento no Brasil, principalmente em razão da expansão do segmento de bens de consumo e da demanda por embalagens com maior tecnologia agregada, maior apelo visual e conteúdo informativo. O consumo de rótulos e etiquetas é estimado em 40 bilhões de metros quadrados/ano em todo o mundo, dos quais 16 bilhões de metros quadrados (ou seja, 40\%) são autoadesivos e cerca de 50\%, Glue Applied (o papel com cola) (ABIA, 2013).

A avaliação de riscos é o processo que proporciona um método de avaliar e de melhorar comportamentos relativamente à prevenção de incidentes e de acidentes no local de trabalho, através da gestão efetiva de riscos perigosos e de riscos, é um método lógico e gradual de decidir o que é necessário fazer, como fazer melhor, de acompanhar os progressos no sentido dos objetivos estabelecidos e de identificar áreas a aperfeiçoar (ILO-OSH, 2011).

O risco pode ser dividido em três interpretações aceitável, potencial e efetivo (OHSAS 18.001, 2007):

i. Risco Aceitável: risco que foi reduzido a um nível que pode ser tolerado pela organização, levando em conideração suas obrigações legais e sua própria política de saúde e segurança; ii. Risco Potencial: está associado ao fato de a resistência do corpo, eventualmente atingido, ser inferior a uma determinada energia (causadora de acidente, por exemplo); iii. Risco Efetivo: é a probabilidade de o homem estar exposto a um risco potencial.

Na visão de Trivelato (2002), a implantação de sistemas de gestão da segurança e saúde no trabalho tem sido a principal estratégia para atacar o sério problema social e econômico dos acidentes e doenças relacionadas ao trabalho, e ainda pode ser usado pelas empresas como um fator para o aumento de sua competitividade.

A compreensão de que a gestão da segurança é uma atividade coletiva e que deve ser exercida e realizada por todos é o primeiro passo para que a implantação deste sistema de gestão alcance o sucesso esperado; gerando, a partir disso, uma linguagem comum, que gera sinergia entre os colaboradores da organização em torno de uma mentalidade orientada para a segurança (OLIVEIRA, 2008). Estudos mostram que o sucesso na implantação de um sistema de segurança e saúde em uma organização depende da habilidade dos agentes responsáveis pelas mudanças em controlar situações complexas e imprevisíveis (HASLE; JENSEN, 2006)

O autoadesivo é definido como uma classe especial de adesivos indicado para aderir na maioria das superfícies com uma leve pressão (CRETON, 2003). Para Varanese (1998), o autoadesivo é uma categoria distinta de fitas adesivas que na forma seca adere agressiva e permanentemente a temperatura ambiente.

A estrutura de um autoadesivo é constituída de um protetor (ou liner), uma camada de silicone, uma camada de adesivo e do frontal, conforme se ilustra na Figura 1. O protetor é a parte do autoadesivo que é descartado após o uso, de onde se destaca o frontal que recebe a impressão (GEORGES, 2010).

Figura 1- Estrutura do Autoadesivo

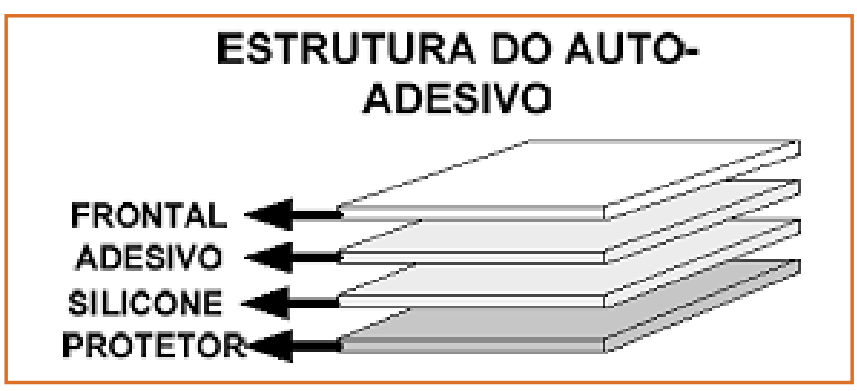

Fonte: Georges (2010)

De acordo com Associação Brasileira das Indústrias de Etiquetas Adesivas, existem 37 laminadores no Brasil que produzem 92\% de todo o material usado para conversão no Brasil, sendo apenas $8 \%$ o volume importado. Foram laminados em 2004 cerca de 172 
milhões de metros quadrados de papéis e filmes autoadesivos, sendo que em $60,3 \%$ deste volume se usou papel como substrato, em 39,1\% deste volume se usou filme plástico como substrato e $0,6 \%$ outros materiais (ABIEA, 2005).

A indústria de autoadesivos possui etapas automatizadas em sua produção e estudos dos riscos ocupacionais neste segmento ainda são pouco conhecidos, os quais devem ser identificados e analisados de acordo com seu grau de gravidade para que sejam elaborados planos de ação e prevenção visando a segurança do trabalhador e garantindo também produtividade da indústria e evitar problemas legais com acidentes de trabalho.

Nesse contexto, o presente artigo tem por objetivo analisar o sistema de gestão de riscos no setor com maior incidência de acidentes de trabalho em uma indústria de autoadesivos e propor medidas de melhoria no processo de gerenciamento de riscos no setor.

\section{MATERIAIS E MÉTODOS}

2.1 IDENTIFICAÇÃO DA METODOLOGIA DE GERENCIAMENTO DE RISCOS EMPREGADA PELA ORGANIZAÇÃO

A identificação da metodologia empregada pela empresa para gerenciamento dos riscos (GR) foi realizada através de observação no local de trabalho (setor de rebobinadeira) e questionamentos a respeito do setor de segurança ao técnico de segurança do trabalho da empresa.

\subsection{IDENTIFICAÇÃO DOS PERIGOS OCUPACIONAIS}

Os perigos foram analisados através do levantamento do processo produtivo na indústria, relacionando cada etapa aos seus respectivos perigos. O processo de levantamento do risco seguiu as seguintes etapas:

I. Consultar os registros de acidentes de trabalho da empresa;

II. Solicitação dos dados do Programa de Prevenção dos Riscos Ambientais (PPRA) e mapa de risco do setor estudado;

III. Levantar a quantidade de funcionários com o encarregado do cada setor;

IV. Aplicação de um check-list de inspeção de segurança para averiguação dos perigos no local;

\subsection{AVALIAÇÃO E QUALIFICAÇÃO DOS RISCOS}

Após o levantamento inicial foi selecionado o setor em que havia maior ocorrência de acidentes de trabalho para avaliação seguindo a metodologia proposta por Rego (2005) que baseou-se nas normas ISO 14001, OHSAS 18001, BS 8800 e AS/NZS 4360. Para análise do risco avaliou-se os seguintes parâmetros como fatores de risco: Frequência de Exposição; Controle e Percepção do Risco, que serão avaliados nos aspectos de Segurança Meio Ambiente e Saúde dos processos e Efeito do Impacto; Mitigação e Repercussão, que serão avaliados nos impactos de segurança do trabalho dos processos.

Ao final gerou-se uma planilha de avaliação de tais parâmetros na unidade industrial. No topo da planilha: identificação da gerência, local, área, processo avaliado, data da avaliação e documentos utilizados:

I. Identificação dos aspectos/impactos de SMS nas tarefas;

II. Caracterização da situação operacional das tarefas: normal ou emergência;

III. Análise do risco: através da aplicação de análise de: probabilidade (frequência, controle e percepção do risco - relativo aos aspectos) e consequência (severidade, mitigação e repercussão - relativa aos impactos);

IV. Avaliação do risco: segundo os critérios de significância; determinação da significância do risco, da categoria de risco (Figura 2);

V. Definição da tolerabilidade do risco: definição pela organização, da categoria do risco na qual será definida a tolerabilidade;

VI. Avaliação da tolerabilidade: avaliação da categoria de risco em cada tarefa avaliada do processo e sua significância. 
Figura 2 - Classificação de significância do risco

\begin{tabular}{||lll|}
\hline \multicolumn{3}{|c|}{ Classificação da significância } \\
\hline Trivial & Até 24 & NÃo SIGNIFICATIVO \\
Tolerável & de 25 a 49 & \\
moderado & de 50 a 73 & \\
substancial & de 74 a 97 & SIGNIFICATIVO \\
intolerável & de 98 a 121 & \\
\hline
\end{tabular}

Fonte: Rego (2005)

Após avaliação e priorização dos riscos levantados foram propostas medida de melhoria, mitigação ou eliminação dos riscos levando em conta a legislação pertinente e a melhoria das condições de trabalho.

\section{RESULTADOS E DISCUSSÃO}

\subsection{IDENTIFICAÇÕES DO LOCAL DE ESTUDO E METODOLOGIA DE GR DA ORGANIZAÇÃO}

A empresa estudada localiza-se no oeste do Paraná atuando a treze anos, com área instalada de 17.769 m2, produz mais 200 itens que são fornecidos para indústrias, empresas de serviço e varejo, possui Sistema de Gestão da Qualidade ABNT NBR ISO 9001 e Sistema de Gestão Ambiental ABNT NBR ISO 14001. $\mathrm{Na}$ visita inicial constatou-se através do relatório anual de acidentes de trabalho fornecido pelo responsável da área, que dentre os setores (estoque, laminadora, administrativo, cortadeira e expedição) o setor de rebobinadeira (Figura 3) é o que mais apresentava acidentes, sendo então o escolhido para o estudo.

Figura 3 - Setor de Rebobinadeira

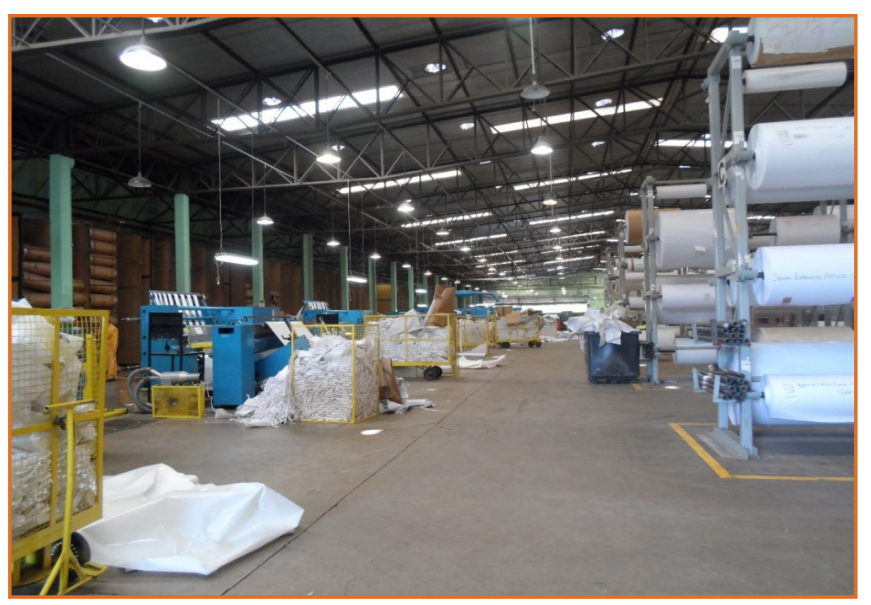

Fonte: Os Autores (2015)
Este setor conta com 25 a 27 funcionários por turno e trabalha em três turnos, possui oito rebobinadeiras KAMPF que pode alcançar a velocidade de até 550 $\mathrm{m} / \mathrm{s}$, o processo produtivo deste que é um setor de acabamento na indústria é constituído basicamente das etapas apresentadas na Figura 4.

Figura 4- Processo Produtivo do Setor Rebobinadeira

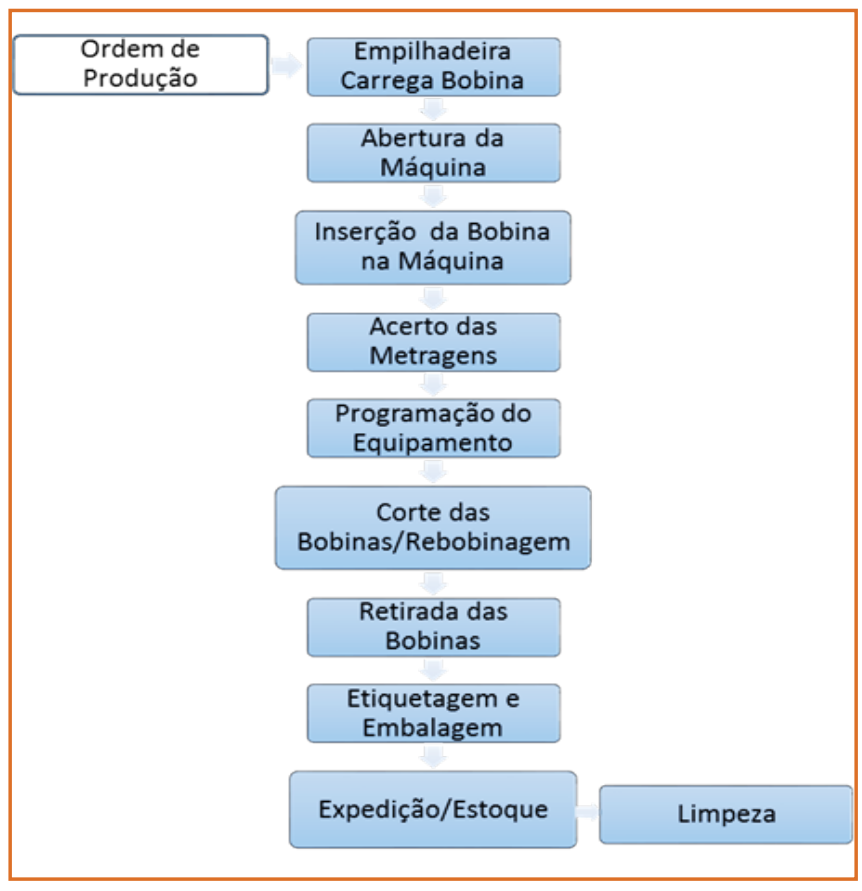

Fonte: Os Autores (2015)

A organização conta com aproximadamente 400 funcionários apresenta um sistema de controle de segurança do trabalho baseado nas normas e legislações vigentes, contando com apenas um funcionário responsável pelo setor: um técnico de segurança do trabalho. Tal situação não caracterizou um sistema de gestão de segurança do trabalho estruturado que possa identificar e controlar os riscos ocupacionais de forma interligada e eficaz, de modo a trazer melhorias significativas para os colaboradores e ambiente de trabalho.

\subsection{IDENTIFICAÇÃO DOS PERIGOS E RISCOS}

Os riscos observados durante as visitastécnicas ao setor foram coerentes com os fornecidos pelo mapa de risco, devido às atividades desenvolvidas pelos operadores durante o processo de produção que é realizada em pé, e durante o ajuste das facas e contra- 
facas pode causar o corte das mãos e dedos, e é o que torna este o setor com maior número de acidentes na fábrica. O mapa de risco indicou os seguintes riscos apresentados no Quadro 1.

Quadro 1 - Informações obtidas do Mapa de Risco no Setor da Rebobinadeira

\begin{tabular}{|l|l|l|}
\multicolumn{1}{|c}{ Grupo do Risco } & \multicolumn{1}{c|}{ Intensidade } & Causa \\
\hline Ergonômico & Grande & $\begin{array}{l}\text { Corte das mãos e } \\
\text { dedos }\end{array}$ \\
\hline Físico e Acidentes & Médio & Produtos de limpeza \\
\hline Químicos & Pequeno & \\
\hline
\end{tabular}

Fonte: Os Autores (2015)

Do programa de prevenção de riscos ambientais (PPRA) do setor, fornecido pela empresa, observouse seis cargos atuando (operador da rebobinadeira, líder, supervisor, ajudante de produção,auxiliar adminstrativo e operador de movimentação de materiais) sendo as princicpais fontes geradoras de riscos associadas a maquinário, movimentos repetitivos, postura inadequada e movimentação de materiais. Na aplicação do check list algumas falhas foram observadas nos seguintes quesitos:

- Equipamentos de Proteção Individual: não havia local adequado para o armazenamento dos EPI's;

- Edificações: falta de proteção/isolamento térmico no teto do barracão;

- Instalações Elétricas: as extensões elétricas não apresentavam bom estado de conservação;

- Ergonomia: falta de assento para os operadores e suporte adequado para leitura de documentos;

- Produtos Químicos: o produto de limpeza do maquinário (benzina) estava disposto no chão sem rótulo de identificação.

\subsection{AVALIAÇÃO E QUALIFICAÇÃO DOS RISCOS}

Após a identificação inicial dos processos/etapas de produção e das tarefas desempenhadas pelos colaboradores do setor e posterior identificação dos perigos e riscos, seguiu-se para avaliação e qualificação dos riscos adaptando a metodologia proposta por Rego (2005).

As planilhas de aspectos e impactos obtidas são apresentadas na Tabela 1 sendo que foram observados seis riscos significativos, classificados em substancial (dois) e moderados (quatro), e sete não significativos, sendo classificados em um trivial e seis toleráveis.

Na Tabela 2 é apresentada o \% dos Riscos relativos, de acordo com a classificação dos riscos obtidos. 
Tabela 1 - Identificação dos Aspectos e Impactos no setor estudado (continua)

\begin{tabular}{|c|c|c|c|c|c|c|c|c|c|c|c|c|c|c|}
\hline \multicolumn{3}{|c|}{ Local: Rebobinadeiras } & \multicolumn{10}{|c|}{ Análise } & \multicolumn{2}{|c|}{ Avaliação do Riso } \\
\hline Tarefa & Aspecto & Impacto & $N / E$ & Freq. & $\begin{array}{l}\text { Controle } \\
\text { Associado }\end{array}$ & $\begin{array}{l}\text { Percepção } \\
\text { do Risco }\end{array}$ & $\mathrm{S} 1$ & $\begin{array}{l}\text { Efeito de } \\
\text { Impacto }\end{array}$ & Mitigação & Rep. & S2 & $\mathrm{P}$ & Categoria & Significância \\
\hline $\begin{array}{l}\text { Carregamento } \\
\text { Bobinas }\end{array}$ & $\begin{array}{l}\text { Queda do } \\
\text { Material }\end{array}$ & $\begin{array}{l}\text { Acidentes/ } \\
\text { Lesões }\end{array}$ & $E$ & 5 & 1 & 1 & 7 & 1 & 1 & 1 & 3 & 21 & Trivial & $\begin{array}{l}\text { Não } \\
\text { Significativo }\end{array}$ \\
\hline $\begin{array}{l}\text { Carregamento } \\
\text { Bobinas }\end{array}$ & $\begin{array}{l}\text { Falta do uso } \\
\text { do Cinto de } \\
\text { Segurança }\end{array}$ & $\begin{array}{l}\text { Acidente/ } \\
\text { Lesões }\end{array}$ & $\mathrm{N}$ & 5 & 2 & 2 & 9 & 3 & 2 & 1 & 6 & 54 & Moderado & Significativo \\
\hline $\begin{array}{l}\text { Inserção da } \\
\text { Bobina na } \\
\text { Rebobinadeira }\end{array}$ & $\begin{array}{l}\text { Queda do } \\
\text { Material }\end{array}$ & $\begin{array}{l}\text { Acidente/ } \\
\text { Lesões }\end{array}$ & $E$ & 5 & 2 & 2 & 9 & 1 & 2 & 1 & 4 & 36 & Tolerável & $\begin{array}{l}\text { Não } \\
\text { Significativo }\end{array}$ \\
\hline $\begin{array}{l}\text { Inserção da } \\
\text { Bobina na } \\
\text { Rebobinadeira }\end{array}$ & $\begin{array}{l}\text { Repetição dos } \\
\text { Movimentos }\end{array}$ & $\begin{array}{l}\text { Lesões por } \\
\text { esforço } \\
\text { repetitivo }\end{array}$ & $\mathrm{N}$ & 5 & 2 & 3 & 10 & 2 & 2 & 1 & 5 & 50 & Moderado & Significativo \\
\hline $\begin{array}{l}\text { Acerto das } \\
\text { Metragens }\end{array}$ & $\begin{array}{l}\text { Uso incorreto } \\
\text { das contra- } \\
\text { facas }\end{array}$ & $\begin{array}{l}\text { Cortes/ } \\
\text { Lesões } \\
\text { nas mãos }\end{array}$ & $\mathrm{N}$ & 5 & 3 & 2 & 10 & 3 & 3 & 2 & 8 & 80 & Substancial & Significativo \\
\hline $\begin{array}{l}\text { Acerto das } \\
\text { Metragens }\end{array}$ & $\begin{array}{l}\text { Improvisação } \\
\text { de ferramenta }\end{array}$ & $\begin{array}{l}\text { Cortes/ } \\
\text { Lesões nas } \\
\text { Mãos }\end{array}$ & $\mathrm{N}$ & 5 & 3 & 3 & 11 & 3 & 3 & 2 & 8 & 88 & Substancial & Significativo \\
\hline $\begin{array}{l}\text { Programação } \\
\text { da } \\
\text { Rebobinadeira }\end{array}$ & $\begin{array}{l}\text { Alta } \\
\text { Velocidade }\end{array}$ & Acidentes & $E$ & 5 & 2 & 2 & 9 & 2 & 1 & 1 & 4 & 36 & Tolerável & $\begin{array}{l}\text { Não } \\
\text { Significativo }\end{array}$ \\
\hline Rebobinagem & $\begin{array}{l}\text { Acesso de } \\
\text { Pessoas não } \\
\text { treinadas }\end{array}$ & Acidentes & $N$ & 5 & 2 & 1 & 8 & 3 & & 1 & 4 & 32 & Tolerável & $\begin{array}{l}\text { Não } \\
\text { Significativo }\end{array}$ \\
\hline Rebobinagem & $\begin{array}{l}\text { Realização do } \\
\text { trabalho todo o } \\
\text { tempo em pé }\end{array}$ & $\begin{array}{l}\text { Lesões por } \\
\text { esforço } \\
\text { repetitivo/ } \\
\text { Cansaço }\end{array}$ & $\mathrm{N}$ & 5 & 2 & 1 & 8 & 2 & 2 & 1 & 5 & 40 & Tolerável & $\begin{array}{l}\text { Não } \\
\text { Significativo }\end{array}$ \\
\hline $\begin{array}{l}\text { Retirada das } \\
\text { Bobinas da } \\
\text { Rebobinadeira }\end{array}$ & $\begin{array}{l}\text { Ser atingido por } \\
\text { um rolo durante } \\
\text { empurrar ou } \\
\text { transmitir }\end{array}$ & $\begin{array}{l}\text { Lesões/ } \\
\text { Acidentes }\end{array}$ & $E$ & 5 & 2 & 1 & 8 & 2 & 2 & 1 & 5 & 40 & Tolerável & $\begin{array}{l}\text { Não } \\
\text { Significativo }\end{array}$ \\
\hline $\begin{array}{l}\text { Envio para } \\
\text { Expedição }\end{array}$ & $\begin{array}{l}\text { Queda de } \\
\text { Materias }\end{array}$ & Acidentes & $E$ & 5 & 2 & 1 & 8 & 2 & 1 & 1 & 4 & 32 & Tolerável & $\begin{array}{l}\text { Não } \\
\text { Significativo }\end{array}$ \\
\hline $\begin{array}{l}\text { Limpeza da } \\
\text { Rebobinadeira }\end{array}$ & $\begin{array}{l}\text { Uso de Benzina } \\
\text { para Limpeza }\end{array}$ & $\begin{array}{l}\text { Irritação da } \\
\text { pele e } \\
\text { olhos, } \\
\text { náuseas } \\
\text { e dores de } \\
\text { cabeça }\end{array}$ & $N$ & 5 & 2 & 2 & 9 & 3 & 2 & 1 & 6 & 54 & Moderado & Significativo \\
\hline $\begin{array}{l}\text { Limpeza da } \\
\text { Rebobinadeira }\end{array}$ & $\begin{array}{l}\text { Não } \\
\text { cumprimento } \\
\text { do } \\
\text { Procedimento }\end{array}$ & Acidentes & $N$ & 5 & 2 & 2 & 9 & 3 & 1 & 2 & 6 & 54 & Moderado & Significativo \\
\hline
\end{tabular}

Legenda: N/E= Normal/ Emergência ; Frer= frequência; Rep= repercurssão $\mathrm{P}=(\mathrm{S} 1 \times \mathrm{S} 2) ; \mathrm{S} 1=$ (Frequência+ Cat. Do Risco+ Percepção do Risco); S2= (Efeito do Impacto+ Mitigação+ Repercussão) 
Tabela 2 - Demonstrativo do Cálculo do Índice de Risco significativo (IRS)

\begin{tabular}{l|l|l|l|l|l|l|l|}
$\begin{array}{l}\text { Quantidade de } \\
\text { Riscos Identificados }\end{array}$ & $\begin{array}{l}\text { Classificação dos } \\
\text { Riscos }\end{array}$ & Pesos & $\begin{array}{l}\text { Frequência } \\
\text { relativa corrigida } \\
\text { (Frc) }\end{array}$ & $\begin{array}{l}\text { Frequência } \\
\text { acumulada } \\
\text { corrigida } \\
\text { (Fac) }\end{array}$ & $\begin{array}{l}\text { \% Riscos } \\
\text { Relativos }\end{array}$ & $\begin{array}{l}\text { \%Riscos } \\
\text { Acumulados }\end{array}$ \\
\hline 2 & Substancial & 4 & 8 & 8 & 24,2 & 24,2 \\
\hline 4 & Moderado & 3 & 12 & 20 & 36,4 & 60,6 \\
\hline 6 & Tolerável & 2 & 12 & 32 & 36,4 & 97,0 \\
\hline 1 & Trivial & 1 & 1 & 33 & 3,0 & 100 \\
\hline Total 13 & & & 33 & & 100 & \\
\hline
\end{tabular}

Cálculo da frequência relativa corrigida $(F r c)=$ Quantidade de riscos i dentificados ${ }^{\star}$ peso Cálculo do \% Riscos relativos $=$ $\sum \operatorname{Frc}(n)^{\star} 100 / \operatorname{Frc}(n)$

Fonte: Os Autores (2015)

As atividades de risco classificadas como substanciais, ou seja, as mais perigosas, são as relacionadas a tarefa acerto das metragens das facas da rebobinadeira que fazem os cortes nas bobinas, em que podem ocorrer cortes e lesões nas mãos dos operadores riscos obtidos

Os riscos que mais contribuíram foram os moderados, com 36,4 \%, e toleráveis, 36,4\%, seguido pelo risco substancial, 24,2\%. A partir da Tabela 2 foi possível obter o índice de Risco Significativo (IRS). Este índice possibilita, ao gestor de segurança acompanhar de forma sistemática o nível de segurança dos processos e tarefas da organização além da possibilidade de constante atualização.

Os riscos avaliados não significativos devem ser registrados e monitorados pelos responsáveis da gestão de segurança do trabalho, já os significativos também devem ser registrados e as medidas necessárias devem ser solicitadas e implantadas pela gerência da organização.

O índice de risco no setor foi IRS $=60,6 \%$ é obtido através do resultado do somatório da porcentagem de riscos relativos: moderados, substanciais e intoleráveis. O processo estudado encontra-se vulnerável na razão de $60,6 \%$.

Este índice representa o quão vulnerável/perigoso é um processo em relação a segurança do trabalho para os colaboradores envolvidos nas atividades produtivas. O ideal para um processo é que este índice

seja o mais próximo de IRS=0\%, demonstrando a total segurança das condições de trabalho, ou seja, que os riscos avaliados no processo são não significativos.

\subsection{MEDIDAS CORRETIVAS E PREVENTIVAS SUGERIDAS}

Os riscos classificados como moderados e substanciais foram avaliados como significativos, portanto devem ser tomadas medidas de controle e melhorias imediatas, estes são elencados no Quadro 2 com sua respectiva sugestão de correção e melhoria (plano de ação).

Quadro 2 - Riscos Significativos no setor de Rebobinadeira

Riscos Moderados

i. Falta de uso do cinto de segurança na operação da empilhadeira

ii. Lesão por esforço repetitivo na inserção e retirada de bobinas;

iii. Uso de Benzina para limpeza

da rebobinadeira e falha no

cumprimento do procedimento de

Limpeza do equipamento.

\section{- Moderados:}

i. Este tipo de risco pode gerar acidentes graves na indústria, uma maior conscientização, treinamento dos colaboradores e fiscalização e cobrança por parte dos responsáveis pelo setor de movimentação de materiais colaborando assim com o responsável pela segurança do trabalho na empresa; 
ii. Este tipo de esforço é inerente a atividade desenvolvida pelos operadores e auxiliares, podem ser amenizados com a realização de programa de ginástica laboral no início e também no final do turno de trabalho durante, pelo menos, 3 vezes por semana;

iii. A benzina atua como um solvente da cola residual do adesivo na rebobinadeira, apesar do uso dos equipamentos de proteção individual (máscara e luvas) ainda podem ocorrer acidentes na operação de limpeza, logo este produto pode ser substituído por solventes ecológicos ou solvente substituto de benzina disponíveis no mercado.

- Substanciais:

O acerto das metragens é o procedimento responsável pelo setor de rebobinagem apresentar o maior índice de acidentes da empresa, para eliminação do risco sugere-se a troca dos equipamentos ou a substituição do sistema de metragens dos cortes por um automático.

i. Como medida alternativa além de um programa de manutenção semanal das ferramentas para que haja a substituição das danificadas e se possível uma parceria com universidades ou cursos técnicos locais para o desenvolvimento de uma ferramenta que substitua ou elimine o risco de corte na utilização contra faca.

ii. A fiscalização por um técnico de segurança no terceiro turno se faz necessária, para que possam ser realizados treinamentos e diálogos diários de segurança do trabalho com os trabalhadores incentivando as práticas prevencionistas efetivas também neste turno.

Para que essas ações possam ser analisadas pelo setor responsável e administração da organização uma ferramenta para elaboração de planos de ação $5 \mathrm{~W} 2 \mathrm{H}$ pode ser utilizada. É uma ferramenta utilizada em gestão de projetos, gestão da qualidade, análise de negócios, e planejamento estratégico.

\section{CONCLUSÃO}

A partir deste estudo foi possível identificar, avaliar, classificar e quantificar numericamente os riscos ocupacionais de uma indústria de autoadesivos. A situação da gestão de riscos encontrada ainda é relativa a legislação vigente, não caracterizando um sistema de gestão, mas é possível através da metodologia apresentada iniciar-se um processo de integração da gestão de segurança. A organização apresenta condições para este desenvolvimento englobando toda a empresa de maneira gradual, não só em um setor específico.

O aspecto que apresentou maior risco foi de encontro com a caracterização dos acidentes apresentados cortes/lesões das mãos na operação de acerto das metragens da rebobinadeira, contribuindo com 36,4\% no IRS, e o índice geral do setor foi de $60,4 \%$.

Para que o sistema de gestão de risco seja implantado é necessário o estudo de todos os setores de forma integrada, com a contribuição dos colaboradores, encarregados e gestores da organização. Também seria interessante o rodízio de horários ou aumento do pessoal no setor de segurança do trabalho para que seja possível este estudo e implantação. Além da elaboração de uma política de segurança do trabalho especifica para que no futuro, se de interesse da organização, a certificação de uma norma de segurança seja facilitada.

Sendo interessante utilizar uma estratégia ainda pouco explorada no país, que são os programas de recompensas baseados em pontos premiando os setores ou trabalhadores que demostrarem atitudes proativas, sugestões, participações em treinamentos, diminuição de acidentes, entre outros.

\section{REFERÊNCIAS}

[1] ABIEA - ASSOCIAÇÃO BRASILEIRA DAS INDÚSTRIAS DE ETIQUETAS ADESIVAS; O Autoadesivo, ano 1, n. 2, jul/ago, 2005.

[2] ABIEA - ASSOCIAÇÃO BRASILEIRA DAS INDÚSTRIAS DE ETIQUETAS ADESIVAS Embalagens com conteúdo. Revista Pack 188 p. 38-39 Abril 2013. Disponivel em: <http:// issuu.com/revistapack/docs/revistapack188/38>. Acesso em: 17 mai 2015. 
[3] CRETON, C. Pressure-Sensitive Adhesives: An Introductory Course. Material Research Society Bulletin, June 2003. Disponível em <http://www.mrs.org/publication/ bulletin>. Acesso em 29 jul. 2005.

[4] GEORGES, Marcos R. R. Metodologia para cálculo do diâmetro e do comprimento de bobina de papel autoadesivo. IJIE - Iberoamerican Journal of Industrial Engineering. Florianópolis. SC, vol.2, nำ 2, p. 108-123, jun. 2010 ISSN 2175-8018

[5] HASLE, P.; JENSEN, P. L. Changing the internal health and safety organization through organizational learning and change management. Human Factors and Ergonomics in Manufacturing, vol. 16, issue 3, p. 269-284, 2006

[6] European Agency for Safety and Health at Work. OSHA 2014. Avaliação de riscos. Disponível em:<https://osha. europa.eu/pt/topics/riskassessment/index_html/definitions $>$. Acesso em: 07 mai 2015.

[7] ILO-OSH. Diretrizes sobre Sistemas de Gestão da Segurança e Saúde no Trabalho. Versão Brasileira das Diretrizes da OIT (ILO-OSH 2011). Fundacentro, Brasil, 2005. Disponível em: <http://www.oitbrasil.org.br/sites/default/ files/topic/safework/pub/diretrizes_sobre_gestao_364.pdf>. Acesso em: 23 ago 2015.

[8] OLIVEIRA, A. B.; Oliveira, J. O. Diretrizes gerais para a implantação de Sistemas de Gestão da Segurança e Saúde no Trabalho. Revista Gestão Industrial. v. 04, n. 03: p.160176, 2008.
[9] OHSAS 18.001- Especificação da Gestão em Saúde e Segurança do trabalho. Practice: A Guidebook. MPG Books Group, UK: Ashgate, 2007a.

[10] REGO, M. A. M. Metodologia qualitativa de gestão de riscos operacionais de segurança, meio ambiente d saúde ocupacional: Uma contribuição ao programa de segurança de processos. Dissertação (Mestrado em Sistema de Gestão) Universidade Federal Fluminense - UFF- Niterói, 2005.

[11] SINAIT - Sindicato Nacional dos Auditores Fiscais do Trabalho. Divulgados números de acidentes de trabalho em 2012 no Anuário Estatístico da Previdência Social Disponível em: <https://www.sinait.org.br/?r=site/noticiaView\&id=8346> Acesso em: 08 mai. 2015.

[12] TRIVELATO, G. C. Sistema de gestão da segurança e saúde no trabalho: fundamentos e alternativas. FUNDACENTRO, Belo Horizonte, MG, 2002. Disponível em <http://www.fundacentro.gov.br/ CTN/sistemas_gestao_ saude_trabalho.pdf>. Acesso em 01 jun. 2015

[13] VARANESE, D. V. The fundamentals of selecting pressure-sensitive adhesives. Medical Plastics and Biomaterials Magazine, p. 32-44, Jan. 1998. 


\title{
CAPÍTULO 10
}

\section{PROPOSTADEAVALIAÇÃODOCOMPORTAMENTOTRIDIMENSIONAL DOS TRABALHADORES E SUA RELAÇÃO COM O AUMENTO DA PRODUTIVIDADE NA EMPRESA}

\author{
Ana Carolina de Almeida Alvarenga \\ Lays Costa Faria \\ Joseane Pontes
}

Resumo: O presente trabalho tem como objetivo propor uma metodologia para avaliar o comportamento do trabalhador de acordo com o modelo tridimensional de Meyer e Allen (1991) para o aumento da produtividade. A metodologia a ser desenvolvida a partir do levantamento bibliográfico e análise exploratória. Como resultado, o trabalho propõe demonstrar como obter a melhoria da produtividade através da identificação do comprometimento existente na empresa.

Palavras Chave: Produtividade, Comportamento Organizacional Tridimensional, Motivação. 


\section{INTRODUÇÃO}

De acordo com Lerry, Seiders e Gresham (1997) é necessário que os funcionários recebam investimentos em qualidade de vida, incluindo diferentes oportunidades de crescimento para que os resultados dos mesmos sejam efetivos. Deste modo, é imprescindível que os trabalhadores sejam incentivados através de técnicas motivacionais para que os resultados e metas da empresa sejam alcançados diante de um mercado cada vez mais competitivo.

Com a facilidade cotidiana ao acesso às informações, o mercado de trabalho encontra-se cada vez mais globalizado e competitivo, consequentemente mais acirrado e exigente. De acordo com dados do censo do IBGE (2010), o índice de pessoas com o nível de ensino superior cresceu de $11,5 \%$ para $19,2 \%$ entre os anos de 2000 e 2010. Isso mostra o aumento pela busca de habilidades técnicas para o mercado de trabalho. Todavia, de acordo com Carnegie (1999) apenas 15\% do sucesso de um profissional está relacionado com suas habilidades e conhecimentos técnicos.

Outra pesquisa realizada pela Consultoria de Recrutamento Robert Halfcom em 2014 com diretores de $\mathrm{RH}$ no Brasil, revela as principais causas de demissões no Brasil. Segundo esta pesquisa, 34\% das demissões ocorrem em razão do baixo desempenho por parte dos profissionais nas organizações. O segundo motivo com $26 \%$, aparece pela ausência da adequação dos mesmos à cultura da empresa. O terceiro lugar da pesquisa fica com $16 \%$, onde as demissões ocorrem pelo relacionamento ruim com a equipe. Finalizando a mesma, o quarto e quinto lugar aparecem respectivamente com $12 \%$ e $10 \%$, em virtude de atrasos e faltas, e pela ausência de um bom relacionamento com o supervisor (Folha de São Paulo, 2014).

A presente pesquisa se equipara as investigações de Carnegie (1999), uma vez que ele afirma que o sucesso profissional é resultado de $15 \%$ de seus conhecimentos técnicos e $85 \%$ de sua perícia em engenharia humana, ou seja, a capacidade de liderança e sua personalidade.
Perante os resultados observadas, questiona-se o motivo do insucesso profissional não estar relacionado diretamente ou primordialmente com as habilidades técnicas adquiridas ao longo da formação da carreira acadêmica. De acordo com Robbins, Judge, Sobral (2014) para que a empresa seja eficiente e rentável, é preciso que os funcionários estejam comprometidos e envolvidos através de atitudes comportamentais com a organização. A carência de tais fatores como o comprometimento, que constituem os recursos humanos da empresa, pode comprometer a produtividade da organização. Desta forma, surge a seguinte pergunta de pesquisa: Como estimular a produtividade do trabalhador com base no seu comportamento, em especial o seu comprometimento com o trabalho?

Diante de tais fatores comportamentais, o presente trabalho propõe uma metodologia para estimular a produtividade do trabalhador através da avaliação do comportamento do mesmo de acordo com o modelo tridimensional de Meyer e Allen (1991).

A metodologia a ser aplicada no presente trabalho é de cunho exploratório, baseado no levantamento bibliográfico.

Com o intuito de responder à pergunta de pesquisa, o trabalho está estruturado nos seguintes tópicos: comportamento humano, necessidades humanas, produtividade, comprometimento organizacional, ferramentas e proposta de modelo, conclusão, referências bibliográficas e apêndice.

\section{COMPORTAMENTO HUMANO}

Para uma análise do entendimento do comportamento humano, é necessário um breve regresso ao início do século $X X$, onde se tem datado o surgimento do Behaviorismo. O mesmo surgiu para a psicologia como o indício da existência de algum fenômeno que se expressa através do comportamento, fazendo com que a mesma estudasse a consciência e/ou a mente humana (Matos, 1993).

O ano de 1912 é marcado com o surgimento do Behaviorismo Clássico, onde psicólogo John Broadus 
Watson publica o artigo 'Psychology as a Behaviorist Views It'. Watson é referenciado como o fundador dessa teoria - também conhecida como Behaviorismo Metodológico, o qual defende a psicologia como ciência natural, tornando-se uma disciplina aplicada (Strapasson, 2012). De acordo com Matos (1993), a Teoria Watsoniana afirma que todo fenômeno tem uma causa, e a causa de um determinado comportamento é fruto do ambiente em que o indivíduo se encontra. Prontamente, a causa é o produto da instigação do estímulo - ação ou operação. Representa-se essa operação como $S \rightarrow R$, onde:
-S é o ambiente;

- R é o comportamento,

- ( é a causa ou ação desencadeante.

Conforme a tabela 01 - Motivos de Demissão, é perceptível que o comportamento humano está conexo com a rotatividade dos colaboradores em uma organização. Logo, evidencia-se que o uso adequado de certas ferramentas da teoria da motivação, pode agir otimamente na solução desses gaps encontrados no comportamento dos trabalhadores, que tanto prejudica os indicadores de desempenho da empresa.

Tabela 01 - Motivos de Demissão

\begin{tabular}{|ccc|}
\hline Posição & Motivo & Entrevistados que concordam com o motivo (\%) \\
\hline $1^{\circ}$ & Baixo Desempenho & $36 \%$ \\
\hline $2^{\circ}$ & $\begin{array}{c}\text { Não se adequou à cultura da } \\
\text { empresa }\end{array}$ & $26 \%$ \\
\hline $3^{\circ}$ & $\begin{array}{c}\text { Relacionamento ruim com a } \\
\text { equipe }\end{array}$ & $16 \%$ \\
\hline $4^{\circ}$ & Atrasos e Faltas & $12 \%$ \\
\hline $5^{\circ}$ & $\begin{array}{c}\text { Relacionamento ruim com o } \\
\text { supervisor }\end{array}$ \\
\hline
\end{tabular}

Fonte: Adaptado da Pesquisa realizada pela Consultoria de Recrutamento Robert Half (Folha de São Paulo,2014)

\subsection{NECESSIDADES}

Os maiores indicadores e impulsores do comportamento humano são gerados a partir das necessidades, sejam elas e inconscientes ou conscientes. O ser humano busca satisfazê-las utilizando o trabalho como meio (Pedro, 2003).

As necessidades de acordo com a Pirâmide de Maslow propõem que, quanto menor o nível de satisfação do ser humano, maior deverá ser a motivação dominante no mesmo (Maslow, 1943). No instante em que o indivíduo começa a se satisfazer de determinado hierárquico, mais próximo ele estará de atingir o próximo nível, deste modo, o estado anterior existe apenas em um plano potencial (Hesketh e Costa, 1980).

A figura 01 mostra os níveis hierárquicos da pirâmide de Maslow, mostrando a satisfação fora do trabalho e dentro do trabalho. 


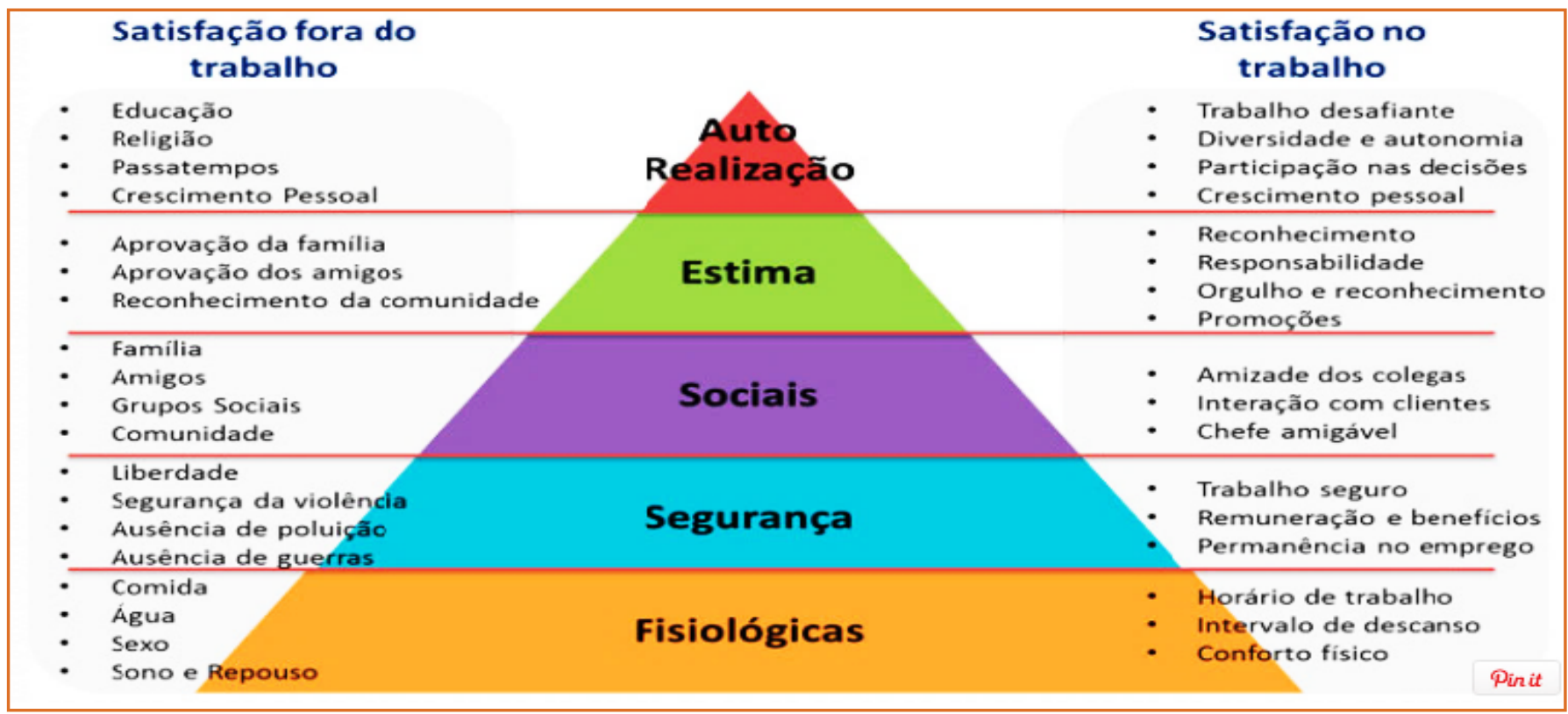

Ainda de acordo com Maslow (1943) por meio do artigo "A Theory of Human Motivation", que, selecionado um indivíduo arbitrário, é possível afirmar que este estará $85 \%$ satisfeito em suas necessidades fisiológicas, $70 \%$ em suas necessidades de segurança, 50\% em suas necessidades de sociabilidade, $40 \% \mathrm{em}$ suas necessidades de auto estima e 10\% em sua autorrealização.

Por meio desses indicadores, questiona-se como persuadir o trabalhador de uma organização para que sua produtividade seja significativa e quantitativa para os objetivos da empresa. Sabe-se que quanto maior for o nível de reclamações e frustrações, maior será o nível de qualificação de um indivíduo. Possivelmente, a organização em que este indivíduo se dedica será mais desenvolvida (Maslow, 1971).

Os próximos temas terão abordagens dos itens produtividade e comprometimento organizacional, para que haja o cumprimento do objetivo do presente trabalho.

\subsection{PRODUTIVIDADE}

A indústria passa a ter sua produtividade computada a partir da década de 70, onde inicia-se a correlação entre o trabalhador versus produção e conceito de produtividade física por trabalhador. Após o ano de 1985 tem-se o surgimento da produção física por hora paga, onde a mesma deteve-se a tentativa de controlar melhor a produção. Contextualizando que o país vinha enfrentando a recessão à frente da metade dos anos 80 (Salm, Saboia e Carvalho 1997). Em 1993 a indústria volta a crescer, porém não existe um aumento real da taxa de emprego. Todos esses fatores resultaram na necessidade do desenvolvimento da produtividade como estratégia de mercado.

Segundo Cardoso e Junior (1997) "Os índices de produtividade sempre foram um recurso largamente utilizado pelas empresas para medir seu desempenho, tanto a nível global como localizado". Dessa maneira, houve a premência de encontrar um índice eficiente que realmente mostrasse como mensurar a produtividade. Os índices tradicionais são diretamente influenciados pela variação encontrada na produção. Sendo a produtividade medida pela razão dos resultados efetivos gerados pela produção e os recursos produtivos aplicados a mesma.

Dessa maneira, relaciona-se como indicador de produtividade: peças/homem ou toneladas/ homem (quantidade de produto produzido 
mensalmente dividido pela quantidade de horas total mensal); peças/hora trabalhada ou toneladas/hora (quantidade de produto final produzidas mensalmente dividida pelo total de horas trabalhadas); índice de não conformidade do produto final (em porcentagem \% ou em partes por milhão - ppm).

O grau de competitividade da indústria está diretamente relacionado com a importância da produtividade em sua cultura. Portanto, uma metodologia mais específica como shift-share apresentada em Fagerberg (2000) traz resultados que abrangem o meio econômico relacionado com a empresa.

De acordo com Galeano e Wanderley (2013) é possível identificar uma maneira para se encontrar a produtividade em uma empresa. Relacionando a fórmula:

$$
P=\frac{Q}{N} \text {, onde }
$$

P é relacionado à produtividade agregada do trabalho, Qé o valor da transformação industrial e Né o número de trabalhadores na empresa. Essa fórmula será utilizada no estudo como uma análise empírica do indicador de qualidade no ambiente da empresa. Sendo possivel fazer a análise comparativa dos cenários antecessor e sucessor, após a aplicação da metodologia utilizada.

A produtividade pode ser analisada conforme o nível de comprometimento organizacional, que será descrito a seguir.

\subsection{COMPROMETIMENTO ORGANIZACIONAL}

O comprometimento organizacional segundo os autores Meyer, Allen (1991) e Jaros (2007), vem sendo estudado no decorrer dos anos com diferentes enfoques. Bonavides, Oliveira e Medeiros (2006) ilustram que o comprometimento para com a organização ultrapassa as barreiras de uma postura de lealdade passiva, baseando-se em um relacionamento ativo que visa sempre o bem-estar da organização como um todo. Este enfoque, está diretamente relacionado à identificação do indivíduo com a empresa levando à congruência entre os valores individuais e organizacionais.

Pode-se fundamentar a produtividade do colaborador da empresa de acordo com Meyer e Allen (1991), relacionando com as necessidades apresentadas a priori por Maslow. O comprometimento como estado psicológico é tridimensional, ou seja, dividido em três componentes separáveis: O primeiro componente é o Desejo que apresenta como fundamento o comprometimento afetivo (atitudes); o segundo é a Necessidade que leva em consideração o comprometimento instrumental (benefícios oferecidos pela empresa); o terceiro é a Obrigação que estabelece uma relação com o comprometimento normativo (normas).

O trabalhador pode apresentar em seu comportamento um mix que relaciona diferentes graus de cada um. Por exemplo, o funcionário pode apresentar um nível afetivo com o trabalho elevado e um coeficiente de necessidade e obrigação baixo, ou pode apresentar uma baixa condição de desejo e altos coeficientes de necessidade e obrigação. É possível também, a relação do estado de comprometimento com os cargos estabelecidos na empresa, onde cargos de gerência apresentam uma maior ocorrência de comprometimento afetivo.

Para que haja um comprometimento que resulte em produtividade para a empresa, é necessário um aumento de funcionários no primeiro estágio do comportamento tridimensional (Meyer e Allen, 1991). Segundo Valentim (1992), há muitas vagas não ocupadas nas empresas, todavia falta o engajamento do trabalhador. Uma questão abordada é como aumentar o comprometimento do funcionário para aumentar a sua produtividade. Assim, o presente estudo tem como objetivo avaliar o desempenho do trabalhador e caracterizá-lo conforme o comportamento tridimensional usando a motivação e o marketing interno como ferramenta para o aumento da produtividade.

Para a obtenção do sucesso do objetivo deste trabalho, é necessário entender como certas ferramentas, modelos e técnicas atuarão na implantação do projeto proposto em uma organização. 


\subsection{ANÁLISE DO MODELO TRIDIMENSIONAL}

Meyer e Allen (1991) e Jaros (2007), desenvolveram o modelo dos Três Componentes do Comportamento Organizacional para explicar o comprometimento dos trabalhadores e como os mesmos se sentem sobre a organização em que trabalham. Os componentes são organizados em uma estrutura tridimensional:

a. Comprometimento Afetivo: Os trabalhadores permanecem na organização porque querem;

b. Comprometimento Instrumental: Ostrabalhadores continuam na empresa porque precisam;

c. Comprometimento Normativa: Os trabalhadores permanecem na empresa porque são obrigados.

O modelo sugere a consolidação em todos os tipos de organização, seja industrial ou de serviço, acarretando como possíveis benefícios o aumento do comprometimento e o engajamento dos trabalhadores. Para a identificação do estilo de comprometimento dos trabalhadores da organização o qual se encontram, será aplicada o questionário baseado no modelo que Jaros (2007) propôs. Esse questionário encontra-se no Apêndice do presente trabalho.

\subsection{MARKETING INTERNO}

O Marketing é em sua essência descrito por Kotler e Keller (2012) na contemporaneidade, como a ferramenta da empresa para enfrentar os momentos de crise que vem perturbando o cenário econômico a partir do século XXI. Uma vez que sem a demanda por produtos não há sentido a existência dos outros setores dentro da empresa.

No final da década de 70, com o objetivo de redução de custos da produção, surgiu na literatura o conceito de marketing interno. Esse destroncamento do marketing é apresentado por Berry (1991) como uma ferramenta de gestão para potencializar a atividade humana da empresa.

O marketing interno objetiva desenvolver uma organização centrada no cliente que gere um serviço ou produto de qualidade. Baseado na motivação, satisfação e perspectiva dos colaborados que passam a ser classificados como clientes internos da organização (Azêdo e Alves, 2013).

Segundo Wilson Cerqueira (1994 apud INKOTTE, 2000) para um projeto bem-sucedido de marketing interno, também tratado por endomarketing - uma visão mais engajada do funcionário quanto a empresa; visa ações a serem consolidadas na base cultural do comprometimento dos trabalhadores com o desenvolvimento adequado das suas diversas técnicas, objetivando:

a. A prática dos valores estabelecidos como base da nova cultura;

b. A manutenção de um clima ideal de valorização e reconhecimento das pessoas;

c. A obtenção de índices maiores de produtividade e qualidade, com a consequente redução de custos;

d. Estabelecimento de canais adequados de comunicação interpessoal, que permitirão a eliminação de conflitos e insatisfações, que possam afetar o sistema organizacional;

e. A melhoria do relacionamento interpessoal;

f. Estabelecimento da administração participativa;

g. A implantação de ações gerenciais preventivas.

As técnicas motivacionais se correlacionam às ferramentas de marketing interno e endomarketing e são descritas a seguir como forma de complementar o presente estudo.

\subsection{TÉCNICAS MOTIVACIONAIS}

As técnicas motivacionais serão baseadas nas premissas motivacionais já existentes e estão baseadas nas necessidades de cada trabalhador, conforme verifica-se na figura 01 . No quadro 2 é possível identificar uma síntese das teorias e suas premissas. 
Quadro 02 - Principais Teorias Motivacionais e suas premissas

\begin{tabular}{|c|c|c|c|}
\hline Autores & Ano & Teoria Motivacional & Premissas \\
\hline Maslow & 1954 & $\begin{array}{l}\text { Teoria da Hierarquia } \\
\text { das Necessidades }\end{array}$ & $\begin{array}{l}\text { As pessoas são motivadas por necessidades hierarquizadas. Só depois } \\
\text { de satisfazer as necessidades do nível anterior as mesmas irão avançar } \\
\text { para o nível. }\end{array}$ \\
\hline Mcclelland & 1961 & $\begin{array}{l}\text { Teoria das } \\
\text { Necessidades }\end{array}$ & $\begin{array}{l}\text { As necessidades de realização ou sucesso, as de poder e as de } \\
\text { afiliação são necessidades básicas que originam a motivação para o } \\
\text { desempenho. }\end{array}$ \\
\hline Herzberg & 1966 & Teoria dos 2 Fatores & $\begin{array}{l}\text { Os fatores motivadores são a realização, o reconhecimento, o próprio } \\
\text { trabalho, a responsabilidade e a possibilidade de progredir. }\end{array}$ \\
\hline Ryan e Deci & 1975 & Teoria da Motivação & $\begin{array}{l}\text { As emoções de prazer despoletadas pelas experiências de competência } \\
\text { e autonomia são as determinantes de um comportamento intrinsicamente } \\
\text { motivada. }\end{array}$ \\
\hline Locke e Latha & 1990 & Teoria dos Objetivos & $\begin{array}{l}\text { A motivação resulta da comparação que é feita entre os objetivos } \\
\text { propostos e o desempenho. }\end{array}$ \\
\hline
\end{tabular}

Fonte: Adaptação segundo Azêdo e Alves (2013)

Para a tríplice dos tipos de comprometimento, as teorias motivacionais distribuídas em uma nova tabela conforme exemplo abaixo. Portanto a continuação da presente pesquisa permitirá que técnicas motivacionais existentes sejam estudadas e alocadas de acordo com as teorias alocadas em cada grupo.

Quadro 03 - Tipos de Comprometimento e Técnicas Motivacionais

\begin{tabular}{|c|c|c|c|}
\hline Tipo de Comprometimento & Definição & Teoria Motivacional & $\begin{array}{l}\text { Técnicas } \\
\text { Motivacionais }\end{array}$ \\
\hline Afetivo & $\begin{array}{l}\text { Os trabalhadores continuam na } \\
\text { empresa porque querem. }\end{array}$ & $\begin{array}{c}\text { Teoria da Motivação - Ryan e } \\
\text { Deci }\end{array}$ & \\
\hline $\begin{array}{l}\text { Normativo } \\
\text { Instrumental }\end{array}$ & $\begin{array}{l}\text { Os trabalhadores continuam na } \\
\text { empresa porque precisam. } \\
\text { Os trabalhadores continuam na } \\
\text { empresa porque são obrigados. }\end{array}$ & $\begin{array}{c}\text { Teoria das Necessidades - } \\
\text { Maslow e Mcclelland } \\
\text { Teoria dos } 2 \text { Fatores - Herzberg } \\
\text { Teoria dos Objetos - Locke e } \\
\text { Latha }\end{array}$ & $\begin{array}{l}\text { Serão relacionadas } \\
\text { com a necessidade de } \\
\text { cada trabalhador. }\end{array}$ \\
\hline
\end{tabular}

Fonte: Adaptação Própria

Assim, a proposta do modelo para o aumento da produtividade fundamentara-se na análise dos números quantificados por demissões e produtividade, resultado da identificação dos tipos de comprometimento na organização. Os mesmos podem ser influenciados através do uso de ferramentas e técnicas motivacionais conforme será verificado a seguir.

\section{PROPOSTA DA METODOLOGIA}

A proposta da metodologia visa o aumento da produtividade dos trabalhadores na empresa através das quatro fases conforme o fluxograma 1 que será detalhado a seguir.

Fluxograma 1: Fases da implantação da proposta de modelo

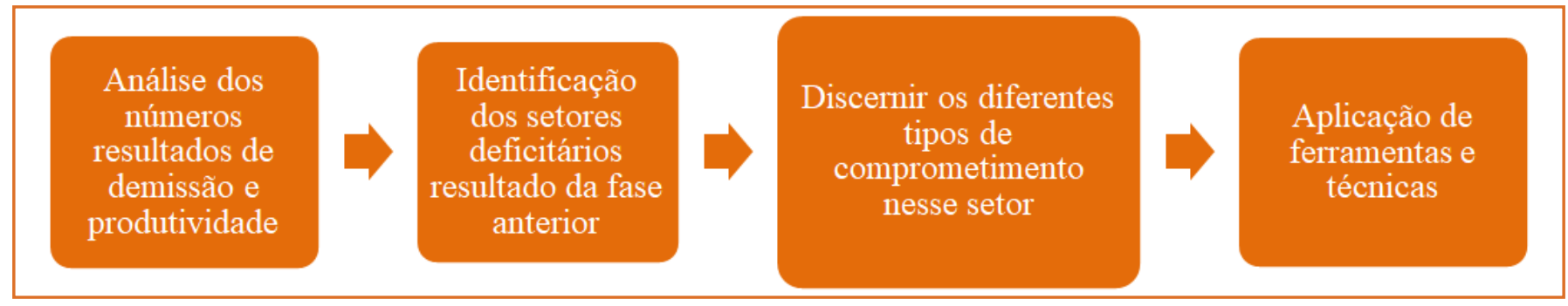


FASE 01: Análise dos números resultados de demissão e produtividade

Quantificar os números e resultados de demissão e baixa produtividade. Para a criação do indicador de demissão propõe-se a análise dos números de demissão a serem disponibilizados pelo $\mathrm{RH}$ - Recursos Humanos da empresa. O indicador de produtividade será elaborado através da fórmula proposta por Galeano e Wanderley (2013) nos diferentes setores da organização, conforme discussão no item 2.2 Produtividade do presente trabalho.

\section{FASE 02: Identificação dos setores deficitários resultado da fase anterior}

Enumerar os números da produtividade, será feita a identificação e separação dos possíveis setores com um baixo desempenho. Para a mesma, algumas ferramentas da qualidade, como Brainstorming, Diagrama de Ishikawa e Pareto serão utilizados. O gráfico de dispersão também será aplicado com os possíveis dados disponibilizados pelo $\mathrm{RH}$, visto que se procura uma possível relação, considerando os números de demissão e produtividade.

\section{FASE 03: Discernir os diferentes tipos de comprometimento}

Identificar os setores, inicia-se a busca pelos diferentes tipos de comprometimento. Para tal, será aplicado o questionário baseado em Meyer e Allen (1991) e Jaros (2007), anexado no apêndice. Os resultados obtidos estarão dispostos em tabela e gráficos para uma melhor visualização e compreensão dos dados. Para identificação dos tipos de comportamento, será utilizado algumas ferramentas da qualidade. Inicialmente o Diagrama de Pareto e a Curva ABC farão parte do projeto para priorização dos componentes deficitários. Concluída essa primeira etapa, o Diagrama de Ishikawa será empregado para que se possa atuar efetivamente na causa raiz desses componentes.

\section{FASE 04: Ferramentas e Técnicas}

Concretizado os setores e identificado o tipo de comprometimento nos mesmos, inicia-se a viabilidade da proposta. Para a ocorrência da mesma a utilização das ferramentas apresentadas logo abaixo, de acordo com os dados obtidos durante a fase 01 e a fase 02 .

A primeira ferramenta apresentada é o marketing interno que compreende o fortalecimento da marca diante do trabalhador. Dessa maneira, o próprio sentirá parte de um todo em que ele admira. Assim, aumenta-se a taxa dos fatores intrínsecos utilizados pela empresa, baseando-se na necessidade social apresentada por Maslow (1973).

Já a segunda medida seria a implantação do programa de pagamento contingente, pelo qual os trabalhadores são remunerados de acordo com o seu desempenho na organização. De acordo com Locke, Feren, Shaw e Denny (1980) espera-se um aumento de produtividade associada ao comportamento de aproximadamente $30 \%$ com o uso dessa proposta.

Para a finalização da proposta do modelo e com o objetivo de aumentar a parcela de funcionários no primeiro estágio da tríplice, as teorias motivacionais serão aplicadas. Visto que seus trabalhadores se tornem pessoas mais confiantes, comprometidas, estimuladas e que por consequência consigam atingir os objetivos da organização através do trabalho desenvolvido. Trabalhadores motivados atingem a autorrealização e a organização em troca demostra o respeito e valor do indivíduo (Azêdo e Alves, 2013).

\section{CONCLUSÃO}

Para a implantação da presente proposta, é importante salientar que a possibilidade de analisar a relação entre os fatores do comportamento humano, neste caso o comprometimento, e o desempenho dos trabalhadores. O estudo possibilita mapear os componentes de comprometimento deficitários através da utilização das teorias da motivação para tangenciar a produtividade.

A proposta poderá ser consolidada em todos os setores ou tamanhos organizacionais. Dessa maneira, busca-se apresentar referências para a relação entre produtividade e comportamento dos trabalhadores. 
Para a efetivação da presente metodologia, sugerese aos futuros trabalhos pesquisa sobre técnicas motivacionais associadas ao comprometimento com demais s demais fatores do comportamento humano, relacionando a produtividade e indicadores de desempenho.

\section{REFERÊNCIAS}

[1] BERRY, Leonard L.; PARASURAMAN, A. Serviços de Marketing: Competindo Através da Qualidade . São Paulo: Maltese-Norma, 1992.

[2] BONAVIDES, Renata de Oliveira Paiva; OLIVEIRA, José Arimatés de; MEDEIROS, Carlos Alberto Freire. Comprometimento Organizacional: Um Estudo de Consequentes do Comprometimento para os Trabalhadores. Enanpad, Salvador - Bahia, 2006.

[3] CARDOSO, Eng. Jose Claudio Macedo; VIEIRA JUNIOR, Prof.dr. Milton.Calculo de Produtividade Visando a Participação nos Lucros da Empresa. In: ENEGEP, XVII.1997, Gramado.

[4] CARNEGIE, Dale. O líder em você : como fazer amigos, influenciar pessoas e ter sucesso em um mundo em mutação. 8. ed. Rio de Janeiro: Record, 1999. 249 p. Tradução de: The leader in you: How to win friends, influence people, and succeed in a changing world.

[5] FOLHA DE SÃO PAULO.Pesquisa indica os 5 principais motivos de demissões no país. Folha de São Paulo: Empregos e Carreiras. São Paulo, 27 out. 2014. Disponível em: <http:// classificados.folha.uol.com.br/empregos/2014/10/1539066pesquisa-indica-os-5-principais-motivos-de-demissoes-nobrasil.shtml>. Acesso em: 03 mar. 2015.

[6] GALEANO, Edileuza Aparecida Vital; WANDERLEY, Lívio Andrade.Produtividade Industrial do Trabalho e Internsidade Tecnológica nas Regiões do Brasil: Uma análise Regional e Setorial para o Período 1996-2007. Planejamento e Políticas Públicas, v. 40, 2013

[7] HESKETH, José Luiz; COSTA, Maria T. P. M..Construção de um instrumento para medida de desempenho no trabalho. Administração de Empresa, Rio de Janeiro, v. 20, n. 3, p.5968, jul. 1980.

[8] INSTITUTO BRASILEIRO DE GEOGRAFIA E ESTATÍSTICA. CENSO 2010:Censo 2010: mulheres são mais instruídas que homens e ampliam nível de ocupação. Brasil, 2012.

[9] INKOTTE, Alexandre Luz. Endomarketing: Elementos para a construção de um marco teórico. 2000. Curso de Engenharia de Produção, Universidade Federal de Santa Catarina., Florianópolis, 2000.
[10] JAROS, Stephen. Meyer and Allen Model of Organizational Commitment: Measurement Issues. Thelcfai Journal of Organizational Behavior. Louisiana, p. 07-25. out. 2007.

[11] MASLOW, Abraham Harold.A Theory of Human Motivation. Psychological Review. Brooklyn College, p. 370396. jul. 1943.

[12] MASLOW, Abraham Harold.The farther reaches of human nature. New York: Viking Press, 1971. 401 p.

[13] MATOS, MARIA AMÉLIA (Campinas). Departamento de Psicologia - Usp. O Behaviorismo Metodológico e suas relações com o Mentalismo e o Behaviorismo Radical. 1993. Palestra apresentada no II Encontro Brasileiro de Psicoterapia e Medicina Comportamental, Campinas, out/93. Versão revisada encontra-se publicada em: Bernard Rangé (org) Psicoterapia comportamental e cognitiva: pesquisa, prática, aplicações e problemas. Disponível em: <www. itcrcampinas.com. br/txt/behaviorismometodologico.pdf $>$. Acesso em: 05 mar. 2015

[14] MEYER, John P.; ALLEN, Natalie J..A three-component conceptualization of organizational commitment. Human Resource Management Review, Ontario v. 1, n. 1, p.61-89, 1991.

[15] MOTOVANI, Fernando. Diretor de Operações da Robert Half. Pesquisa indica os 5 principais motivos de demissões no país. São Paulo: Folha de São Paulo, 2014.

[16] PEDRO, Andreia Maria.Características comportamentais dos empreendedoresa no modelo de ciclo de vida das organizações de greiner. 2013. 107 f. Dissertação (Mestrado) - Curso de Engenharia de Produção, Universidade Federal de Santa Catarina, Florianopólis, 2003.

[17] ROBBINS, Stephen P.; JUDGE, Timothy A.; SOBRAL, Filipe. Comprometimento Organizacional. 14. ed. São Paulo: Pearson, 2014.

[18] SALM, Claudio; SABOIA, João; CARVALHO, Paulo Gonzaga M de.Produtividade na Indústria Brasileira: Questões Metodológicas e Novas Evidências Empíricas. Pesquisa Planejamento Economico, Rio de Janeiro, v. 27, n. 2, p.377-396, ago. 1997.

[19] STRAPASSON, Bruno Angelo.A caracterização de John B. Watson como behaviorista metodológico na literatura brasileira: possíveis fontes de controle.Estudos de Psicologia, Natal, v. 17, n. 01, p.83-90, jan. 2012. Trimestral.

[20] VALENTIM, O. Há vagas. In: Recursos humanos - foco na modernidade. Rio de Janeiro: Qualitymark, 1992. p. 183185. 


\begin{tabular}{|c|}
\hline $\begin{array}{c}\text { Questionário à ser Aplicado nas Organizações (Baseado no estudo em Allen e } \\
\text { Meyer (1990) com Revisão de Jaros (2007) }\end{array}$ \\
\hline Escala dos Itens de Comprometimento \\
\hline Escala dos Itens de Comprometimento Afetivo
\end{tabular}

i. Eu sou muito feliz em fazer parte desta organização.

0 Concordo Totalmente 0 concordo 0 não concordo nem discordo 0 discordo 0 Discordo Totalmente

ii. Eu gosto de discutir sobre a minha empresa com pessoas que não trabalham comigo.

0 Concordo Totalmente 0 concordo 0 não concordo nem discordo 0 discordo 0 Discordo Totalmente

iii. Eu realmente sinto que esta organização também é um problema meu.

0 Concordo Totalmente 0 concordo 0 não concordo nem discordo 0 discordo 0 Discordo Totalmente

iv. Eu acredito que eu poderia me apegar a outra organização da mesma maneira que eu estou apegado com essa empresa.

0 Concordo Totalmente 0 concordo 0 não concordo nem discordo 0 discordo 0 Discordo Totalmente

v. Eu não sinto como parte da familia nesta organização.

0 Concordo Totalmente 0 concordo 0 não concordo nem discordo 0 discordo 0 Discordo Totalmente

vi. Eu não me sinto emocionalmente ligado nesta organização

0 Concordo Totalmente 0 concordo 0 não concordo nem discordo 0 discordo 0 Discordo Totalmente

vii. Esta empresa tem um grande significado para mim.

0 Concordo Totalmente 0 concordo 0 não concordo nem discordo 0 discordo 0 Discordo Totalmente

viii. Eu não sinto um forte senso de pertencer à minha organização.

0 Concordo Totalmente 0 concordo 0 não concordo nem discordo 0 discordo 0 Discordo Totalmente 


\section{Questionário à ser Aplicado nas Organizações (Baseado no estudo em Allen e Meyer (1990) com Revisão de Jaros (2007) \\ Escala dos Itens de Comprometimento Instrumental}

i. Eu não tenho medo do que aconteceria comigo caso eu perdesse meu atual emprego, sem ter algum outro trabalho planejado.

0 Concordo Totalmente $\mathrm{O}$ concordo 0 não concordo nem discordo $\mathrm{O}$ discordo $\mathrm{O}$ Discordo Totalmente

ii. Seria muito dificil para eu sair dessa empresa agora, mesmo que essa fosse a minha vontade.

0 Concordo Totalmente 0 concordo 0 não concordo nem discordo 0 discordo 0 Discordo Totalmente

iii. Muitos planos em minha vida seriam interrompidos se eu deixasse a organização agora.

O Concordo Totalmente 0 concordo 0 não concordo nem discordo 0 discordo 0 Discordo Totalmente

iv. Eu não perderia nada caso eu deixasse a empresa agora.

0 Concordo Totalmente $\mathrm{O}$ concordo $\mathrm{O}$ não concordo nem discordo $\mathrm{O}$ discordo $\mathrm{O}$ Discordo Totalmente

v. Nesse momento, ficar na organização é mais uma questão de necessidade do que vontade.

O Concordo Totalmente 0 concordo 0 não concordo nem discordo 0 discordo 0 Discordo Totalmente

vi. Eu sinto que tenho pouquíssimas opção quando considero a hipótese de deixar a organização

O Concordo Totalmente 0 concordo 0 não concordo nem discordo 0 discordo 0 Discordo Totalmente

vii. Uma das grandes consequências em deixar essa organização seria a escassez de oportunidades para se encontrar outra vaga de emprego.

0 Concordo Totalmente $\mathrm{O}$ concordo $\mathrm{O}$ não concordo nem discordo $\mathrm{O}$ discordo $\mathrm{O}$ Discordo Totalmente

viii. Uma das maiores razões para eu continuar a trabalhar nessa empresa, é que essa decisão requer um considerável sacrificio pessoal, onde talvez a outra organização pode não ter todos os beneficios que eu tenho aqui.

0 Concordo Totalmente 0 concordo 0 não concordo nem discordo 0 discordo 0 Discordo Totalmente 


\begin{tabular}{|c|}
\hline $\begin{array}{c}\text { Questionário à ser Aplicado nas Organizações (Baseado no estudo em Allen e } \\
\text { Meyer (1990) com Revisão de Jaros (2007) }\end{array}$ \\
\hline Escala dos Itens de Comprometimento \\
\hline
\end{tabular}

\section{Escala dos Itens de Comprometimento Normativo}

i. Eu penso que atualmente, as pessoas têm trocado de empresa com muita frequência.

0 Concordo Totalmente 0 concordo 0 não concordo nem discordo 0 discordo 0 Discordo Totalmente

ii. Eu acredito que uma pessoa não precisa ser sempre leal à sua empresa.

0 Concordo Totalmente 0 concordo 0 não concordo nem discordo 0 discordo 0 Discordo Totalmente

iii. Trocar sempre de uma empresa para outra não soa algo antiético.

0 Concordo Totalmente 0 concordo 0 não concordo nem discordo 0 discordo 0 Discordo Totalmente

iv. Uma das razões das quais eu continuo nesta organização é que eu acredito que lealdade é importante e, portanto, um senso de obrigação permanece.

0 Concordo Totalmente $\mathrm{O}$ concordo 0 não concordo nem discordo 0 discordo 0 Discordo Totalmente

v. Se eu receber uma oferta de trabalho melhor em outro lugar eu não sentiria que é correto deixar a minha empresa.

0 Concordo Totalmente 0 concordo 0 não concordo nem discordo 0 discordo 0 Discordo Totalmente

vi. Eu fui ensinado que acreditar nos valores das empresas significam lealdade para a organização.

O Concordo Totalmente $\mathrm{O}$ concordo $\mathrm{O}$ não concordo nem discordo $\mathrm{O}$ discordo $\mathrm{O}$ Discordo Totalmente

vii. Algumas coisas são melhores atualmente quando as pessoas permanecem em uma organização para uma carreira melhor.

O Concordo Totalmente 0 concordo 0 não concordo nem discordo 0 discordo 0 Discordo Totalmente 


\section{CAPÍTULO 11}

\section{MENSURANDO OS ÍNDICES DE CONCENTRAÇÃO: A INDÚSTRIA DO ESTADO DO ESPÍRITO SANTO SOB ANÁLISE}

Fabrício Alves de Almeida

Antônio Suerlilton Barbosa da Silva

Resumo: Este artigo tem como objetivo principal mensurar o nível de concentração industrial da indústria de transformação do Estado do Espírito Santo, para o período 2002-2012, fazendo uso dos índices de concentração (Razão de Concentração, Hirchsman-Herfindahl e o Coeficiente de Entropia de Theil). A principal fonte de dados utilizada nesta pesquisa foi a Relação Anual de Informações Sociais (RAIS), do Ministério do Trabalho e Emprego (MTE), que informa anualmente por meio do Cadastro Geral de Empregados e Desempregados (CAGED) o número de vínculos empregatícios (variável utilizada na mensuração dos índices de concentração) por setor da atividade econômica. Os resultados mostraram uma razoável concentração no setor estudado, com uma reversão dessa concentração no final do período analisado. 


\section{INTRODUÇÃO}

A noção de estrutura de mercado desempenha um papel fundamental dentro do paradigma da estruturaconduta-desempenho (BOFF; RESENDE, 2002). Ainda, a quantificação do componente estrutural, em termos de medidas sintéticas, encontra ampla utilização em Economia Industrial. Mas, de acordo com os autores citados anteriormente, as aplicações empíricas frequentemente se amparam em medidas de concentração deficientes, o que vem servindo de motivação para apresentações comparativas das principais medidas empregadas em estudos na área. Os resultados dessas motivações fizeram surgir, nos últimos anos, uma vasta gama de estudos que abordam diferentes linhas metodológicas com ênfase na concentração industrial, mas, encontrando resultados com elevado grau de divergência (CROCCO et al., 2003; CASSIOLATO; LASTRES, 2003; FEIJÓ et al., 2003; KRUGMAN, 1991; HOLMES; STEVENS, 2002; LAFOURCADE; MION, 2007).

No processo de migração regional de indústrias observam-se novas aglomerações industriais surgindo em regiões periféricas, induzindo a realização de pesquisas sobre concentração industrial, assim, contribuindo para que esses estudos ganhem mais espaço no debate acadêmico e nos órgãos de promoção do desenvolvimento local, regional e nacional, como também em instituições de apoio às micro e pequenas empresas. Esse processo, por seu efeito, chama a atenção dos órgãos de apoio à pesquisa para a valorização e, consequentemente, patrocínio ao desenvolvimento de investigações cujo objetivo é a verificação e explicação sobre o fenômeno da concentração industrial.

A concentração industrial ocorre de maneira sistemática e envolve toda a economia contemporânea. Ela é um processo que incide no crescimento do poder de mercado sobre as atividades econômicas, exercido por empresas de grande porte. A concentração industrial é a responsável pela acumulação de riqueza, renda e produção (BRAGA, MASCOLO, 1982).

Porém, existem aspectos positivos, a priori, decorrentes dessa concentração. Exemplo disso é: "a existência de alta concentração em um mercado não implicar, necessariamente, em existência de práticas oligopolistas, dado que as empresas líderes, além da obtenção de economias de escala podem ser levadas a buscar inovações tecnológicas e a se modernizar" (LEITE, 1998, p. 2).

As aplicações empíricas da concentração se suportam em medidas de concentração. Essas medidas têm o objetivo de captar de que forma agentes econômicos evidenciam um "comportamento dominante" em determinado mercado, e nesse sentido os diferentes indicadores consideram as participações no mercado dos agentes, por exemplo, por meio do número de empregados de cada empresa no total dos vínculos empregatícios do setor, de acordo com diferentes critérios de ponderação. Medidas de concentração industrial são úteis para indicar, preliminarmente, os setores para os quais se espera que o "poder de mercado" seja significativo (BOFF; RESENDE, 2002).

Analisar o nível de concentração da indústria de transformação capixaba, para o período 2002-2012, é o principal objetivo deste estudo. Conhecer a estrutura de mercado de um determinado local (país, estado ou região) é útil, dentre outros, para o estabelecimento de estratégias e políticas de preços por parte das firmas.

A principal fonte de dados utilizada nesta pesquisa foi o Relatório Anual de Informações Sociais (RAIS), do Ministério do Trabalho e Emprego (MTE), que informa anualmente por meio do Cadastro Geral de Empregados e Desempregados (CAGED) o número de vínculos empregatícios (variável utilizada na mensuração dos índices de concentração) por setor da atividade econômica.

\section{REVISÃO DA LITERATURA}

Os estudos sobre estruturas de mercado sugerem a ponderação da concentração nos diferentes mercados (LEITE, 1998). Ao se comparar os mercados e suas características, Varian (2012) aponta quatro distinções básicas de estruturas de mercados, que são: concorrência perfeita, monopólio, concorrência monopolista e oligopólio.

Um mercado oligopolista apresenta uma pequena parcela de firmas concorrendo uma com as outras 
ou uma grande quantidade de firmas em que apenas algumas delas lideram o mercado (MELO; TAVARES, 2009). Além de outras características, esse tipo de estrutura de mercado apresenta barreiras que bloqueiam ou atrapalham a entrada de novos concorrentes. A existência dessas barreiras é constituída, principalmente, pela diferenciação de produtos, custos de mudança, necessidade de capital acessibilidade e economia de escala (PORTER, 1986).

Conhecer a estrutura de mercado de um determinado local é variável importante para o estabelecimento de estratégias e políticas de preços por parte das firmas. Para Mason (1939), esse conjunto de estratégias é definido como a conduta da empresa, sendo caracterizado em virtude do modelo de estruturaconduta-desempenho (ECD).

O objetivo do modelo de ECD é o de comparar o resultado de um determinado mercado "imperfeito" com o resultado esperado de um mercado operando em concorrência perfeita e verificar em que magnitude tais imperfeições afetam a demanda por bens e serviços

Segundo Melo e Tavares (2009), a competição em uma estrutura de mercado, como o oligopólio, é intensa, sendo propícia ao surgimento de certas aquisições e fusões de firmas, o que caracteriza um aumento da concentração. Contudo, a concentração, diante da descrição de estruturas de mercado, torna-se um indicador vital para se classificar mercados, sejam monopólios, concorrenciais ou oligopólios (SILVA, 1998).

A concentração industrial ocorre de maneira sistemática e envolve toda a economia contemporânea, focando o poder em poucos, ou até mesmo em apenas um agente econômico (PINHO; VASCONCELOS, 1996). A concentração industrial é um processo que incide no crescimento do poder de mercado exercido por empresas de grande porte sobre as atividades econômicas, sendo ela responsável pela acumulação de valores como renda e produção (BRAGA, MASCOLO, 1982).

A concentração da produção está ligada à quantidade e ao porte das empresas que ofertam certo produto em que sua distribuição influencia de forma direta o comportamento de suas rivais (GEORGE; JOLL, 1983). Complementando, Sousa (2005) afirma que o processo de concentração é dependente do crescimento da eficiência técnica e da minimização dos custos, formando complexos produtivos que apresentam grande competência e que, consequentemente, podem (sobre certas circunstâncias) prejudicar a concorrência.

Os níveis de concentração envolvem toda uma estrutura de produção, destacando-se dentro delas os fatores tecnológicos avaliados de acordo com seu porte e sua estabilidade no poder de mercado. O aumento desses níveis de concentração pode levar, segundo Varian (2012), a geração de monopólios. Um determinado setor com grandes níveis de concentração e com uma quantidade minimizada de grandes firmas, prejudica diretamente a competição, dando-lhes o poder de determinar preços, quantidade de produtos e acordos favoráveis a elas (KON, 1999).

Para Silva (1998), a concentração pode ser estática ou dinâmica. No caso da primeira, há a referência a algum ponto específico no tempo e, no segundo caso, a percepção de ondulações durante momentos específicos. Nesta, também, pode-se analisar a competição em um segmento, relacionando a quantidade de firmas envolvidas no processo de concentração, os reflexos devidos à definição de quantidades e preços e a diferença de porte das empresas, ou seja, na sua capacidade de inovação e imposição de barreiras.

Boff e Resende (2002) afirmam que os índices de concentração são utilizados para demonstrar de maneira sintética um indicador de concorrência de um mercado específico, em que quanto maior a concentração menor é o grau da concorrência.

Mensurar a concentração fornece os elementos empíricos que se precisa para avaliar a situação de competição de um determinado mercado, o que favorece a identificação, inclusive, do grau de concentração de um mercado (KON, 1999). 


\section{MATERIAIS E MÉTODOS}

Nesta pesquisa, o "campo de análise" é constituído pela totalidade de empresas da indústria de transformação do estado do Espírito Santos.

Para Resende (1994) existem duas categorias de indicadores de concentração, a saber: parciais ou sumárias, positivas ou normativas, em que cada uma delas está atrelada a um ou mais índices. Na primeira categoria ("parciais"), - em que se encontra o índice "Razão de Concentração" - verifica-se a utilização de apenas parte do mercado, usualmente apenas das maiores do segmento em análise. Para a mensuração deste índice basta utilizar algumas informações do setor (não sendo necessário, por exemplo, o número total de firmas). Já na segunda categoria ("sumária") existe a necessidade de se utilizar informações de todas as firmas do setor que se quer fazer a verificação. Exemplos desses índices são "Hirschman-Herfindahl" $(\mathrm{HHI})$ e o "Coeficiente de Entropia de Theil" (ET).

As medidas positivas não dependem de parâmetros, sejam eles relacionados aos produtores ou consumidores, mas em função da estrutura do mercado. Medidas positivas representam de maneira mais abrangente os aspectos estatísticos encontrados no nível de concentração. Entretanto, não se adequam de maneira absoluta em uma análise econômica do desempenho industrial.

As medidas de concentração normativas consideram os parâmetros comportamentais (referentes às preferências dos consumidores e da firma) e também a estrutura da indústria. Estas, por sua vez, buscam examinar "normativamente" o desempenho da indústria, seja de uma perspectiva da firma ou do consumidor.

Esta proposta de pesquisa tratará, unicamente, das medidas positivas, nas quais a utilização de seus indicadores demonstra, de maneira sintética, o poder de mercado, possibilitando-se, assim, a análise da concentração do setor em estudo.

O índice de Razão de Concentração é utilizado para determinar a participação de grandes empresas no mercado. O resultado varia de 0 (zero) a 1 (um), em que "0" encontra-se uma situação de concorrência perfeita; e "1" indica uma condição de concentração intensa. Para o cálculo deste índice, considera-se o total da participação de mercado das maiores empresas participantes. Este índice é representado da seguinte forma:

$$
C R k=\sum_{i=1}^{k} P i
$$

Em que:

$\mathrm{k}=$ Representa a quantidade de grandes empresas do mercado.

$\mathrm{Pi}=$ Representa a participação da empresa de ordem i no mercado

Sabendo-se que a variação do resultado do índice CRk é de "0" a "1", é necessário ponderar-se o resultado dentro dessa escala. Braga e Mascolo (1982) fornecem dados para melhor análise do índice. Esses dados são apresentados no Quadro 1, colocado abaixo:

Quadro 1 - Padrões do grau de concentração pelo índice CRk

\begin{tabular}{c|c|c|}
$\begin{array}{c}\text { Parcela de mercado } \\
\text { das } 4 \text { maiores } \\
\text { empresas } \\
\text { CRk4 }\end{array}$ & $\begin{array}{c}\text { Parcela de mercado } \\
\text { das } 8 \text { maiores } \\
\text { empresas } \\
\text { CRk8 }\end{array}$ & $\begin{array}{c}\text { Grau de } \\
\text { Concentração }\end{array}$ \\
\hline $75 \%$ ou mais & $90 \%$ ou mais & Muito Alto \\
\hline $65 \%-75 \%$ & $85 \%-90 \%$ & Alto \\
\hline $50 \%-65 \%$ & $70 \%-85 \%$ & $\begin{array}{c}\text { Moderadamente } \\
\text { Alto }\end{array}$ \\
\hline $35 \%-50 \%$ & $45 \%-70 \%$ & $\begin{array}{c}\text { Moderadamente } \\
\text { Baixo }\end{array}$ \\
\hline $35 \%$ ou menos & $45 \%$ ou menos & Baixo \\
\hline
\end{tabular}

Fonte: Adaptado de Braga e Mascolo (1982).

O índice Razão de Concentração proporciona uma conexão da concentração técnica do setor estudado com seu nível de faturamento ou participação de um mercado específico. Por outro lado, este índice apresenta alguns pontos negativos, a saber: ele considera as $\mathrm{k}$ maiores firmas, as mesmas podem variar durante o período analisado, assim impossibilitando o índice CRk de demonstrar o nível de concentração relativa entre as empresas; ele também desconsidera o tamanho de cada empresa envolvida no cálculo. 
Como se pode ter grandes diferenças de porte entre elas, este fato pode gerar problemas à análise. Tal problema também é indagado por Kon (1999), que afirma que para minimizar o efeito deste problema, são considerados apenas os valores agregados, não ilustrando o tamanho das empresas.

Por outro lado, o Índice de Hirchsman-Herfindahl $(\mathrm{HHI})$ refere-se à soma dos quadrados da participação de uma firma no mercado. Essa participação pode ser analisada por meio de qualquer variável que possa representar a mesma. Tem-se, assim:

Em que:

$$
H H I=\sum_{i=1}^{k}(P i)^{2}
$$

$\mathrm{k}=$ Representa a quantidade de empresas no mercado.

$\mathrm{Pi}=$ Representa a participação da empresa de ordem i no mercado.

A expressão reverencia de forma implícita os pesos desse indicador ao submeter cada parcela da empresa ao quadrado, ela atribui maior grau de concentração às maiores firmas. Consequentemente, quanto mais elevado for o valor de HHI, maior será seu nível de concentração e menor será a concorrência (BOFF; RESENDE, 2002).

Os resultados da execução do índice $\mathrm{HHI}$ tem variação entre " $1 / n$ " e " 1 ", em que o valor mínimo de " $1 / n$ " pode chegar a zero (0) em caso de concorrência perfeita com uma enorme quantidade de empresas participantes no mercado. Em contrapartida, o valor máximo apresentado pelo índice é associado a uma situação monopolística, no qual uma única firma retém toda participação do mercado, indicando, assim, o limite superior do índice HHI, chegando-se ao valor de "1". Assim, o índice de Hirchsman-Herfindahl apresenta variação de $1 / n \leq H H I \leq 1$. Resende (1994) fornece as informações necessárias para melhor interpretação dos resultados do índice, ilustradas no Quadro 2:
Quadro 2 - Padrões do grau de concentração pelo índice $\mathrm{HHI}$

\begin{tabular}{|l|l|}
\hline HHI & Justificativa \\
\hline Inferior a 0,1 & Indústria pouco concentrada \\
\hline Entre 0,1 e 0,18 & $\begin{array}{l}\text { Indústria com concentração } \\
\text { moderada }\end{array}$ \\
\hline Superior a 0,18 & Indústria muito concentrada \\
\hline
\end{tabular}

Fonte: Resende (1994).

O índice HHI sobrepõe-se ao índice CRk por sua análise considerar o total das empresas e não apenas as maiores, dando, assim, maior confiabilidade aos resultados alcançados.

Por fim, o coeficiente de Entropia de Theil (ET) pode ser aplicado em Economia Industrial (RESENDE; 1994). Nele, deve-se considerar em seu cálculo todas as empresas do mercado, levando-se em consideração o valor do market-share de cada firma (GEORGE; JOLL, 1983). Assim, quanto menor o valor do índice, maior será sua concentração. Tem-se, formalmente:

$$
E T=\sum_{i=1}^{k}\left[\mathrm{Pi} \cdot \ln \left(\frac{1}{\mathrm{Pi}}\right)\right]
$$

Em que:

$\mathrm{k}=$ Representa a quantidade de empresas no mercado. $\mathrm{Pi}=$ Representa a participação da empresa de ordem i no mercado.

Essa medida é empregada para definir o grau de incerteza de um mercado, em que um grande número de empresas concorrentes leva a uma maior incerteza de se manter um cliente, desconcentrando-o e elevando o valor de ET.

Tal coeficiente corresponde ao contrário da Razão de Concentração (CRk), sendo que seu valor diminui à medida que o grau de concentração das firmas aumenta. Logo, um resultado de valor ET = 0 indica a concentração máxima do mercado, caracterizando-se uma situação monopolística.

Para um melhor comparativo desse índice com os demais já apresentados - CRk e HHI -, Resende (1994) afirma que o coeficiente (ET) pode ser ajustado fixando-se sua amplitude de variação e tornando-s e sua medida como as demais, variando seu valor de 
zero a um. Esta "transformação" (também índice) é chamada de Entropia Relativa:

$$
E R=\left[\frac{1}{\ln (\mathrm{k})}\right] \mathrm{ET}
$$

Em que a medida ER varia de 0 (zero) a 1, tornando seu resultado adequado para uma análise intertemporal com os demais índices.

Resende (1994) assegura que os indicadores $\mathrm{HHI}$ e ET são superiores, quando comparados ao de Razão de Concentração e afirma, também, que os índices de Razão e o HHI não são proporcionais, consequentemente substituem-se um ao outro.

Resende (1994) e George e Joll (1983) chamam a atenção para verificação de algumas características a serem verificadas nos índices de concentração, antes de sua aplicação, a saber:

- Devem apresentar apenas uma dimensão, de modo que seus valores superiores indiquem a empresa mais concentrada e seu valor inferior a menos concentrada;

- Independer da variável estudada, sendo função das parcelas de mercado de todas as empresas;

- Devem se alterar sob qualquer mudança no market-share de modo a afetar a magnitude do indicador;
- Devem atender ao critério de que a divisão de cada uma das firmas em duas, de tamanhos simétricos, reduziria o índice pela metade, favorecendo-se à cardinalidade do indexador de concentração;

- Uma vez tendo-se o market-share idêntico, o grau de concentração deve decrescer à medida que aumenta o número de empresas no mercado;

- Os indicadores devem apresentar variação de resultado entre 0 e 1, facilitando-se, assim, a avaliação e análise dos resultados.

É verídico se ressaltar que o único índice que se encontra dentro dos critérios de avaliação formulados por Resende (1994) é o HHI. Porém, neste estudo, optou-se por também aplicar os demais indicadores.

Para George, Joll e Lynk (1995) nenhum índice será sempre ideal, seja qual for a situação, pois, a utilização de todos eles possibilita uma melhor utilização dos dados e, consequentemente, resultados mais satisfatórios.

\section{RESULTADOS}

A Tabela 1 mostra o número de vínculos empregatícios em cada um dos subsetores da indústria de transformação do Espírito Santo, no período 20022012:

Tabela 1 - Número de vínculo empregatício da indústria de transformação do Espírito Santo - por subsetor - (2002 - 2012)

\begin{tabular}{|cccccccccccc|}
\hline Item & $\mathbf{2 0 1 2}$ & $\mathbf{2 0 1 1}$ & $\mathbf{2 0 1 0}$ & $\mathbf{2 0 0 9}$ & $\mathbf{2 0 0 8}$ & $\mathbf{2 0 0 7}$ & $\mathbf{2 0 0 6}$ & $\mathbf{2 0 0 5}$ & $\mathbf{2 0 0 4}$ & $\mathbf{2 0 0 3}$ & $\mathbf{2 0 0 2}$ \\
\hline Prod. Mineral não Metálico & 24.387 & 23.717 & 22.614 & 21.112 & 20.580 & 20.913 & 20.145 & 18.266 & 16.264 & 14.508 & 14.137 \\
Indústria Metalúrgica & 16.714 & 16.282 & 15.639 & 15.882 & 17.205 & 13.728 & 13.609 & 11.639 & 10.497 & 9.380 & 9.096 \\
Indústria Mecânica & 9.035 & 8.792 & 9.053 & 7.676 & 7.268 & 7.135 & 7.373 & 5.490 & 4.649 & 4.260 & 2.916 \\
Elétrico e Comunic & 2.636 & 1.768 & 1.066 & 1.147 & 986 & 605 & 713 & 335 & 325 & 467 & 427 \\
Material de Transporte & 1.578 & 1.506 & 1.391 & 1.225 & 1.081 & 1.190 & 1.089 & 897 & 1.109 & 867 & 532 \\
Madeira e Mobiliário & 9.362 & 9.359 & 8.988 & 8.480 & 8.412 & 8.707 & 8.931 & 7.949 & 7.775 & 7.035 & 7.182 \\
Papel e Gráf & 5.069 & 4.978 & 5.372 & 5.483 & 5.612 & 5.246 & 4.818 & 4.277 & 4.109 & 3.950 & 4.105 \\
Borracha, Fumo, Couros & 2.722 & 2.326 & 2.289 & 1.908 & 2.035 & 1.769 & 1.694 & 1.560 & 1.488 & 1.088 & 1.102 \\
Indústria Quimica & 8.150 & 8.046 & 7.733 & 5.243 & 5.472 & 5.391 & 5.014 & 4.225 & 3.949 & 3.441 & 3.534 \\
Indústria Têxtil & 15.683 & 17.220 & 17.168 & 17.081 & 16.976 & 17.536 & 17.487 & 17.107 & 16.632 & 14.762 & 14.411 \\
Indústria Calçados & 2.077 & 1.931 & 1.419 & 1.267 & 1.128 & 1.286 & 1.262 & 1.388 & 1.623 & 1.354 & 1.377 \\
Alimentos e Bebidas & 26.547 & 25.724 & 24.670 & 27.383 & 23.606 & 22.065 & 21.230 & 18.694 & 16.263 & 14.607 & 14.267 \\
\hline
\end{tabular}

Fonte: MTE (2012) 
A partir das informações da Tabela 1 foi possível mensurar os índices de concentração propostos para esta análise. Os mesmos estão alocados na Tabela 2 (a seguir):

Tabela 2 - Evolução da concentração dos subsetores de transformação dado o número de empregados (2002-2012).

\begin{tabular}{lllllll|} 
Subsetores & $\mathbf{2 0 0 2}$ & $\mathbf{2 0 0 7}$ & $\mathbf{2 0 1 2}$ & $\mathbf{\Delta} \% \mathbf{2 0 0 2 / 2 0 0 7}$ & $\mathbf{\Delta \%} \mathbf{2 0 0 7 / 2 0 1 2}$ & $\mathbf{\Delta \%} \mathbf{2 0 0 2 / 2 0 1 2}$ \\
\hline CR2 & 0,3924 & 0,4071 & 0,4109 & 3,75 & 0,93 & 4,72 \\
CR4 & 0,7103 & 0,7032 & 0,6722 & $-0,99$ & $-4,41$ & $-5,35$ \\
CR8 & 0,953 & 0,9541 & 0,9273 & 0,12 & $-2,81$ & $-2,69$ \\
HHI & 0,1473 & 0,1445 & 0,1371 & $-1,93$ & $-5,07$ & $-6,9$ \\
eT & 2,0848 & 2,5060 & 2,7795 & 20,20 & 10,91 & 33,32 \\
\hline
\end{tabular}

Fonte: Elaborado pelo autor (2015)

O resultado da mensuração do Índice CR2, ilustrado na Tabela 2, mostra que o subsetor alimentos e bebidas foi o que mais empregou mão-de-obra no período 2002-2012, evidenciando um nível de concentração de 39,24\% (CR2 = 0,3924), indicando ascensão até o ano de 2007 (CR2 = 0,4071), de 3,75\%, e voltando a aumentar em 2012, CR2 =0,4109, indicando um aumento significativo de $4,72 \%$ na concentração durante o período analisado.

$\mathrm{Na}$ análise dos quatro maiores subsetores (Alimentos e bebidas; Mineral não metálicos; Indústria metalúrgica; Indústria têxtil), obteve-se um CR4 =0,7103. Ou seja, os quatros maiores subsetores dessa indústria concentraram $71,03 \%$ dos vínculos empregatícios, em 2002, com um sutil redução de 0,99\% até 2007 , e redução de $4,41 \%$, em 2012, totalizando, ao longo do período estudado, uma redução de 5,35\%, contrariando o comportamento do indicador CR2.

$\mathrm{Na}$ análise dos oito maiores subsetores (Alimentos e bebidas; Mineral não metálicos; Indústria metalúrgica; Indústria têxtil; Madeira e mobiliário; Indústria mecânica; Indústria química; Papel e gráfica) verificou-se um CR8 = 0,9530, evidenciando um nível de concentração, em 2002, de 95,30\%, o que reflete um comportamento diferente dos índices CR2 e CR4. Até o ano de 2007, o CR8 apresentou um leve aumento de 0,12\%, seguido de uma queda, até 2012 , de 2,81\%. O período 20022012 apresentou uma redução de 2,69\%, chegando a $92,73 \%$.
Pela mensuração do índice de Hirchsman-Herfindahl $(\mathrm{HHI})$, inferiu-se que a concentração dos subsetores apresentou uma queda de 1,93\%, entre 2002 e 2007, seguindo de uma nova redução de 5,07\%, entre 2007 e 2012. Analisando-se o período 2002-2012, o índice $\mathrm{HHI}$ mostrou uma redução da concentração de $6,9 \%$. O HHI confirmou o resultado dos indicadores CR2 e CR4, a saber, uma diminuição do grau de concentração dos principais subsetores, ilustrando, assim, a inexistência de um subsetor dominante na indústria de transformação do Estado do Espírito Santo, no período estudado.

O Coeficiente de Entropia de Theil (ET) confirma o resultado dos demais índices, mostrando que o nível de concentração caiu durante o período em análise, $2002(E T=2,0848)-2012(E T=2,7795)$.

Diante dos resultados apresentados percebe-se que, de maneira geral, os subsetores apresentaram um nível razoável de concentração que, de modo cíclico, tende a diminuir, como ilustrado nas tabelas 1 e 2 .

\section{CONCLUSÃO}

Este artigo teve como objetivo principal mensurar o nível de concentração da indústria de transformação do Estado do Espírito Santo, para o período 2002-2012, a partir dos índices de concentração evidenciados pela literatura econômica (Razão de Concentração, Hirchsman-Herfindahl e o Coeficiente de Entropia de Theil). A variável utilizada para o cálculo dos índices 
foi o número de empregados, extraído da Relação Anual de Informações Sociais (RAIS), do Ministério do Trabalho e Emprego (MTE).

Verificou-se que todos os subsetores da indústria de transformação do Estado do Espírito Santo apresentaram consideráveis níveis de concentração, independentemente do indicador utilizado. Embora seja observado um leve início de desconcentração, de maneira geral, cuja tendência só poderá ser confirmada analisando-se dados mais recentes e um período maior. O valor médio da concentração verificada nesses setores (para o caso do índice CR8) foi de 0,94.

\section{REFERÊNCIAS}

[1] BRAGA, H. C.; MASCOLO, J. L. Mensuração da concentração industrial no Brasil. Pesquisa e Planejamento Econômico. v. 12, n. 2, p. 399-354, ago 1982.

[2] BOFF, H.; RESENDE, M. Concentração Industrial. In: HASENCLEVER, Lia; KUPFER, David. (Org.). Economia industrial: fundamentos teóricos e práticas no Brasil. Rio de Janeiro: Campus, 2002. p. 73-90.

[3] CASsiolato, J. E.; LAStRES, H. M. M. O foco em arranjos produtivos e inovativos locais de micro e pequenas empresas. In: LASTRES, H. M. M. CASSIOLATO, J. E.; MACIEL, M. L. Pequena empresa: cooperação e desenvolvimento local. Rio de Janeiro: Relume Dumará: UFRJ, Instituto de Economia, 2003. p. 21-34.

[4] CROCCO, M.A.; GALINARI, R.; SANTOS, F.; LEMOS, M.B.; SIMÕES, R. Metodologia de identificação de arranjos produtivos locais potenciais: uma nota técnica. Texto para discussão no 191. Abril de 2003. Belo Horizonte-MG: CEDEPLAR/FACE/UFMG, 2003.

[5] FEIJO, C. ; CARVALHO, P. G. M.; RODRIGUEZ, M. S. Concentração industrial e produtividade do trabalho na indústria de transformação nos anos 90: evidências empíricas. Economia, Niterói (RJ), v. 4, n. 1, p. 19-52, jan./ jun. 2003.

[6] GEORGE, K.; JOLL C. Organização industrial: crescimento e mudança estrutural. Rio de Janeiro: Zahar, 1983.

[7] GEORGE, K. D.; JOLL, C.; LYNK, E. L. Industrial Organization: competition, growth and structural change. London: Routledge, 1995.
[8] HOLMES,T. J.; STEVENS, J. J. Geographic concentration and establishment scale. The Review of Economic and Statistic. v. 84, n.4, p. 682-690, nov.2002.

[9] KON, A. Economia Industrial. São Paulo: Nobel, 1999.

[10] KRUGMAN, P. Geography and Trade. M-I.T. Press, Cambridge, MA, 1991.

[11] LAFOURCADE, M.; MION, G. Concentration, agglomeration and the size of plants. Regional Science and Urban Economics. v. 37, n. 1, p. 46-68, 2007.

[12] LEITE, A. L. S. Concentração e desempenho competitivo no complexo industrial de papel e celulose. Universidade Federal de Santa Catarina. Programa de Pós-Graduação em Engenharia de Produção. Dissertação de Mestrado. 1998.

[13] MASON, E.S. Price and Production Policies of LargeScale Enterprise. The American Economic Review, v. 29, no. 1, Supplement, Papers and Proceedings of the Fifty-first Annual Meeting of the American Economic Association, p. 61-74, Mar., 1939.

[14] MELO, E. S.; TAVARES, J. M. Índices de concentração industrial em Minas Gerais: uma análise sectorial (20052007). Reuna. v. 14, n. 1, p. 11-27, 2009.

[15] MTE - Ministério do Trabalho e Emprego. Relatório Anual de Informações Sociais (RAIS). Brasília, 2012.

[16] PINHO, D. B.; VASCONCELOS, M. A. S. (orgs.). Manual de Economia. Equipe de Professores da USP. 2 ed. São Paulo: Saraiva, 1996.

[17] PORTER, M. E. Estratégia Competitiva. 7 ed. Rio de Janeiro: Campus, 1986.

[18] RESENDE, M. Medidas de Concentração Industrial: uma resenha. Revista Análise Econômica, Porto Alegre, v. 12, n. 21/22, p. 24-33, mar./set. 1994.

[19] SILVA, A. L. Concentração e desempenho competitivo no complexo industrial de papel e celulose entre 1987-1996. Florianópolis: UFSC, 1998.

[20] SOUSA, L. G. Economia Industrial. 2005. Disponível em: <http://www.eumed.net/libros/2005/lgs-ei> Acesso em: 17 mar. 2013.

[21] VARIAN, H. R. Microeconomia: princípios básicos. 8. ed. Rio de Janeiro: Elsevier, 2012. 


\title{
CAPÍTULO 12
}

\section{GESTÃO ESTRATÉGICA E ORGANIZACIONAL EM EMPRESAS COMERCIAIS DE MICRO, PEQUENO E MÉDIO PORTE DO MUNICÍPIO DE IRATI - PR}

\author{
Andréia Gura \\ Mauricio João Atamanczuk \\ Everaldo Veres Zahaikevitch \\ Antônio Cecílio Silvério \\ Flávio Fuhr
}

Resumo: $O$ presente estudo analisou o uso de ferramentas financeiras por parte das empresas comerciais de micro, pequeno e médio porte do município de Irati - PR. A pesquisa caracterizou-se como descritiva, de caráter quantitativo e quanto ao método de coleta das informações como levantamento ou survey. O universo da pesquisa foi constituído por 25 empresas, sendo a definição da amostra por acessibilidade. Como instrumento de coleta foi utilizado um questionário estruturado, com 22 questões relacionadas a administração financeira. É possível concluir no presente estudo que a grande maioria das empresas comerciais de Irati usa ferramentas financeiras em sua gestão e que seu uso é muito importante para prever a receita e as vendas, conhecer o poder de pagamento da empresa e ter melhor controle sobre os estoques. Somente duas empresas não usam ferramentas financeiras em sua administração. Um dos principais empecilhos encontrados na gestão financeira foi a centralização de atividades no proprietário.

Palavras Chave: ferramentas financeiras, administração financeira, empresas comerciais. 


\section{INTRODUÇÃO}

O cenário financeiro e econômico estão sempre em constantes mudanças, gerando incertezas e maior competitividade para as empresas. Diante da competição cada vez mais acirrada é importante ter profissionais preparados para administrar buscando meios de extrair informações que ajudem na tomada de decisão, como informações advindas da contabilidade e ferramentas que contribuam na gestão da empresa. Para Rodrigues (2013, p. 13) "as empresas precisam se municiar de instrumentos que thes deem maior segurança em suas operações, como forma de se prepararem para enfrentar a elevada concorrência".

A administração financeira é essencial para todas as empresas, sejam elas de micro, pequeno, médio e grande porte. Através do uso de ferramentas financeiras a empresa ganha importantes respaldos na formulação de estratégias de curto e longo prazo e melhores condições para previsões de venda e de receita, melhor gerenciamento do caixa, visão de novos investimentos e maior controle sobre toda a empresa.

A administração financeira adequada para o comércio varejista, objeto de estudo deste trabalho, é destacada em função da importante participação na economia e na geração de empregos no país. De acordo com Serviço Brasileiro de Apoio as Micro e Pequenas Empresas - SEBRAE (2012) as micro e pequenas empresas representavam 99\% dos estabelecimentos, $51,7 \%$ dos empregos privados não agrícolas formais no país e quase $40 \%$ da massa de salários. Ainda segundo Serviço Brasileiro de Apoio as Micro e Pequenas Empresas - SEBRAE (2012), de um total de 514.516 micros e pequenas empresas no Estado do Paraná, 257.511 são empresas comerciais, ou seja, $50 \%$ do total de empresas. As pequenas empresas comerciais empregavam 3.287.356 pessoas, enquanto as empresas comerciais de médio porte possuíam 921.735 empregados.

Considerando a importância das empresas comerciais e a necessidade das empresas obterem vantagens competitivas, o presente estudo pretende investigar o uso de ferramentas contábeis e de administração financeira em empresas comerciais de micro, pequeno e médio porte do município de Irati - PR, para tanto serão apresentado conceitos de micro, pequena e média empresa, abordagem de administração financeira em micro, pequenas e médias empresas e ferramentas financeiras que podem ser utilizadas pelas empresas.

\section{REVISÃO DE LITERATURA}

\subsection{ADMINISTRAÇÃO FINANCEIRA NAS MICROS, PEQUENAS E MÉDIAS EMPRESAS}

Com o passar do tempo a administração financeira, além de ter como objetivo o lucro para as empresas, incorporou outras funções como utiliza-la para se manter e sobressair diante da globalização e da concorrência. Para Assaf Neto, (2010, p. 8) "a administração financeira se tornou mais reveladora referente ao mercado em geral, fornecendo explicações mais lógicas e completas dos vários fenômenos financeiros, ampliando sobremaneira sua esfera de atuação e importância".

A conscientização dos administradores quanto a importância da administração financeira é necessária, assim como o envolvimento de todos os departamentos da empresa, somente com a mudança nos procedimentos, atitudes e com controles é possível incorporar uma administração que auxilie efetivamente na tomada de decisão e contribua para o melhor desenvolvimento da empresa.

A relevância da administração financeira é notória para as empresas de todos os tamanhos. A ideia de que somente grandes empresas tinham a necessidade de possuir uma administração financeira ficou no passado, hoje é de suma importância que micro, pequenas e médias empresas façam uso de ferramentas financeiras que possibilitem um melhor gerenciamento, mais lucro e por consequência consigam manter-se competitivas no mercado.

Apesar desta necessidade, observa-se que pequenas e médias empresas tem dificuldades de gerenciamento dos aspectos financeiros. Para Santos e Veiga (2011) as pequenas e médias empresas encerram suas atividades por falta de uma gestão adequada, falta ou dificuldade de obter crédito das instituições financeiras, problemas fiscais ou tributários, falta de preparo dos 
gestores. Muitos dos problemas estão vinculados aos aspectos financeiros. Ainda segundo os mesmos autores as pequenas e médias empresas têm como desafios a competitividade no ambiente global e a necessidade de acompanhar a harmonização contábil internacional.

Segundo Santos, Ferreira e Faria (2009) apesar deste cenário desfavorável quanto a gestão das pequenas empresas, práticas como elaboração de relatórios financeiros e capacitação dos gestores podem ser determinantes para a sobrevivência destas no dinâmico ambiente empresarial.

Uma administração financeira bem estruturada, buscando sempre o auxílio de ferramentas que forneçam informações valiosas que levem a decisões assertivas, pode resolver ou minimizar os problemas enfrentados pelas empresas de qualquer porte. $\mathrm{Na}$ sequência do trabalho apresenta-se as ferramentas financeiras que dão suporte para o administrador na tomada de decisões.

\subsection{BALANÇO PATRIMONIAL}

Conforme Santos e Veiga (2011, p. 26) "Balanço Patrimonial (BP) é um dos componentes das demonstrações contábeis das entidades e demonstra a situação patrimonial e financeira das organizações em determinada data".

O Balanço Patrimonial é composto pelo Ativo, no qual estão evidenciados basicamente os direitos da empresa, Passivo que demonstra as obrigações que empresa possui e patrimônio Líquido que consiste na diferença entre o ativo e passivo da empresa.

O Balanço patrimonial demonstra todas as operações da empresa que já aconteceram e as que ainda irão se realizar. Este demonstrativo pode ser muito útil na tomada de decisão dos gestores, pois representa qual é a situação financeira da empresa em um determinado momento. Bruni (2010) afirma que com a elaboração do Balanço Patrimonial é possível demonstrar a situação patrimonial e econômico-financeira da organização. balanço possibilita tomar decisões importantes quanto os recursos disponíveis e quanto as fontes de financiamento, o que é fundamental para a continuidade da empresa.

\subsection{Demonstração de Resultado do Exercício (DRE)}

A Demonstração do Resultado do Exercício (DRE) é fundamental para que seus usuários consigam visualizar de forma clara e precisa como o resultado de determinado período foi composto, auxiliando desta forma a uma melhor tomada de decisão. Santos e Veiga (2011) expõe que a análise mensal da DRE é uma importante ferramenta para a gestão. Fazendo uma análise vertical desta demonstração podese obter as variações quanto as vendas líquidas, e fazer ajustes, caso necessário. Já através da análise horizontal da DRE pode proporcionar a comparação no tempo, seja mensal, trimestral, semestral ou anual, do comportamento das receitas, custos despesas e demais itens que compõe a mesma, tendo como principal objetivo o lucro líquido, pois o mesmo é o principal foco das empresas comerciais, industriais e prestadoras de serviços, também sendo considerado como superávit para outras entidades, podendo o mesmo ser utilizado como medida de eficiência e êxito na concretização dos objetivos traçados.

\subsection{DEMONSTRAÇÃO DE FLUXO DE CAIXA. (DFC)}

Para Hoji (2001, p.79) "Fluxo de Caixa é um esquema que representa as entradas e saídas de caixa ao longo do tempo. Em um Fluxo de caixa, deve existir pelo menos uma saída e pelo menos uma entrada (ou viceversa)".

O planejamento específico do uso dos recursos financeiros da empresa pode ser feito através do fluxo de caixa organizacional. Segundo Gonçalves (2007, p.97) "O controle de caixa da empresa é de vital importância já que por meio dos registros realizados pode-se conhecer a origem e a quantidade de dinheiro que é movimentada diariamente na empresa". Trata-se de uma fonte segura de informação para elaboração de planejamento estratégico financeiro das organizações. Santos e Carneiro (2009, p.13) pontuam que "através do conhecimento da movimentação de caixa poderá se fazer uma eficiente análise financeira da empresa, 
quanto à capacidade de gerar caixa, pagar dívidas, fazer investimento, etc."

\subsection{CUSTO-VOLUME-LUCRO}

Uma vez que em todas as empresas existe uma grande preocupação nas variações das relações do custo-volume-lucro, a contabilidade junto com seus profissionais contribui diretamente com os gestores para melhor tomada de decisão. Conforme relata ludícibus (2010) uma das maiores e mais antigas apreensões dos gerenteséverificar os reflexos, no lucro, da variação de volume e de custos fixos e variáveis. A contabilidade em si têm fornecido respostas simples quanto despretensiosas a tais perguntas, pois os contadores estão cientes das limitações de se supor a linearidade das funções custo e receita, em certas circunstâncias. Entretanto, têm experiência suficiente para saber qual o intervalo de variação de volume em que a linearização é, se não ideal, pelo menos aceitável em termos de praticabilidade, tempo e custo.

Neste sentido se pode perceber que o conhecimento profundo das relações custo/volume/lucro é uma das ferramentas mais poderosas da contabilidade gerencial, a serviço da administração, para as melhores e mais corretas tomadas de decisões.

Dentro da análise da relação custo/volume/lucro dois aspectos são evidenciados: margem de contribuição e ponto de equilíbrio.

\subsubsection{MARGEM DE CONTRIBUIÇÃO}

A margem de contribuição é uma importante ferramenta de gestão, pois ela permite verificar se o produto está ou não gerando lucro e quanto cada unidade vendida contribuiu na receita total auferida pela empresa. Para Crepaldi (2011, p. 128) "a margem de contribuição é a diferença entre o preço de venda e a soma dos custos e despesas variáveis".

Rodrigues (2013) ressalta que os gestores de todas as empresas deveriam conhecer a margem de contribuição, devido a sua importância de gerar informações como, por exemplo, o valor que deve ser disponibilizado para cobrir os custos fixos após deduzidos os custos variáveis, e qual o lucro almejado para cada produto.

\subsubsection{PONTO DE EQUILÍBRIO}

O ponto de equilíbrio é o ponto em que a empresa consegue cobrir os custos fixos totais, a partir deste ponto a empresa passa a ter lucro. Santos (2011, p.37) esclarece que "o ponto de equilíbrio será obtido quando o total dos lucros marginais, de todos os produtos comercializados, equivalerem ao custo estrutural fixo do mesmo período de tempo objeto da análise".

Para Crepaldi (2011, p. 133) "o ponto de equilíbrio é obtido quando a soma das margens de contribuição totalizar o montante suficiente para cobrir todos os custos e despesas fixos".

Santos (2011) lista algumas questões que são respondidas através do ponto de equilíbrio, como a quantidade necessária de um produto que deve ser vendida para obter um determinado lucro; o que pode ocorrer com o lucro se o preço do produto aumentar ou diminuir; o que pode ocorrer com o ponto de equilíbrio se a matéria prima tiver um determinado aumento $e$ esse aumento não puder ser repassado ao produto; o desempenho de cada unidade vendida através da análise do lucro marginal; planejamento e controle de vendas e de resultados.

\subsection{FORMAÇÃO DO PREÇO DE VENDA}

Para a definição do preço de venda, vários aspectos devem ser levados em conta. Não adotar nenhum critério para formar o preço de venda pode levar a empresa a diminuir suas vendas e consequentemente perder espaço no mercado e ir á falência. Crepaldi (2011) evidencia que se o preço estabelecido for muito elevado pode-se perder mercado, porém se for muito baixo poderá comprometer o negócio.

Para Crepaldi (2011) o fator mais importante para a estruturação do preço de venda são os objetivos que a empresa deseja alcançar, desta forma preços mais competitivos podem ser estabelecidos se a empresa quiser obter um retorno a longo prazo. 
A adoção de ferramentas para formar o preço de venda deve sempre levar em consideração o consumidor, os concorrentes e os custos, dependendo do ramo de atividade em que a empresa atua.

\subsection{ORÇAMENTO EMPRESARIAL}

Para conseguir definir e alcançar seus objetivos e metas as empresas necessitam de ferramentas que possibilitem visualizar as ações que devem ser tomadas, e uma importante ferramenta que cumpre este papel é o orçamento. Almeida (2007, p. 40) "o orçamento empresarial é a expressão do ato ou efeito de orçar, avaliar, calcular e computar dados relativos a operação e às finanças da empresa. Ou seja, expressa quantitativamente o plano de ação futuro da administração para certo período."

O orçamento é uma ferramenta que possibilita prever quantas unidades de cada produto será vendida, qual possibilita maior lucro para a empresa, pode identificar também as vendas totais da empresa, prever problemas antecipadamente dentre outras funções.

Para Atkinson (2000) o orçamento também serve para coordenar muitas atividades de uma empresa, demonstra a interação dos níveis de vendas com diversas atividades da empresa como atividades de compras, de produção, administrativas, quantidade de funcionários necessária para atender os clientes, portanto através do orçamento é possível organizar de uma forma geral todas as atividades da organização, permitindo assim a identificação dos problemas de coordenação.

\subsection{CONTROLES FINANCEIROS}

Para Santos, Ferreira e Faria (2009) controlar as operações financeiras é uma tarefa difícil, portanto é importante definir maneiras adequadas para o gerenciamento de recursos da empresa, independente do seu porte.

Segundo Atkinson (2000) o uso correto destes controles propicia resultados financeiros que ajudarão na avaliação da viabilidade da empresa a longo prazo e a visualização dos processos que necessitam de melhorias. O controle financeiro serve de auxilio a outras ferramentas, sendo que é somente um resumo de desempenho.

No presente trabalho foi investigado se além das ferramentas financeiras as empresas utilizam controles mais simples em sua administração como planilhas de controle de caixa, controle de contas a receber, controle de contas a pagar, controle de estoques, controle de vendas e controle de clientes.

\section{METODOLOGIA}

A pesquisa classifica-se, quanto ao nível de abordagem, como descritiva. Para Gil (2010, p. 27) "as pesquisas descritivas tem como objetivo a descrição das características de determinada população. Podem ser elaboradas também com a finalidade de identificar possíveis relações entre variáveis". Quanto a sua natureza, trata-se de pesquisa quantitativa. Prodanove Freitas (2013, p. 69) relatam que a pesquisa quantitativa "considera que tudo pode ser quantificável, o que significa traduzir em números opiniões e informações para classificá-las e analisá-las".

Empregou-se, como técnica de pesquisa, o levantamento ou survey, buscando identificar através de questionários quais as ferramentas contábeis e financeiras as empresas comerciais utilizam em sua gestão financeira. Para Gil (2010, p. 35) "as pesquisas deste tipo caracterizam-se pela interrogação direta das pessoas, cujo comportamento se deseja conhecer. Gil (2010) cita como vantagens dos levantamentos o conhecimento direto da realidade, economia e rapidez e quantificação. As limitações são a ênfase nos aspectos perceptivos, pouca profundidade no estudo da estrutura e dos processos sociais e limitada apreensão do processo de mudança.

A construção do questionário para a pesquisa tomou por base o estudo de Rodrigues (2013) que analisou quais as Práticas e os Problemas de Gestão Financeira nas Micro e Pequenas Empresas do Setor Supermercadista de Mossoró-RN. Foram elaboradas 22 questões de múltipla escolha, para identificar quais as ferramentas que as empresas comerciais da cidade de Irati - PR utilizam na sua gestão financeira. 
Neste sentido buscou-se, em específico para este estudo, compreender o uso de ferramentas financeiras e contábeis empregadas pelos gestores para auxiliar na administração de suas organizações e ajudar na tomada de decisão.

A definição da amostra é por acessibilidade, aplicando questionário nas micros, pequenas e médias empresas comerciais do município de Irati. Foram distribuídos 30 questionários, obtendo um retorno de 25 questionários respondidos.

A análise foi desenvolvida com o auxilio de gráficos e tabelas que demonstram o posicionamento dos respondentes referente a cada um dos temas abordados. Os resultados são apresentados quanto a caracterização das empresas respondentes, informações sobre o uso de ferramentas contábeis e financeiras, uso dos controles financeiros, gestão do capital de giro e benefícios observados com o uso das ferramentas e controles as quais foram apresentadas no referencial deste estudo.

\section{ANÁLISE DOS RESULTADOS \\ 4.1 CARACTERIZAÇÃO DAS EMPRESAS}

Para traçar o perfil das empresas estudadas foram considerados relevantesos seguintes questionamentos: ramo em que a empresa atua, número de funcionários, tempo de existência da empresa e porte de acordo com o faturamento.

A maioria das empresas participantes da pesquisa são do setor de roupas, calçados e acessórios com $60 \%$, móveis e eletrodomésticos representam $28 \%$ e outras empresas (farmácia e materiais de construção) representam $12 \%$.

O desvio padrão alto quanto ao número de funcionários mostra que não há padronização entre os valores para os ramos de roupas e calçados e acessórios e Outros. Já o ramo de Móveis e elétro tem desvio menor para número de funcionários, o que significa que as empresas tem quantidade de funcionários parecida.

Observa-se que o ramo de roupas calçados e assessórios tem mais empresas de micro e pequeno porte, sendo 5 micro e 9 de pequeno porte. Já o ramo de móveis e eletro somente empresas de médio porte. Para o ramo Outros há somente empresas de pequeno porte.

Quanto a análise do total de empresas pesquisadas temos que 12 são de pequeno porte, 8 de médio porte e apenas 5 são micro empresas.

Quando o questionamento foi quem é o responsável pela administração financeira da empresa ficou evidente que as micros e pequenas empresas têm predominância de gerente proprietário, enquanto que nas de porte médio a predominância é de gestor financeiro.

Quanto ao ramo de atuação das empresas, observase que no setor de roupas, calçados e acessórios a responsabilidade pela administração financeira fica a cargo do proprietário, e isso devido a maioria ser micro e pequeno porte. A tendência das micro e pequenas empresas de não possuir um profissional específico para cuidar das questões financeiras é evidenciada em outras pesquisas. Neste sentido pode-se citar Rodrigues (2013) constatou que apenas 3,1\% das empresas possuíam sócios com capacitação em gestão financeira e $87,5 \%$ informaram que os proprietários são os responsáveis pela gestão financeira.

\subsection{FERRAMENTAS UTILIZADAS}

Entre as ferramentas consultadas sobre seu uso como forma de auxiliar na administração financeira das empresas estão o balanço patrimonial, demonstração do resultado do exercício, ponto de equilíbrio, margem de contribuição, fluxo de caixa, formação do preço de venda, previsão de vendas, orçamento e custo da mercadoria vendida.

No gráfico abaixo observa-se que a maioria das empresas utiliza várias ferramentas em sua administração financeira. Apenas 2 empresas de pequeno porte (que representam $8 \%$ do total de empresas) informaram que não fazem uso de nenhuma das ferramentas da pesquisa, alegando como motivo para não adoção de ferramentas que a empresa não possui pessoal com conhecimento específico disponível para fazê-lo. 
Gráfico 1 - Uso das ferramentas

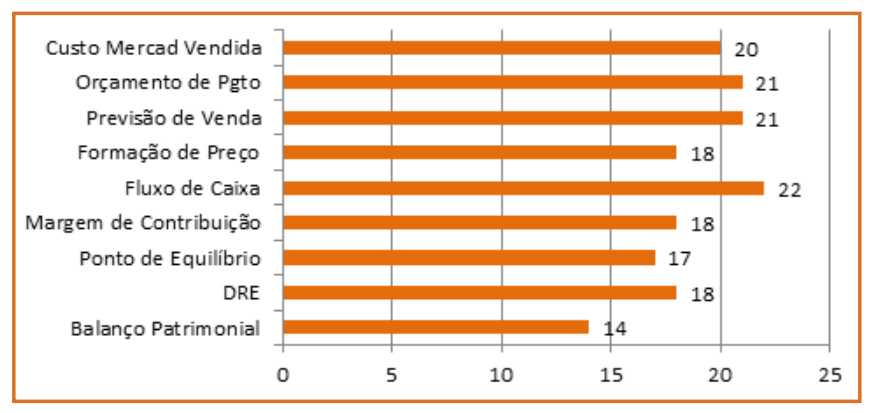

Fonte: Os Autores (2014)

No gráfico acima chamam atenção o fato de que são menos usados o balanço patrimonial ( $56 \%$ das empresas) e ponto de equilíbrio (68\% das empresas). Destacam-se como mais usadas as ferramentas fluxo de caixa sendo que $88 \%$ das empresas utilizam, orçamento e previsão de vendas com o mesmo percentual de utilização de $84 \%$. Quanto ao tempo de utilização é possível notar que o balanço patrimonial é a ferramenta que a menos tempo é utilizada, em média 1 a 2 anos. Todas as outras ferramentas tem tempo de utilização semelhantes, com média de 5 anos.

O resultado encontrado referente ao uso do Balanço Patrimonial estão de acordo com o estudo de Cunha (2002), na qual 50\% das empresas pesquisadas utilizam o Balanço Patrimonial.

Outro fator importante a ser destacado é que 7 empresas (28\%) não usam o ponto de equilíbrio e margem de contribuição e uma delas não informou sobre o uso do ponto de equilíbrio, o que significa no caso do ponto de equilíbrio que os gestores deixam de ter conhecimento do ponto em que a receita cobre os custos e despesas fixos totais, ou seja deixam de ter conhecimento a partir de que momento a empresa começa a ter lucro.

Já quanto a margem de contribuição os gestores deixam de conhecer o valor destinado a cobrir os custos fixos, após deduções dos custos variáveis, e o percentual do lucro que se deseja sobre cada produto. Neste caso as empresas que não calculam a margem de contribuição não sabem o quanto a empresa consegue gerar de recursos para pagar as despesas fixas e obter lucro, ou seja, o administrador não sabe quanto cada produto está gerando de lucro.
Quanto o conhecimento de custos Rodrigues (2013) encontrou resultado parecido em sua pesquisa, sendo que $50 \%$ das empresas pesquisadas afirmaram ter conhecimento apenas parcial dos custos de cada um de seus produtos e $28,57 \%$ os desconhecem parcial ou totalmente.

Quando analisado por porte da empresa, constata-se que exceto as ferramentas balanço patrimonial (usado por $75 \%$ das empresas de porte médio) e ponto de equilíbrio (usado por $86 \%$ das empresas de porte médio) todas as demais são empregadas por todas as empresas de porte médio (100\% das empresas). Há uma demonstração que o porte da empresa influencia no uso das ferramentas financeiras. Cita-se que há exceção para algumas ferramentas dentre as micro empresas uma vez que todas (5 empresas) citaram usar fluxo de caixa, orçamento e custo da mercadoria vendida.

Analisando as empresas de acordo com o ramo de atuação constatou-se que o fluxo de caixa é a ferramenta mais utilizada em todos os ramos de atividade. O ramo que o uso das ferramentas é mais acentuado é o ramo de móveis e elétro com todas as empresas citando seu uso, exceto para o balanço patrimonial (86\% das empresas usam) e ponto de equilíbrio (86\% das empresas usam).

Importante ressaltar que todas as empresas do ramo móveis e elétro são de médio porte reforçando a afirmativa de que o porte da empresa influencia no uso de grande número de ferramentas de gestão financeira. Quanto maior a empresa, o uso de ferramentas como forma de auxiliar na tomada de decisão é mais frequente.

Porém outro ponto importante que merece destaque é que no ramo de roupas, calçados e acessórios as ferramentas fluxo de caixa $(93 \%$ das empresas citaram) e previsão de vendas (93\% das empresas citaram) foram citadas pela maioria dos entrevistados o que traz como indicativo que estas ferramentas têm seu uso independente do porte da empresa.

As empresas também foram questionadas sobre a elaboração de relatórios financeiros, foi possível 
identificar que das 25 empresas respondentes apenas 8\% (2 empresas) delas não elaboram relatórios financeiros, sendo que uma delas alegou como motivo da não elaboração a falta de tempo para fazê-lo e outra não informou o motivo. Dentre as 23 que responderam afirmativamente todas elaboram relatórios mensalmente.

Quanto a relatórios financeiros, é encontrado resultado distinto na pesquisa de Cunha (2002), na qual $47 \%$ das empresas tem conhecimento da situação financeira através de relatórios elaborados para este fim. $\mathrm{Na}$ pesquisa de Santos Ferreira e Faria (2009) 65,9\% dos empresários das micro e pequenas empresas elaboram relatórios financeiros.

\subsection{CONTROLES FINANCEIROS}

O gráfico 2 foi construído em função da frequência das respostas de cada grupo "tamanho da empresa".

Gráfico 2 - Uso de controles financeiros - porte da empresa

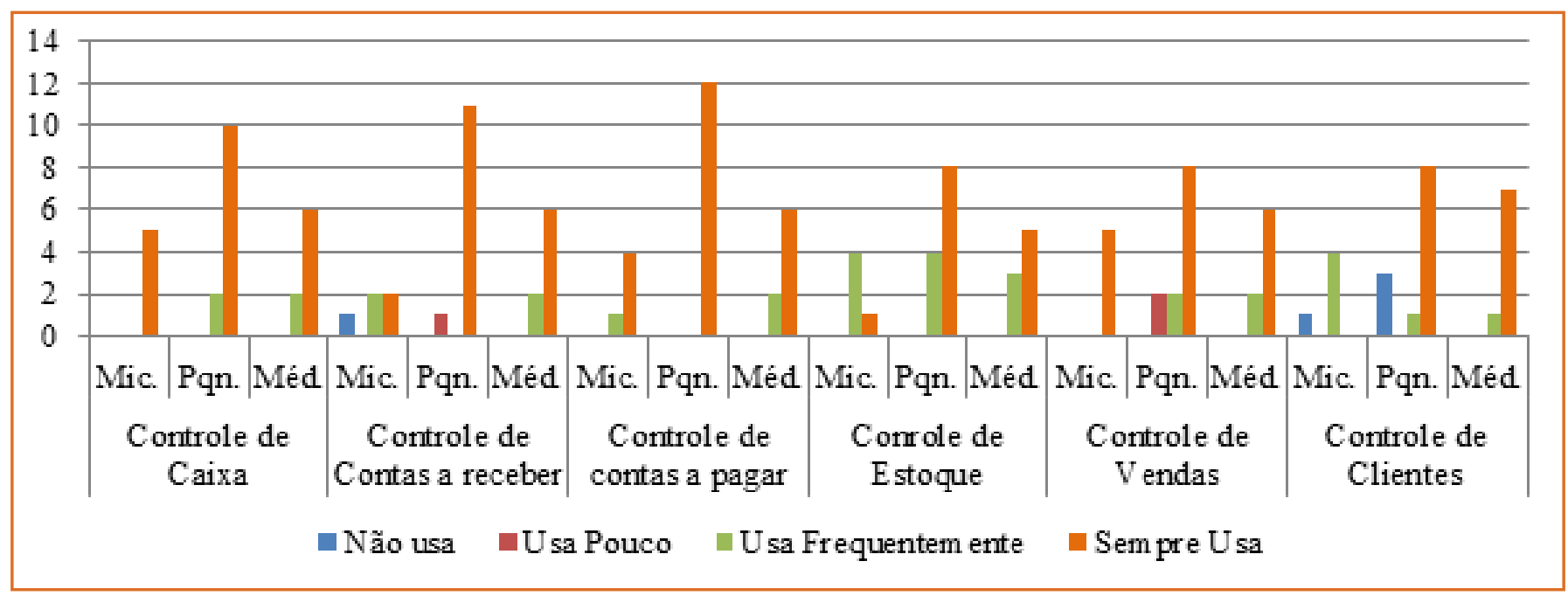

Fonte: Os Autores (2014)

A partir do mesmo observa-se que os controles mais utilizados pelas micro empresas são o controle de caixa, controle de contas a pagar e controle de vendas.

As empresas de pequeno porte utilizam praticamente todos os controles na mesma proporção, ficando evidente o uso menor de controle de clientes e de vendas e o maior uso de controle de contas a pagar. As empresas de médio porte usam todos os tipos de controle na mesma proporção. O objetivo deste gráfico é demonstrar que os gestores se preocupam em fazer uso de controles simples, em forma de planilhas, com o intuito de auxiliar no gerenciamento da empresa.

\subsection{GESTÃO DO CAPITAL DE GIRO}

Neste quesito de gestão, das 25 empresas entrevistadas 24 realizam vendas a prazo. A que não realiza vendas a prazo é uma pequena empresa do ramo de roupas calçados e acessórios.

A maioria das empresas, 37,5\% fornece 60 dias de prazo médio nas vendas, enquanto que $25 \%$ fornecem um prazo médio de 90 dias e também $25 \%$ o prazo de 120 dias. Apenas 8,33\% fornecem mais de 120 dias e $4,16 \%$ (somente uma empresa) somente 30 dias de prazo.

Nota-se que as compras são na maioria de 30 dias de prazo, já as vendas podem ser maiores, entre 60 e 90 dias. Não foi consultado o percentual de vendas e compras a prazo por isso não é possível calcular a necessidade de capital de giro das empresas. No entanto, pode-se perceber que há uma tendência de vender mais a prazo que comprar o que implica em necessidade de investimentos maiores em capital de giro.

Quando as empresas foram questionadas sobre os 
recursos para suprir a falta de capital em caixa, constatase que a maioria das empresas $54,17 \%$ indicaram o capital próprio como fonte de recurso para suprir a falta de dinheiro em caixa, seguido de empréstimo, sendo $37,5 \%$ das empresas. Uma empresa informou desconto de duplicata e uma desconto de cheques. Ainda uma empresa não informou como faz para levantar dinheiro, caso falte no seu caixa.

\subsection{INVESTIMENTOS}

As empresas foram questionadas sobre os principais investimentos que realizaram nos últimos 12 meses. Os investimentos mais significativos entre as empresas foram treinamentos com $56 \%$ e computadores e softwares com $52 \%$. Esses investimentos indicam que as empresas estão se preparando cada vez mais diante da competitividade, percebendo a importância de se ter pessoal preparado para os desafios em conjunto com a tecnologia, pois ter sistemas consistentes e atualizados é também um diferencial.

\subsection{BENEFÍCIOS OBSERVADOS}

Em relação aos benefícios observados com o uso das ferramentas de administração financeira foi solicitado para que os respondentes indicassem o quanto as ferramentas contribuem para alguns requisitos da gestão atribuindo notas de 1 a 5 sendo 1 para pouco benefício e 5 para muito.

Para as empresas de porte médio o uso de ferramentas são muito importantes para obter previsões de venda e de receita $(5,0)$; observar possibilidade de novos investimentos $(4,8)$; conhecimento sobre o poder de pagamento da empresa $(4,8)$ e melhor controle sobre os estoques (valores e quantidades).

As empresas de pequeno porte consideram importante o benefício de ter melhor compreensão do custo do produto $(4,7)$, as pequenas empresas são as que atribuíram importância bem parecida para todos os benefícios apresentados. As micro empresas foram as que atribuíam maior grau de importância aos benefícios considerando como muito importante, com 5,0 para previsões de venda e de receita, controle de caixa da empresa, conhecimento sobre o poder de pagamento da empresa.

As micro empresas consideram que o uso das ferramentas não é importante para avaliar o patrimônio da empresa, as pequenas empresas compreendem que o uso de ferramentas não auxilia na visualização de novos investimentos e as médias empresas definem grau de importância elevado para todas as melhorias apresentadas.

As outras duas empresas do ramo de materiais de construção informaram não utilizar ferramentas financeiras em sua administração, portanto não podem avaliar os benefícios alcançados com seu uso.

Esta questão permitiu identificar qual a visão que as empresas têm quanto as vantagens que podem ser obtidas com as ferramentas financeiras e demonstrativos contábeis em sua administração financeira. Todas as empresas atribuíram grau de importância acima de 4,0, o que evidencia que as empresas consideram vantajoso o uso de ferramentas financeiras, e que o uso possibilita todas as vantagens apresentadas neste trabalho.

\section{CONCLUSÕES}

Em meio ao cenário da globalização, e grande concorrência na qual é necessário se reinventar e buscar alternativas para se manter no mercado competitivo, o uso de ferramentas pode ajudar e muito as empresas a não somente se manterem, mas se destacarem em seus ramos de atuação. A partir desta pesquisa foi possível visualizar como as empresas comerciais de Irati se comportam em sua administração financeira.

É plausível destacar que apesar de $72 \%$ das empresas ser gerenciada pelo proprietário e apenas 20\% por cargo específico relacionado somente com finanças, e 8\% pelo contador, as empresas estão conseguindo se manter no mercado, sendo a média de existência de 18,5 anos.

De uma forma geral as empresas possuem controles financeiros, sendo indicado como "sempre usa" por maior número de empresas, o controle de caixa 
e o controle de contas a pagar, o que indica que as empresas estão preocupadas em cumprir com suas obrigações e de forma que sempre possuam dinheiro em caixa. Os gestores temem os juros, caso fiquem sem dinheiro em caixa e esse é provavelmente o motivo que os mesmos se preocupem com o caixa, para que não tenham que recorrer a empréstimos.

Quanto ao efetivo uso das ferramentas financeiras apresentadas neste trabalho, ficou evidente novamente a preocupação com a entrada e saída de recursos da empresa, 22 empresas, ou seja, $88 \%$ das empresas pesquisadas utiliza o Fluxo de Caixa na sua gestão financeira. A preocupação com as vendas também fica clara, $84 \%$ empresas informaram usar o orçamento e a previsão de vendas, o orçamento ajuda a cumprir as metas, a empresa pode, portanto através do orçamento fazer previsões e estimativas de quanto pretende vender de cada produto. Chama a atenção o fato de $28 \%$ das empresas não utilizar a margem de contribuição e ponto de equilíbrio. Essas empresas provavelmente encontrarão dificuldades futuras quanto aos seus custos, pois se percebe que as mesmas não têm total controle sobre seus custos. A DRE também não é utilizada por $28 \%$ das empresas. O demonstrativo contábil balanço patrimonial é o menos usado, $56 \%$ das empresas informaram o seu uso. Neste sentido é possível supor que um possível motivo para a não utilização é a falta de conhecimento de como utilizar o balanço como ferramenta, já que somente duas empresas indicaram o contador como o profissional responsável pela gestão financeira.

A maioria dos participantes da pesquisa considera a utilização de ferramentas contábeis muito importantes para fazerem a previsão de vendas e de receita.

A maioria das empresas comerciais de micro, pequeno e médio porte faz uso de ferramentas financeiras como forma de auxiliar nas decisões e somente duas empresas não usam nenhum tipo de ferramenta financeira. Porém essas duas empresas informaram que sempre usam planilhas de controle de contas a receber, controle de contas a pagar, controle de vendas e controle de clientes e que usa frequentemente controle de caixa e controle de estoque.
Finalmente, o estudo evidencia que as empresas comerciais têm buscado alternativa para a administração financeira. As empresas buscam principalmente a gestão das atividades operacionais voltadas ao caixa. Salienta-se que a pesquisa não avaliou a qualidade do uso de tais ferramentas e controles, mas apenas evidenciou a utilização ou não destes pelos respondentes.

\section{REFERÊNCIAS}

[1] ALMEIDA, Cíntia de. O orçamento como ferramenta para a gestão de recursos financeiros no terceiro setor: um estudo nas organizações do estado do Rio Grande do Norte. Dissertação (Mestrado em Ciências Contábeis) Universidade de Brasília, Universidade Federal da Paraíba, Universidade Federal de Pernambuco, Universidade Federal do Rio Grande do Norte, Centro de Ciências Sociais Aplicadas, Programa Multiinstitucional e Inter-Regional de Pós-Graduação em Ciências Contábeis, Natal, 2007.

[2] ASSAF NETO, Alexandre. Finanças Corporativas e Valor. São Paulo: Editora Atlas S.A, 2010

[3] ATKINSON, A. Anthony. Contabilidade Gerencial. São Paulo:Atlas, 2000

[4] BRUNI, Adriano Leal. A Administração de Custos, Preços e Lucros. 4 Ed. São Paulo: Atlas, 2010.

[5] CREPALDI, Silvio Aparecido. Contabilidade Gerencial. 5 Ed. São Paulo: Atlas, 2011.

[6] CUNHA, Marco Antônio Nascimento da. O Perfil da Administração Financeira das Pequenas e Médias Empresas. Dissertação (Mestrado Executivo em Administração) Fundação Getúlio Vargas, Escola Brasileira de Administração Pública, Centro de Formação Acadêmica e Pesquisa, Rio de Janeiro, 2002.

[7] GIL, Antonio Carlos. Como Elaborar Projetos de Pesquisa. 5. Ed. São Paulo: Atlas, 2010.

[8] GONÇALVES, Márcia Regina. Os controles financeiros como ferramenta do processo de decisão nas micro e pequenas empresas. 2007. 140f. Monografia. Universidade de Taubaté. 2007.

[9] HOJI, Masakazu. Administração financeira: uma abordagem prática: matemática financeira aplicada, estratégias financeiras, análise, planejamento e controle financeiro.3. Ed. São Paulo: Atlas, 2001.

[10] IUDÍCIBUS, S. de.; MARION, J. C. Contabilidade Comercial. 9. Ed. São Paulo: Atlas, 2010.

[11] PRODANOV, Cleber Cristiano; FREITAS, Ernani Cesar. Metodologia do Trabalho Científico: Métodos e Técnicas da Pesquisa e do Trabalho Acadêmico. 2 Ed. Novo Hamburgo: Feevale, 2013. 
[12] RECEITA FEDERAL. Lei Complementar nำ 139, de 10 de novembro de 2011. Disponível em: http://www.receita. fazenda.gov.br/Legislacao/LeisComplementares/2011/ leicp139.htm. Acesso dia 10/04/2014.

[13] RODRIGUES, Jamile Pereira Cunha. Análise do Sistema de Gestão Financeira: Estudo de Caso de uma Microempresa de Itabuna - BA. IX Congresso Nacional de Excelência em Gestão, 20, 21 e 22 de junho de 2013 ISSN 1984-9354.

[14] RODRIGUES, João Paulo Lima. Gestão Financeira em Micro e Pequenas Empresas: Um Estudo no Setor Supermercadista de Mossoró - RN. Dissertação (Mestrado Profissional em Administração) - Universidade Potiguar, Natal, 2013.

[15] SANTOS, Cleide da Costa; CARNEIRO, Eda Janina Dias Mendes. Fluxo de Caixa como Ferramenta de Gestão Financeira. Artigo (Especialização em Gestão Financeira) Universidade Católica de Góias, Goiânia, 2009.
[16] SANTOS, F.de A.; VEIGA, W. E. Contabilidade com Ênfase em Micro, Pequenas e Médias Empresas. São Paulo: Atlas, 2011.

[17] SANTOS, Joel José. Contabilidade e Análise de Custos. 6 Ed. São Paulo: Atlas, 2011.

[18] SANTOS, Lucas Maia dos; FERREIRA, Marco Aurélio Marques; FARIA, Evandro Rodrigues de. Gestão Financeira de Curto Prazo: Características, Instrumentos e Práticas Adotadas por Micro e Pequenas Empresas. Revista de Administração da UNIMEP, v. 7, n.3, Setembro / Dezembro, 2009.

[19] Serviço Brasileiro de Apoio as Micro e Pequenas Empresas - SEBRAE. Anuário do Trabalho na Micro e Pequena Empresa. Disponível em http://www.dieese. org.br/anuario/2013/anuarioSebrae2013.pdf. Acesso dia 10/04/2014. 


\section{CAPÍTULO 13}

\section{POTENCIALIDADES DO MARKETING PORTUÁRIO: UM ESTUDO DE CASO DO PORTO DE IMBITUBA SANTA CATARINA}

\section{Ibaldo Gonçalves Pedra Júnior}

\section{Maria Helena de Souza}

Natália Martins Gonçalves

Resumo: O setor portuário possui um papel significativo na competitividade do comércio exterior de uma nação, por meio da navegação de longo curso. Presente nos projetos de investimento e infraestrutura do Plano Nacional de Logística Portuário (PNLP), o Porto de Imbituba busca adequar-se às necessidades e expectativas do setor empresarial. Com um calado natural de 12 metros de profundidade, extensão de zona primária e secundária e localização, o porto se diferencia dos demais portos brasileiros, tornando-se mais competitivo nestes quesitos. Neste contexto, o presente estudo tem como objetivo analisar as potencialidades do marketing portuário, com destaque para os obstáculos e fatores relevantes, visando a elevação da competitividade do Porto de Imbituba. Com relação à metodologia, a pesquisa de abordagem qualitativa, se enquadra quanto aos fins de investigação como descritiva; bibliográfica e um estudo de caso, quanto aos meios de investigação. Para a coleta dos dados utilizou-se um roteiro semiestruturado para a entrevista em profundidade junto ao responsável pelo Departamento Comercial do Porto de Imbituba. Observou-se que o porto está em um processo de modificações administrativas e estruturais, estando vinculado ao governo do Estado de Santa Catarina, por meio de uma concessão de 25 anos. Para o Departamento de Marketing, o grande obstáculo a ser vencido é convencer os armadores que existe demanda de cargas conteinerizadas. Um programa de aproximação junto aos interessados da Região Sul e também das demais regiões do país, favorece a ampliação de um mix de destinos internacionais ofertados. O alcance desses resultados tem também o objetivos de favorecer o desenvolvimento regional.

Palavras Chave: Marketing Portuário, Competitividade, Porto de Imbituba. 


\section{INTRODUÇÃO}

A movimentação de mercadorias pelos mares vem acontecendo há milhares de anos, sendo um dos primeiros meios de transportes de cargas usado pelo homem para alcançar povos longínquos, possibilitando o estabelecimento de relações comerciais. O Brasil nasceu graças à navegação, porém, houve significativo avanço no intercâmbio com o mercado internacional através dos portos brasileiros, com a assinatura da Carta Régia da Abertura dos Portos. A transferência da coroa portuguesa para o Brasil e a abertura dos portos brasileiros contribuíram para a inserção definitiva no comércio internacional, estimulando o processo de emancipação política e econômica do Brasil (BRASIL.MDIC, 2010).

Outro fato histórico mais recente, já na década de 1990, contribuiu para que os portos brasileiros aumentassem a sua participação na movimentação demercadorias para ocomércio internacional: o país abria as portas ao mercado externo, implementando novas medidas em favor da liberdade cambial, redução das alíquotas de importação e mudanças nas regras do comércio exterior (TAVARES, 1992). Aliado a isso, houve também progressivo aumento nas exportações mundiais, motivado pelo crescimento do comércio favorecido pela queda de barreiras comerciais no mundo globalizado.

Em decorrência desses episódios, o ambiente do mercado internacional globalizado passa a depender do transporte marítimo para o avanço do intercâmbio comercial, considerando que este meio de transporte favorece a logística de distribuição para grandes quantidades e distâncias, refletindo em ganhos de produtividade pelo baixo custo comparado aos demais modais de transporte. Fica evidente que nesta nova era o desenvolvimento econômico dos países passa pelos oceanos; por este caminho se movimentam suprimentos alimentícios, matérias primas, tecnologia e novos empreendimentos.

Diante deste contexto, a procura do setor portuário aumentou, devido ao crescimento dos volumes movimentados. Essas transformações colocaram - seguimento portuário também em acirrada competitividade e, por isso, o mesmo deve procurar oferecer melhores estruturas de operação, tarifas, maior número de armadores e mão de obra adequada para um serviço eficiente e ágil, com tempo e custo reduzidos, tendo como objetivo captar o máximo de clientes e suas respectivas mercadorias. Devido às constantes mudanças na economia, relacionadas ao mercado externo e a volatilidade na movimentação de cargas nos portos brasileiros, fazem-se necessários investimentos e aperfeiçoamentos para o atendimento da demanda, além de se ter que trabalhar fortemente na fidelização desses clientes.

Considerando o acima exposto, o presente estudo tem como objetivo analisar as potencialidades do marketing portuário, com destaque para os fatores relevantes no processo de operacionalização das estratégias voltadas para a busca da elevação da competitividade do Porto de Imbituba, SC, com vistas ao alcance dos objetivos de elevação de produtividade dos investimentos necessários para o desenvolvimento do Porto e da região.

\section{FUNDAMENTAÇÃO TEÓRICA 2.1 COMPETITIVIDADE}

Para Kay (1996) a vantagem competitiva é algo relativo; o modelo de gerir seu negócio é que faz a diferença, levando a organização a ter o diferencial sobre os demais concorrentes, por exemplo quando esta possui algo que o mercado ainda não ofereça, quer seja um iniciante no seguimento ou talvez alguém que já tenha uma bagagem de experiência acumulada ao longo do tempo. Para cada mercado existirá uma estratégia diferenciadora, seja ele um atrativo baseado na reputação, inovação, arquitetura ou características técnicas, contribuindo para um posicionando no mercado onde atua. As empresas possuem características diferenciadas umas das outras. Essas diferenças são relativas a fatores externos ou internos, podendo ser geridos ou não (SILVA, 2002), o que potencializa o ambiente de competitividade.

Para se manter um negócio viável é necessário que a empresa busque alternativas compatíveis ao que o mercado vem exigindo, pois aquelas que estão em busca deste diferencial procuram fazer melhor ou 
igual ao que seus concorrentes estão oferecendo neste cenário desafiante, tornando este processo mercadológico bastante competitivo. Estes fatores tendem a levar as organizações a direcionar seus esforços para a singularidade, originalidade e inovação para conseguir atingir seus objetivos de mercado com eficiência (ZOGBI, 2008).

Um dos fatores chave para se conseguir competitividade é se primar por uma boa estrutura logística. No caso do Brasil, este é um dos elementos fundamentais para apoio ao desenvolvimento da indústria nacional, considerando as condições de circulação e movimentação de cagas nas metrópoles, influenciada pelo seu crescimento desordenado e falta de planejamento urbano, implicando na mobilidade de pessoas e no escoamento da produção ou na entrada de matéria prima. Estas condições logísticas afetam os custos dos fatores de produção e as tarifas na movimentação de cargas (COUTINHO; FERRAZ, 1995).

A competitividade também está envolvida no relacionamento com o cliente. Um ponto básico neste processo, é a determinação das estratégias para satisfazer um ou mais clientes, utilizando-se de vantagens competitivas para disputar em outros mercados (HIIT; IRELAND; HOSKISSON, 2008). A busca pela competitividade contínua, direciona as empresas para múltiplas estratégicas, permitindo focar em diferentes seguimentos visando alcançar um volume maior de clientes, diferentes produtos, métodos necessários para a expansão do negócio, como política de preços, aliados à qualidade da mercadoria ou serviço prestado e a eficiência organizacional (SERRA, 2004).

A conquista de vantagem competitiva na liderança de custos das empresas exige atenção diária nas operações, com objetivo de reduzir custos relacionados à inovação e treinamento operacional, dentre outros fatores. Para que isto ocorra, o sistema cultural da organização deve estar voltado a uma condição mais participativa com os seus colaboradores, para que este ajuste seja realmente incorporado na empresa. Adicionalmente, pode ser aconselhável a incorporação de algumas estratégias promocionais para que se possa alcançar esse objetivos (SERRA, 2004).

A concorrência deve ser examinada freqüentemente. A empresa deve manter observância constante do ambiente externo para saber quem poderia entrar em cena e captar seus clientes, além de sempre medir a sua capacidade de reação. O comportamento da organização pode ser dirigido pelo seu entendimento consensual do mercado, conforme sua intuição pode lhe projetar em ação futura (PORTER, 1986).

\subsection{MARKETING}

Um dos obstáculos encontrados pelas empresas está em diagnosticar as verdadeirasnecessidades de seus clientes; entender qual é o grau de satisfação de cada cliente, considerando que suas necessidades e seus desejos mudam constantemente. Por isso, é fundamental a forma de apresentação da qualidade do serviço oferecido para que o mesmo possa entender quanto vale e qual o nível de preço aceitável por cada serviço prestado. Este fator tem implicação direta na rentabilidade desejada pela empresa e em todo processo de relacionamento e fidelização dos clientes (ROJAS, 2014)

Caldeirinha (2011) argumenta sobre a necessidade do alinhamento das estratégias e do mix de marketing para que seja possível elevar a competitividade do setor portuário, identificando os pontos fortes e fracos, como também as oportunidades e ameaças do processo, adequando assim à oferta do porto às necessidades dos clientes. A apresentação dos produtos ofertados pelo porto pode ser um primeiro passo. O Quadro 1 descreve alguns parâmetros chave para a descrição dos produtos portuários. 
Quadro 1 - Produtos de marketing portuário.

\begin{tabular}{|c|c|}
\hline FATOR & DESCRIMINAÇÃO \\
\hline $\begin{array}{l}\text { Localização e posição } \\
\text { geoestratégica }\end{array}$ & $\begin{array}{l}\text { - Do porto face aos mercados, aos locais de produção, às rotas de mercadorias e aos nichos de mercado; } \\
\text { - Acessibilidades do porto às redes nacionais e internacionais, aos centros logísticos e industriais e às cidades; } \\
\text { - Características físicas do porto, como a proteção aos ventos e agitação marítima, fundos naturais, tipos de } \\
\text { terrenos, áreas protegidas. }\end{array}$ \\
\hline Atributos técnicos & $\begin{array}{l}\text { - Infraestrutura do porto, cais, terraplenos, edifícios, equipamentos de parque e de cais, acessos marítimos e } \\
\text { acessos terrestres próximos; } \\
\text { - Superestrutura ou software do porto, que inclui a organização, o sistema de informações, os recursos humanos, } \\
\text { a rede de empresas e serviços, a área administrativa; } \\
\text { - Estrutura logística do porto, ou seja, as áreas de armazenagem, a interface modal e os parques logísticos de } 2^{\underline{a}} \\
\text { linha }\end{array}$ \\
\hline Logística do porto & $\begin{array}{l}\text { - Espaço físico do porto onde se movimentam o navio e a mercadoria, considerando as suas dimensões e layout; } \\
\text { - Modo como são realizadas as operações de manuseamento e deslocação da carga e dos navios; } \\
\text { - Áreas e formas de armazenagem da carga no porto; } \\
\text { - Gestão e controlo do processo logístico associado ao manuseamento, armazenagem e outros serviços à carga } \\
\text { no terminal. }\end{array}$ \\
\hline Marca do porto & $\begin{array}{l}\text { - Imagem associada à marca, logotipo, designação; } \\
\text { - Identidade e diferenciação do porto face aos concorrentes; - Cultura interna do porto; } \\
\text { - Atributos do porto percebidos pelo cliente; } \\
\text { - Gestão e controlo do processo logístico associado ao manuseamento, armazenagem e outros serviços à carga } \\
\text { no terminal. }\end{array}$ \\
\hline
\end{tabular}

Fonte: Caldeirinha (2011).

Para uma empresa ser bem sucedida, faz-se necessário estar atento ao mercado e ao seus oponentes, saber avaliar seus pontos fracos e fortes, para partir para um ataque estratégico, seguindo um planejamento em longo prazo, buscando fatores que contribuam para o seu fortalecimento diante dos concorrentes para se proteger posteriormente (RIES; JACK, 1989).

A comunicação é uma pilastra na sustentação do marketing. A comunicação integrada de marketing pode ser considerada como o resumo de várias ferramentas como, propaganda, publicidade, promoção, merchandising dentre outras, envolvendo diferentes tipos de oportunidades diretas ou indiretamente. Um estratégia de comunicação adequada pode atrair diferentes tipos de público, dentro dos interesses da organização, e fortalecer a sua imagem no mercado (COSTA, 2007). O Planejamento de marketing e de comunicação devem estar adequados para resolver problemas específicos, resultando no alcance dos objetivos esperados pelo organização. por isso é necessário seguir um plano que defina claramente seu propósito, nos mínimos detalhes, condizentes com a forma como é dirigida mecanicamente a execução operacional deste sistema (COSTA, 2007).

Serra (2004) argumenta que a perspectiva do marketing faz com que as organizaçõesidentifiquem melhor o mercado em que estão atuando, podendo analisar com maior eficiência a real necessidade dos consumidores e, assim decidir qual decisão tomar referente à qualidade do produto, atendimento, preço, direcionando estes dados para determinar a lucratividade e a projeção que a empresa espera. No plano de marketing a empresa precisa desenvolver as ações necessárias para as áreas mais importantes de cada setor, com o objetivo pontuar metas para a marca, categorias de produto, novos produtos, a segmentação do mercado onde atuar, localização geográfica e a categoria de cliente-alvo (KOTLER, 
1999).

O preço é um dos atributos na tomada de decisão de compra pelos consumidores; este fator determina grande parte da relação entre a empresa e o cliente. Dessa forma, o preço deve ser competitivo para bloquear uma ação negativa na tomada de decisões. Portanto, os preços devem ter acompanhamento constante no mercado, tanto com relação à percepção dos clientes quanto aqueles praticados pela concorrência (COSTA, 2007).

No mercado, de forma geral, o marketing é um jogo onde as empresas precisam se superar todos os dias, tomando decisões adequadas para que se possa alcançar as expectativas esperadas pelas organizações. Erros nas decisões poderá acarretar em um posicionamento inesperado do público alvo, provocando reações na oferta, preço, praça ou publicidade. Porisso, é fundamental saber interpretar os sinais do mercado e avaliar com cautela os diagnósticos fornecidos, fazendo um monitoramento preventivo e contínuo dos procedimentos adotados (KOTLER, 1999).
Neste contexto a produtividade e a qualidade trilham no mesmo caminho em busca de um objetivo em comum, procurando oferecer ao mercado um serviço rápido, eficiente e com custo reduzido, identificando métodos adequados na melhoria de processos e na satisfação do cliente. Para se alcançar este propósito é necessário que os setores de marketing, operacional e recursos humanos trabalhem alinhados, dividindo experiências e sugestões para se chegar aos resultado esperados pela organização (LOVELOCK; WIRTZ, 2006).

Para Gianesi e Corrêa (1996) é necessário entender - mercado para aprofundar-se em uma estratégia de operações buscando alcançar seus objetivos por meio da competitividade. Para que seja possível a medição do alcance dos objetivos propostos, devese estabelecer os atributos mais relevantes para a operação dos serviços, diante das expectativas e satisfação dos clientes e da qualidade no serviço prestado. O Quadro 2 ilustra alguns destes atributos, para melhor compreensão.

Quadro 2 - Critérios competitivos nas operações de serviços.

\begin{tabular}{|l|l|}
\hline Consistência & Conformidade com experiência anterior, ausência de variabilidade no resultado ou processo; \\
\hline Competência & $\begin{array}{l}\text { Habilidade e conhecimento para executar o serviço. Relacionado com as necessidades "técnicas" dos } \\
\text { consumidores; }\end{array}$ \\
\hline Velocidade no Atendimento & $\begin{array}{l}\text { Prontidão das empresas e seus funcionários em prestar o serviço. Relaciona-se com o tempo de espera } \\
\text { (real percebido). }\end{array}$ \\
\hline Atendimento Atmosfera & Atenção personalizada ao cliente; boa comunicação; cortesia e ambiente; \\
\hline Flexibilidade & Baixa percepção de risco; habilidade de transmitir confiança; \\
\hline Credibilidade/ Segurança & Facilidade de contato e acesso; localização conveniente; horas de operação. \\
\hline Acesso & $\begin{array}{l}\text { Qualidade e/ou aparência de qualquer evidência física (bens facilitadores, equipamentos, instalações, } \\
\text { pessoal e outros consumidores; }\end{array}$ \\
\hline Custo & Fornecer serviço de baixo custo. \\
\hline
\end{tabular}

Fonte: Gianesi e Corrêa (1996, p. 103).

\section{PROCEDIMENTOS METODOLÓGICOS}

A presente pesquisa seguiu uma abordagem qualitativa para a coleta e a análise dos dados. Teve como finalidade ser descritiva, levando em conta o processo de analisar e descrever as potencialidades do marketing portuário, com destaque para fatores relevantes e os obstáculos no processo de marketing, visando elevar a competitividade do Porto de Imbituba, SC, tendo como referência a concorrência no transporte de cargas marítimas e o aperfeiçoamento no processo de marketing portuário.

Neste contexto, os meios de investigação utilizados foram a pesquisa bibliográfica e o estudo de caso. Considera-se bibliográfica devido à consulta a 
acervos com temas relacionados à gestão portuária, comércio internacional, logística, marketing dentre outros assuntos disponibilizados na biblioteca da instituição (UNESC); ferramentas de internet como Google acadêmico, Scielo, DOAJ, disponibilizando dissertações, artigos e monografias; Webesites oficiais como o do Ministério do Desenvolvimento da Indústria e Comércio (MDIC), Receita Federal, Alice Web, Radar e do próprio Porto de Imbituba. O estudo de caso lança mão de diferentes técnicas e procedimentos de coleta e análise de dados, como: Observação direta in loco, pesquisa documental e de campo.

Desta forma, foram feitas visitas ao Porto de Imbituba, SC, para se obter dados e informações para a realização do estudo. Através das observações, foi possível descrever as áreas portuárias e retroportuárias, além das operações realizadas no cais e nas áreas adminsitrativas e de armazenagem. Somado a isso, foram utilizados documentos fornecidos pelo Porto para se checar tais informações. Considera-se uma pesquisa documental aquela que permite 0 compartilhamento de informações em documentações oficiais, podendo ser representadas por meio escrito ou não, no momento da pesquisa ou após o seu acontecimento (LAKATOS; MARCONI 2006). Diante dos fatos, a pesquisa documental possibilitou ao pesquisador ver as evidências das características de competitividade na infraestrutura fornecidas pelo Porto, apresentadas pelos departamentos responsáveis.

A pesquisa de campo tem como prioridade coletar um número de informações relevantes de certa situação problema, retiradas do próprio ambiente onde os fatos ocorrem, gerando uma resposta para os acontecimentos (LAKATOS; MARCONI 2006). Neste procedimento foi usado um questionário semiestruturado, para a realização de uma entrevista com a atual administração do Porto de Imbituba, procurando desenvolver a compreensão dos processos utilizados, do modelo de gestão e das dificuldades que interferem no desenvolvimento e aperfeiçoamento para se alcançar a competitividade almejada pelo Porto de Imbituba, SC.

\section{O PORTO DE IMBITUBA - SANTA CATARINA 4.1 A INFRAESTRUTURA PORTUÁRIA}

Para Lopez e Gama (2002), a infraestrutura física dos portos brasileiros são ineficientes, comparadas com portos de outros países. Os fatores relacionados à profundidade de canal e à dragagem do mesmo para movimentação de navios com maior capacidade, aos equipamentos que contribuem para a desaceleração na movimentação dos produtos, são alguns dos fatores que explicam a perda de competitividade com os demais países. Outro fator relevante é que o sistema portuário brasileiro conta com uma deficiência no acesso terrestre para carregamento e descarregamento de mercadorias. O Estado tem como responsabilidade planejar e estabelecer métodos de execução nas operações da logística brasileira, caracterizado por parâmetros de complementaridade, economicidade, descongestiona mento e do fluxo de caixa (SILVA, 2003).

A infraestrutura de um porto é o cartão postal para a entrada de novos clientes e de suas respectivas mercadorias. O Porto de Imbituba encontra-se localizado numa enseada aberta, abrigada por um molhe de 850 metros com sua bacia de evolução de $300 \mathrm{~m}$ de extensão e 12 metros de profundidade. Uma das grandes vantagens do porto de Imbituba é seu calado natural que contribui para uma baixa manutenção referente à dragagem do seu canal, fato que reflete no custo para melhoria deste processo. Sua localização está a uma distancia de 286 milhas marítimas do Porto de Santos e a 322 milhas do Porto de Rio Grande, a Figura 1 ajudará na visualização destas dimensões (PORTO DE IMBITUBA, 2014).

O porto de Imbituba oferece 3 berços para atracação, sendo o berço 1 e 2 com 11,50 metros e o berço 3 com 10,80 metros de profundidade. Tendo em vista a nova dragagem o calado poderá chegar a 17 metros de canal e 15,5 metros de evolução nos berços. Passando diferentes tipos de mercadorias vindas de diferentes partes do mundo e também direcionada para diversos países, sua localização privilegiada no epicentro do MERCOSUL, favorece a logística para as demais regiões do Sul do país como 
também para a América do Sul em geral. Somado a estes fatores relevantes, localiza-se em uma enseada aberta, permitindo manter seu calado por um período longo sem ter que fazer manutenções de dragagem, dado o baixo nível de assoreamento. A Figura 2 ilustra os detalhes citados (PORTO DE IMBITUBA, 2014).

Figura 2- Berço de atracação Porto de Imbituba.

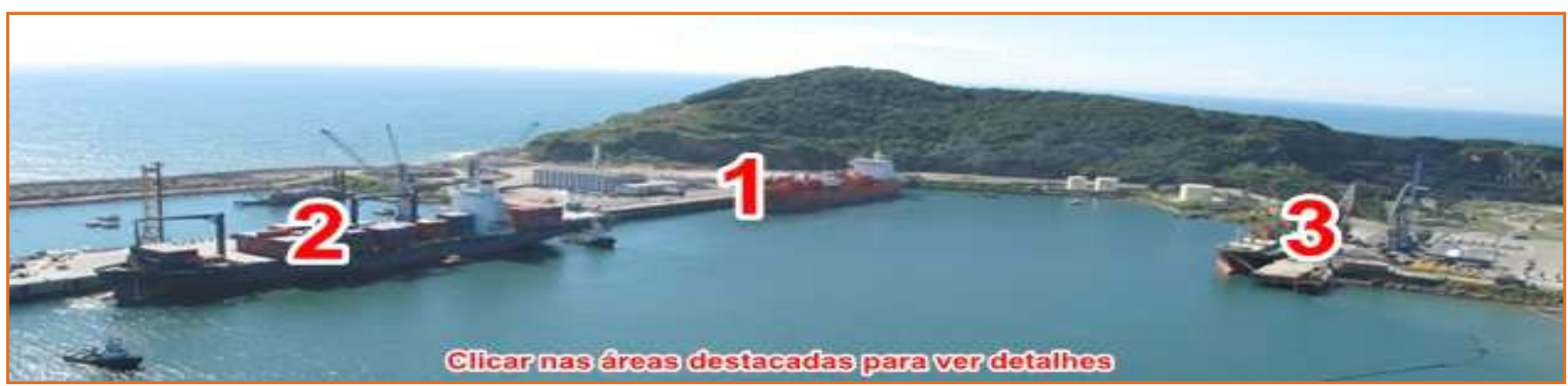

Fonte: Porto de Imbituba (2014).

Devido ao Porto é possível identificar a presença de investimentos e oportunidades de trabalho para o setor logístico nos arredores, contribuindo para o desenvolvimento do setor e da região. Os operadores arrendatários têm participação relevante nesse desenvolvimento. O Quadro 4 mostra uma lista dos operadores do porto de Imbituba, devidamente divididos por categorias de operação.

Quadro 4 - Categoria dos operadores portuários.

\begin{tabular}{|c|c|c|c|c|c|}
\hline \multirow[b]{2}{*}{ OPERADOR PORTUÁRIO } & \multicolumn{4}{|c|}{ CATEGORIA / GRUPOS DE ATIVIDADES } & \multirow[b]{2}{*}{$\begin{array}{c}\text { Carga perigosa } \\
\text { (ABNT e IMO) }\end{array}$} \\
\hline & $\begin{array}{c}\text { Carga Geral } \\
\text { Diversificada }\end{array}$ & \begin{tabular}{|} 
Containers e \\
"Roll-on / Roll-off"
\end{tabular} & $\begin{array}{l}\text { Granéis } \\
\text { Sólidos }\end{array}$ & $\begin{array}{l}\text { Granéis } \\
\text { Líquidos }\end{array}$ & \\
\hline Three Workers Serviços Marítimos Ltda. & $x$ & $x$ & $x$ & $x$ & $x$ \\
\hline AGIL Armazéns Gerais Imbituba Ltda & $x$ & $x$ & $x$ & $x$ & \\
\hline ILP Imbituba Logística Portuária Ltda. & $x$ & $x$ & $x$ & $x$ & $x$ \\
\hline Serra Morena Corretora Ltda & $x$ & $x$ & $x$ & $x$ & $x$ \\
\hline Fertisanta - Fertilizantes Santa Catarina & $x$ & $x$ & $x$ & $x$ & $x$ \\
\hline CRB Operações Portuária & & & $x$ & & \\
\hline Imbituba Operadora Portuária Ltda & $x$ & $x$ & $x$ & $x$ & $x$ \\
\hline OPL Operadora Portuária e Logística Ltda. & $x$ & $x$ & $x$ & $x$ & $x$ \\
\hline Manuchar Comércio Exterior Ltda & $x$ & & $x$ & & \\
\hline Imbituba Equipamentos Mecânicos & $x$ & $x$ & & & \\
\hline Santos Brasil Participações S/A & $x$ & $x$ & $x$ & $x$ & $x$ \\
\hline
\end{tabular}

Fonte: Porto de Imbituba (2014). 
Atualmente o Porto de Imbituba conta com um armador principal e bem conhecido dentro do setor marítimo que é a Hamburg Süd, atendendo linhas regulares semanalmente, vindas de Manaus, outra com saídas de Imbituba para o Golfo do México e outra saindo para Argentina, estabelecendo um ponto de apoio para o Porto. Além do armador citado acima, também existem outros armadores que prestam serviço conforme a necessidade encontrada pelos importadores. O serviço para movimentação de mercadorias no porto é disponibilizado também, por exemplo, para fertilizantes e carvão coque. Estes navios de linhas não regulares, freqüentam o porto quando solicitados pelos seus importadores.

Para obter agilidade no gerenciamento dos negócios, com diferentes oportunidades oferecidas pelo mercado internacional é necessária a introdução de serviços operacionais especializados na área logística, com sistemas modernos, permitindo facilidade nas atividades diárias, redução de tempo e custo nas operações, considerando que o setor de logística interno é indispensável nas negociações da logística internacional, onde as operações são executadas por gigantes internacionais, altamente especializadas e competitivas (LUDOVICO, 2007).

O operador responsável pela movimentação no porto é a Santos Brasil, que tem capacidade de movimentar anualmente 450.000 TEUs, disponibilizando uma área total de $207.000 \mathrm{~m}^{2}$. O berço 1 e 2 totalizam 660 metros de comprimento, com 11,50 metros de profundidade, podendo chegar 12 a 15 metros com as modificações, permitindo operar simultaneamente 2 navios de 330 metros no costado do porto, fato que contribui para que alguns modelos de embarcações que tem dificuldades em operar em outros portos, devido ao seu tamanho, possam operar ali. No berço 1 estão alocadas as câmeras frigoríficas. Conta também com o berço 3, com 245 metros de comprimento e com 10,80 metros de profundidade, oferecendo instalações especificas para movimentação de granéis sólidos, dispondo de uma área de $318.991 \mathrm{~m}^{2}$ para o armazenamento dos produtos. profundidade e um costado para agilidade da movimentação das mercadorias, o porto também conta com uma retro área diferenciada aos demais portos do Brasil e de alguns lugares do mundo. Próxima as margens da BR 101, a em torno de 4 quilômetros do porto, conta com uma área de aproximadamente 7 milhões de metros quadrados, disponíveis para fazer uma grande plataforma logística na região Sul do Brasil, oferecendo uma possibilidade de expansão para a região e para os interessados em estabelecerse nesta localidade. Atualmente o porto recebe visitas constantes de importadores e exportadores que operam no Porto de Santos e demais Portos do Brasil, buscando alternativas para desenvolver parcerias junto ao porto de Imbituba.

Para Oliveira (1999), um porto moderno, eficaz e com baixo custo exige entroncamentos ferroviários e rodo ferroviários para que os transportes das mercadorias possam chegar à área portuária mais rápido e com custo reduzido. O Porto de Imbituba apresenta uma estrutura de acesso facilitado nos seus três berços de atracação por meio de estradas pavimentadas e sinalizadas. Parte dos recursos investidos vem de empresas privadas que arrendam áreas para armazenamento de mercadorias no porto. Investem buscando dar atendimento adequado às necessidades do mercado.

O acesso ferroviário conta com outro parceiro que disponibiliza de um porto seco para movimentação de cargas originadas da região sul, mais especificamente da Região Carbonífera (Criciúma, Içara e arredores), interligando também a cidade de Tubarão até o porto, por meio da via férrea Tereza Cristina. As mercadorias mais movimentadas são: cerâmica, arroz, dentre outros. Este parceiro é o Terminal Intermodal Sul (TIS), localizado na cidade de lçara, SC. Foi constituído por um consórcio de empresários que estão injetando investimentos para melhoria do processo logístico por meio de ferrovias. Os investimentos abrangem um espaço para estufagem e armazenamento de contêineres em suas dependências.

O acesso rodoviário é feito por uma das principais rodovias do país, a BR 101, que liga diretamente

Além de contar com um calado de grande 
- MERCOSUL ao Nordeste do Brasil. O Porto está localizado às margens dessa rodovia Federal, o que facilita a entrada ou saída de mercadorias por via rodoviária. O acesso aéreo pode ser feito pelo Aeroporto Internacional Hercílio Luz, localizado na cidade de Florianópolis/ SC, ou pelos aeroportos regionais das cidades de Criciúma e Jaguaruna, localizados os dois há menos de 100 quilômetros de distância.

\subsection{LOCALIZAÇÃO DOS PRINCIPAIS CLIENTES}

Os principais clientes do porto de Imbituba estão localizados na região Sul de Santa Catarina, movimentando cargas de cerâmica, arroz, carvão, dentre outras mercadorias. O Rio Grande do Sul contribui também como parte deste empuxo para o escoamento da produção do granel. Os Estados do Mato Grosso e Goiás também escoam parte de sua produção de grãos pelo porto.
O crescimento da demanda para o comércio exterior e poucas alternativas oferecidas pelos portos brasileiros, o Porto de Imbituba se destaque aos demais portos pela sua infraestrutura. Em entrevista foi citado que na safra do ano de 2013, alguns portos do Paraná chegaram a pagar U\$\$1.000.000,00 por navio por meio de demurge, pela espera dos navios nestes portos. Fato relevante pela quantia elevada paga em conseqüência da operação mal sucedida logisticamente nestas áreas portuárias. Por isso os Estados de Mato Grosso e Goiás decidiram escoar sua produção de granéis por meio rodoviário até Imbituba, dando continuidade por acesso marítimo através do porto, visando a redução de custos e tempo, ocorrido em períodos anteriores. Com as linhas dirigidas a Manaus, constitui em uma alternativa para que a serra gaúcha possa movimentar suas mercadorias via acesso marítimo, ao invés de circularem pelas rodovias do Brasil, reduzindo assim o tráfego e o custo de modo geral nestas operações. A Figura 4 apresenta os tipos de cargas movimentadas pelo Porto de Imbituba.

Figura 4 - A movimentação de mercadorias - em \%

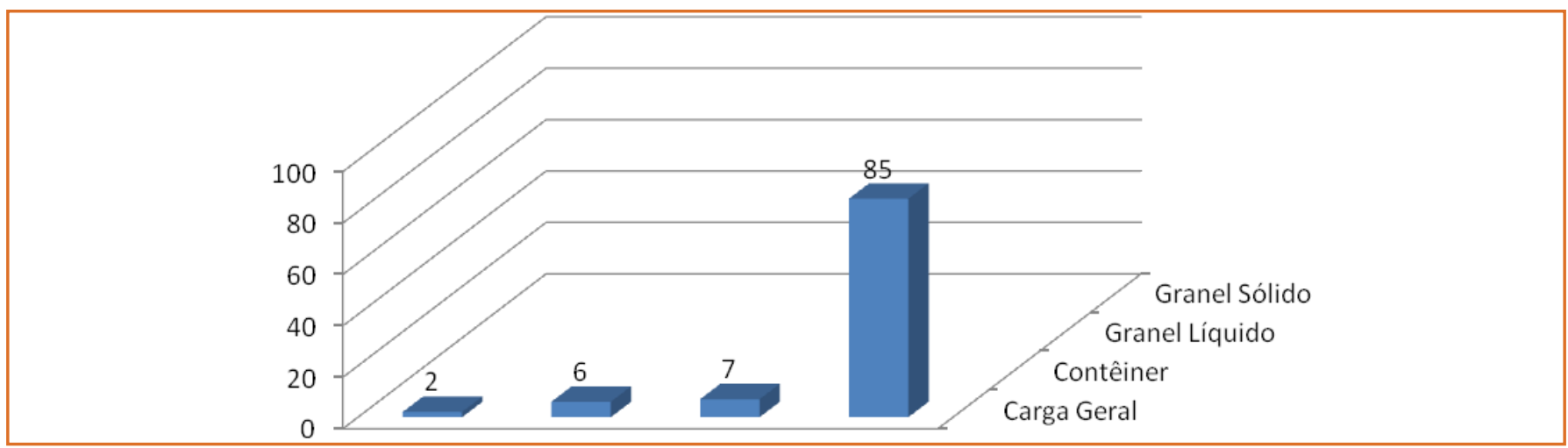

Fonte: Dados obtidos pela pesquisa (2014).

\section{O MARKETING PORTUÁRIO}

Em um planejamento de marketing e de comunicação, as estratégias devem estar adequadas a resolverem problemas específicos, resultando no alcance dos objetivos esperados. Neste caso é necessário seguir um plano que defina claramente seu propósito, nos mínimos detalhes, de forma a mostrar como é dirigida mecanicamente a execução operacional deste sistema, maturando o perfil e as expectativas deste público motivado pela sua participação (COSTA, 2007). O Porto de Imbituba está desenvolvendo um novo modelo de marketing para posicionaremse no mercado, adequando suas perspectivas às novas condições impostas nesta etapa, demandando de investimento e estratégias para a divulgação destas estratégias.

Serra (2004) argumenta que a perspectiva do marketing faz com que as organizações identifiquem melhor o mercado que estão atuando, analisando com maior eficiência à real necessidade de seus consumidores. A partir daí poder tomar a decisão adequada referente à qualidade do produto, 
atendimento, infraestrutura, busca de novos clientes, alicerçadas nos objetivos e metas de lucratividade ou projeção que a empresa espera obter.

Neste sentido, o Porto de Imbituba está desenvolvendo um trabalho de divulgação pelo departamento comercial e de todos relacionados ao setor, como um mecanismo de levar informações aos interessados em querer fazer parte de uma parceria com o porto. A concessão de 25 anos obtida pelo porto, contribui para uma credibilidade maior com os armadores, exportadores, importadores e empresários, para que estes grupos venham investir uma quantia maior na melhoria dos processos logísticos e na movimentação de mercadorias pelo porto.

Neste contexto as melhorias realizadas na infraestrutura no calado do porto com 15 metros de profundidade possibilitarão a entrada de navios da classe Pós-Panamax de 60.000 a 80.0000 toneladas, além da aquisição de equipamentos modernos por intermédio dos operadores e arrendatários objetivando a agilidade e a eficiência nas operações do porto. Esta superestrutura vem permitir movimentar na área portuária de Imbituba uma quantia de 6,0 milhões de tonelada ano. O porto já conseguiu no ano de 2013 um aumento nas operações de $21,2 \%$ em comparação ao período do ano anterior, estimando-se para o ano de 2014, um crescimento de 35\%, prevendo um acumulado de 3,3 milhões de toneladas a mais do que o ano anterior.

Conforme Lopez e Gama (2002), os portos brasileiros passam por grandes dificuldades em oferecer uma estrutura adequada para a entrada de navios com grande capacidade. Estes necessitam de mares profundos para sua navegação. Com as alterações realizadas pelo porto será possível a entrada de linhas vindas da Ásia, Europa e outros continentes que utilizam deste tipo de embarcação. Estes fatores contribuirão para a inserção dos exportadores e importadores do Sul do Estado de Santa Catarina e do Estado vizinho Rio Grande do Sul na utilização dos serviços ofertados pelo porto.

Ries e Jack (1989) argumentam que a busca do sucesso por uma empresa é necessário estar atento ao mercado e ao seu oponente, avaliando seus pontos fracos, permitindo um ataque estratégico e fortalecido ao seu concorrente, contando com um planejamento em longo prazo. Diante destes fatos, o Porto de Imbituba busca estratégias e atributos que o diferencie dos demais portos concorrentes. Além das vantagens na área portuária, outro diferencial é o espaço retro-portuário que o Porto detém, oferecendo possibilidade de expansão de curto e de longo prazo às empresas interessadas em estabelecer-se em suas proximidades.

Para Silva (2003) o Estado tem grande responsabilidade no desenvolvimento logístico do país. Neste caso foi possivel identificar por meio da pesquisa, que a participação na atual gestão do Porto de Imbituba pelo Estado de Santa Catarina, sendo mantenedor destas instalações, tem oferecido confiança para os interessados em fechar uma aliança, seja por intermédio de investimentos públicos, privados ou da própria utilização dos serviços prestados pelo porto.

Conforme Caldeirinha (2011), é necessário possuir uma estratégia de marketing para fazer frente à competitividade dosetor portuário. Paraistoénecessário identificar os pontos fortes e fracos como também as oportunidades e ameaças do processo, adequando assim, a oferta do porto às necessidades do cliente. Neste contexto ao contrário desta força encontrada da nova gestão por parte do Estado de Santa Catariana, a fraqueza encontrada pelo departamento comercial é fazer o armador confiar que existe carga suficiente para ele desviar das outras rotas previstas em seu itinerário e entrar na área portuária, das instalações serem apropriadas para suas necessidades e também convencer os exportadores e importadores que terá armadores suficientes para atender o transporte de suas mercadorias. Portanto, pontos típicos para serem tratados e solucionados pelo marketing portuário.

Seguindo a mesma linha de pensamento do autor citado acima, outra dificuldade encontrada pelo porto é a concorrência pelos demais portos localizados em Santa Catarina comentado anteriormente. Os armadores já estão habituados a fazerem linhas regulares para portos mais expressivos, como o Porto de Itajaí, que opera atualmente com aproximadamente 17 armadores. Importante ressaltar que o Porto de 
Itajaí foi se desenvolvendo gradativamente pela presença de indústrias estabelecidas em seu em torno e pela própria procura dos armadores pelo porto para movimentação destas cargas, fato que o Porto de Imbituba espera acontecer nos próximos anos.

Kay (1996) argumenta que vantagem competitiva é algo relativo; considera que o modelo de gerir seu negócio é que faz a diferença, levando a organização a ter o diferencial sobre os demais concorrentes, por esta possuir algo que ainda não tenha no mercado. Diante disto, outra oportunidade competitiva apresentada pelo porto é a localização geográfica ao qual ele encontra-se: próximo à margem da BR 101, que atravessa o Brasil; está a 286 milhas marítimas do Porto de Santos e a 322 milhas marítimas do Porto de Rio Grande. Além disso, considera-se a proximidade com o Estado vizinho para o apoio ao escoamento da produção. É de grande relevância a retro área disponível para crescimento, com 7 milhões de metros quadrados, às margens desta rodovia, 0 que oportuniza seu crescimento e desenvolvimento, pois poucos portos no mundo detêm desta quantia de área em seu entorno. Este fator poderá atrair 0 interesse para este tipo de público que pretende fazer investimentos em longo prazo. A profundidade do calado e de estar em mar aberto para entrada de navios de grande porte, também ajuda a se destacar. A qualidade na prestação de serviço e a parte social do município também contribuem no processo de desenvolvimento do porto.

\section{CONSIDERAÇÕES FINAIS}

O presente estudo teve como objetivo analisar as potencialidades para o desenvolvimento do marketing portuário, com destaque para os obstáculos e fatores relevantes no processo, visando a elevação da competitividade do Porto de Imbituba, SC.

Em uma análise referente à gestão do porto de Imbituba, foi possível perceber que existe o interesse em divulgar sua infraestrutura, promover os serviços, considerando a concessãoobtida para 25 anos, após longo tempo administrado por uma gestão privada. A gestão demonstra grande agressividade na busca do seu crescimento, objetivando trazer investimentos e parcerias comercias para estabelecerse em sua região.

Outro fator apresentado pelo porto é a sua infraestrutura diferenciada aos demais portos do Brasil, devido à sua localização estar privilegiada, contando com bacia de evolução e calado natural, berços de atracação para receber navios de grande capacidade, uma área de grande expressividade em metros quadrados ao redor das dependências do porto, fator que diferencia dos demais portos do Brasil por não existir mais a possibilidade de expansão dos mesmos diante do crescimento urbano descontrolado. Esta situação permite o estabelecimento de empresas de vários seguimentos e tamanhos para utilizar dos serviços prestados pela companhia, fazendo com que o porto de Imbituba venha a ganhar mercado perante seus concorrentes, podendo tornar-se um porto de referência no Sul do Brasil.

Nas questões estratégicas do marketing utilizado pelo porto para a divulgação das suas instalações, foi possível perceber grande esforço e desafios encontrados pelo departamento comercial. Este setor passa por modificações, buscando diversas alternativas para captar novos clientes para utilizarem da sua infraestrutura. Outro fator que expressa o empenho por parte do departamento comercial foi a conquista de um número maior de cargas no último ano, e o esforço para buscar outros armadores a fim de aumentar as linhas regulares para diferentes partes do mundo, o que poderá gerar maior eficiência para a movimentação de suas mercadorias, ponto chave para seu desenvolvimento.

\section{REFERÊNCIAS}

[1] BONAPARTE, Tony $\mathrm{H}$; FLAHERTY, John E. Peter Drucker: Filosofia e métodos. São Paulo: Ed. Pioneira, 1976.

[2] BRASIL. BNDES. <http://www.bndespar.gov.br/ SiteBNDES/export/sites/default/bndes_pt/Galerias/Arquivos/ co nhecimento/revista/rev2508.pdf,>Acesso em: 12 set. 2014

[3] BRASIL. MDIC.Acesso em 10 de abril de 2015. http://www.mdic.gov.br//sitio/interna/index.php?area=5 
[4] CALDERINHA, Vitor, Marketing Portuário Associação dos porto de Portugal, 2011, <http://www. portosdeportugal. pt/sartigo/index.php?x=7069>, acesso em: 16 set. 2014.

[5] CERVO; Amado Luiz; BERVIAN, Pedro Alcino. Metodologia Científica. 5⿳ㅗㄹ, ed, São Paulo: Prentice Hall, 2002.

[6] COSTA; Antonio Roque; CRESCITELLI, Edson. Marketing Promocional para mercados Competitivos: planejamento, implementação, controle. São Paulo: Atlas, 2007.

[7] COUTINHO G Luciano, FERRAZ, João Carlos. Estudo da competitividade da indústria brasileira. 3a ed Campinas, SP: Papirus; Editora da Universidade Estadual de Campinas, 1995.

[8] HITT. A, Michael, Duane Ireland, Robert E. Hoskisson, Administração estratégica competitiva e globalização. São Paulo 2008.

[9] KAY, John. Fundamentos do sucesso empresarial: como as estratégias de negócios agregam valor, Rio de Janeiro, Campus 1996.

[10] KOTLER, Philip; ARMSTRONG, Gary. Princípios de marketing .9. ed. Rio de Janeiro: Prentice Hall, 2003.

[11] KOTLER, Philip. Marketing para o século XXI: como criar, conquistar e dominar mercados. São Paulo. Futura 1999.
[12] LOVELOCK, Christopher; WIRTZ, Jochen. Marketing de serviços: pessoas, e resultados. São Paulo: Pearson Prentice hall, 2006.

[13] LUDOVICO Nelson. logística internacional um enfoque em comércio exterior. São Paulo, Saraiva, 2007.

[14] OLIVERIRA, Carlos Tavares. Comércio Exterior e a Questão Portuária. São Paulo Aduaneiras 1992.

[15] OLIVERIRA, Carlos Tavares. Comércio internacional: China, EUA, e Portos, São Paulo, Aduaneiras, 1999.

[16] PORTER; Michael E. Estratégia Competitiva: técnicas para análise de indústrias e da concorrência. 16 ed. Rio de janeiro: Ed. Campus, 1986.

[17] RIES Al, Jack Trout. Marketing da Guerra. São Paulo 1989.

[18] ROCHA, Paulo César A. Logística e Aduana. São Paulo 2001.

[19] ROJAS, Pablo. Introdução à logística portuária e noções de comércio exterior. Porto Alegre: Bookmam, 2014.

[20] SILVA, Christian Luiz da. Competitividade na cadeia produtiva. Curitiba, Juruá, 2002. 


\section{CAPÍTULO 14}

\section{UMA PROPOSTA DA ESTRUTURA ORGANIZACIONAL DO SETOR DE ENGENHARIA NUMA INSTITUIÇÃO PÚBLICA FEDERAL DE ENSINO}

\section{Kazuo Khatakeyama \\ Rommel Souza da Silva \\ Mehran Misaghi}

Resumo: A mudança organizacional tornou-se vital para organizações em todo as esferas desde o privado até o público, devido a crescente necessidade de oferecer serviços com melhores resultados econômicos, eficiência e de utilidade funcional para o atendimento das expectativas do público em geral. $\mathrm{O}$ artigo referencia teoricamente uma abordagem da estrutura organizacional no setor de projetos de obras públicas, relatando o impacto da informação e as decisões tomadas para execução do projeto. A influência desses fatores no ciclo de vida do projeto que atinge diretamente ao usuário, a economicidade e eficiência.

Palavras Chave: Ciclo de vida em projetos; Estrutura organizacional; Gerenciamento de projetos; Planejamento Estratégico. 


\section{INTRODUÇÃO}

$\mathrm{Na}$ sociedade moderna observa-se que $\mathrm{O}$ compartilhamento de informações tem sido compartilhado cada vez mais rápida, e essas mudanças estão cada vez mais presentes no cotidiano das pessoas. O mesmo vem ocorrendo com as mudanças organizacionais, as quais dinamicidade do ambiente organizacional tem exigido das organizações o desenvolvimento da capacidade de adaptaremse às mudanças com o propósito de torna-se eficaz e eficiente. Sendo assim, necessário acompanhar as transformações para que se possa prestar um serviço de qualidade ao público interno e externo, que estão em exigência a evolução do mercado.

Este artigo abrange uma instituição pública de ensino na esfera federal, que atua no estado de Santa Catarina, Brasil. Nesta organização identifica-se insatisfação do corpo discente, docentes e técnicos administrativos em relação a falhas nos projetos de obras. Devido às falhas apresentadas na estrutura ou falta de equipamentos que não foram inclusos, por falha na previsão desse equipamento ou de verba para sua aquisição, advindos de uma não coesão relacionamento estrito - entre orçamento e projeto, em função da falta de orientação do gerenciamento de projeto em todo seu ciclo de vida.

Para minimização desse tipo de problema, propõese uma estruturação de mudança organizacional no processo de desenvolvimento de projetos básicos. Para o artigo, portanto, fica que a gestão seja adequadamente conduzida ou capacitada para dar uma maior qualidade na elaboração de projetos básicos e os que surgiram como necessidade após a sua execução.

\section{REFERENCIAL TEÓRICO}

A parceria entre setores ou correlatores pode trazer benefícios em termos de menos relações antagônicas e maior eficiencia do projeto, embora as barreiras à parceria incluem a falta de confiança, comprometimento, comunicação, papel clareza, coerência da abordagem e flexibilidade (BROWN et al., 2001).
Por Lo e Humphreys (2000), as técnicas de Project Management (PM) que podem ser usadas para desenvolver uma rede de recursos a serem obtidos para produção de projetos que venham a assegurar uma implementação eficaz e eficiente na gestão. Pode ser que as instituições federais orientadas por projetos básicos tenham características que Ihes permitam desenvolver ou aperfeiçoar um sistema de gestão e atenda às suas necessidades de desempenho.

Assim como Eweje et al., (2012), declaram que a informação recebida é um critério para o processo de execução do projeto. Uma relação positiva desse meio pode trazer uma eficiência no desenvolvimento de como facilitar as decisões práticas na execução, e programar uma organização temporária; suas observações mostram que as inadequações, as inviabilidades arquitetônicas e a falta ou pouca informação, causa conflitos entre decisões da realização, política interna e planejamentos.

No setor público os projetos produzidos em comparação com o setor privado, apresenta um extenso caminho a ser percorrido e um ciclo de vida longo, são significativamente menos previsíveis em termos de tempo e escopo, pois dificilmente há repetição dos projetos o que aumenta a requisição de analisar e estudar cada situação imposta ao projeto, a repetição traz com o passar do tempo a qualidade e velocidade de sua produção. Em vista de assumir o compromisso com a legalidade, o projeto deve ser irreversível, em licitações de obras e serviços de engenharia, através da súmula 261 do Tribunal de Contas da União (TCU) é necessária a elaboração de projeto básico adequado e atualizado, assim considerado aquele aprovado com todos os elementos descritos no art. 6º, inciso IX, da Lei no 8.666, de 21 de junho de 1993, constituindo prática ilegal a revisão de projeto básico ou a elaboração de projeto executivo que transfigurem o objeto originalmente contratado em outro de natureza e propósito diversos, daí vem a necessidade de criar uma estrutura de informação com alta probabilidade de reduzir falhas, apresentado neste artigo uma proposta que compacte-o e desvie as falhas que giram em torno de sua entrada para produzir projetos de obras públicas na esfera federal. 
Traçar um planejamento estratégico, convém formar uma aliança sólida aos formadores de opinião técnica e engaja-los em um alinhamento base que se forma com a estrutura organizacional do setor.

$\mathrm{Na}$ elaboração dos projetos, não deixam a vida socioeconômica da sociedade, que será impactada por sua implementação, além do financeiro $e$ as requisições desse objeto, entre sociais e gestão, no setor de engenharia são amplas as relações, possibilitando pôr em risco a funcionalidade da edificação e a estabilidade econômica envolvida no país (MILLER, 2000).

O governo vem passando por cortes no orçamento e os recursos extra para fechamento do projeto tem sido manipulada com respostas negativas. Esses desafios na gestão pelas partes interessadas podem ser atribuídos na relação da incerteza e complexidade no ambiente de projetos (BURTON; OBEL, 2003).

Não compete apenas aos seus conhecimentos e experiência profissional, a precisão da avaliação e julgamento dos gerentes de projeto muitas vezes diminuem à medida que o projeto cresce em tamanho e complexidade. As estruturas organizacionais refletem os projetos por ela gerenciados, uma vez que a importância dada ao projeto, disponibilidade dos envolvidos e o interesse da organização são influenciados diretamente pela natureza da estrutura organizacional (VARGAS, 2005).

A base para a identificação das partes interessadas e priorização também não é forte devido à cognição limitado de gerentes de projeto e das partes envolvidas. Segundo Ward e Chapman (2008), apontam que as partes relacionadas são a principal fonte de incerteza em grandes projetos de construção, a qual as entidades comprometidas e suas alegações com interrelações a cada fase do projeto são as principais incertezas associadas pelas partes dedicadas.

Em projetos da construção civil é elevada a complexidade que o compreendem muito mais do que as partes interessadas ao projeto, levando a um maior número de incertezas e riscos relacionados com as partes envolvidas (CICMIL; MARSALL, 2005).
De acordo com a NBR 13531 (ABNT, 1995), a elaboração de projeto de edificações determina os atributos funcionais, formais e técnicas de elementos a ser construído, abrangendo desde as suas fundações percorrendo até as instalações prediais.

Etapas da elaboração de projetos parte da melhor alternativa de solução para a edificação, gera as especificações em sua estrutura analítica de projeto (EAP), o que possibilita a execução na sua integra, apresenta todos os detalhes, informações e memoriais, definindo a edificação (KERZNER, 2002).

De acordo com Emuze e Smallwood (2011), revelou que nos países em desenvolvimento, as competências dos departamentos do setor público, em partes colaboradores, eram incapacitados e que consequentemente ficava comprometido o desempenho do projeto.

Os gerentes de projeto têm encontrado maiores obstáculos para equilibrar reivindicações das partes interessadas e manter relacionamentos sólidos em projetos de grandes dimensões do que em tamanho normal, necessitando de uma análise mais aprofundada. Os colaboradores têm interesses e influências, que gera conflitos geralmente no desenvolvimento do projeto construtivo por ser diversos os interesses, percepções e expectativas de inúmeros servidores envolvidos. As diferentes prioridades que são levadas em relevância pelos profissionais são encontradas em infraestruturas projetadas com diferentes portes, em certo tempo dada pela ênfase excessiva trazidas pela requisição na economia possível gera sua concepção no projeto, um foco em grande parte dele, e o efeito do projeto sobre o grupo social a ser atingido, é considerado uma concepção tangenciável (MOK; SHEN; YANG, 2015).

Os interesses e as ações dos colaboradores a diferentes tipos de projetos são influenciados por fatores locacionais como a cultura local, meios de comunicação, os sistemas políticos e regulamentos (DOOMS et al., 2013). Prevendo a real limitação frente a legislação municipais vigente e normas brasileiras atualizadas, os colaboradores não devem deixar incompletos os projetos sobre efeito negativo do inesperado na execução do projeto. Algumas literaturas 
existentes prestam especial atenção ao processo de estrutura organizacional nas fases iniciais do projeto. $\mathrm{Na}$ fase de planejamento do projeto, o escrutínio de soluções de projeto alternativas e comunicação de valores do projeto são partes importantes do processo da estrutura organizacional (OLANDER; LANDIN, 2008). Os processos de integração e gerenciamento dos servidores interessados no setor de projetos durante as fases de planejamento do projeto, tem iniciação com esboços que também são caracterizados como pertencerem aos ciclos de longa vida e compiladas nas divisões do departamento.

Quanto ao PMBOK/PMI® (2013) define o ciclo de vida do projeto, delimitado pelos grupos de processo: iniciação, planejamento, execução, controle e avaliação, e encerramento. Este ciclo abriga 44 processos gerenciáveis que se distribuem por nove áreas de conhecimento: integração, escopo, prazos, custos, qualidade, recursos humanos, comunicação, riscos e aquisições. No gerenciamento de projetos e para que se tenha um melhor controle do projeto, se cria a interdependência entre as atividades dividindoos em fases, como por exemplo, fase anteprojeto e projeto legal, passando por aprovações municipais e dos órgãos competentes, seguindo para o projeto executivo, constituindo o chamado ciclo de vida do projeto. O ciclo de vida do projeto define que as técnicas serão utilizadas em cada fase, como na elaboração de corte, fachadas e detalhamentos construtivos e as pessoas envolvidas em cada fase, assim como os arquitetos e engenheiros. Em algumas situações, fazer o "fast-tracking ou caminho rápido" que consiste em executar a fase posterior antes de se concluir e iniciar a fase anterior, por serem teoricamente antecessoras e predecessoras umas das outras, assim é visto em projetos de instalações que pode ser iniciado com apenas as plantas baixa do projeto arquitetônico, ou seja, sem que finalize na sua totalidade, dando início ao esboço ou primeiros caminhos da sua formação, o mesmo pode ser realizado com o projeto estrutural. Então, o ciclo de vida do projeto descreve o que é necessário para trabalhar no projeto, passando ao ponto de estruturar organizacionalmente, tendo como estruturas organizacionais: a funcional tradicional (hierárquica); funcional project expediter; funcional project cordinator; matricial (fraca, balanceada, forte); projetizada. Para contexto do artigo a projetizada é a mais indicada devido a estrutura separada e vertical que é estabelecida no setor público, envolvida assim para cada atividade, tendo todos os servidores se reportando ao gerente de projeto, (LINHARES; QUARTAROLI, 2004).

Dentro da organização segue em níveis diferenciados, iniciando pelo institucional que abrange o planejamento estratégico, plano por qual foca a longo prazo, com objetivos globais, ainda, identifica o "Porquê" e "Quando" deve acontecer as ações, além de ser uma forma de aprendizagem organizacional, é um processo de construção de consenso que compreende toda a organização, nesse nível encontramos os diretores. Por segundo, o nível organizacional intermediário, engloba o planejamento tático, que densa no departamento de atuação, o coordenador utiliza este planejamento para delinear o que as várias partes da organização, deve fazer para que a organização alcance sucesso no decorrer do período de seu exercício, focando então no médio prazo e o objetivo do detalhamento, respondendo "Onde" e "Como" a execução deve proceder. Por último, o nível operacional que acumula o fator execução de atividades realizada por indivíduos, antecedido nesse ambiente pelo planejamento operacional, direcionando o processo de curto prazo, que já foi detalhado pelo planejamento tático, sendo a partir desse momento especificado pelo servidor atuante e responsável pela atividade, além de responder "O quê" é executado (CHIAVENATO, 2004; KERZNER, 2002; PMBOK/PMI, 2013). 
Figura 1 - A interligação entre planejamento estratégico, tático e operacional.

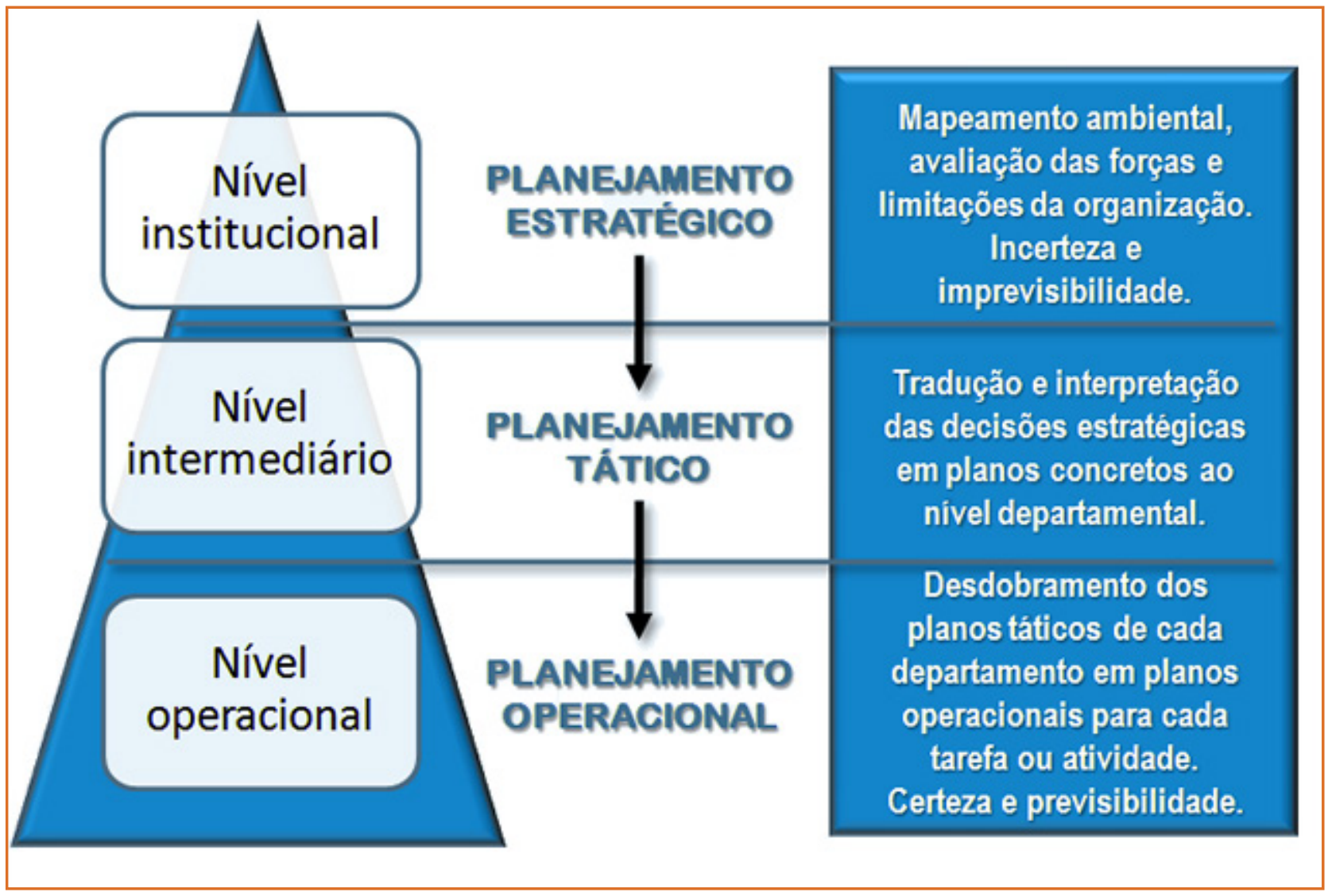

Fonte: Chiavenato, 2004.

\section{PROCEDIMENTO METODOLÓGICO}

A pesquisa apresentada neste artigo se classifica como revisão bibliográfica porque objetiva gerar conhecimentos por meio da pesquisa bibliográfica dirigida a uma solução de um problema específico. Em relação aos objetivos se classifica como descritiva porque envolveu levantamento bibliográfico, entrevistas com pessoas que tiveram experiências práticas com o problema pesquisado e o registro e descrição de fatos observados.

Quanto aos procedimentos, esta pesquisa pode ser classificada como um estudo de caso, pois consistiu da coleta e análise de informações sobre uma organização a fim de estudar aspectos variados de sua vida de acordo com o assunto da pesquisa (PRODANOV; FREITAS, 2013).

Algumas reuniões informais, no próprio local de trabalho, foram realizadas com o intuito de obter melhor entendimento sobre a dinâmica da rotina das atividades desenvolvidas na área.

\section{INTRODUÇÃO DA PROPOSTA NA ESTRUTURA ORGANIZACIONAL \\ 4.1 PROPOSTA DE ADAPTAÇÃO A ESTRUTURA ORGANIZACIONAL}

De acordo com a lei federal no 8.666/93, os projetos básicos deve ser realizado em acordo com elementos necessários e suficientes, com nível de precisão adequado para caracterizar a obra ou serviço, identificando os elementos constituintes com clareza, soluções técnicas globais (tipo de estrutura) e localizadas (tipo de tubulação no banheiro); informações que possibilitem o estudo e a dedução de métodos construtivos, os tipos de serviços a executar, materiais e equipamentos a incorporar o projeto, subsídios para montagem do plano de licitação e gestão da obra, orçamento detalhado com custo global. Ainda, as mesmas somente poderão ser licitadas quando houver projeto básico aprovado pela autoridade competente, e disponível para exame dos 
interessados em participar do processo licitatório.

Antes da iniciação da obra, submete-se para projetos de construção o dever ser aprovado nas municipalidades e órgãos competentes, incluindo o plano de construção, material específico. Outros prérequisitos, tais como: planilha orçamentaria, planos de controle de qualidade e métodos de inspeção também precisa ser estabelecido antes da licitação e liberação do vencedor à execução do objeto licitado. Para atual estrutura organizacional não ocorre algumas etapas que são desejadas, além da necessidade de aprovação dos projetos para regularização de sua execução.

Figura 2 - Atual Estrutura Organizacional

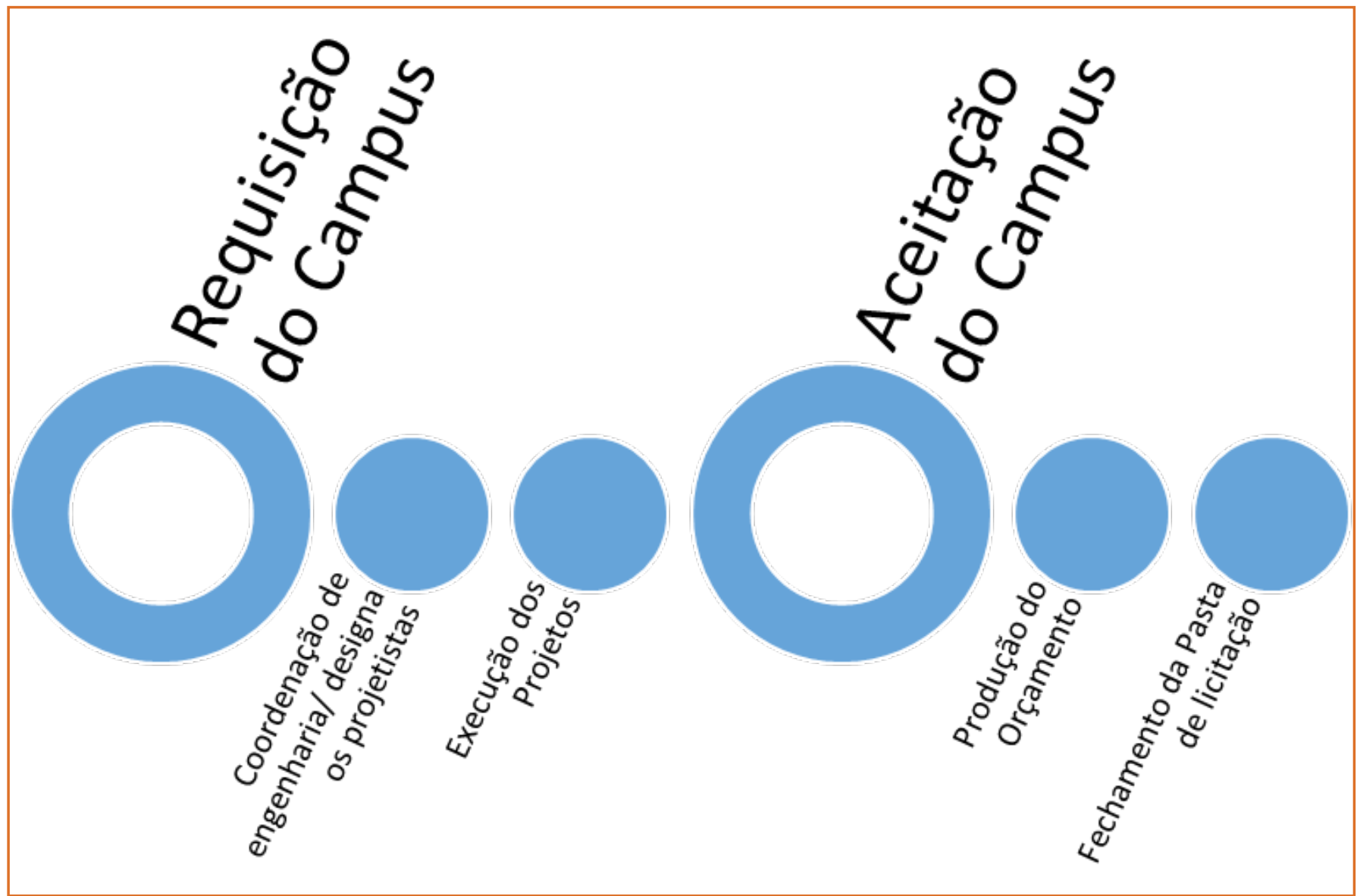

Fonte: O autor, 2015

A atual estrutura organizacional do setor de projetos públicos da instituição federal tem um fluxo próprio que gera o ciclo de vida do projeto, baseandose na experiência adquirida pela coordenação de engenharia ao longo de sua gestão, essa esteve numa tentativa de atender a expansão patrimonial da instituição; foi relatado um número elevado de requisições (pedido de elaboração de projeto) partida dos Campus para a equipe existente, tendo essa que atender a demanda em curto espaço de tempo. A estruturação não ocorreu de maneira satisfatória, devido as reclamações foi exigido um corpo técnico maior, assim houve uma melhora ao avanço intelectual e produtivo. No setor o processo do projeto seguido era ordenar as requisições advindas dos Campus, os diretores eram os responsáveis pelo pedido, não havia formalização nos pedidos, apenas ocorria uma visita ao Campus com uma conversação a respeito do ambiente que atenderia as suas necessidades, com a verba encaminhada pelo Governo. Desse passo em diante era levantado as medidas do terreno, caso não existisse nenhuma planta com as informações do terreno, ainda visualmente ou por técnicas rudimentares era observado a topografia sobre o qual 
seria elevado a edificação.

Com as informações anotadas em prancheta, o encaminhamento era feito ao setor de projetos, que seria demandado a um profissional técnico que apresentasse menor demanda, sendo assim aleatório a escolha do corpo técnico intelectual produtivo. Com a prática e organização dada pelo coordenador de engenharia, foi notado um avanço em pedido de aditivos ou supressão da execução da edificação. A equipe de engenharia não atendia a demanda existente, assim como não apresentava um cronograma de execução dos projetos, tendo datas de entrega sem uma prefixação ou cronograma que forme uma linha de base para ter um ciclo de projeto visível.

Para maximizar os efeitos estabelecidos com as alternativas dos projetos básico, pelo seu valor para engenharia, consiste em uma equipe de engenharia ter suas habilidades e conhecimentos através da experiência adquirida no universo vivenciado, conduzindo o desenvolvimento desse e as avaliações econômicas da produção em sua fase de manutenção; quem vem a ser um fator importante no sucesso da proposta. Aprimorando assim, a condução de três aspectos relevantes como: economia, funcionalidade e conveniência ao usuário.

Projetos de obras pública pode exibir três papéis importantes no desenvolvimento estratégico de uma sociedade: (1) satisfazer as necessidades humanas, econômicas e sociais; (2) elevar imagem social de um país; e (3) a visibilidade em principais eventos internacionais (JIA et al., 2011).

Usando uma estratégia adequada, as partes interessadas podem aumentar a atenção do coordenador de engenharia e arquitetura em satisfazer as suas reivindicações e contribuir deste modo com os resultados do projeto. É sugerido ainda que as estratégias de partes interessadas que influenciam na dinâmica do ciclo de vida do projeto inteiro, como partes interessadas em assumir diferentes papéis e ações para lidar com as possíveis mudanças dos projetos.

Em conclusão, em relação ao projeto original, as alternativas de desenho, serão mostrados para ser vantajoso nos aspectos usufruto ao público e econômicos do ciclo de vida. Como tal, utilizando a proposta desenvolvida, o estudo poderá conduzir a análise alternativa de desenho nos aspectos qualitativo e econômicos por fase do projeto, desde a concepção à fase de operação e manutenção.

\subsection{PARA REALIZAR A ESTRUTURAÇÃO ORGANIZACIONAL}

A estruturação vem para alinhar em uma base todas as informações que estrutura a formação dos projetos, para organizar esse ambiente está sendo proposto no artigo uma estrutura organizacional com vista nas atividades da instituição federal de ensino superior, de acordo com a Figura 3.

Figura 3 - Proposta de Estrutura Organizacional

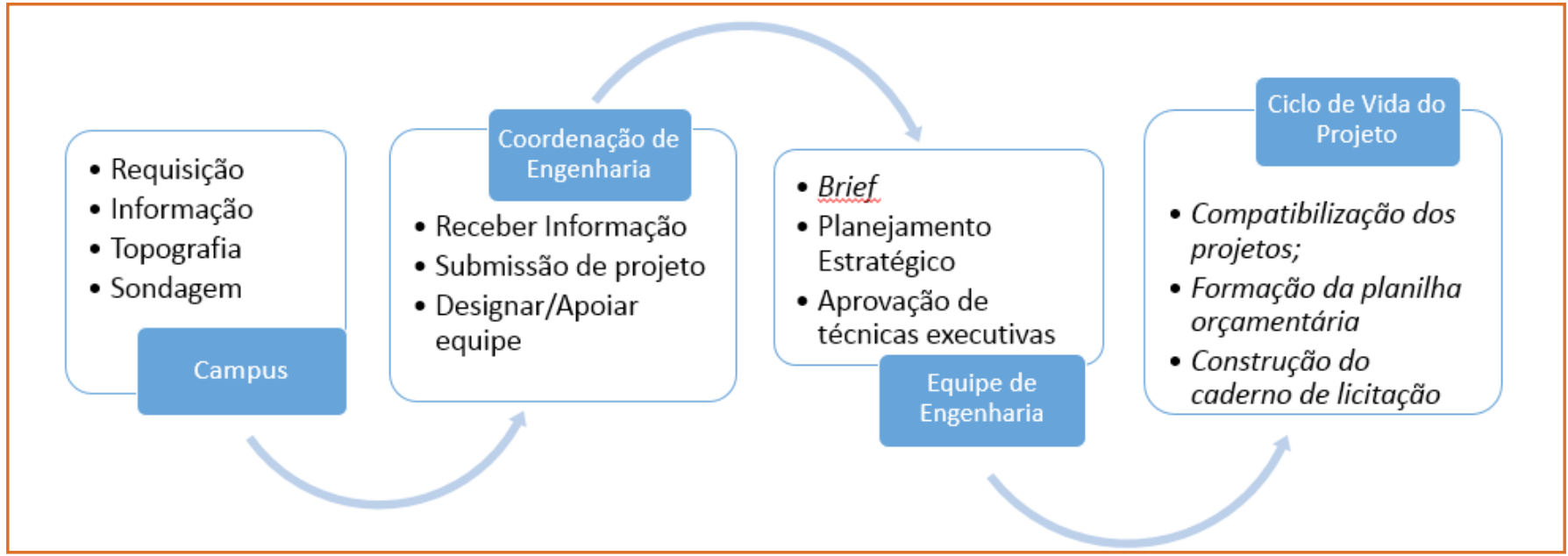


O Campus é detentor de orçamento que possibilita aplicar em investimentos, esse recurso quando aplicado em edificações como forma de aumento do seu patrimônio, vem a atender seus anseios na formação de ambientes específicos, voltados ao ensino, seja ele uma sala de aula, laboratório, refeitório, ou seja, uma serie de possibilidades de projetos, cada qual com amplitudes e requisições de matérias específicos para sua utilização. Sendo o Diretor do Campus administrador de maior hierarquia, é dele que vem as informações sobre edificação, em vista do seu conhecimento a formação de dados será fornecido por um formulário em que se tenha a resposta de informações mínimas e necessárias para preparação do projeto básico, o que vem a ser respondido é qual ambiente será construído, identificando assim a EAP para essa finalidade, mas anterior a isso, saber se o terreno apresenta estudos técnicos preliminares (serviços de sondagem e topografia do terreno), propiciando o nível de precisão adequado para a elaboração do projeto básico, e em conformidade ao planejamento estratégico.

Seguindo com captura das informações básicas, a coordenação designa a equipe que terá em sua responsabilidade a montagem do processo de projetar, já firma o plano tático, com reunião prévia com os servidores, esboçando medidas técnicas que soluciona de forma econômica, funcional e almejando sua eficácia, diante da aprovação, passada por esse brief, um estágio será avançado.

Em conjunto, a equipe pode se comunicar com a finalidade informativa, ou ainda como engenharia simultânea, pois as experiências passadas de cada servidor e sua apropriação na atividade engajada elimina erros ocorridos em um histórico da instituição e se fizer necessário aumentar o conhecimento desse servidor, que seja capacitado para sua atividade fim, enriquecendo o quadro de conhecimento, podendo ainda ser um reprodutor de conhecimentos, ganho que é percebido na solução de falhas, anteriormente repetitivas.

Ao fim, todos os projetos devem se reencontrarem em uma medida qualitativa conhecida como compatibilização de projetos, a compatibilização de projetos compreende a atividade de sobrepor os vários projetos e identificar as interferências, nessa fase programa-se reuniões com as agentes, projetistas e a coordenação, com o objetivo de resolver interferências que tenham sido detectadas. Logo, a compatibilização de projetos torna os projetos compatíveis, proporcionando soluções que vem a integrar as diversas áreas da edificação formatando-o exequível.

Figura 4 - Ciclo de Projeto

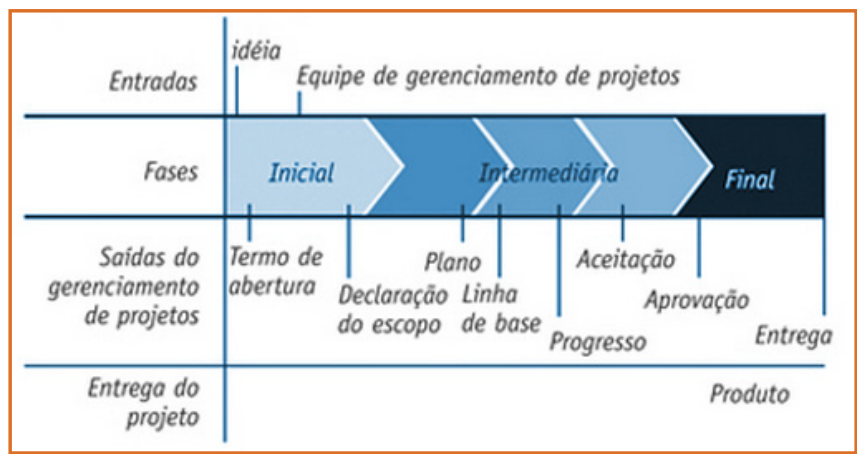

Fonte: Manual para Elaboração do Programa de Eficiência Energética da ANEEL (MPEE), 2008

A formação de ciclo de vida do projeto proposto neste artigo, assim como indicado pelo MPEE (2008), é advinda de uma apuração de boas práticas pela qual a instituição e da experiência dos servidores adquiridas em anos de trabalho em grandes empresas do setor privado, o ciclo vem a auxiliar na consolidação da execução e previsibilidade de resultados com eficiência, economia e funcionalidade.

Com a soma de todos os memoriais, especificações, de cada projeto, em formato compatibilizado, vem a somar como qualidade na construção da planilha orçamentária, que é também em sua essência um planejamento da obra, sendo que em forma de quantificação dos insumos, mão de obra, equipamentos, tempo de execução dos serviços, ou seja, resultante dos serviços previstos e planejados, o qual são necessários para a execução da obra, além de prever os custos, e precificação da edificação.

A percepção do servidor pode ser conseguida através da formação e sensibilização definindo o roteiro, métricas e mensuração (MEHTA et. al., 2012). O servidor orçamentista, que tem a responsabilidade de 
orçar, esse quando munido da experiência prática de como executar uma obra, provem de uma carga de conhecimento que o possibilita em não falhar no custeio da edificação, pois, conhece as técnicas executivas o que agrega valor na EAP do orçamento, não gera superfaturamentos, falta de previsão de serviços necessário à execução, essas falhas são ratificadas com o uso de aditivos em pedido de reajuste do valor orçado e prazo adicional.

A reunião dos projetos, com os devidos memoriais, especificações, planilha orçamentária, forma o caderno de licitação, a qualidade do caderno de licitação é intrínseca ao que foi produzido, o ciclo se fecha com a entrega desse objeto, mas elimina a responsabilidade que foi empregada pela equipe.

\section{CONSIDERAÇÕES FINAIS}

Conforme foi conduzido no artigo, o setor de projetos de obras públicas de uma instituição de ensino público federal, é responsável pela produção de projetos, que responde aos anseios da população interna e externa, exigindo assim a readequação do setor em sua estruturação, sendo o gerente de projeto a pessoa que conduz a apropriação, auxiliou o planejamento estratégico e desenvolveu o seu ciclo de vida.

A conclusão que estratificou o fator de percepção em fatores intrínsecos (compromisso) e fatores externos (comunicação) que afetavam a eficácia, economicidade e funcionalidade dos projetos. Sugerido como uma possibilidade de transformação, que ficou na responsabilidade dos servidores, coordenadores e comunicação, os métodos de trabalho. Para ser prontamente objetivo se faz necessário que as percepções dos servidores sejam influenciadoras no posicionamento tomado pelos responsáveis de cada setor (coordenadores e diretores). Implantar métodos de trabalho como forma de rotina, auxiliou o servidor na identificação do seu envolvimento, particularmente o compromisso, na participação da estruturação organizacional, se explorou o seu conhecimento prévio na resolução de projetos e troca de informação em engenharia simultânea. sistemática, auxiliou no plano de suas atividades, essas geraram especificações técnicas com qualidade e maior grau de acerto, a própria interação da equipe com troca de informações e experiências, possibilitou a uma rápida compatibilização dos projetos; ensejados diretamente na produção da planilha orçamentária, que por sua vez margeou preços finais com maior eficácia e menor geração de aditivos, pois, foi encontrado menores quantidades de erros nos projetos e na orçamentação (relação dos serviços na edificação).

A compilação dos documentos que foram gerados no decorrer do ciclo, formou o caderno de licitações, apresentado com mais informações para o desenvolvimento do edital de licitação, e com menos lacunas que favorecem aos pedidos de aditivos.

Dessa forma, concluiu-se que o planejamento estratégico não se alinhava a uma estrutura organizacional. Para a proposta do artigo, apresentou práticas observadas como ponto facilitador na estruturação organizacional. No geral, o início e término do planejamento estratégico seguem o propósito dos princípios da gestão de projeto, os meios se utilizaram de técnicas normatizadas para captação de informação, produção dos projetos, qualificação desses pela compatibilização e estruturação organizacional.

Sugere-se, para fins de pesquisas futuras, que se estude maneiras de capacitar os condutores do planejamento estratégico e da gestão de projeto, e levantar dados dos erros e acertos correlacionados aos pedidos de aditivos e reformulações de projetos, visando assim, melhor efetividade em suas práticas.

\section{REFERÊNCIAS}

[1] BRASIL. Lei № 8.666, DE 21 DE JUNHO DE 1993 Regulamenta o art. 37, inciso XX I, da Constituição Federal, institui normas para licitações e contratos da Administração Pública e das outras providencias. Disponível em: http:// www. planalto.gov.br/ccivil_03/Leis/L8666cons.htm. Acesso em 23/09/2015.

[2] BROWN, D.C.; ASHLEIGH, M.J.; SHAW, R.D. New Project Procurement Process. J. of Man. In Eng. 17 (4), 192201, 2001. 
[3] BURTON, R.M.; OBEL, B. Strategic Organizational Diagnosis and Design: Developing Theory for Application. Kluwer Academic Publisher, Boston, 2003.

[4] CICMIL, S.; MARSHALL, D. Insights into collaboration at the project level: complexity, social interaction and procurement mechanisms. Build. Res. Inf. 33, 523-535, 2005.

[5] CHIAVENATO, IDALBERTO. Administração nos novos tempos. Elsevier: Rio de Janeiro, 2004.

[6] DOOMS, M., VERBEKE, A., HAEZENDONCK, E. Stakeholdermanagement and path dependence in largescale transport infrastructure development: the port of Antwerp case (1960-2010). J. Transp. Geogr. 27, 14-25, 2013.

[7] EMUZE, F., SMALLWOOD, J. Criticality of intelligent clients in the infrastructure sector. Proc. Inst. Civ. Eng. Munic. Eng. 164, 251-257, 2011.

[8] EWEJE, JOHN; TURNER, RODNEY; MULLER, RALF. Maximizing strategic value from megaprojects: The influence of information-feed on decision-making by the project manager. International Journal Of Project Management, [s.I.], v. 30, n. 6, p.639-651, 2012.

[9] LINHARES, JORGE; QUARTAROLI, CLÁUDIO MÁRCIO. Guia de Gerenciamento de Projetos e Certificações PMP. Rio de Janeiro: Editora Ciência Moderna Ltda., 2004.

[10] LO, V.; HUMPHREYS, P. Project management benchmarks for SMEs implementing ISO 9000. Benchmarking: An International Journal, [s.I.], v. 7, n. 4, p.247-260, 2000.

[11] JIA, G.S.; YANG, F.J.; WANG, G.B.; HONG, B.N.; YOU, R. A study of mega project from a perspective of social conflict theory. Int. J. Proj. Manag. 29, 817-827, 2011.

[12] KERZNER, HAROLD. Gestão de projetos: as melhores práticas. Tradução Marco Antônio Viana Borges, Marcelo Klippel e Gustavo Severo Borba, Porto Alegre: Bookman, 2002.
[13] KO, CHIEN-HO; LI, SHUN-CHI. Enhancing submittal review and construction inspection in public projects. Automation In Construction, [s.I.], v. 44, p.33-46, ago, 2014.

[14] MILLER, R., LESSARD, D.R. The Strategic Management of Large Engineering Projects - Shaping Institutions, Risks and Governance. MIT Press, Cambridge, MA, 2000.

[15] MEHTA, RAJESH KUMAR; MEHTA, DHARMENDRA; MEHTA, NAVEEN K. An Exploratory study in employee's perception towards lean manufacturing systems. Management\&marketing, Volume X, 2012.

[16] MOK, KA YAN; SHEN, GEOFFREY QIPING; YANG, JING. Stakeholder management studies in mega construction projects: A review and future directions. International Journal Of Project Management, [s.I.], v. 33, n. 2, p.446-457, fev. 2015.

[17] OLANDER, S., LANDIN, A. A comparative study of factors affecting the external stakeholder management process. Constr. Manag. Econ. 26, 553-561, 2008.

[18] PMBOK/PMI® - Project Management Institute. Um Guia do Conjunto de Conhecimentos em Gerenciamento de Projetos (PMBOK®). 5aㅡ Edição. Project Management Institute, Inc. 2013.

[19] PRODANOV, CLEBER CRISTIANO; FREITAS, ERNANI CESAR DE. Metodologia do trabalho científico [recurso eletrônico]: métodos e técnicas da pesquisa e do trabalho acadêmico. 2. ed. Novo Hamburgo: Feevale, 2013.

[20] VARGAS, R. Gerenciamento de Projetos: estabelecendo diferenciais competitivos. 6.ed. Rio de Janeiro, 2005.

[21] WARD, S., CHAPMAN, C. Stakeholders and uncertainty management in projects. Constr. Manag. Econ. 26, 563-577, 2008. 


\section{CAPÍTULO 15}

\section{MODELO DE APOIO À TOMADA DE DECISÃO PARA SELEÇÃO DE FORNECEDORES POR MEIO DO ANALYTIC HIERARCHY PROCESS (AHP)}

\section{Wellington Gonçalves}

\section{Rodrigo Randow de Freitas}

Resumo: A tomada de decisão na seleção de fornecedores pode ser considerado peculiarmente como um problema multicritério. Esta é uma decisão de relevância estratégica para as empresas, de maneira geral, a natureza desta decisão é complexa e não estruturada. Técnicas de gestão da ciência podem ser ferramentas úteis para esses tipos de problemas de tomada de decisão. O objetivo deste trabalho é aplicar o Analytic Hierarchy Process (AHP) na seleção de fornecedores por meio de um método customizado, como forma de auxiliar os gestores em suas tomadas de decisão, proporcionando o máximo de satisfação para os critérios determinados. Foram entrevistados especialistas da empresa pesquisada envolvidos diretamente no processo de seleção e relacionamento com fornecedores, sendo selecionados os critérios mais importantes considerados pelos respondentes, os quais foram utilizados como parâmetros de entrada para o modelo proposto. Segundo os especialistas, ao realizar uma análise multicritério para comparar empresas fornecedoras, os resultados alcançados podem ser considerados dentro dos padrões de mercado.

Palavras Chave: Tomada de decisão, Seleção de fornecedores, Sistemas de apoio à decisão, Analytic Hierarchy Process (AHP). 


\section{INTRODUÇÃO}

As frutas, verduras e legumes podem ser considerados essenciais à saúde humana, e seu consumo tende auxiliar na prevenção de doenças. Por conseguinte, a Organização Mundial da Saúde (OMS) recomenda o consumo mínimo de 400 g/dia destes produtos, o equivalente a cinco porções diárias. Assim, o estímulo ao consumo passa ser justificado na agenda das políticas públicas de saúde em diversos países, até mesmo no Brasil. No entanto, a ingestão destes alimentos está aquém da quantidade recomendada pela OMS, havendo um baixo consumo em todo território brasileiro (BRASIL, 2013). Com isso, a promoção do aumento da ingestão de frutas, legumes e verduras pode ser entendida como prioridade em termos de saúde pública.

Também, quando analisamos os principais entraves atuantes nas taxas de consumo per capta nacional, observa-se que os riscos de produção, de preço, de crédito, de conduta e de contratos podem ser considerados como importantes no processo de disponibilização de produtos ao consumidor. Porém, é preciso considerar que os produtos que são originários da agroindústria, possuem ainda variáveis que são suscetíveis ao meio ambiente (PUTTI). Como por exemplo, as mudanças climáticas que afetam o ciclo desde o plantio até a colheita. Por isso, tornase necessário um planejamento que possa auxiliar na elaboração de previsões de tais intempéries.

Assim, considerando os pressupostos anteriormente explanados, é possível considerar como essencial a realização de uma seleção adequada dos produtos ofertados aos consumidores, nesse sentido, os métodos multicritérios tendem a prestar um grande auxílio nesse processo de tomada de decisão. Tanto por sua propriedade de integrar múltiplas diversidades, quanto em proporcionar aos julgadores possibilidades de escolhas baseadas em suas preferências (UYSAL; YAVUZ, 2014).
A partir do exposto, este trabalho tem como objetivo principal aplicar a ferramenta Analytic Hierarchy Process (AHP) na seleção de fornecedores, por meio de um método customizado, como forma de auxiliar os gestores em suas tomadas de decisão. Por último, como forma de validação, realizou-se um estudo de caso no setor de frutas e verduras de um supermercado localizado na região nordeste do Estado do Espírito Santo (ES).

\section{REFERENCIAL TEÓRICO}

O processo de seleção de fornecedores pode ser entendido como uma das atividades mais importantes da função compras, e para tanto, as empresas buscam selecioná-los da melhor forma, desde que possuam à qualidade desejada dos produtos, com os menores custos, dentre outros critérios. Sendo que este processo depende de diversos critérios, nos quais abordados extensivamente na literatura como um problema de tomada de decisão, no qual critérios específicos devem ser considerados no julgamento das possíveis empresas fornecedoras. Nesse contexto, os métodos multicritérios de apoio a tomadas de decisões podem ser empregados no desenvolvimento de modelos para seleção de alternativas para tal problema (CHAl; LIU; NGAI, 2013).

Esses problemas que envolvem o emprego de métodos multicritério são definidos por um número finito de alternativas, e que, por conseguinte, possuem critérios e subcritérios relacionados as alternativas e ao objetivo da tomada de decisão (SAATY, 1977). Por exemplo, a literatura indica a existência de diversos métodos, que sugerem soluções diversificadas de acordo com o objetivo que se deseja alcançar, sendo os mais citados: o TOPSIS (Technique for Order Preference by Similarity to Ideal Solution), o AHP e o ELECTRE (ELimination and Choice Expressing the REality), Tabela 1. 
Tabela 1 - Indicação comparativa de métodos multicritérios

\begin{tabular}{|c|c|c|c|c|c|}
\hline Características & AHP & TOPSIS & ELECTRE I & ELECTRE II & ELECTRE III \\
\hline Processo central & $\begin{array}{c}\text { Criação de estrutura } \\
\text { hierárquica e matrizes } \\
\text { de comparação } \\
\text { paritária }\end{array}$ & $\begin{array}{c}\text { Calcula a distância ao } \\
\text { ponto ideal (positivo e } \\
\text { negativo) }\end{array}$ & $\begin{array}{l}\text { Determinação } \\
\text { de índices de } \\
\text { concordância e } \\
\text { discordância }\end{array}$ & $\begin{array}{l}\text { Determinação } \\
\text { de índices de } \\
\text { concordância e } \\
\text { discordância }\end{array}$ & $\begin{array}{l}\text { Determinação } \\
\text { de índices de } \\
\text { concordância e } \\
\text { discordância com } \\
\text { limiares entre } \\
\text { indiferença e } \\
\text { preferência }\end{array}$ \\
\hline $\begin{array}{l}\text { Necessidade } \\
\text { de quantificar } \\
\text { a importância } \\
\text { relativa dos } \\
\text { critérios }\end{array}$ & Sim & Sim & Sim & Sim & Sim \\
\hline $\begin{array}{l}\text { Determinação de } \\
\text { pesos }\end{array}$ & $\begin{array}{c}\text { Matrizes de } \\
\text { comparação de pares } \\
\text { (escala 1-9) }\end{array}$ & $\begin{array}{l}\text { Nenhum método } \\
\text { específico. } \\
\text { Normalização linear ou } \\
\text { vetorial }\end{array}$ & $\begin{array}{c}\text { Nenhum método } \\
\text { específico. Com } \\
\text { base no tomador de } \\
\text { decisão }\end{array}$ & $\begin{array}{l}\text { Nenhum método } \\
\text { específico. Com } \\
\text { base no tomador } \\
\text { de decisão }\end{array}$ & $\begin{array}{c}\text { Nenhum método } \\
\text { específico. Com } \\
\text { base no tomador de } \\
\text { decisão }\end{array}$ \\
\hline $\begin{array}{l}\text { Número e tipo } \\
\text { de relações de } \\
\text { subordinações }\end{array}$ & $N(N-1) / 2$ & 1 & 1 & 2 & 1 Fuzzy \\
\hline $\begin{array}{l}\text { Verificação de } \\
\text { consistência }\end{array}$ & Fornece & Nenhuma & Nenhuma & Nenhuma & Fornece \\
\hline $\begin{array}{l}\text { Estrutura do } \\
\text { problema }\end{array}$ & $\begin{array}{l}\text { Pouco número de } \\
\text { alternativas e critérios, } \\
\text { análise quantitativa ou } \\
\text { qualitativa de dados }\end{array}$ & $\begin{array}{l}\text { Grande número de } \\
\text { alternativas e critérios, } \\
\text { utiliza dados objetivos } \\
\text { e quantitativos }\end{array}$ & $\begin{array}{c}\text { Grande número de } \\
\text { alternativas e critérios, } \\
\text { utiliza dados objetivos } \\
\text { e quantitativos }\end{array}$ & $\begin{array}{c}\text { Grande número } \\
\text { de alternativas e } \\
\text { critérios, utiliza } \\
\text { dados objetivos e } \\
\text { quantitativos }\end{array}$ & $\begin{array}{l}\text { Dados objetivos e } \\
\text { quantitativos, uso da } \\
\text { lógica fuzzy }\end{array}$ \\
\hline Resultados Finais & Ordenação geral & Ordenação geral & $\begin{array}{l}\text { Subconjunto de } \\
\text { alternativas }\end{array}$ & $\begin{array}{l}\text { Parcialmente } \\
\text { ordenado }\end{array}$ & $\begin{array}{l}\text { Parcialmente } \\
\text { ordenado }\end{array}$ \\
\hline
\end{tabular}

Fonte: Adaptado de Saaty (1977), Lima Júnior e Carpinetti (2015) e Kou et al. (2012)

O Analytic Hierarchy Process (AHP) também conhecido na literatura por Hierarchical Analysis Method (HAM), foi selecionado por utilizar em sua resolução características quantitativas e qualitativas do problema abordado, podendo levar um consenso de preferência aos tomadores de decisão, concentrando o conhecimento e as prioridades de especialistas (SAATY, 1977; SUBRAMANIAN; RAMANATHAN, 2012). Este método foi elaborado na década de 70 pelo matemático Thomas Lorie Saaty, e tem sido aplicado na tomada de decisão em diversos cenários complexos, em que as percepções humanas, julgamentos e consequências possuem repercussão de longo prazo (SAATY, 1977; DURBACH; LAHDELMA; SALMINEN, 2014).
O AHP pode ser entendido pela composição de três fases distintas: (i) decomposição dos elementos de um problema como uma hierarquia formadas por critérios, subcritérios, atributos e alternativas, segundo a opinião dos especialistas envolvidos; (ii) comparação par a par dos julgamentos dos critérios, subcritérios, atributos e alternativas nos níveis da hierarquia; e (iii) o cálculo dos pesos e análise da consistência lógica (SAATY, 2008). A exposição do problema deve ser clara, assertiva e estruturada em formato hierárquico, disposta em forma de árvore como indicado na Figura 1. 
Figura 1 - Estrutura Hierárquica básica do AHP

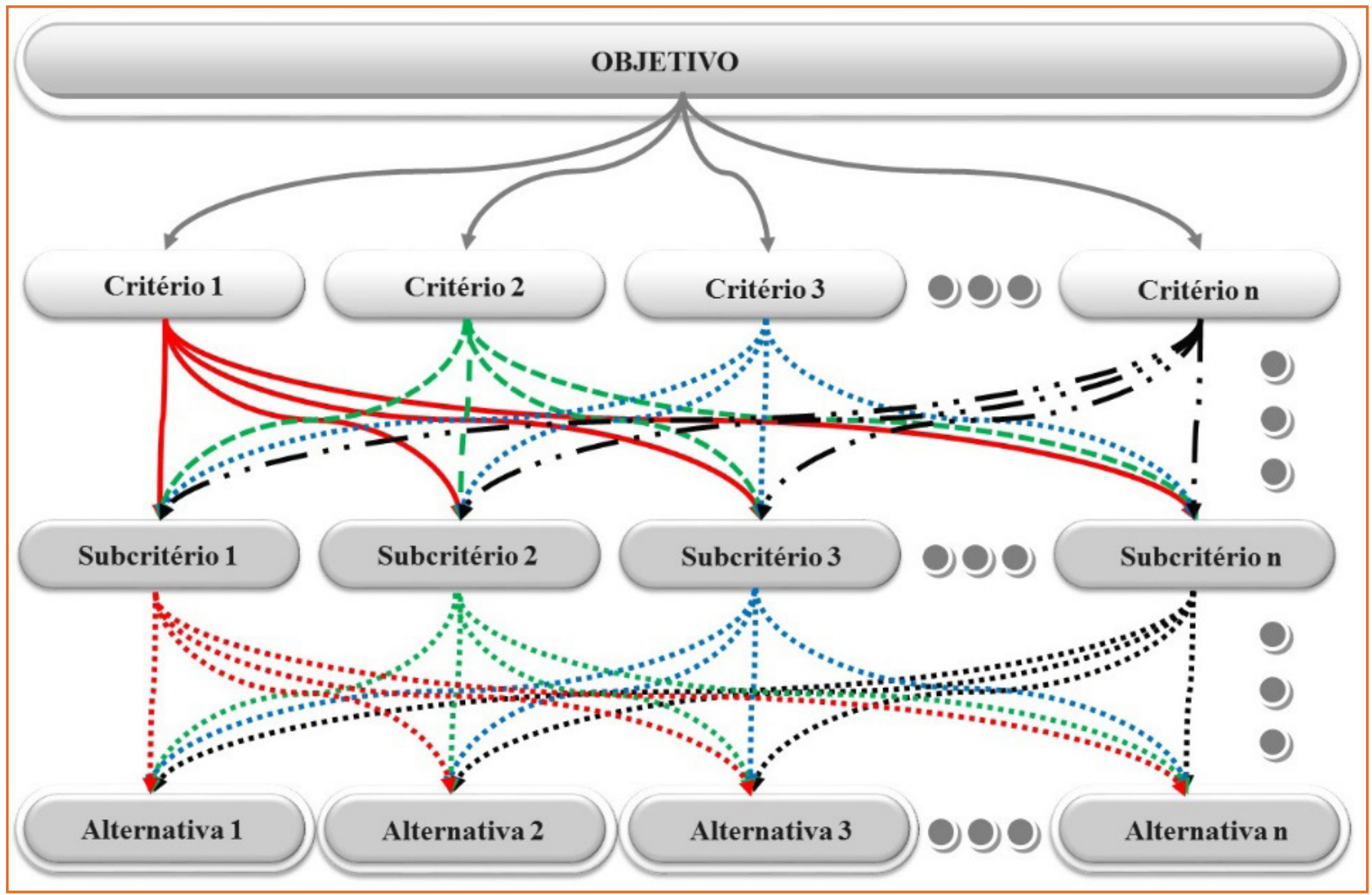

Fonte: Adaptado pelos autores a partir de Saaty (2008)

A avaliação de cada elemento da estrutura hierárquica passa ser possível devido a transformação das comparações empíricas em valores numéricos, os quais são processados e comparados par a par, vale destacar que a capacidade de conversão de dados práticos em valores numéricos, pode ser apontada como um dos destaques do AHP em comparação com outros métodos (SAATY, 1977).

A comparação entre elementos paritários pode ser realizada de diferentes formas, no entanto, a escala de importância relativa entre duas alternativas proposta por Saaty é a mais utilizada na literatura (TRIANTAPHYLLOU; MANN, 1995; BRUNO et al., 2012). A partir da atribuição de valores que variam de 1 a 9 (Tabela 2), a escała determina a importância relativa de uma alțernativa com relação à alternativa $j$ expressa por , sendo o inverso a comparação da alternativa $j$ em relação à alternativa $i$ expresso
Tabela 2 - Escala de importância relativa de Saaty

\begin{tabular}{|c|c|c|c|}
\hline Escala verbal & $\begin{array}{c}\text { Escala } \\
\text { numérica } \\
\left(\begin{array}{c}\left.a_{i j}\right) \\
\end{array}\right.\end{array}$ & Escala verbal & $\begin{array}{c}\text { Escala } \\
\text { numérica } \\
\left(\begin{array}{c}\left.a_{i j}\right)\end{array}\right.\end{array}$ \\
\hline $\begin{array}{c}\text { Extremamente } \\
\text { preferido }\end{array}$ & 9 & $\begin{array}{c}\text { Entre } \\
\text { moderado e } \\
\text { forte }\end{array}$ & 4 \\
\hline $\begin{array}{c}\text { Entre muito forte e } \\
\text { extremo }\end{array}$ & 8 & & 3 \\
\hline $\begin{array}{c}\text { Muito fortemente } \\
\text { preferido }\end{array}$ & 7 & $\begin{array}{l}\text { Entre igual e } \\
\text { moderado }\end{array}$ & 2 \\
\hline $\begin{array}{l}\text { Entre forte e muito } \\
\text { forte }\end{array}$ & 6 & $\begin{array}{l}\text { Igualmente } \\
\text { preferido }\end{array}$ & 1 \\
\hline $\begin{array}{c}\text { Fortemente } \\
\text { preferido }\end{array}$ & 5 & & \\
\hline
\end{tabular}

Fonte: Adaptado pelos autores a partir de Saaty (1977) A utilização da escala de importância relativa na avaliação dos critérios, subcritérios, atributos e alternativas irá gerar uma matriz de resultados com valores numéricos (Tabela 3), a qual é empregada 
na comparação par a par dos elementos da estrutura hierárquica.

Tabela 3 - Exemplo de matriz de avaliação dos critérios ou atributos

\begin{tabular}{|l|l|l|l|l|}
\multicolumn{1}{|c}{ Atributos } & \multicolumn{1}{c}{$\begin{array}{c}\text { Atributo } \\
1\end{array}$} & \multicolumn{2}{c|}{$\begin{array}{c}\text { Atributo } \\
2\end{array}$} & \multicolumn{1}{c|}{ Atributo } \\
\hline Atributo 1 & 1 & $1 / a_{21}$ & $\ldots$ & $1 / a_{N 1}$ \\
\hline Atributo 2 & $a_{21}$ & 1 & $\ldots$ & $1 / a_{N 2}$ \\
\hline & $\ldots$ & $\ldots$ & $\ldots$ & $\ldots$ \\
\hline Atributo N & $a_{N 1}$ & $a_{N 2}$ & $\cdots$ & 1 \\
\hline
\end{tabular}

Fonte: Adaptado pelos autores a partir de Saaty (1977)

As atribuições de pesos devem ser feitas por cada um dos $\mathrm{K}$ especialistas respondentes, a partir destas ações serão geradas matrizes de avaliação com as respostas obtidas, no entanto, é necessário estabelecer um único conjunto de matrizes (atributos e alternativas por atributos) que represente todo o processo de avaliação (SAATY, 1977; BRUNO et al., 2012).

Nesse contexto, Aczél e Saaty (1983), destacam que deve ser utilizada a média geométrica dos valores obtidos, com o objetivo de manter as características dos pesos e seus recíprocos, em que cada elemento

$a_{i j}^{c}$ das matrizes consolidadas pode ser determinado (Equação 1).

$$
a_{i j}^{c}=\prod_{i=1}^{k} a_{i j}^{1 / k}
$$

Então, dada a obtenção das matrizes consolidadas, os valores devem ser padronizados com relação a cada elemento obtido, como apresentado na Tabela 4.

Tabela 4 - Exemplo de matriz com atributos padronizados

\begin{tabular}{|c|c|c|c|c|}
\hline \multicolumn{2}{|c}{$\begin{array}{c}\text { Atributo } \\
\text { Atributos }\end{array}$} & $\begin{array}{c}\text { Atributo } \\
2\end{array}$ & \multicolumn{2}{c|}{ Atributo } \\
\hline Atributo 1 & & & $\ldots \ldots$ & \\
\hline$\cdot$ & & & $\ldots . .$. & \\
\hline. & $\ldots \ldots$ & $\ldots \ldots$ & $\ldots \ldots$ & $\ldots \ldots$ \\
\hline Atributo N & & & $\ldots \ldots$ & \\
\hline
\end{tabular}

Fonte: Adaptado pelos autores a partir de Saaty (1977)

Em que cada elemento da matriz com atributos padronizados é obtido a partir da Equação 2.

$a_{i j}^{c}=a_{i j}^{c} / \sum_{i=1}^{j} a_{i j}^{c}$

A partir da matriz dos atributos consolidada e padronizada, é possível calcular os pesos relativos entre os critérios e subcritérios, que podem ser determinados pelo cálculo da média aritmética dos elementos das linhas correspondentes a cada um deles (Equação 3).

$$
p a_{i j}=\sum_{i=1}^{j} a_{i j}^{c} / N
$$

Após a determinação dos pesos de cada critério, subcritério e atributo é possível estabelecer a hierarquia entre os mesmos, nesse caso, é obtido o grau de importância que os especialistas atribuíram em cada julgamento.

Desta forma, o mesmo processo matemático deve ser realizado para cada alternativa sblf $a_{i a}$ ótica de cada atributo, os valores dos pesos ( ) indicam a classificação hierárquica das alternativas. Desta forma, para que se possa obter o resupire final da análise, determina-se o peso global ( ) de cada alternativa, calculando-se a média ponderada dos pesos (Equação 4).

$$
p g_{i}=\sum_{i=1}^{j}\left(p_{i}\right) \bullet g\left(p a_{i j}\right)
$$


O método AHP foi idealizado para minimizar as possíveis inconsistências pessoais dos especialistas, assim, ao serem alcançadas as matrizes de julgamentos, devem ser verificadas suas consistências lógicas (SAATY, 1977). Para tanto, é calculada a Razão de Consistência $(R C)$, que pode ser obtida por meio da Equação 5.

$$
R C=I C / R C
$$

A RC indica a confiabilidade do julgamento dos especialistas, além isso, deve haver o atendimento a condição $R C \leq 0,10$, para não causar necessidades de aprimoramento com a operação real e seus julgamentos (SAATY, 2008). O Índice de Consistência (IC) randômica elaborado por uma matriz recíproca de ordem $n$, é gerado randomicamente com elementos não negativos (Equação 6).

$$
I C=\left(\ddot{e}_{\text {máx. }}-n\right) /(n-1)
$$

Em que o IC indica a coerência dos julgamentos, sendo quanto mais próximo estiver de zero, maior será a consistência global da matriz de comparação, entretanto, se estas condições não forem atendidas, será necessário refazer todos os julgamentos, ou até descartar a avaliação (SAATY, 1977).

Ao serem conhecidos os pesos globais, passa a ser possivel hierarquizar as alternativas, e dentro do planejamento desejado e prioridades de execução, pode ser possível selecionar a opção mais adequada ao momento decisório, o que não significa que a solução com maior peso seja utilizada.

\section{MÉTODOS ETÉCNICAS DE PESQUISA}

Para atender ao objetivo proposto foi elaborada uma metodologia para utilização do AHP, a qual foi subdividida em 5 etapas (Figura 2), corroborando, para validação do artigo foi realizado um estudo de caso no setor de frutas e verduras de um supermercado localizado na região nordeste do Estado do Espírito Santo (ES).

Figura 2 - Etapas metodológicas para aplicação do AHP

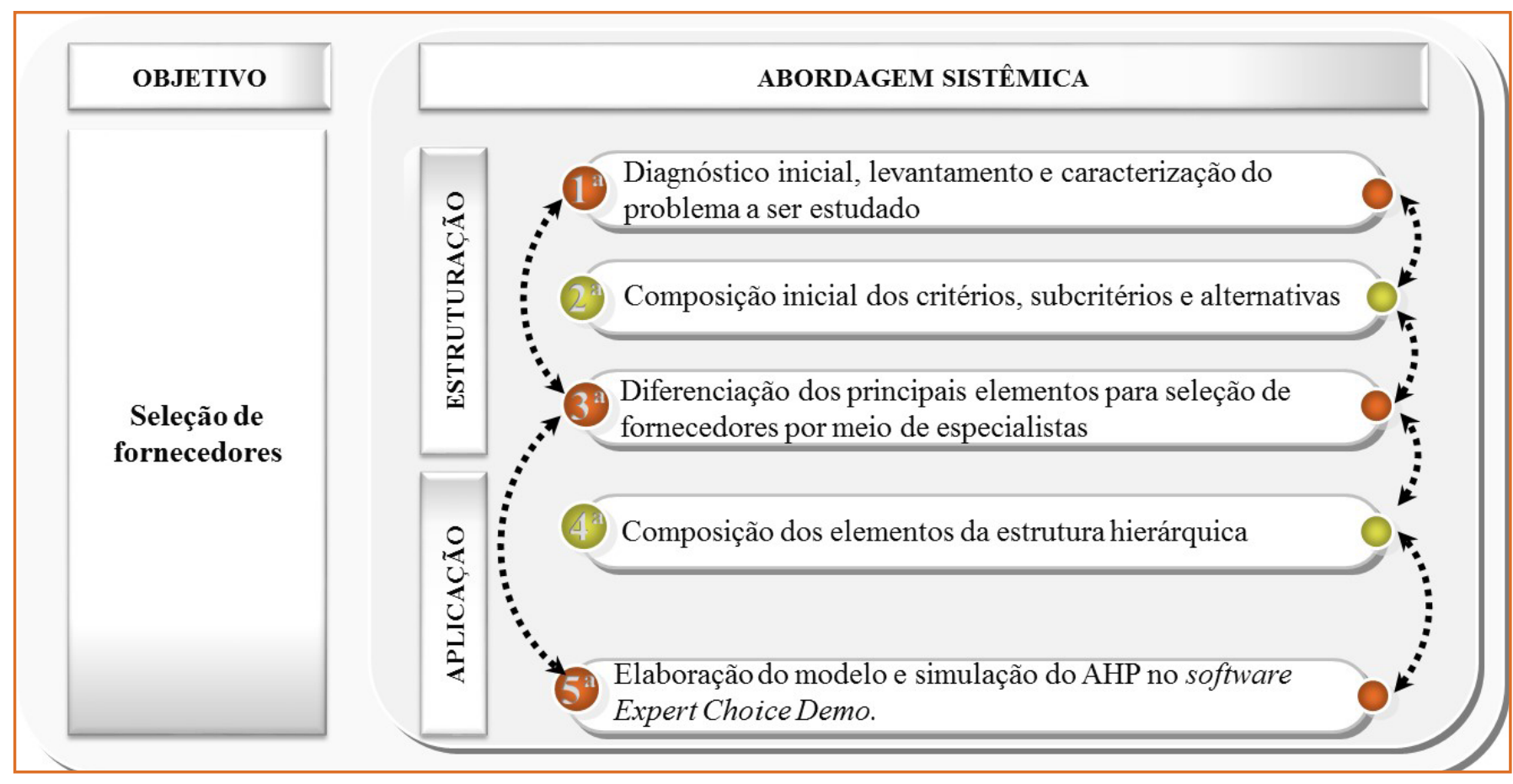

A primeira etapa do método customizado constituise do diagnóstico das condições que configuram o problema estudado, seguido do levantamento e caracterização das necessidades da seleção de fornecedores.
Na sequência é realizada a composição inicial dos critérios, subcritérios e atributos (segunda etapa), sendo concretizada por meio de levantamento juntos aos especialistas do supermercado (gerentes geral e de compras, e o supervisor do setor de frutas e 
verduras), a partir do alinhamento dos dados obtidos e do escopo geral do trabalho.

A terceira etapa evidencia pela diferenciação dos principais elementos para seleção de fornecedores, sendo realizada por meio de uma pesquisa survey junto aos especialistas. Por conseguinte, os elementos da estrutura hierárquica serão compostos tendo como parâmetros o objetivo a ser atingido, além dos critérios, subcritérios, atributos e alternativas levantados junto aos especialistas (quarta etapa).

Por fim, a quinta etapa é evidenciada pelo emprego do software Expert Choice Demo para calcular os pesos relativos de cada elemento estabelecido obtidos na terceira e quarta etapa, contribuindo para a formação e cálculo das árvores ou estruturas hierárquicas de decisão.

\section{APLICAÇÃO E DISCUSSÃO DOS RESULTADOS}

A partir destes pressupostos anteriores, nesta seção, é apresentado um estudo de caso que aborda a seleção de fornecedores de frutas e verduras em um supermercado localizado na região nordeste do Estado do Espírito Santo (ES).

Ao realizar o diagnóstico junto aos especialistas e na empresa, foi possível verificar a relevante importância de que as frutas e verduras são produtos perecíveis, e que necessitam chegar ao consumidor final com frescor, aroma e textura característicos de cada produto. Assim, os fornecedores devem levar em consideração alguns critérios para atender a estes quesitos.

Considerando a expertise dos especialistas, no qual os mesmos afirmam que devido as características intrínsecas dos produtos em questão, o número máximo de fornecedores deve ser limitado. Com isso, foi adotado o quantitativo de 4 fornecedores (Fornecedor A, Fornecedor B, Fornecedor C e Fornecedor D) como alternativas a serem selecionadas, atendendo as prerrogativas levantadas (primeira etapa).

Por conseguinte, considerando o diagnóstico inicial, levantamento e caracterização do problema junto aos especialistas, foi realizada a composição inicial dos critérios, subcritérios, alternativas e atributos (segunda etapa - Tabela 5).

Tabela 5 - Composição inicial dos critérios, subcritérios, alternativas e atributos

\begin{tabular}{|l|l|}
\hline Objetivo & $\begin{array}{l}\text { Seleção de fornecedores para o departamento } \\
\text { de frutas e verduras de um supermercado. }\end{array}$ \\
\hline Critérios & Qualidade, entrega, financeiro. \\
\hline Subcritérios & $\begin{array}{l}\text { Relacionados à qualidade: integridade física dos } \\
\text { produtos, ou seja, produtos isentos de avarias } \\
\text { e vetores; consumo de produtos em estado } \\
\text { adequado para venda (estado de maturação); } \\
\text { uso, emprego e controle de defensivos agrícolas } \\
\text { na produção. } \\
\text { Relacionados à entrega: transporte dentro dos } \\
\text { padrões estabelecidos por órgãos fiscalizadores } \\
\text { e intervenientes para se conservar o produto; } \\
\text { atendimento ao pedido em termos quantitativos } \\
\text { considerando a demanda e suas flutuações; } \\
\text { produtos entregues no prazo estabelecido. } \\
\text { Relacionados ao financeiro: preço de aquisição } \\
\text { produto com relação a concorrência; custo do } \\
\text { frete compatível com o mercado. }\end{array}$ \\
\hline Alternativas & $\begin{array}{l}\text { Fornecedor A, Fornecedor B, Fornecedor C e } \\
\text { Fornecedor D. }\end{array}$ \\
\hline
\end{tabular}

Uma pesquisa survey foi realizada junto aos especialistas com o objetivo de assinalar os principais elementos para seleção dos fornecedores (terceira etapa). Na sequência, os elementos da estrutura hierárquica (Figura 3) foram compostos tendo por parâmetro o objetivo a ser atingido, além dos critérios, subcritérios, atributos e alternativas levantados junto aos especialistas nas etapas anteriores (quarta etapa). 
Figura 3 - Composição dos elementos da estrutura hierárquica

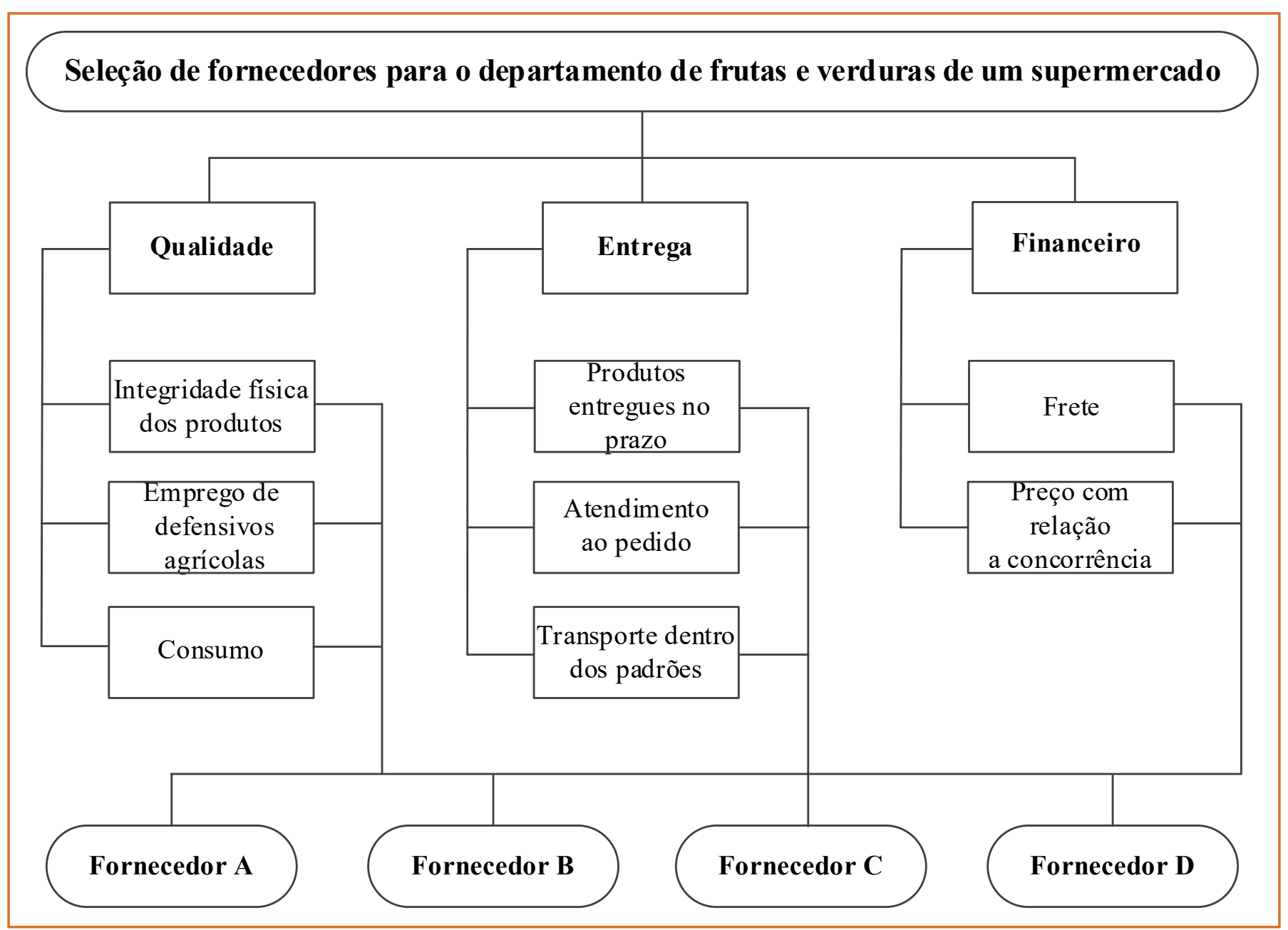

Por fim, a quinta etapa é evidenciada pelo emprego do software Expert Choice Demo para calcular os pesos relativos de cada elemento estabelecido obtidos na terceira e quarta etapa, contribuindo para a formação e cálculo das árvores ou estruturas hierárquicas de decisão. Assim, o modelo foi aplicado e simulado tendo por base a composição dos elementos da estrutura hierárquica (etapa anterior), na sequência, foram calculados os pesos relativos de cada elemento (Figura 4). 
Figura 4 - Julgamentos globais

\section{Seleção de fornecedores para o departamento de frutas e verduras de um supermercado}

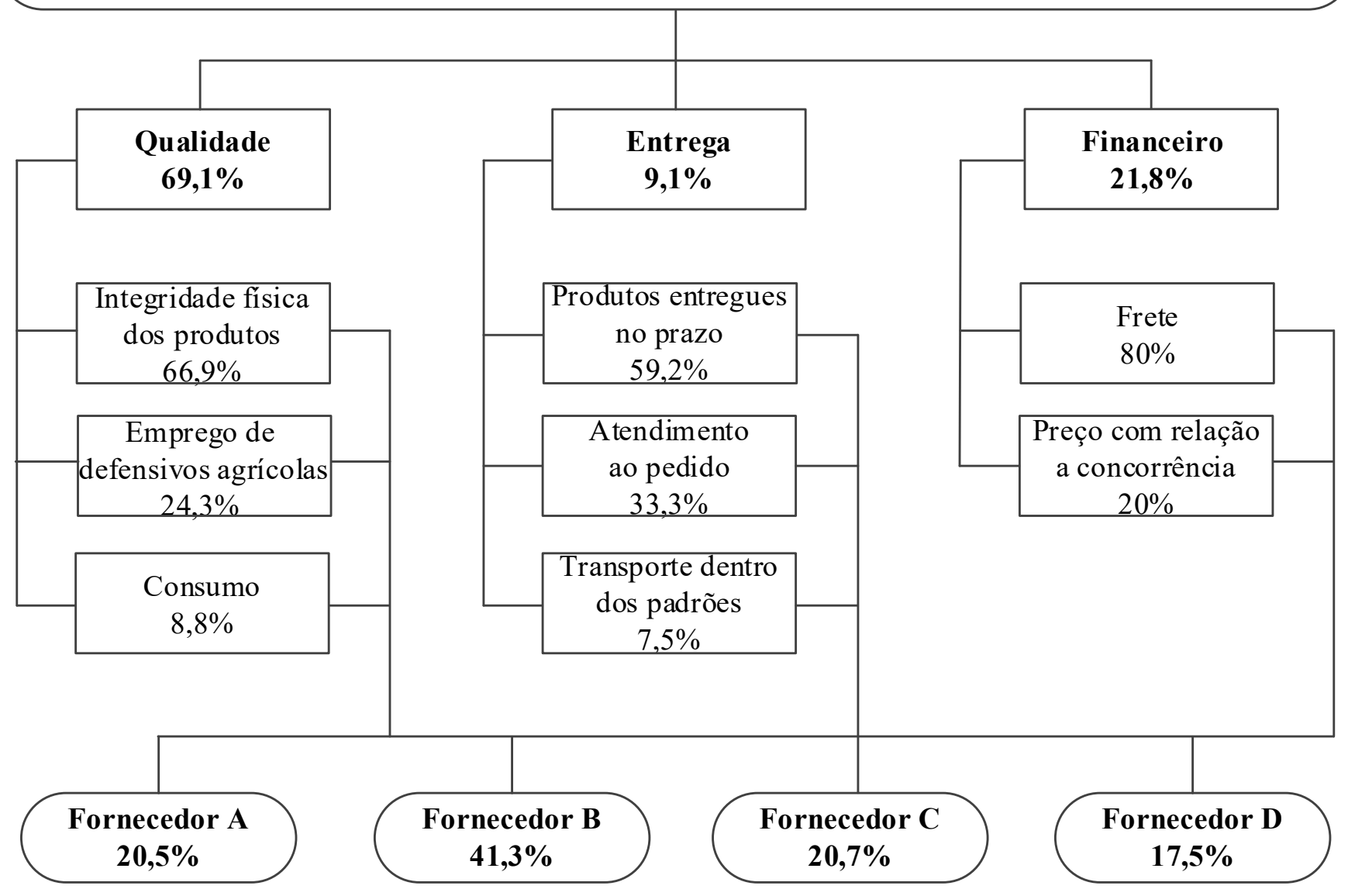

Os valores das médias obtidas da matriz inicial normalizada relacionados aos critérios, subcritérios e alternativas avaliados pelos especialistas, indicaram o critério qualidade com $69,1 \%$, como sendo o mais importante, tendo o financeiro com $21,8 \%$ ocupando a segunda posição e a entrega ficou na terceira posição com 9,1\%. A matriz ainda apresentou um IC igual a 0,05, que segundo Saaty (1980) pode ser considerada como boa a consistência global apresentada. Em que a sensibilidade dinâmica representa o peso médio de cada critério avaliado, tendo por base os julgamentos dos especialistas por meio de comparação paritária (Figura 5).
Figura 5 - Gráfico de sensibilidade dinâmica

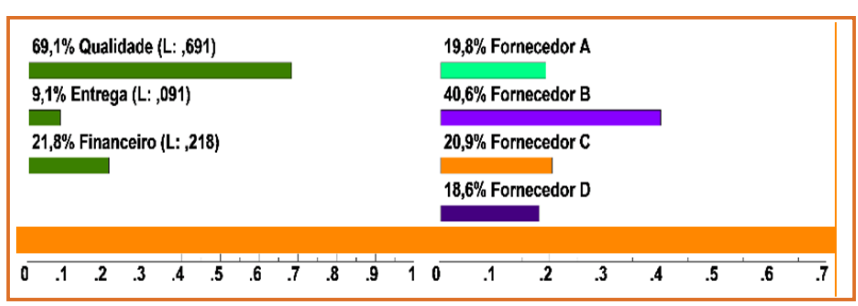

Com a combinação dos dados, observa-se a um distanciamento dos pesos obtidos, onde a qualidade se destaca com 69,1\%, seguida pelo financeiro com 21,8\% e entrega com 9,1\%, respectivamente. Por conseguinte, observa-se a preocupação dos gestores com a qualidade das frutas e verduras, visando $\mathrm{o}$ atendimento aos anseios e expectativas dos órgãos fiscalizadores e da demanda. Neste sentido, - Fornecedor B, apresentou melhores resultados individuais para os subcritérios do critério qualidade, assim como, na análise global. 
Também, os dados de análise de performance facilitam o entendimento e identificação dos elementos avaliados que apresentam pesos abaixo da média estimada pelos especialistas, e que podem representar pontos de vulnerabilidade. A partir desta visão, a Figura 6 apresenta uma análise da performance de cada critério, relacionada aos subcritérios e alternativas que compreendem a estrutura hierárquica.

Figura 6 - Performance dos critérios a partir das preferências dos especialistas

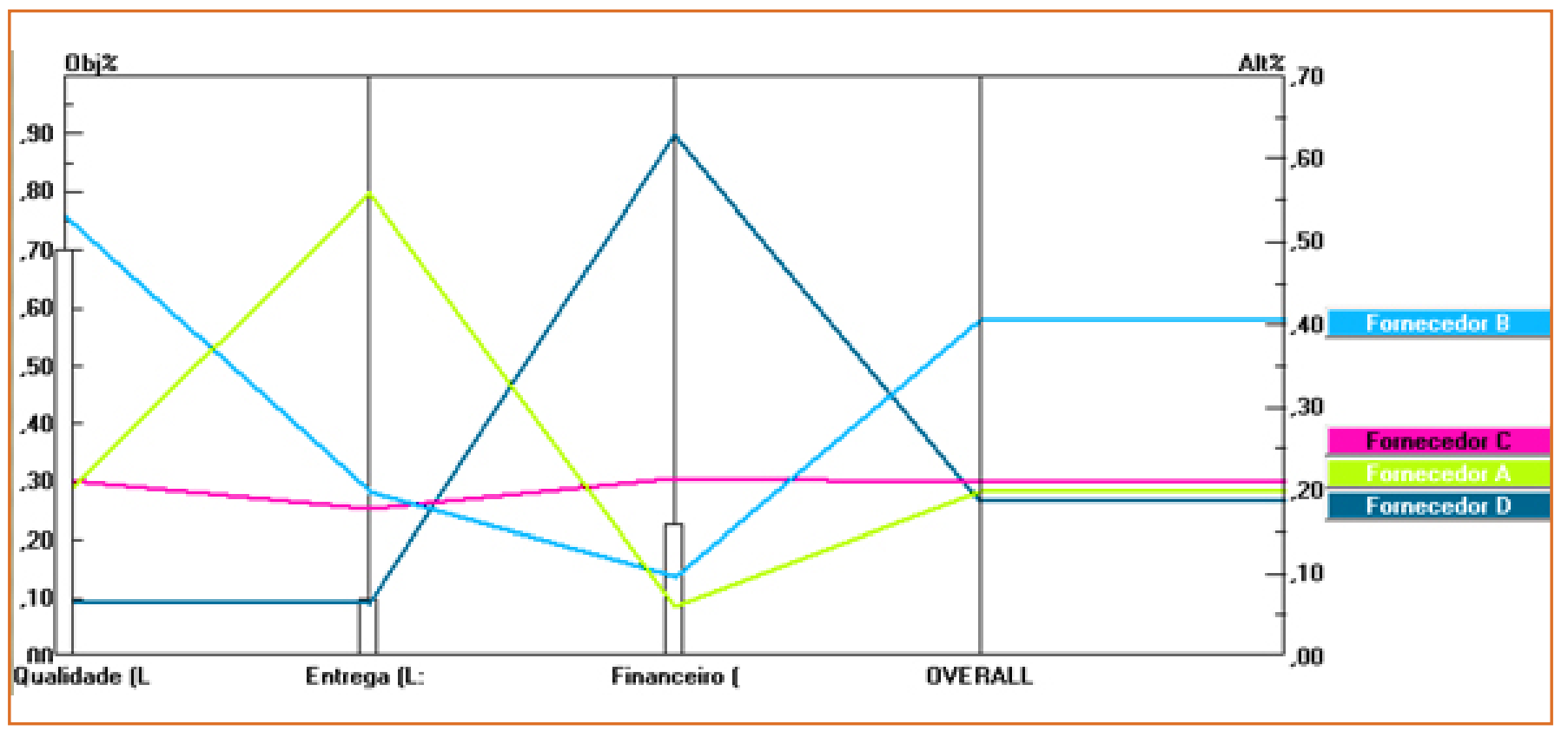

Dessa forma, considerando a combinação das informações apresentadas pelos pressupostos anteriores, que podem ser observados nas figuras 4, 5 e 6, o critério qualidade apresenta maior relevância em comparação aos demais, sendo este responsável por atender as expectativas e satisfação dos órgãos fiscalizadores, interveniente e consumidores de frutas e verduras, segundo os critérios levantados neste trabalho.

\section{CONSIDERAÇÕES FINAIS}

No contexto competitivo atual em que as organizações se encontram, faz-se necessário o planejamento e elaboração de diferenciais que possam auxiliar a sobrevivência em um mercado em constante transformação. Nesse cenário, os critérios, subcritérios e possíveis alternativas devem ser estabelecidos e revistos quando da avaliação e seleção de fornecedores.

Ao se propor um modelo baseado no método multicritério AHP para selecionar o melhor fornecedor para um supermercado, de maneira geral, ele utiliza matrizes para equalizar uma tomada de decisão, empregando uma relação hierárquica entre os níveis de decisão. Por esta capacidade de agregação de informações, o modelo foi capaz de lidar com múltiplos critérios, permitindo incorporar 11 critérios e subcritérios para avaliar os fornecedores. Assim, concluímos que B é o melhor fornecedor com uma pontuação global de 0,406 prioridade.

Os resultados também permitiram verificar que a qualidade dos produtos é um critério que deve ser priorizado pelas empresas que atuam no setor junto à organização em estudada. Desta forma, pode-se argumentar que a abordagem realizada conseguiu cumprir o objetivo, segundo os especialistas, além de estar dentro dos padrões desejados pela empresa e da demanda, os resultados alcançados podem ser considerados dentro dos padrões de mercado.

Também, o modelo desenvolvido e apresentado aqui pode ser adaptado à diferentes realidades e contextos que busquem indicar as melhores alternativas para tomadas de decisões que envolvam variáveis que 
possam ser qualificáveis e quantificadas. Em que o processo de seleção de fornecedores necessita ser reavaliado cotidianamente, observando as necessidades organizacionais e da demanda, caso isso não aconteça poderá ocorrer a perda de competitividade, com uma possível baixa no market share.

\section{AGRADECIMENTOS}

Agradecemos ao Núcleo de Pesquisa em Gestão de Sistemas de Produção - NP GSP da Universidade Federal do Espírito (UFES)/ Centro Universitário Norte do Espírito Santo (CEUNES) pelo apoio ao desenvolvimento deste trabalho.

\section{REFERÊNCIAS}

[1] ACZÉL, J.; SAATY; T. L. Procedures for synthesizing ratio judgements. Journal of mathematical Psychology. Vol. 27, n.1, p.93-102, 1983.

[2] BRASIL. Vigilância de fatores e risco e proteção para doenças crônicas por inquérito telefônico. Brasília: Ministério da Saúde, 2013.

[3] BRUNO, G. et al. AHP-based approaches for supplier evaluation: Problems and perspectives. Journal of Purchasing and Supply Management. Vol. 18, n.3, p.159-172, 2012.

[4] CHAI, J.; LIU, J.N.K.; NGAI, E.W.T. Application of decisionmaking techniques in supplier selection: a systematic review of literature. Expert Systems with Applications. Vol. 40, n.10, p.3872-3885, 2013.
[5] DURBACH, I.; LAHDELMA, R.; SALMINEN, P. The analytic hierarchy process with stochastic judgements. European Journal of Operational Research. Vol. 238, n.2, p.552-559, 2014

[6] KOU, G. et al. Evaluation of classification algorithms using MCDM and rank correlation. International Journal of Information Technology \& Decision Making. Vol. 11, n.1, p.197-225, 2012.

[7] LIMA JÚNIOR, F.R.; CARPINETTI, L.C.R. A comparison between TOPSIS and Fuzzy-TOPSIS methods to support multicriteria decision making for supplier selection. Gestão \& Produção. Vol. 22, n.1, p.17-34, 2015.

[8] PUTTI, F.F. et al. Multivariate analysis of production of perishable goods in the state of São Paulo. Brazilian Journal of Biosystems Engineering. Vol. 8, n. 3, p. 227-233, 2014.

[9] SAATY, T.L. A Scaling Method for Priorities in Hierarchical Structures. Journal of Mathematical Psychology. Vol. 15, p.234-281, 1977.

[10] _. Decision making with the analytic hierarchy process. International journal of services sciences. Vol. 1, n.1, p.83-98, 2008.

[11] SUBRAMANIAN, N.; RAMANATHAN, R. A review of applications of Analytic Hierarchy Process in operations management. International Journal of Production Economics. Vol. 138, n.2, p.215-241, 2012.

[12] TRIANTAPHYLLOU, E.; MANN, S.H. Using the analytic hierarchy process for decision making in engineering applications: some challenges. International Journal of Industrial Engineering: Applications and Practice. Vol. 2, n.1, p.35-44, 1995.

[13] UYSAL, H.T.; YAVUZ, K. Selection of Logistics Centre Location via ELECTRE Method: A Case Study in Turkey. International Journal of Business and Social Science. Vol. 5, n. 9, p. 276-289, 2014 


\section{CAPÍTULO 16}

\section{MODELO DE AQUISIÇÃO DE EQUIPAMENTOS DE INFORMÁTICA PARA EMPRESA DE MÉDIO PORTE}

Diego Ricardo Krohl

Guilherme Constantini

Maikon Bridi

Thiago Crestani

Ana Paula de Carli Bertaioli

Resumo: Este artigo trata da análise e implantação de equipamentos de Tecnologia da Informação em uma empresa prestadora de serviços em TI de médio porte, seguindo modelos desenvolvidos para evitar a má distribuição de recursos. Inicialmente são detalhados fatores relevantes para a aquisição de equipamentos pelas empresas no geral, bem como a importância da analise de como as empresas trabalham em relação a esse processo. 0 levantamento dos equipamentos foi realizado analisando todo o ambiente, funcionários e recursos da empresa. Além disso, fornecedores distintos foram considerados, não só para a comparação de custos, mas também para comparação da qualidade dos equipamentos. Por fim foi realizada a análise das alternativas encontradas, para escolha da opção mais viável.

Palavras Chave: Tecnologia da Informação, Equipamentos, Hardware. 


\section{INTRODUÇÃO}

Atualmente empresas de vários setores tem sentido cada vez mais a necessidade de um departamento de Tecnologia da Informação eficaz e consistente, facilitando os trabalhos do dia a dia e aumentando sua produtividade. Entretanto, a área de tecnologia da empresa muitas vezes sofre com a falta de projeção, em que os dispositivos de tecnologia são implantados de forma desordenada, sem o aproveitamento de custos e também sem a análise de desempenho necessária. Dessa forma a empresa acaba por gerar gastos excessivos, sem ter o verdadeiro beneficio que os equipamentos poderiam proporcionar. Assim, para a implantação de sistemas de informática dentro da empresa, é necessário fazer uma análise ampla de vários fatores, que compreendem o ambiente, o orçamento e as atividades desempenhadas pelos usuários.

Para que haja uma implementação correta de um sistema, é necessário não apenas analisar os custos de implementação finais, mas sim, analisar os custos a longo prazo. Os investimentos também devem ser coordenados de forma a não restringir o projeto, evitando que baixos orçamentos disponíveis comprometam o funcionamento final do sistema, que por sua vez pode afetar a produtividade da empresa. Além disso, o ambiente interno da organização deve ser analisado, definindo as atividades exercidas por cada profissional, para que dessa forma os equipamentos sejam disponibilizados corretamente, com desempenho e funções adequadas.

Este artigo pretende demonstrar o cenário de uma empresa prestadora de serviços de tecnologia da informação, que deseja reformular alguns equipamentos que compõe sua infraestrutura. Para isso é analisado o ambiente interno da empresa descrevendo os funcionários e atividades realizadas. Então, são apresentadas tabelas com orçamentos de determinadas fornecedoras de equipamentos para que no final seja feita a comparação das opções a curto e médio prazo, permitindo a escolha do melhor fornecedor de acordo com o custo beneficio dos equipamentos.

Utilizamos como metodologia para esse trabalho, a pesquisa bibliográfica, para a fundamentação base do estudo e a pesquisa de mercado, simulando a necessidade real da empresa em questão a qual apoiou esse levantamento visando a implantação futura da solução apontada.

\section{CONCEITOS E FUNDAMENTAÇÃO TEÓRICA}

Esse capítulo relata conceitos de gestão em tecnologia da informação (T.I), levando em conta a importância da informação em uma empresa, os custos para implantação e outros fatores relevantes para o sucesso de uma empresa utilizando a tecnologia em prol de melhorias significantes em sua atuação.

\subsection{A IMPORTÂNCIA DA INFORMAÇÃO NAS ORGANIZAÇÕES}

A informação é considerada como fator essencial, e por sua vez é adquirida com um prolongado processo de aprendizado. Este aprendizado requer das organizações um treinamento contínuo (BRAGA, 2000).

A informação se tornou uma necessidade crescente para qualquer setor da atividade humana. Uma empresa em atividade por natureza, é um sistema aberto e iterativo composto por uma rede de processos articulados, onde os canais de comunicação existem dentro da empresa e entre esta e o seu meio envolvente são irrigados por informação (BRAGA, 2000).

As empresas que utilizam uma administração de informação com uma maneira eficaz, podem ter um desempenho maior, conseguindo dominar a concorrência. Com isso, podendo melhorar significativamente seu desempenho obtendo vantagens sobre a concorrência. Caso uma empresa não se preocupar com sua administração, esta pode passar por um processo de degradação do desempenho, sem que ela se de conta disso (LESCA, 2010).

Segundo Lesca (2010) ao todo existem três grupos de empresas. O primeiro é formado por empresas que buscam administrar a informação de forma estratégica, fazendo com que a informação se torne uma arma competitiva. Já o segundo grupo são as 
empresas que não administram estas informações de maneira estratégica, contudo começam a dedicar seu esforço neste sentido obtendo assim resultados inferiores aos que poderiam ser atingidos. E por fim o terceiro grupo que são as empresas que não atuam com a administração da informação, e que de certa forma não se importam com estas informações. Estas empresas são a maioria que por sua vez, tendem a diminuir, pois em algum momento irão perceber o erro que cometem e evoluirão, ou simplesmente despencaram do mercado.

\subsection{O USO DA TECNOLOGIA PELAS EMPRESAS}

O avanço da Tecnologia de Informação tem influenciado o comportamento da sociedade. É possível notar uma forte relação entre as ferramentas tecnológicas que foram criadas pelo homem, através do crescimento de seus conhecimentos e a mudança do seu comportamento. Foi com a técnica que o homem conseguiu aperfeiçoar seus utensílios, tendo como estágio inicial os utensílios que eram apenas uma estrutura física, e depois com as máquinas, a energia humana foi substituída pela mecânica (ALBERTIN, 2003).

O uso de tecnologia de informação atualmente oferece benefícios para o negócio que incluem custo, inovação, produtividade, flexibilidade e qualidade, sendo que cada vez usada, tem-se uma composição destes benefícios. Desta maneira, a administração das tecnologias de informação estão se tornando cada vez mais comuns em uma organização. Pois, com seus processos de planejamento, organizações, direção e controle, proporciona uma realização bem sucedida dos esforços como também a mensuração dos seus impactos no desempenho empresarial (LESCA, 2010). Para que se possa usufruir de benefícios das tecnologias de informação, é preciso realizar investimentos. Estes investimentos devem ser analisados considerando os benefícios que oferecem, as técnicas elaboradas para a avaliação destes investimentos, e o desempenho empresarial no qual estes benefícios devem se refletir. Deste modo pode-se afirmar que estes benefícios irão ser convertidos em contribuições efetivas para o resultado empresarial (ALBERTIN, 2003).
Deste modo ALBERTIN e MOURA (2002) exemplifica que estes benefícios de TI podem ser definidos como produtividade, custo, qualidade, flexibilidade e inovação, sendo que estes benefícios são entendidos como oferta que esta tecnologia traz para as organizações. Contudo, tão importante quanto a oferta é o seu aproveitamento no desempenho da organização.

\subsection{INVESTIMENTOS EM TECNOLOGIAS}

A maioria das empresas no geral, não possuem sistemas informatizados, desta forma seus controles são feitos em sua maior parte por meios de papeladas intermináveis. Contudo com o custo cada vez menor dos computadores, e a aquisição cada vez maior de softwares, incentivam o pequeno empresário a investir pesado neste setor buscando melhores desempenho para a empresa com relação aos concorrentes (BERALDI e FILHO, 2000).

Investimentos como estes costumam ser desastroso para a empresa se os funcionários não estejam totalmente capacitados para lidar com a nova tecnologia implantada na empresa.

Segundo Beraldi e Filho (2000) é aconselhável fazer uma avaliação antes de investir, colocando em conta aspectos como quantidade de clientes e fornecedores, orçamento, encomendas, estoque, análises financeiras, quantidade de empregados, quantidade de registros e documentos.

\subsection{ESCOLHADEEQUIPAMENTOSDEINFORMÁTICA}

Empresas com sistemas totalmente informatizados que funcionam de maneira eficaz e eficiente, proporcionam grandes vantagens. Estas vantagens podem ser em relação à otimização, a facilidade de obtenção de informações, a organização, a previsão e outros aspectos que contribuirão para o sucesso das empresas (BERALDI; FILHO, 2000).

Assim, uma empresa que é informatizada com equipamentos de qualidade, ganham eficácia e eficiência melhorando a sua competitividade como também aumentando seus lucros (BRAGA, 2000). 
Segundo Zimmerer (1994), algumas vantagens destas empresas que optam por se informatizarem com equipamentos modernos são: automatizar as tarefas de rotina; melhorias no controle interno das operações; melhoria nas informações para tomada de decisão; aumenta a capacidade de reconhecer problemas mais cedo; melhoria do processo produtivo ajuda o gerente a testar decisões antes de colocá-las em prática; aumenta a competitividade e produtividade; melhora o atendimento ao cliente.

\subsection{PROFISSIONAIS}

Nas últimas décadas, os profissionais dentro das empresas na área de informática teve um crescimento rápido, impulsionado pela intensa concorrencia. Este crescimento criou uma demanda por profissionais na área de tecnologia da informação que tenham uma interação com as pessoas fora do departamento de informática. Para pessoas que pensam que o mercado só está apto para jovens e profissionais altamente especializados na área de T.l, estão enganadas. Devido que há grandes oportunidades para qualquer faixa etária ou especialização (HUARNG, 2001).

Mas ainda existem grandes oportunidades para a geração $Y$, pois estes já nasceram na era da Internet e do celular e conseguem aprender mais rapidamente as inovações tecnológicas. O profissional que tende a seguir uma carreira de gerente de uma empresa, precisa desenvolver uma visão abrangente sobre a empresa que trabalha, para assim conseguir transformar o departamento de TI em uma área estratégica, gerando grandes resultados para sua organização (SAKAMOTO, 2015).

\section{A EMPRESA}

Essa seção trata da analise de uma empresa que atua na prestão de serviços na área de tecnologia da informação que necessita melhorar seus equipamentos de informática. É feito um levantamento de seus requisitos, dois orçamentos com valores reais pesquisados em sites de venda de equipamentos de informática, e um caso de locação dos equipamentos utilizando um valor médio com base nas empresas que oferecem este tipo de serviço. Por fim, é realizada uma análise do que seria melhor para empresa com base nos valores levantados.

\subsection{CENÁRIO}

A empresa possui 1 filial na cidade de Videira, Santa Catarina, ela deseja equipar o setor de TI para agilizar as atividades dos profissionais e consequentemente prestar melhores serviços aos clientes.

A empresa trabalha com conserto e locação de impressoras para lojas do comércio varejista em geral, escritórios e empresas. A empresa possui 13 funcionários distribuídos nas seguintes áreas;

- 5 técnicos

- 1 pessoa para o $\mathrm{RH}$

- 2 pessoas para assuntos administrativos

- 4 vendedores

- 1 Secretária

A empresa deseja renovar todos os seus equipamentos de informática, que já estão desatualizados. Dentro dela cada funcionário utiliza um computador, além de impressoras para uso comum, servidores para email, hospedagem de conteúdo web e backup de dados.

Inicialmente para os técnicos são necessários computadores de boa performance, capazes de executar atividades do dia a dia, como navegar na internet, abrir documentos, executar programas para teste, com facilidade e fluidez. Para os setorres de recursos humanos, administrativo e recepção, não são necessários computadores com performance excepcional, mas capazes de navegar na web, abrir documentos e planilhas.

Os vendedores, no entanto, necessitam de computadores com performance similar ao o pessoal do $\mathrm{RH}$, administrativo e recepção, porém precisam de portabilidade, sendo ideal computadores do tipo notebook.

A empresa utiliza três tipos de servidores. O primeiro é do tipo WEB, que mantém online o site da empresa, um serviço de suporte e chamados para o cliente, e o sistema administrativo da empresa, que compreende ordens de serviço, pagamentos, recebimentos, 
pedidos, entre outros serviços. É esperado que esse sistema tenha alta disponibilidade, e seja altamente seguro.

O servidor de e-mails armazena e gerencia os e-mails de todos os funcionários da empresa, ele deve ter espaço suficiente para armazenar mensagens por no mínimo 5 anos, e também deve ter alta performance para fazer o envio dos e-mails.

A empresa também necessita de um servidor para backup de dados, este servidor deve possuir espaço para armazenar projetos, orçamentos e arquivos em geral, além de possuir hardware capaz de gerenciar transferência de arquivos de forma rápida.

Novas impressoras também fazem parte do plano de aquisição. A empresa imprime cerca de 8000 folhas ao mês. Além disso cerca de $20 \%$ das impressões necessitam ser coloridas. Como a empresa trabalha com o aluguel de impressoras ela consegue valores de impressão de 10 centavos para folha preto e branco e 15 centavos para folha colorida, por isso caso os valores sejam muito altos a empresa irá adquirir apenas o pacote com os computadores e servidores.
A empresa dispõe de no máximo $\mathrm{R} \$ 70.000$ para a implantação do projeto, entretanto ela optará pelo fornecedor que conceder o melhor custo beneficio, qualidade nos equipamentos e tiver o melhor suporte. Têm-se a necessidade de implantação em até 45 dias a partir da data da aprovação do projeto, por isso o prazo também será importante na escolha do fornecedor.

A empresa tem a possibilidade de adquirir os equipamentos, ou poderá alugar com contrato prédeterminado, ação que dependerá de valores e propostas dos fornecedores.

\subsection{ORÇAMENTOS}

A seguir são apresentados 3 orçamentos realizados por fornecedores que atendiam as necessidades à serem implantadas, por motivo da não exposição dos fornecedores seus nomes não serão divulgados.

$\mathrm{Na}$ tabela 1 estão descritos os equipamentos, a quantidade, o valor unitário e o valor total referente ao fornecedor 1 .

Tabela 1 - Orçamento fornecedor 1

\begin{tabular}{|c|c|c|c|}
\hline Equipamento & Quantidade & Valor Unitário & Valor Total \\
\hline $\begin{array}{l}\text { Servidor IBM X3500 M4; Forma: Torre; Processador: Intel Xeon E5- } \\
\text { 2620V2 Hexa Core 2.1GHZ - Cache: 15MB - 1600Mhz; Memória: } 1 \text { x } \\
\text { Memória de 16GB RDIMM, 2133MT/s, DR, x4, BCC; Rede: Quad Port } \\
\text { Gigabit (Intel I350AM4); Tipo de disco: SAS/SATA 2,5 Hot-Swap; Discos: } \\
\text { 2 x 2TB 7.2K RPM SATA 6Gbps 3.5in Cabled Hard Drive; Controladora } \\
\text { M1115 SAS/SATA, RAID 1, } 0 \text { e 10; Drive óptico: DVD-ROM; Fonte: } 2 \text { x } \\
\text { 550W Redundante; Garantia: } 3 \text { anos. }\end{array}$ & 1 & $\mathrm{R} \$ 10.039,00$ & $\mathrm{R} \$ 10.039,00$ \\
\hline $\begin{array}{l}\text { Notebook Lenovo G40; Processador: Intel® Core }{ }^{\mathrm{TM}} \text { i3-4005U (1.7GHz; } \\
\text { 3MB Cache); Memória: 4GB (1x4GB) DDR3L 1600MHz; Disco Rígido: } \\
\text { 1TB (5400rpm); Tela: 14" HD LED (1366x768); Gravador de DVDs e } \\
\text { CDs; Portas: 1x HDMI, 1x USB 3.0, 2x USB 2.0, 1x VGA; Garantia: } 1 \text { ano. }\end{array}$ & 4 & $\mathrm{R} \$ 1.899,00$ & $\mathrm{R} \$ 7.596,00$ \\
\hline $\begin{array}{l}\text { All-in-One Lenovo E73z; Processador: Intel Core i3-4130 (3.4 GHz; 3MB } \\
\text { Cache); Memória: 4GB (1x4GB) DDR3 SODIMM 1600MHz; Disco Rígido: } \\
\text { 500GB (7200rpm); Tela: 20"; Gravador de DVDs e CDs; Portas: } 2 \text { USB } \\
\text { 3.0, } 4 \text { USB 2.0, } 1 \text { VGA, } 1 \text { RJ45; Mouse e Teclado USB; Garantia: } 1 \text { ano. }\end{array}$ & 9 & $\mathrm{R} \$ 2.113,00$ & $\mathrm{R} \$ 19.017,00$ \\
\hline & & Preço Total: & $R \$ 36.652,00$ \\
\hline
\end{tabular}

Fonte: Os autores (2015)

Na tabela 2 estão descritos os equipamentos, a quantidade, o valor unitário e o valor total ofertados pelo fornecedor 2 . 
Tabela 2 - Orçamento fornecedor 2

\begin{tabular}{|c|c|c|c|}
\hline Equipamento & Quantidade & Valor Unitário & Valor Total \\
\hline $\begin{array}{l}\text { Servidor Dell PowerEdge T430; Processador: Intel Xeon E5-2609V3 } \\
\text { Hexa Core 1.9GHZ - Cache: 15MB - 1600Mhz; Memória: } 1 \text { x Memória de } \\
\text { 16GB RDIMM, 2133MT/s, DR, x4, BCC; Rede: Placa On-Board; Discos: } \\
2 \text { x 2TB 7.2K RPM SATA 6Gbps 3.5in Cabled Hard Drive; Controladora } \\
\text { Onboard SATA; Drive óptico: DVD-ROM; Fonte: } 1 \text { x 450W. }\end{array}$ & 1 & $\mathrm{R} \$ 9.171,00$ & $\mathrm{R} \$ 9.171,00$ \\
\hline $\begin{array}{l}\text { Notebook Dell Inspiron Série 3000; Processador: Intel@ Core } \text { CM }^{\mathrm{TM}} 3-4005 \mathrm{U} \\
\text { (1.7GHz; 3MB Cache); Memória: 4GB (1x4GB) SDRAM DDR3 1600MHz; } \\
\text { Disco Rígido: 500GB (5400rpm); Placa de video integrada Intel HD } \\
\text { Graphics 4400; Tela: 15,6" HD LED (1366x768); Gravador de DVDs e } \\
\text { CDs; Garantia: } 1 \text { ano. }\end{array}$ & 4 & $R \$ 1.699,00$ & $\mathrm{R} \$ 6.796,00$ \\
\hline $\begin{array}{l}\text { Dell Inspiron Small Desktop; Processador: Intel Core i3-4160 (3.6 GHz; } \\
\text { 3MB Cache); Memória: 4GB (1x4GB) SDRAM DDR3 1600MHz; Disco } \\
\text { Rígido: 500GB (7200rpm); Tela: 18,5" HD LED (1366x768); Gravador de } \\
\text { DVDs e CDs; Mouse e Teclado sem fio; Garantia: } 1 \text { ano. }\end{array}$ & 9 & $\mathrm{R} \$ 2.049,00$ & $\mathrm{R} \$ 18.441,00$ \\
\hline & & Preço Total: & $\mathrm{R} \$ 34.408,00$ \\
\hline
\end{tabular}

Fonte: Os autores (2015)

Na tabela 3 estão descritos os equipamentos, a quantidade, o valor unitário e o valor total ofertados pelo fornecedor 3 para locação.

Tabela 3 - Orçamento fornecedor 3 (Locação)

\begin{tabular}{|c|c|c|c|}
\hline Equipamento & Quantidade & Valor Unitário & Valor Total \\
\hline $\begin{array}{l}\text { Servidor HP ProLiant ML350e Gen8 v2; Processador: Intel Xeon 2418L v2 } \\
\text { Hexa Core 2.0GHZ - Cache: 15MB - 1600Mhz; Memória: } 1 \text { x Memória de } \\
\text { 16GB DDR3; Rede: Placa On-Board; Discos: } 2 \text { × 2TB 7.2K RPM SATA } \\
\text { 6Gbps; Controladora B120i; Drive óptico: DVD-ROM; Fonte: } 1 \text { x 500W; } \\
\text { Garantia: } 3 \text { anos. }\end{array}$ & 1 & $\mathrm{R} \$ 400,00$ & $\mathrm{R} \$ 400,00$ \\
\hline $\begin{array}{l}\text { Notebook HP 14-R051BR; Processador Intel巴 Core }{ }^{\mathrm{TM}} \text { i3-4005U } 1.7 \mathrm{GHz} \text {; } \\
\text { Memória: 4GB; Disco Rígido: 500GB (5400rpm); Placa de video integrada } \\
\text { Intel HD Graphics 4400; Tela: 14"; Gravador de DVDs e CDs. }\end{array}$ & 4 & $\mathrm{R} \$ 80,00$ & $\mathrm{R} \$ 320,00$ \\
\hline $\begin{array}{l}\text { HP All in One 19-2200BR; Processador Intel® Core }{ }^{\mathrm{TM}} \text { і3-4150T } 3.0 \\
\text { GHz; Memória: 4GB; Disco Rígido: 500GB (7200rpm); Tela: } 19 " \text { HD } \\
\text { LED(1366x768); Gravador de DVDs e CDs; Mouse e Teclado USB. }\end{array}$ & 9 & $R \$ 60,00$ & $\mathrm{R} \$ 540,00$ \\
\hline & & Preço Total: & $R \$ 1.260,00$ \\
\hline
\end{tabular}

Fonte: Os autores (2015)

\subsection{ANÁLISE DOS ORÇAMENTOS}

Nos orçamentos 1 e 2 foi projetado que a empresa terá um gasto mensal de $R \$ 125,00$ de manutenção dos computadores e do servidor, não levando em conta o caso de algum computador ou alguma peça apresentar problema, mas o valor do gasto mensal será reservado mesmo que não seja utilizado. Caso seja optado por um dos orçamentos com aquisição dos equipamentos, no primeiro ano ao custo já está somado o valor da manutenção e da aquisição dos equipamentos, no restante dos anos será apenas o custo da manutenção. No caso da locação, todos os anos possuem o mesmo valor devido a ter apenas o valor mensal de locação dos equipamentos. Neste caso a manutenção não é cobrada pela empresa locadora, caso seja necessária, ela será feita sem custos.

A tabela 4 mostra a projeção da aquisição nos três casos no período de 5 anos, seus valores anuais e valor total. 
Tabela 4 - Projeção de custos (5 anos)

\begin{tabular}{|l|l|l|l|l|l|l|}
\hline Opção & Ano 1 & Ano 2 & Ano 3 & Ano 4 & \multicolumn{2}{c}{ Ano 5 } \\
\hline Orçamento 1 & $38.152,00$ & $1.500,00$ & $1.500,00$ & $1.500,00$ & $1.500,00$ & $44.152,00$ \\
\hline Orçamento 2 & $35.908,00$ & $1.500,00$ & $1.500,00$ & $1.500,00$ & $1.500,00$ & $41.908,00$ \\
\hline Locação & $15.120,00$ & $15.120,00$ & $15.120,00$ & $15.120,00$ & $15.120,00$ & $75.600,00$ \\
\hline
\end{tabular}

Fonte: Os autores (2015)

\subsection{ANÁLISE DOS DADOS}

Analisando as opções disponibilizadas nos orçamentos, foi verificado que a opção de compra dos equipamentos é mais vantajoso, com excessão das impressoras, que vão ser utilizadas da propria empresa.

Entre as opções de compra, a opção do hardware do segundo orçamento se mostrou mais interessante, pois nos dois primeiros levantamentos (tabelas 1 e 2 ) existem maquinas com configurações semelhantes, entretanto o custo do projeto para o segundo fornecedor é mais baixo.

Avaliando os dois orçamentos de compra, não há diferenças expressivas no desempenho e qualidade do hardware, além do suporte das duas empresas serem semelhantes, então nesse caso, o fator determinante para a decisão da compra de um e não o outro foi realmente o custo dos produtos.

Entre as opções disponibilizadas de compra e locação, a segunda se tornou inviável pois analisando os custos a longo prazo a compra teve um custo mais baixo do que a locação, sendo que quanto mais tempo os equipamentos sejam utilizados, mais viável se torna a compra ao invés da locação.

\section{CONCLUSÃO}

Com a crescente necessidade da informação dentro das organizações é necessário que ela seja muito bem gerida, pois ela estará diretamente ligada ao desempenho da organização no mercado. Com isso a administração da tecnologia da informação se mostra indispensável para qualquer empresa, a qual só é obtida através de investimentos em equipamentos de hardware e em softwares, e em funcionários que estejam aptos a trabalhar com a tecnologia dos sistemas informatizados. Na empresa em questão foi realizado o levantamento dos requisitos necessários para a substituição dos seus equipamentos de informática.

Ao avaliar a compra e a locação dos equipamentos foi concluído que a compra dos equipamentos se mostrou um melhor investimento a longo prazo, no primeiro ano o custo seria maior que o da locação, mas nos anos seguintes o único custo seria o de manutenção dos equipamentos, enquanto o de locação seria o mesmo valor em todos os anos, demonstrando então, que a compra é a melhor opção para essa empresa. $\mathrm{Na}$ escolha entre as duas empresas fornecedoras para venda dos equipamentos, a melhor opção foi a da empresa 2 com um custo de $\mathrm{R} \$ 34.408,00$.

O valor resultante projetado para o período de 5 anos na opção escolhida é de $R \$ 41.908,00$ acarretando um menor custo na comparação entre as demais opções orçadas sem comprometer os resuisitos originais do projeto. Com essa escolha espera-se o atendimento completo de todas as necessidades da instituição.

\section{REFERÊNCIAS}

[1] AlBERTIN, A. L.; MOURA, R. M. Amplie seus Horizontes. Information week, 6 de novembro de 2002.

[2] AlBERTIN, A. L. Enfoque gerencial dos Benefícios e Desafios da tecnologia de Informação para o Desempenho Empresarial. Projeto de pesquisa desenvolvido com o apoio do Núcleo de Pesquisa e Publicação (NPP) da Escola de Administração de Empresas de São Paulo (EAESP) da Fundação Getulio Vargas (FGV). São Paulo: FGV-EAESP, 2003

[3] BERALDI, L. C.; FILHO, E.E. Impacto da tecnologia de informação na gestão de pequenas empresas. Brasilia - DF, p.46-50, jan 2000. Disponível em: < http://www.scielo.br/pdf/ ci/v29n1/v29n1a5 >. Acesso em: 15 mai. 2015 
[4] HUARNG, A. S. Burnout Syndrome Among Information System Professionals. Information Systems Managemet 18. 2001. Disponível em: <http://www. scielo.br/sciel o.php?script=sci_nlinks\&ref=000235\&pid $=$ S1807-177520090003 $0000400021 \&$ Ing=en $>$ Acesso em: 10/05/2015.

[5] LESCA, Humberto; ALMEIDA, Fernando C. de. Administração estratégica da informação. Revista de Administração de Empresas. São Paulo. v. 29, n.3, jul 2010.

[6] BRAGA, A. A gestão da informação. Millenium, 19, 20 mai 2015. Disponível em: <https://repositorio.ipv.pt/ bitstream/10400.19/903/1/>. Acesso em: 04/05/2015.
[7] SAKAMOTO, M. As oportunidades no mercado de TI. Idgnow, 19 jan 2015. Disponível em: <http://idgnow.com.br/ ti-corporativa/2015/01/19/oportunidades-no-mercado-de-ti/ >. Acesso em: 18/05/2015.

[8] ZIMMERER, T. W.; SCARBOROUGH, N. M. Essentials of small business management. Macmillan College Publishing Company, 1994. 


\title{
CAPÍTULO 17
}

\section{AVALIAÇÃO DE DESEMPENHO E SELEÇÃO DE FORNECEDORES POR MEIO DA ANÁLISE ENVOLTÓRIA DE DADOS (DEA)}

\author{
Nilton Fabiano Ribeiro \\ Rogério Martins de Azevedo \\ Paulo Rotela Junior
}

Resumo: O desempenho de fornecedores tem grande influência nas atividades realizadas por diversas organizações. Diante da competitividade existente no mercado atual, é de suma importância que se trabalhe com os melhores fornecedores. Este artigo tem como objetivo realizar uma análise de desempenho de fornecedores de uma empresa multinacional do setor de energia localizada no sul de Minas Gerais por meio da Análise Envoltória de Dados (DEA). Para isso, foram coletados dados, segundo critérios pré-estabelecidos, dos 61 maiores fornecedores desta empresa. Observou-se que o modelo DEA-CCR apresentou uma melhor discriminação das unidades de análises comprovando a aplicabilidade da ferramenta utilizada, possibilitando à empresa uma melhor avaliação de seus principais fornecedores, estabelecendo os benchmarks e planos de ação sobre os fornecedores com nível de eficiência insatisfatório, além de estabelecer ranges para uma avaliação estendida aos demais fornecedores e ainda, a possibilidade da extensão da utilização da ferramenta para outros setores da empresa.

Palavras Chave:Fornecedores, Análise Envoltória de Dados, Eficiência, Desempenho, DEA. 


\section{INTRODUÇÃO}

Nos dias atuais as relações cliente-fornecedor têm ganhado cada vez mais importância e por consequência, a busca por uma melhor gestão desta parceria tem sido muito mais procurada pelas organizações. A terceirização no fornecimento de produtos, uma vez que grandes empresas tendem a focar no seu negócio principal, é uma realidade cada vez mais forte, portanto desenvolver e garantir fornecedores que atendam da melhor forma possível as necessidades dos clientes é de vital importância para que as empresas possam manterse competitivas num mercado de disputas cada vez mais acirradas. É inegável que, para oferecer um produto final de qualidade, a um preço competitivo e com cumprimento dos prazos contratuais, certificar-se de estar trabalhando com os melhores fornecedores é um passo fundamental e que merece ser estudado e trabalhado como ponto estratégico pelas empresas.

Porter (1999, p. 46) afirma que: "as empresas devem ser flexíveis para reagir com rapidez às mudanças competitivas e de mercado. É importante que pratiquem de modo constante o benchmark para atingir as melhores práticas. Também devem terceirizar de forma agressiva para conquistar eficiência. E é fundamental que fomentem umas poucas competências essenciais, na corrida para permanecer à frente dos rivais".

Segundo Lima Junior, Osiro e Carpinetti (2013), a seleção de fornecedores se configura como uma das atividades mais críticas para a gestão das cadeias de suprimentos sendo fator de influência direta no desempenho das organizações.

A opção pelos melhores fornecedores deve envolver a negociação por atributos alternativos (tradeoffs), porque raramente estes são claramente superiores aos seus concorrentes de modo que é muito difícil estabelecer uma comparação. Adotar uma classificação baseado em alguns critérios préestabelecidos e/ou atribuir notas e/ou procedimentos de avaliação são as melhores opções (SLACK, CHAMBERS e JOHNSTON, 2009).

Para Zerbini (2006), uma avaliação de desempenho adequada, permite mensurar com eficiência o cumprimento das expectativas na relação entre empresa e seus fornecedores. Isto permite que, ações de melhoria e desenvolvimento possam ser tomadas para ambos.

Por conseqüência da globalização, e as parcerias firmadas entre empresas, é fundamental considerar que as relações entre compradores e fornecedores podem ser, por muitas vezes, contraditórias, ou seja, os objetivos de ambos devem ser respeitados para que a gestão do supply chain possa ser bem sucedida (ALENCAR e SILVA, 2014).

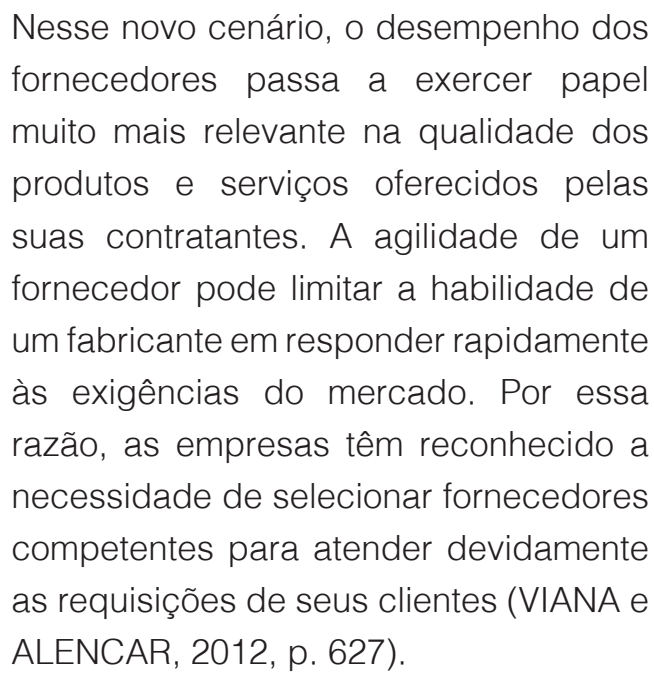

Este artigo tem como objetivo realizar uma análise de desempenho de fornecedores de uma empresa multinacional do setor de energia localizada no sul de Minas Gerais por meio da Análise Envoltória de Dados (DEA).

\section{REVISÃO DA LITERATURA 2.1 FORNECEDORES}

Segundo Viana e Alencar (2010) estudos apontam para uma evolução nos critérios de avaliação e seleção de fornecedores, o que considera uma inclusão de um número considerável de análises quantitativas e qualitativas. Ou seja, as avaliações deixaram de levar em conta somente o fator preço como preponderante para as escolhas, mais do que isso, hoje as empresas tem ido muito além do padrão preço, qualidade e entrega. Fatores como credibilidade, compromisso, capacidade de cooperação, flexibilidade, assim como outros são presença constante nas avaliações. 
Ao tratar - se de questões relacionadas aos fornecedores, vários questionamentos devem ser ponderados, como por exemplo, ter o produto desejado em sua melhor forma, como medir o desempenho de fornecedores, ou ainda, como o seu desempenho influenciará o produto final (AMORIM, ROCHA e BALESTRASSI, 2013). Os autores ainda ressaltam que tal importância no relacionamento cliente-fornecedor tem feito com que indústrias automotivas coloquem seus principais fornecedores dentro do seu parque fabril, diminuindo assim riscos eminentes na relação entre ambos, visto que cada vez mais se trabalha na filosofia Just in Time.

Segue abaixo a definição de avaliação de fornecedores encontrada na norma ISO:

A organização deve avaliar e selecionar fornecedorescombasenasuacapacidade de fornecer produto de acordo com os requisitos da organização. Critérios para seleção, avaliação e reavaliação devem ser estabelecidos.Devem ser mantidos registros dos resultados das avaliações e de quaisquer ações necessárias, oriundas da avaliação (ABNT NBR ISO 9001:2008, p. 10).

Para Moura (2009) a importância de uma empresa focar no seu negócio principal tem feito grandes organizações adotarem a desintegração vertical, conseqüentemente um número maior de fornecedores passam a integrar suas carteiras de fornecedores. Objetiva-se então o aumento da competitividade, uma vez que as empresas deixam de atuar isoladamente e passam a atuar mutuamente. Daí surge a importância de se trabalhar com empresas fornecedoras competentes e confiáveis. Não obstante é preciso desenvolver métodos precisos que indiquem os níveis de eficiência dessas empresas, mostrando quais dentre eles são qualificáveis para satisfazerem os requisitos de seus clientes.

Quanto a classificação e seleção de fornecedores, Godinho (2005) afirma que estes podem ter caráter físico ou jurídico, porém com objetivo de suprir a necessidade de pessoas ou empresas em termos de materiais e/ou serviços. Os critérios de avaliação devem fazer parte da documentação da empresa e que entre os princípios básicos, a serem avaliados estão preço, aspectos técnicos comerciais e a busca por não se ter um fornecedor único, evitando assim a vulnerabilidade ou dependência de fonte única.

Existe o fato de que na relação de empresas com seus fornecedores, estes precisam ser tratados de forma organizada, e critérios bem definidos devem ser adotados, pois tratam-se de empresas diferentes e até mesmo desconhecidas entre si (MOURA, 2009).

Ainda de acordo com Moura (2009) existiriam duas possibilidades para se estabelecer uma cadeia de fornecedores. A primeira delas consiste em deixar o próprio mercado organizar a cadeia criando assim oportunidades de negócios e induzindo a competição. A segunda se reporta a empresa, na qual organizará a cadeia de fornecedores por meio de desenvolvimento e qualificações dos mesmos. Para o autor a primeira não traz o nível de confiança desejável para essa relação, uma vez que a empresa não participa de nenhuma ação que influencia uma tomada de decisão por parte dos fornecedores, desta forma, a competência e confiabilidade desses fornecedores são classificados como duvidosos. Já a segunda alternativa se mostra mais coerente, já que a empresa cliente passa a estabelecer condições a serem atendidas pelos seus fornecedores, complementando assim sua estratégia de negócios. O autor também menciona que apenas adoções de normas internacionais como a ISO 9001 que estabelece condições mínimas de organizações de fornecedores pode não ser suficiente, pelo fato de que as relações ainda seriam limitadas a transações comerciais e haveria o risco de não obter os benefícios mútuos em um processo mais aprofundado de parcerias. Observa-se então que, resta a uma grande empresa que tenha interesse na organização de sua cadeia de fornecedores, que a mesma promova um conjunto de ações e melhorias buscando assim contemplar em sua rede de fornecimento, empresas competentes e confiáveis que busquem melhorias contínuas em seus produtos e serviços prestados a clientes.

De acordo com Rodrigues e Sellitto (2009) a medição 
do desempenho de fornecedores combina múltiplos fatores parciais de desempenho, que podem se valer de, ao mesmo tempo, múltiplas varáveis de análise e também diversas técnicas para se realizar tal medição.

Outra temática que vale ressaltar é o fato que grande parte das empresas fornecedoras é de pequeno porte, e que quando inseridas no mercado, passam a disputar com empresas internacionais que já se consolidaram no mercado com competência e porte. Deve se criar então condições para que os pequenos fornecedores se desenvolvam e qualifiquem se para atender com eficiência as empresas compradoras (MOURA, 2009).

\subsection{INDICADORES}

\subsubsection{INDICADORES DE DESEMPENHO LOGÍSTICO}

O nível de desempenho de um fornecedor pode ser mensurado, entre outros indicadores, pela sua performance de entregas dentro do prazo contratual ou acordado posteriormente com seu cliente (CONCEIÇÃO e QUINTÃO, 2004).

Como fator primordial, é importante destacar que os indicadores de desempenho são importantes para a gestão da qualidade total sendo fundamentais na busca por melhorias e a satisfação dos stakeholders na organização. É muito importante então que, indicadores sejam estabelecidos de maneira que possam efetivmente medir o desempenho em relação aos objetivos do cliente (MARTINS e COSTA NETO, 1998).

Conceição e Quintão (2004) afirmam ainda que, com um excelente nível de desempenho no que tange a questão da logística, a tendência natural é que o valor agregado da cadeia de suprimentos se eleve e que devido a isso, faz-se necessária a busca por maneiras de avaliar os fornecedores em seu nível de serviço logístico prestado.

\subsubsection{CUSTOS E COMPETITIVIDADE}

A preocupação com os custos iniciou-se com a Revolução Industrial com a necessidade de avalição de inventários de matéria prima, produtos acabados e produtos em processo. Atualmente, com a competitividade cada vez maior, a gestão dos custos requer uma atenção especial, pois a sinergia entre necessidades de comprador e vendedor é imprescindível visto que o impacto no lucro das empresas é direto (SILVA, 2014).

Segundo Cooper e Slagmulder (2003), existem muitas formas através das quais fornecedores podem modificar seu comportamento para contribuição na redução dos custos de seus clientes. Por exemplo, entregas com atrasos podem representar um despesa bem alta para o comprador. Através da própria transferência de conhecimento, clientes podem indicar também outros pontos importantes a serem melhorados por parte dos fornecedores como: melhor qualidade, entrega em lotes menores e tempos de fabricação mais curtos.

\subsubsection{CERTIFICADO SISTEMA ISO 14000}

Nas últimas décadas cresceu bastante a importância de questões relacionadas ao meio ambiente principalmente na vida das indústrias. Esta preocupação ambiental tem refletido bastante na relação entre países, produtores e importadores. Isso fez com que a indústria se sentisse na necessidade de dispor de normas para o Sistema de Gestão Ambiental (NAHUZ, 1995).

A International Organization for Standartization (ISO) é projetada para estabelecer critérios estruturais válidos através de regras, testes e certificações encorajando o comércio de bens e serviços. A ISO 14000 é a família de normas desenvolvidas para cuidar da rotulagem ambiental. A série ISO 14000 tem como objetivo um Sistema de Gestão Ambiental que auxilie as empresas a cumprirem suas responsabilidades em relação ao meio ambiente que permeia a organização dentro de conceitos e procedimentos sem perder de vista características e valores regionais(SOLEDADE et al., 2007, p. 6). 


\subsubsection{NÃO CONFORMIDADES}

Para Durski (2003), existe grande dificuldade para um cliente identificar se um produto é melhor ou pior do que um similar, mas por outro lado é importante certificar-se e dar prioridade às características do desempenho do produto e do processo para atender às expectativas dos clientes. Para medir a taxa de qualidade de um fornecedor, devem estar bem estabelecidos os parâmetros de acordo com as características de cada um.

A organização deve assegurar que produtos que não estejam conformes com os requisitos do produto sejam identificados e controlados para evitar seu uso ou entrega não pretendidos. Um procedimento documentado deve ser estabelecido para definir os controles e as responsabilidades e a autoridade relacionadas para lidar com produto não conforme (ABNT NBR ISO 9001:2008, p. 13).

\subsection{ANÁLISE ENVOLTÓRIA DE DADOS (DEA) \\ 2.3.1 EFICIÊNCIA E EFICÁCIA}

Antes de abordar diretamente os conceitos e aspectos do DEA serão feitas algumas considerações relativas aos termos eficiência e eficácia, uma vez que de acordo com Mello et al. (2005) é de extrema importância que o entendimento dos termos mencionados seja claro e conciso.

Quando se pretende avaliar a eficiência de alguma unidade produtiva, ou serviços prestados por terceiros, ou ainda qualquer relação cliente-fornecedor, é importante atentar-se para o termo eficiência. Conforme Chiavenato (2007), quando uma empresa passa por uma avaliação de desempenho e resultados é preciso que a mesma seja considerada sobre o ponto de vista de eficácia e eficiência simultaneamente. De acordo com o autor a eficácia tem como objetivo o alcance dos resultados, enquanto que a eficiência cuida da utilização de recursos nesse processo e que, abordando o tema em termos econômicos, a capacidade de satisfazer a necessidade do cliente através de seus produtos sendo eles bens ou serviços, diz respeito a eficácia, ao passo que a eficiência se define numa relação técnica entre entradas e saidas.

De acordo com Castro (2006), a eficiência se insere nas operações visando os aspectos internos da organização se preocupando apenas com os meios, deixando para a eficácia a preocupação com os fins pela qual seus objetivos serão alcançados focando os apectos externos da organização, porém o autor faz uma observação em relação ao fato de que nem sempre uma organização consegue ser eficiente e eficaz ao mesmo tempo, em um momento a organização pode ser eficiente sem estar sendo eficaz e vice-versa, dai se conclui que o ideal se obtem quando ambas as intenções sejam obtidas ao mesmo tempo, ou seja, ser igualmente eficiente e eficaz. Este conceito partilha da mesma idéia de Chiavenato (2007) quando menciona a possibilidade de que a eficiência e eficácia nem sempre podem andar juntas.

Ilustrando melhor este conceito, Mello et al. (2005) explica a diferença entre eficiência e eficácia. Exemplificando pode se analisar a seguinte situação: se uma unidade produtiva consegue atingir a produção que tinha como meta pode se dizer que ela foi eficaz, porem foi eficiente? A meta de produção pode ter sida definida tanto pela própria empresa quanto externamente. Para se ter certeza se foi ou não eficiente é preciso verificar quais recursos a unidade analisada dispunha, quais tecnologias foram utilizadas, quais foram os resultados obtidos pelos seus concorrentes, dentre outros critérios que possam ser incluídos na análise.

Outro exemplo pode ser analisado de acordo com a relação de eficiência e eficácia de um vendedor, conforme explica Degen (2009): para ser eficiente um vendedor deve fazer um maior numero de ofertas a clientes potenciais num menor tempo, enquanto que sua eficácia será medida em relação a quantas vendas foram realizadas a esses clientes potenciais.

Reforçando os conceitos apresentados Maximiliano (2008) comenta que o desempenho de uma organização se torna válido e aceitável quando a mesma utiliza 
seus recursos de maneira correta gerando a satisfação dos clientes, usuários, funcionários, acionistas, e a sociedade de forma geral.

No Quadro 1 é possível ver de forma resumida a diferença no que diz respeito a eficiência e eficácia.

\section{Quadro 1 - Diferença entre eficiência e eficácia}

\begin{tabular}{l|l} 
Eficiência & Eficácia \\
Como as coisas são feitas: & Para que as coisas são feitas: \\
De que maneiras são & Quais resultados elas trazem; \\
executadas; & Quais objetivos alcançam; \\
Quais os passos para & Ênfase nos resultados; \\
executá-las; & Fazer as coisas corretas; \\
Ênfase nos meios; & Atingir objetivos; \\
Fazer as coisas de maneira & Otimizar a utilização de \\
correta; & recursos; \\
Resolver problemas; & Obter resultados; \\
Salvaguardar os recursos; & Proporcionar eficácia aos \\
Cumprir tarefas e obrigações; & subordinados; \\
Treinar os subordinados; & Máquinas disponíveis. \\
Manter as máquinas. &
\end{tabular}

Fonte: Adaptado de Chiavenato (2007).

\subsubsection{PRODUTIVIDADE}

Conforme explica Maximiliano (2008) a produtividade é um dos critérios mais simples na qual se pode avaliar um processo, organização ou sistema. Define-se como produtividade a relação entre os recursos utilizados e os recursos obtidos (ou produção).

Da mesma forma em relação a produtividade, Mello et al. (2005) define que essa é o resultado da razão entre a quantidade produzida pelo o que foi gasto para produzir. Entretanto sendo o resultado advindo de duas unidades diferentes, a produtividade tem unidades de medidas diferentes para cada caso. Um exemplo pode ser observado no seguinte caso: um agricultor decide analisar sua produtividade. Ele pode dividir a quantidade produzida pela área plantada tendo como unidade de medida toneladas/ hectares. Porém de outra forma, pode haver interesse de se verificar a produtividade pela mão de obra ou gastos com terceiros. É possível comparar essas diferentes produtividades que mostrará a eficiência de um processo ou organização ao adotarmos o uso da ferramenta DEA.

Ainda em relação ao conceito de produtividade qualquer que seja a forma de medida utilizada, de acordo com Maximiliano (2008) de um modo geral, quanto mais elevada for a quantidade de resultados obtidos com a mesma quantidade de recursos, mais produtivo o sistema ou organização é.

\subsubsection{ANÁLISE ENVOLTÓRIA DE DADOS - ASPECTOS GERAIS}

A proposta de uma abordagem por meio da Análise Envoltória de Dados do inglês Data Envelopment Analysis - DEA, foi sugerida por Charnes, Cooper e Rhodes (1978) visando determinar a eficiência encontrada na avaliação de programas públicos. Como objetivo a técnica proposta consistia em fazer uma análise das unidades produtivas com base nas utilizações de seus recursos não importando qual seja a combinação dos mesmos ou ainda quais tecnologias são adotadas. Mais tarde com o objetivo de avaliar o desempenho do ensino básico um segundo modelo clássico foi proposto por Banker, Charnes e Cooper (1984).

Segundo Mello et al. (2005), a Análise Envoltória de Dados consiste numa ferramenta matemática utilizada para medir a eficiência de unidades produtivas e concordando com o autor Casado e Souza (2007) e Souza e Wilhelm (2009) explicam que o DEA é uma técnica não paramétrica que através da utilização da programação matemática, obtém-se com o modelo fronteiras de produção de unidades produtivas. Essas fronteiras avaliam a eficiência relativa dos planos de operação executado pelas unidades produtivas, servindo também como referências para o estabelecimento de metas eficientes para as unidades produtivas ineficientes.

Através dos estudos de Casado e Souza (2007), os mesmos ainda comentam que o Brasil obteve seus primeiros trabalhos utilizando a ferramenta DEA na construção de medidas na avaliação de IES (Instituições de Ensino Superior), com origem em grupos de pesquisa da Universidade Federal de Santa Catarina (UFSC) destacando os trabalhos como de Belloni (2000) que defendendo sua tese de doutorado, construiu uma metodologia DEA para avaliação de 
eficiência das universidades brasileiras.

Na busca do aperfeiçoamento dos métodos existentes na avaliação dos programas de pós-graduação, Lins, Almeida e Bartholo Junior (2004) definem a utilização da análise envoltória de dados como uma ferramenta de auxílio destacando a importância do método no que tange a forma de integração dos diversos aspectos de desempenho no âmbito do processo decisório, onde podem existir, e na maioria das vezes existem variáveis que representam aspectos nos quais não podem ser agregados. Ainda de acordo com o autor uma das vantagens da utilização dos modelos DEA se dá no fornecimento de benchmarks para as unidades ineficientes uma vez que as mesmas são projetadas numa fronteira de eficiência.

Como já mencionado, o modelo DEA analisa o desempenho das unidades produtivas, e por convenção dentro da aplicação do modelo, cada unidade produtiva se constitue numa DMU, sigla que vem do inglês Decision Making Unit - unidades tomadoras de decisões, e que para Mello et al. (2005) o ser ou não ser eficiente se relaciona com as decisões que são tomadas pelas unidades produtivas, ou seja, pelas DMU's.

Casado e Souza (2007) dizem que segundo a literatura relacionada aos modelos DEA, uma firma ou empresa é considerada uma DMU, uma vez que estes modelos detém uma medida para avaliar a eficiência de unidades tomadoras de decisão.

Sousa e Wilhelm (2009) reforçam que o DEA se aplica na resolução de problemas de programação linear tendo como objetivo a projeção dos produtores ineficientes tecnicamente até o conjunto de eficiência forte ou o conjunto de eficiência fraco e que para isso geralmente consideram-se os retornos constantes de escala, retornos não crescentes de escalas e retornos variáveis de escalas. Os mesmos podem ser observados conforme é mostrado na Figura 1:

Figura 1 - Retornos de escala. Fonte: Souza e Wilhelm (2009).

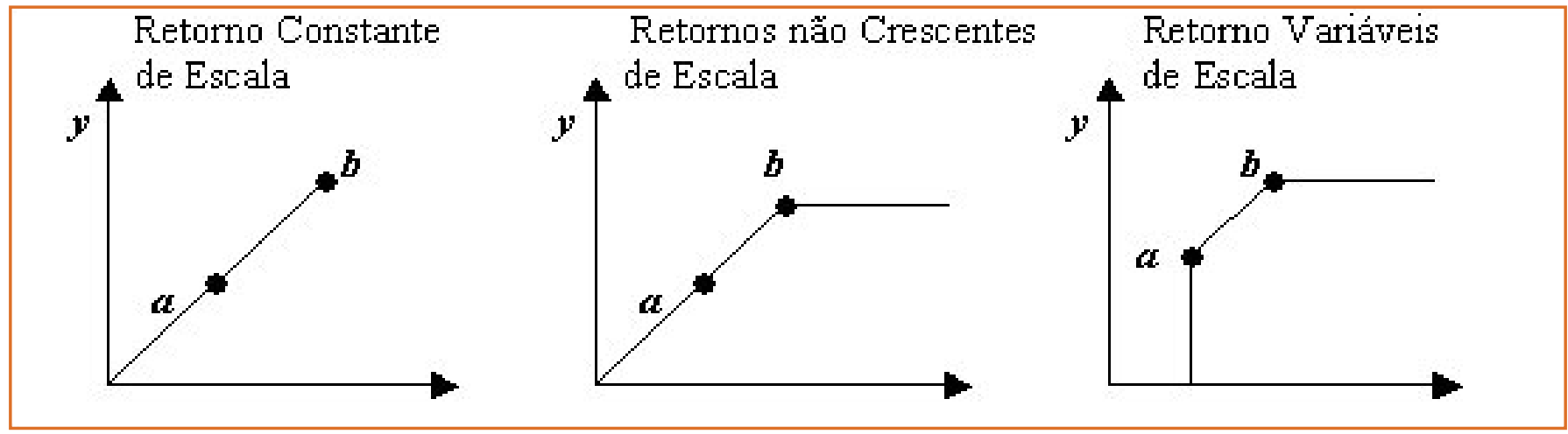

Através de um resumo bem detalhado, Gomes (2008) relatou em seu trabalho as três etapas necessárias, quando se utiliza a modelagem DEA numa avaliação de eficiência e desempenho, sendo elas: seleção e definição de DMU's; seleção de variáveis (inputs entradas e outputs - saídas); escolha e aplicação do modelo DEA.

A autora também comenta sobre as duas formulações equivalentes para DEA, onde uma das formulções define a região viável de produção projetando cada DMU na fronteira dessa região consistindo no modelo por envelope. Já a outra formulação trabalha com a razão da soma ponderada de produtos e recursos, com a ponderação escolhida de forma mais favorável a cada DMU.

\subsubsection{MODELOS CCR E BCC}

Segundo Lins e Almeida Junior (2004), Mello et al. (2005), Gomes (2008) e Rafaelli (2009) os dois modelos clássicos DEA são o CCR e o BCC. O modelo CCR cujo nome faz referência aos seus autores Charnes, Cooper e Rhodes (1978), trabalha com retornos constantes a escala, em outras palavras significa dizer que, 
mais acréscimos nos recursos produzirá acréscimos proporcionais aos produtos. De acordo com Carvalho e Arruda (2012) além das variações de produtos serem proporcionais às variações de insumos, o modelo ainda permite que cada DMU escolha os pesos para cada variável da forma que lhe for mais benéfica, porém esses pesos quando aplicados as outras DMU's não podem gerar uma razão superior a 1. A seguir são demontradas as equações referentes ao modelo CCR.

O modelo CCR é representado conforme equações (1)-(5):

$$
\max w_{o}=\sum_{q=1}^{b} u_{q} y_{q o}
$$

Sujeito a:

$$
\begin{aligned}
& \sum_{p=1}^{a} v_{p} x_{p o}=1 \\
& \sum_{q=1}^{b} u_{q} y_{q i}-\sum_{p=1}^{a} v_{p} x_{p i} \leq 0 \quad i=1,2, \ldots ., n \\
& u_{q} \geq 0, \quad q=1,2, \ldots, b \\
& v_{p} \geq 0, \quad p=1,2, \ldots, a
\end{aligned}
$$

No qual i representa o índice da $D M U, i=1, \ldots, n$; $q$ é o índice da saída, com $q=1, \ldots, b ; p$ é o índice da entrada, $p=1, \ldots, a$; $y_{q i}$ é o valor da q-ésima saída para a i-ésima DMU; $x_{p i}$ é o valor da p-ésima entrada para a i-ésima DMU; $u_{q}$ é o peso associado à q-ésima saída; $v_{p}$ é o peso associado à $p$-ésima entrada; $w_{0}$ é a eficiência relativa de $D M U_{0}$, que é a $D M U$ sob avaliação; e $\mathrm{y}_{\mathrm{qo}}$ e $\mathrm{x}_{\mathrm{po}}$ são, respectivamente, dados de saídas e entradas da $\mathrm{DMU}_{\text {o }}$.

O modelo BCC, cuja a sigla também faz referência aos nomes de seus autores Banker, Charnes e Cooper (1984), surge a exatos 6 anos após a primera publicação do DEA. Seus autores eliminaram a suposição de retornos constantes a escala proposto no modelo CCR substituindo-os por retornos variáveis a escalas, tendo como objetivo a avaliação da eficiência técnica pura das diversas DMU's. Neste contexto é possível a identificação de retornos crescentes e decrescentes de escalas, uma vez que o axioma da proporcionalidade é substituído pelo axioma da convexidade Rafaelli (2009).
O Modelo BCC é representado pelas equações (6)-(10):

$$
\max w_{o}=\sum_{q=1}^{b} u_{q} y_{q o}+c_{o}
$$

Sujeito a:

$$
\begin{aligned}
& \sum_{p=1}^{a} v_{p} x_{p o}=1 \\
& \sum_{q=1}^{b} u_{q} y_{q i}-\sum_{p=1}^{a} v_{p} x_{p i}+c_{o} \leq 0 \quad i=1,2, \ldots, n \\
& u_{q} \geq 0, \quad q=1,2, \ldots, b \\
& v_{p} \geq 0, \quad p=1,2, \ldots, a
\end{aligned}
$$

Vale observar que para obtenção da formulação do modelo BCC foi inserida de forma aditiva nas equações (6) e (8) uma variável auxiliar irrestrita $C_{0}$, denominada fator de escala. Tal variável indica onde a DMU em análise se encontra, seja na porção de retorno crescente, decrescente ou constante de escala (MELLO et al., 2013).

Nas Figuras 2 e 3 são representadas as superfícies envoltórias e a forma de projeção dos modelos CCR e BCC (SOUSA e WILHELM, 2009):

Figura 2 - Modelo DEA/CCR. Fonte: Adaptado de Souza e Wilhelm (2009).

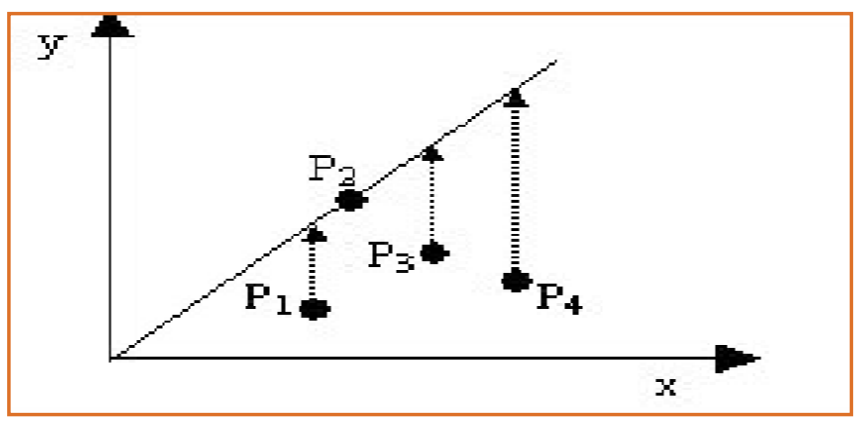


Figura 3 - Modelo DEA/BCC. Fonte: Adaptado deSouza e Wilhelm (2009).

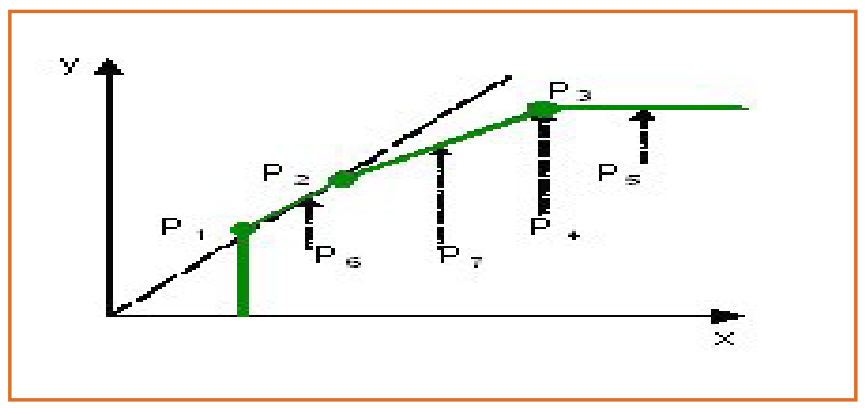

E ainda de acordo com Mello et al. (2005) e Carvalho e Arruda (2012) na Figura 4 é possível observar a diferença entre os modelos CCR e BCC, onde uma maior benevolência quanto ao desempenho das unidades pode ser observada no modelo BCC, isso ocorre devido a possibilidade de variação na escala de produção, enquanto que no modelo CCR por definição esta escala permanece constante.

Figura 4 - Fronteiras do modelo DEA BCC e CCR. Fonte: Mello et al. (2005).

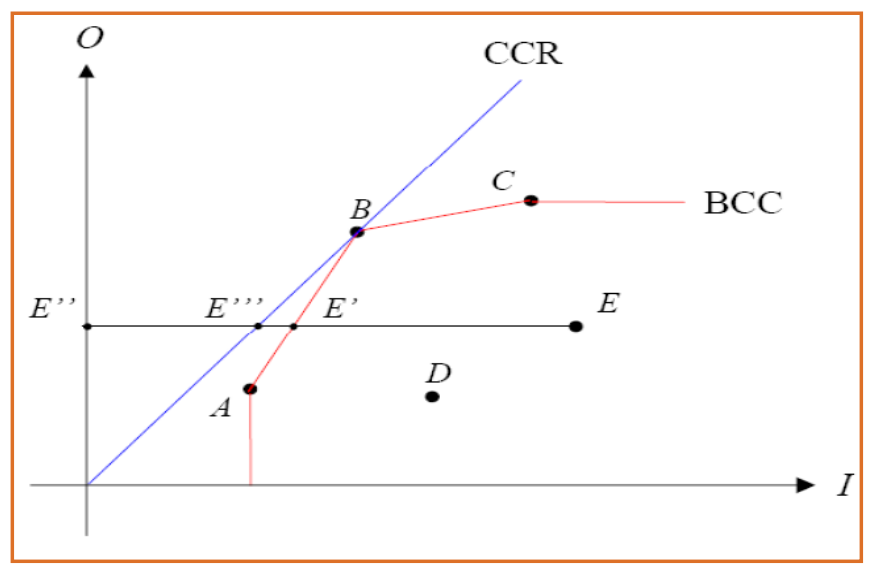

Carvalho e Arruda (2012) explicam que ambos os modelos BCC e CCR podem seguir dois tipos de orientações quanto a modificação nas variáveis, sendo elas a Orientação a input ou Orientação a output, totalizando quatro tipos de modelos básicos: CCR/ input; CCR/Output; BCC/Input; e BCC/Output. Ainda de acordo com o autor em concordância com Mello et al. (2005) quando o modelo está orientado a input, o mesmo força a maximização do decrécimo desta variável enquanto a mesma permanece no espaço de envelopamento. Já quando o modelo se orienta a output, o mesmo força o aumento das variáveis do produto.

A análise feita com a abordagem DEA gera os seguintes resultados de acordo com Sousa e Wilhelm (2009):

- Uma superfície envoltória que permite a identificação das DMU's eficientes e ineficientes;

- Uma medida de eficiência métrica para cada DMU no que diz respeito a (distância da fronteira, a fonte e o grau de ineficiência);

- Uma projeção da DMU sobre a fronteira;

- Um conjunto referência (unidades específicas contra as quais uma DMU particular está sendo comparada).

\section{MÉTODOS DE PESQUISA}

A metodologia de pesquisa adotada para este trabalho foi a modelagem e a simulação matemática.

Modelagem e simulação é o processo de criação e experimento de um sistema físico através de um modelo matemático cujas saídas devem ser destinadas a um propósito específico (MARTINS, MELLO e TURRIONI, 2013)

Ainda segundo Martins, Mello e Turrioni (2013), entre os principais propósitos de se conduzir uma pesquisa utilizando modelagem e simulação estão: conhecer em detalhes o sistema operacionalmente, desenvolver o aperfeiçoamento do sistema, testar novos conceitos e sistemas antes de sua implementação e obter informações sem interferência no sistema corrente.

Neste estudo, utilizaremos da abordagem axiomática normativa, onde partiremos diretamente para a solução do modelo matemático, sem conduzir o experimento simulado, reduzindo as etapas para "modelagemsolução pelo modelo".

Para Tavares Neto (2010), a abordagem axiomática normativa é a mais apropriada quando se deseja a obtenção de estratégias que visam a utilização das melhores soluções para os critérios de desempenho em questão. 


\section{ANÁLISE DOS RESULTADOS}

As etapas da pesquisa estão demonstradas na Figura 5 e são descritas a seguir:

Figura 5 - Fluxograma das etapas da pesquisa

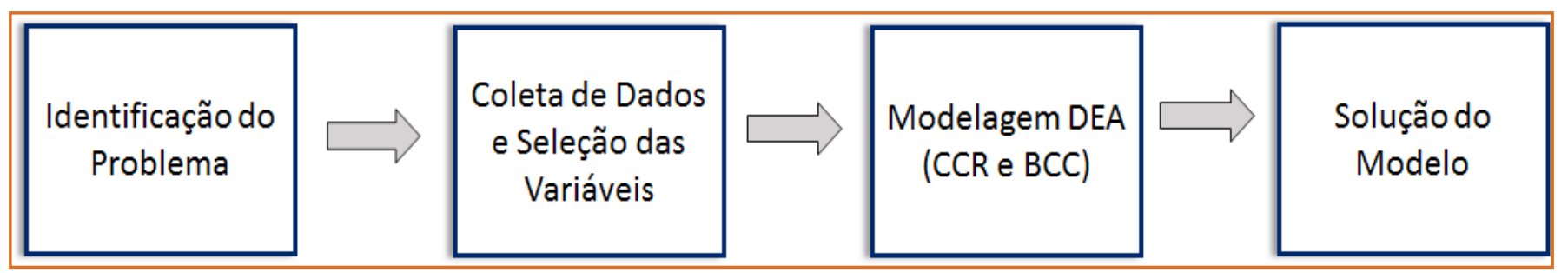

Etapa (a) Identificação do problema: O problema consiste em avaliar o desempenho de fornecedores de uma empresa de energia localizada no sul de Minas Gerais. As DMU's foram definidas como sendo cada um destes fornecedores.

Etapa (b) Coleta dos dados: Primeiramente, a escolha dos fornecedores a serem avaliados no ano (no caso o ano fiscal da empresa é de abril do ano corrente a março do ano seguinte) através de um relatório extraído do software utilizado globalmente pela empresa, que emite um relatório com os fornecedores que mais tiveram entrega de material (levando em consideração valores monetários) durante o último ano. De posse deste relatório, descartam-se os fornecedores de itens considerados não-produtivos, os materiais de consumo ou qualquer outro item que, mesmo que usados no processo produtivo dos equipamentos ofertados pela empresa, não impacte diretamente em suas funcionalidades. Desta forma, limita-se o número de fornecedores críticos que deverão ser avaliados segundo os critérios pré-estabelecidos.

Então, consideraram-se para a realização desta pesquisa os 61 maiores fornecedores (DMU's) da empresa em questão.

Foi considerado como Input o Número de não Conformidades $(X 1)$.

E, como Outputs foram selecionadas as variáveis: Entregas no Prazo (Y1), Custos e Competitividade (Y2) e Certificado Sistema ISO 14000 (Y3).

A Tabela 1 mostra os valores das notas atribuídas às variáveis de Input e Output de cada DMU.
Tabela 1 - Valores de Inputs e Outputs

\begin{tabular}{|lllll|}
\hline DMU's & X1 & Y1 & Y2 & Y3 \\
\hline DMU1 & 50 & 100 & 75 & 0 \\
\hline DMU2 & 100 & 100 & 50 & 0 \\
\hline DMU3 & 100 & 50 & 75 & 0 \\
\hline DMU4 & 100 & 100 & 50 & 0 \\
\hline DMU5 & 100 & 100 & 100 & 0 \\
\hline DMU6 & 50 & 100 & 50 & 0 \\
\hline DMU7 & 100 & 0 & 50 & 0 \\
\hline DMU8 & 100 & 100 & 75 & 0 \\
\hline DMU9 & 100 & 100 & 25 & 0 \\
\hline DMU10 & 100 & 100 & 75 & 0 \\
\hline DMU11 & 75 & 50 & 50 & 0 \\
\hline DMU12 & 50 & 100 & 50 & 100 \\
\hline DMU13 & 100 & 100 & 0 & 0 \\
\hline DMU14 & 100 & 80 & 50 & 0 \\
\hline DMU15 & 100 & 0 & 75 & 0 \\
\hline DMU16 & 50 & 50 & 50 & 0 \\
\hline DMU17 & 100 & 50 & 50 & 100 \\
\hline DMU18 & 100 & 100 & 50 & 0 \\
\hline DMU19 & 100 & 100 & 50 & 0 \\
\hline DMU20 & 25 & 100 & 75 & 0 \\
\hline DMU21 & 100 & 100 & 50 & 0 \\
\hline DMU22 & 100 & 100 & 25 & 0 \\
\hline DMU23 & 100 & 100 & 50 & 100 \\
\hline DMU24 & 100 & 100 & 50 & 100 \\
\hline DMU25 & 100 & 100 & 50 & 0 \\
\hline DMU26 & 50 & 80 & 50 & 0 \\
\hline DMU27 & 100 & 50 & 0 \\
\hline DMU28 & 100 & 50 & 0 \\
\hline DMU29 & 100 & 50 & 100 \\
\hline DMU30 & 100 & 75 & 0 \\
\hline DMU31 & 100 & 50 & 0 \\
\hline DMU32 & 100 & 50 & 0 \\
\hline DMU33 & 100 & 50 & 5 \\
\hline
\end{tabular}




\begin{tabular}{|lllll|}
\hline DMU's & X1 & Y1 & Y2 & Y3 \\
\hline DMU34 & 100 & 100 & 25 & 100 \\
\hline DMU35 & 50 & 100 & 75 & 0 \\
\hline DMU36 & 100 & 100 & 50 & 0 \\
\hline DMU37 & 100 & 100 & 100 & 100 \\
\hline DMU38 & 100 & 50 & 75 & 100 \\
\hline DMU39 & 100 & 100 & 100 & 0 \\
\hline DMU40 & 100 & 0 & 100 & 0 \\
\hline DMU41 & 100 & 100 & 0 & 100 \\
\hline DMU42 & 100 & 100 & 75 & 0 \\
\hline DMU43 & 100 & 100 & 100 & 0 \\
\hline DMU44 & 100 & 50 & 75 & 0 \\
\hline DMU45 & 100 & 100 & 75 & 0 \\
\hline DMU46 & 100 & 100 & 50 & 0 \\
\hline DMU47 & 50 & 100 & 100 & 0 \\
\hline DMU48 & 100 & 100 & 75 & 100 \\
\hline DMU49 & 100 & 100 & 100 & 0 \\
\hline DMU50 & 100 & 100 & 75 & 0 \\
\hline DMU51 & 100 & 50 & 100 & 0 \\
\hline DMU52 & 100 & 100 & 0 & 0 \\
\hline DMU53 & 100 & 100 & 0 & 0 \\
\hline DMU54 & 100 & 100 & 75 & 0 \\
\hline DMU55 & 100 & 100 & 75 & 0 \\
\hline DMU56 & 100 & 100 & 75 & 0 \\
\hline DMU57 & 100 & 100 & 100 & 100 \\
\hline DMU58 & 100 & 100 & 100 & 0 \\
\hline DMU59 & 100 & 100 & 75 & 0 \\
\hline DMU60 & 0 & 100 & 0 \\
\hline DMU61 & 100 & 100 & 100 \\
\hline
\end{tabular}

\begin{tabular}{|c|c|c|}
\hline DMU & Score CCR & Score BCC \\
\hline 5 & 0,333333 & 1 \\
\hline 6 & 0,5 & 1 \\
\hline 7 & 0,166667 & 0,5 \\
\hline 8 & 0,25 & 1 \\
\hline 9 & 0,25 & 1 \\
\hline 10 & 0,25 & 1 \\
\hline 11 & 0,2222222 & 0,5 \\
\hline 12 & 1 & 1 \\
\hline 13 & 0,25 & 1 \\
\hline 14 & 0,2 & 0,8 \\
\hline 15 & 0,25 & 0,75 \\
\hline 16 & 0,333333 & 0,5 \\
\hline 17 & 0,5 & 1 \\
\hline 18 & 0,25 & 1 \\
\hline 19 & 0,25 & 1 \\
\hline 20 & 1 & 1 \\
\hline 21 & 0,25 & 1 \\
\hline 22 & 0,25 & 1 \\
\hline 23 & 0,5 & 1 \\
\hline 24 & 0,5 & 1 \\
\hline 25 & 0,25 & 1 \\
\hline 26 & 0,4 & 0,8 \\
\hline 27 & 0,25 & 1 \\
\hline 28 & 0,333333 & 0,5 \\
\hline 29 & 0,5 & 1 \\
\hline 30 & 0,25 & 1 \\
\hline 31 & 0,583333 & 1 \\
\hline 32 & 0,25 & 1 \\
\hline 33 & 0,25 & 1 \\
\hline 34 & 0,5 & 1 \\
\hline 35 & 0,5 & 1 \\
\hline 36 & 0,25 & 1 \\
\hline 37 & 0,666667 & 1 \\
\hline 38 & 0,583333 & 1 \\
\hline 39 & 0,333333 & 1 \\
\hline 40 & 0,333333 & 1 \\
\hline 41 & 0,5 & 1 \\
\hline 42 & 0,25 & 1 \\
\hline 43 & 0,333333 & 1 \\
\hline 44 & 0,25 & 0,75 \\
\hline 45 & 0,25 & 1 \\
\hline 46 & 0,25 & 1 \\
\hline 47 & 0,666667 & 1 \\
\hline 48 & 0,583333 & 1 \\
\hline
\end{tabular}

Etapa (c) Modelagem: Foram analisadas as eficiências dos fornecedores utilizando os métodos clássicos da Análise Envoltória de Dados. Para isto, optou-se pela utilização do software Max DEA®.

Etapa (d) Solução do Modelo: Os resultados de eficiência dos fornecedores analisados pelos modelos DEA CCR e BCC são demostrados na tabela 2 e nas Figuras 6 e 7 .

Tabela 2 - Resultados de eficiência

\begin{tabular}{|l|l|l|}
\hline DMU & \multicolumn{1}{|l|}{ Score CCR } & Score BCC \\
\hline 1 & 0,5 & 1 \\
2 & 0,25 & 1 \\
3 & 0,25 & 0,75 \\
4 & 0,25 & 1 \\
\hline
\end{tabular}




\begin{tabular}{|c|c|c|}
\hline \multicolumn{1}{|c|}{ DMU } & Score CCR & Score BCC \\
\hline 49 & 0,333333 & 1 \\
50 & 0,25 & 1 \\
51 & 0,333333 & 1 \\
52 & 0,25 & 1 \\
53 & 0,25 & 1 \\
54 & 0,25 & 1 \\
\hline
\end{tabular}

\begin{tabular}{|c|c|c|}
\hline DMU & \multicolumn{1}{c}{ Score CCR } & Score BCC \\
55 & 0,25 & 1 \\
56 & 0,25 & 1 \\
57 & 0,666667 & 1 \\
58 & 0,333333 & 1 \\
59 & 0,25 & 1 \\
60 & 0,333333 & 1 \\
61 & 0,666667 & 1 \\
\hline
\end{tabular}

Figura 6 - Gráfico de resultados DEA - CCR

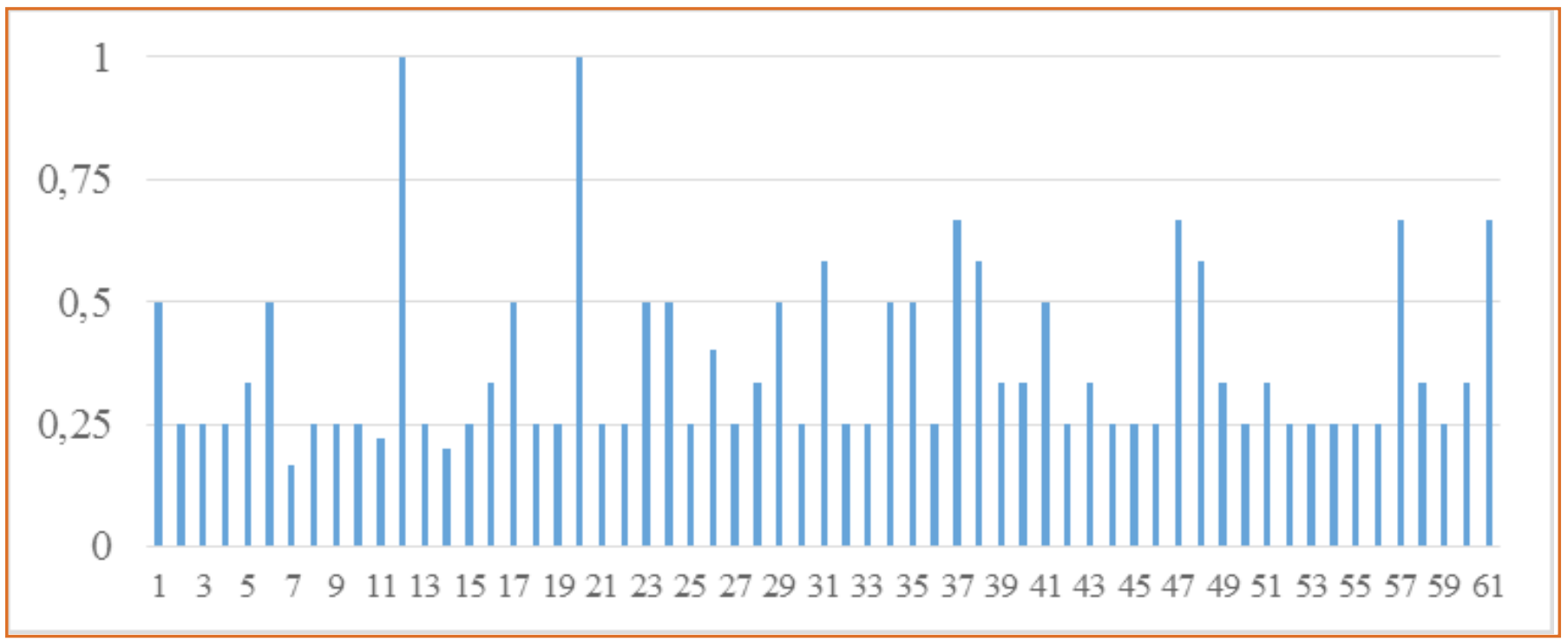

Figura 7 - Gráficos de resultados do DEA - BBC

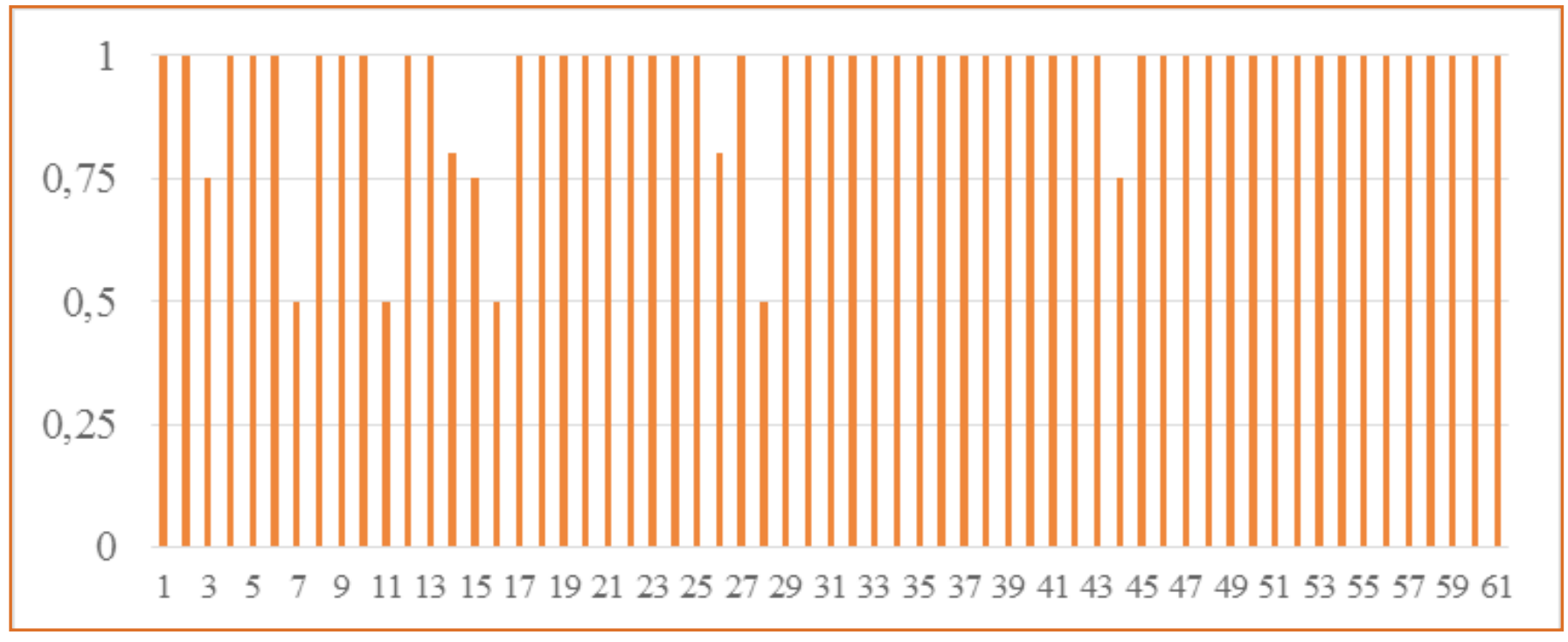

Os resultados obtidos foram apresentados tanto para o modelo DEA CCR quanto para o modelo DEA $B C C$, onde no primeiro modelo foi verificada uma boa discriminação dos resultados entre as DMU's, sendo que as DMU's 12 e 20 se mostraram as mais eficientes entre todas, o que as fazem serem consideradas benchmarks, levando-se em conta os critérios de avaliação adotados. Em contrapartida identifica-se 
que nenhuma outra DMU sequer atingiu os $75 \%$ de eficiência e ainda que mais da metade não ultrapassou a marca de $25 \%$ de eficiência. Este resultado aponta para que ações de melhoria devam ser tomadas para a grande maioria dos principais fornecedores e que, a estratégia do desenvolvimento de novos fornecedores deve ser uma das prioridades para a empresa.

O modelo BCC, como pode se verificar nos gráficos de seus resultados, não apresentou boa discriminação dos resultados, apresentando a maior parte das DMU's com o mesmo nível de eficiência (a maioria 100\%).

\section{CONCLUSÕES}

Em decorrência da acirrada competitividade que muitas organizações se deparam, ganha força no mercado, aquela que atua sob uma nova perspectiva de negócios, construindo uma forte, eficaz e duradoura relação com seus stakeholders.

Dessa forma, muitas empresas buscam aprimorar sua sistemática de desenvolvimento de fornecedores, na tentativa de estabelecer uma metodologia mais robusta de seleção e avaliação de parceiros, além de aferir com mais eficiência, a sinergia entre a empresa e seus fornecedores.

Nesse sentido, a Análise Envoltória de Dados surge como ferramenta-chave para medir a eficiência das organizações, uma vez que essa técnica baseada em programação matemática gera "raias produtivas" que medem a eficácia operacional das empresas.

Para isso, o objeto de estudo desse trabalho foi uma empresa multinacional de energia do sul de Minas Gerais. Dentre os principais fornecedores da organização, coletou-se dados relativos a 61 parceiros.

A coleta e análise desses dados permitiram concluir que o modelo DEA CCR apresenta uma boa discriminação dos resultados entre as unidades avaliadas. Esse modelo foi aplicável para a empresa, refletindo numa avaliação mais robusta de seus fornecedores e identificação de benchmarks.

Além disso, tal modelo auxiliou na elaboração de planos de ação sobre os fornecedores com nível de eficiência insatisfatório, bem como no estabelecimento de ranges para uma avaliação estendida aos demais fornecedores da empresa.

Como trabalhos futuros, sugere-se: aumentar o número de itens (critérios) de avaliação, assim como estender a utilização desta ferramenta de análise, a outros departamentos da empresa.

\section{REFERÊNCIAS}

[1] ALENCAR, L. H.; SILVA, A. G. Seleção de fornecedores: Uma proposta de modelo para uma empresa de impermeabilização. In:XXXIV ENCONTRO NACIONAL DE ENGENHARIA DE PRODUCAO, 2014, Curitiba. Anais... Curitiba, 2014.

[2] AMORIM, G. F.; ROCHA, G. V.; BALESTRASSI, P. P. Gerenciamento da cadeia de suprimentos: uma comparação entre a logística da cadeia total e da cadeia interna. In: XXXIII ENCONTRO NACIONAL DE ENGENHARIA DE PRODUÇÃO 2013, Salvador. Anais... Salvador, 2013.

[3] ASSOCIAÇÃO BRASILEIRA DE NORMAS TÉCNICAS. ISO 9001:2008 - ABNT NBR ISO 90012008 para treinamento - Rev1.

[4] BANKER, R. D.; CHARNES, A.; COOPER, W. W. Some models for estimating technical and scale inefficiencies in data envelopment analysis. Management Science, v. 30, n. 9, p. 1078-1092, 1984.

[5] BELLONI, J. A. Uma Metodologia de Avaliação da Eficiência Produtiva de Universidades Federais Brasileiras. 246 f. Tese (Doutorado) - Programa de Pós-Graduação em Engenharia de Produção, Universidade Federal de Santa Catarina, Florianópolis, 2000.

[6] CARVAlHO, T. C.; ARRUDA, J. B. F. Aplicação da Análise Envoltória de Dados a Cajucultura: Um estudo de caso na região de Aracati/CE e Fortim/CE. In: XXXII ENCONTRO DE ENGENHARIA DE PRODUÇÃO, 2012, Bento Gonçalves, Anais... Bento Gonçalves, 2012.

[7] CASADO, F. L.; SOUZA, A. M. Análise Envoltória de Dados: conceitos, metodologia e estudo da arte na educação superior. Revista do Centro de Ciências Sociais e Humanas, Santa Maria, v. 1, p. 1-154, 2007.

[8] CASTRO, R. B. Eficácia, eficiência e efetividade na administração pública. In: XXX ENCONTRO DA ANPAD, 2006, Salvador. Anais... Salvador, 2006.

[9] CHARNES, A.; COOPER, W. W.; RHODES, E. Measuring the efficiency of decision making units. European Journal of Operational Research, v. 2, n. 6, p. 429-444, 1978.

[10] CHIAVENATO, I. Administração: teoria, processo e prática. 4ed. Rio de Janeiro: Elsevier, 2007. 
[11] CONCEIÇÃO, S. V.; QUINTÃO, R. T. Avaliação do desempenho logístico da cadeia brasileira de suprimentos de refrigerantes. Gestão \& Produção, Belo Horizonte, v. 11, n. 3, p. 441-453, dez. 2004.

[12] COOPER, R.; SLAGMULDER, R. Redução de custos com inteligência $-2^{\circ}$ bimestre. Journal of Cost Management, 2003. Disponível em: <http://www.faculdadesagradafamilia. com.br/admin/app/webroot/anexos/Gestaodecustos2\%C2\%BABim.pdf>. Acesso em: 31 mai. 2015.

[13] DEGEN, R. J. O empreendedor: empreender como opção de carreira. São Paulo: Pearson Prentise Hall, 2009.

[14] DURSKI, G. R. Avaliação do desempenho em cadeias de suprimentos. Revista FAE, Curitiba, v. 6, n. 1, p. 27-38, jan/abr. 2003.

[15] GODINHO, W. B. Gestão de materiais e logística. São Paulo: Ibpex, 2005.

[16] GOMES, E. G. Uso dos modelos DEA em agricultura: Revisão da Literatura. Engevista, v. 10, n. 1, p. 27-51, junho, 2008.

[17] LIMA JUNIOR, F. R.; OSIRO, L.; CARPINETTI, L. C. R. Métodos de decisão multicritério para seleção de fornecedores: um panorama do estado da arte. Gestão \& Produção, São Carlos, v. 20, n. 4, p. 781-801, dez. 2013.

[18] LINS, M. P. E.; ALMEIDA, B. F.; BARTHOLO JUNIOR, R. Avaliação de desempenho na pós-graduação utilizando a Análise Envoltória de Dados: o caso da Engenharia de Produção. Revista Brasileira de Pós-Graduação,n. 1, julho, 2004.

[19] MARTINS, R. A.; MELLO, C. H. P.; TURRIONI, J. B. Guia para elaboração de monografia e TCC em Engenharia de Produção. São Paulo: Atlas, 2013.

[20] MARTINS, R. A; COSTA NETO, P. L. O. Indicadores de desempenho para a gestão pela qualidade total: Uma proposta de sistematização. Gestão \& Produção, São Carlos, v. 5, n. 3, p. 298-311, dez. 1998.

[21] MAXIMILIANO, A. C. A. Introdução a Administração. 7ed. São Paulo: Atlas, 2008.

[22] MELLO, J. C. C. B. S.; MEZA, L. A.; GOMES, E. G.; NETO, L. B.Curso de Análise envoltória de dados. In: XXXVII SIMPÓSIO BRASILEIRO DE PESQUISA OPERACIONAL, 2005, Gramado. Anais... Gramado, 2005.

[23] MELLO, J. S.; MEZA, L.; SILVEIRA, J.; GOMES, E. About negative efficiencies in Cross Evaluation BCC input oriented models. European Journal of Operational Research, v. 229, n. 3, p. 732-737, 2013.

[24] MOURA, L. R. Gestão do relacionamento com fornecedores: analise da eficácia de programa para desenvolvimento e qualificação de fornecedores para grandes empresas. 2009. 335 f. Tese (Doutorado) - Departamento de Engenharia de Produção, Escola Politécnica, Universidade de São Paulo, São Paulo, 2009.
[25] NAHUZ, M. A. R. O sistema ISO 14000 e a certificação ambienta. Revista de administração de empresas, v. 35, n. 1, nov/dez. 1995.

[26] PORTER, M. E. Competição - Estratégias competitivas essenciais. Rio de Janeiro: Vozes, 1999.

[27] RAFAELI, L. A Análise Envoltória de Dados como ferramenta para a Avaliação do Desempenho Relativo. 166f. Dissertação (Mestrado em Engenharia de Produção) - Universidade Federal do Rio Grande do Sul, Porto Alegre, 2009.

[28] RODRIGUES, D. M.; SELlitTO, M. A. Análise do desempenho de uma empresa de manufatura apoiada em análise de aglomerados. Revista Produção, São Paulo, v. 19, n. 1, p. 55-69, jan./abr. 2009.

[29] SILVA, K. S. GESTÃO DE CUSTOS. Curso técnico em logística - módulo IV, Cariacica 12 mar. 2014. Disponível em <http://www.trabalhosfeitos.com/ensaios/Gest\%C3\%A3oDe-Custos/48664086.html> Acesso em: 31 mai. 2015.

[30] SLACK, N.; CHAMBERS, S.; JOHNSTON, R. Administração da produção. São Paulo: Atlas, 2009.

[31] SOLEDADE, M. G. M.; NAPRAVNIK FILHO, L. A. F. K.; SANTOS, J. N.; SILVA, M. A. ISO 14000 e a Gestão Ambiental: uma Reflexão das Práticas Ambientais Corporativas. In: IX ENGEMA - ENCONTRO NACIONAL SOBRE GESTÃO EMPRESARIAL E MEIO AMBIENTE, 2007, Curitiba. Anais... Curitiba, 2007.

[32] SOUZA, P. C. T.; WILHELM, V. E. Uma introdução ao modelo DEA de eficiência técnica. Revista Tuiuti: Ciência e Cultura, Curitiba, n. 42, p. 121-139, 2009.

[33] TAVARES NETO, R. F. Proposta de solução de problemas de scheduling considerando possibilidade de terceirização usando a técnica de otimização por colônia de formigas. 2010. 148 f. Tese (Doutorado) - Centro de Ciências Exatas e Tecnologia, Universidade Federal de São Carlos, São Carlos, 2010.

[34] VIANA, J. C.; ALENCAR, L. H. Análise do processo de seleção e avaliação de fornecedores em indústrias: do setor de alimentos: Um estudo de caso múltiplo. In: XXX ENCONTRO NACIONAL DE ENGENHARIA DE PRODUÇÃO, 2010, São Carlos. Anais... São Carlos, 2010.

[35] VIANA, J. C.; ALENCAR, L. H. Metodologias para seleção de fornecedores: Uma revisão da literatura. Revista Produção, Recife, v. 22, n. 4, p. 625-636, set./dez. 2012.

[36] ZERBINI, R. Avaliação de desempenho de fornecedores: Um estudo de caso em uma grande instituição financeira brasileira. 141f. Dissertação (Mestrado em Administração) Escola de administração de empresas de São Paulo, FGV - Fundação Getúlio Vargas, São Paulo, 2006. 


\section{CAPÍTULO 18}

\section{TÉCNICA DE PESQUisa OPERACIONAL APLICADA NO ESTUFAMENTO DE CONTÊINERES: UM ESTUDO DE CASO PARA A EMPRESA TLE}

\section{Márcia Jussara Hepp Rehfeldt \\ Gabriel Machado Braido}

Resumo: Este caso de ensino tem por intuito apresentar uma situação-problema imbricando as áreas da logística e da pesquisa operacional. Entende-se que o caso pode ser discutido na sala de aula em disciplinas dos cursos de graduação em Logística, Administração e Engenharia de Produção ou em nível de especialização, em cursos de Logística e Operações e em Gerência de Produção e Operações. O case trata da discussão e escolha de contêineres capazes de transportar uma carga de 5.500 caixas, a um custo mínimo, sob determinadas restrições de capacidade (volume), tempo para carregamento e disponibilidade. Para solucionar o problema é apresentada a técnica de programação linear. Por fim, são propostas diferentes questões para discussão em sala de aula.

Palavras Chave: Pesquisa Operacional. Logística. Programação Linear. Estufamento de contêineres. Minimização de custos 


\section{INTRODUÇÃO}

A empresa de Transportes Logísticos Eulália (TLE), cujo nome é fictício, é especializada em transportar produtos secos, bem como refrigerados. Ela mantém sua sede em Lajeado e desloca constantemente mercadorias até o Porto de Rio Grande, sendo ambas as cidades localizadas no Rio Grande do Sul. Para atender seus clientes, ela conta com diferentes contêineres, entre eles, Standard para carga não perecível do modelo 20 pés e de 40 pés, contêiner High Clube, contêiner Open Top de 20 pés e de 40 pés. Na referida empresa há um quadro de 20 funcionários, entre eles o gerente, a equipe administrativa e os responsáveis pelo estufamento de contêineres, sendo que estes últimos dispõem de 80 horas diárias para realizar tais tarefas.

Constantemente a empresa TLE é contatada para realizar o deslocamento de produtos, mas muitas vezes perde a licitação em função dos custos cobrados. A partir desta constatação, o gerente incumbiu um dos seus funcionários do setor administrativo - Carlos e aluno do curso de administração de empresas -, de realizar estudos acerca dos custos de transportes. Como Carlos já havia cursado a disciplina de Pesquisa Operacional, ele resolveu sugerir uma de suas técnicas, a programação linear, no sentido de auxiliar a empresa a encontrar preços menores para executar as tarefas. O início do levantamento de dados deu-se pelo minucioso estudo dos contêineres, suas capacidades de transportes, conforme indicado a seguir.

\section{BACKGROUND DA EMPRESA TRANSPORTES LOGÍSTICOS EULÁLIA}

A empresa TLE adquiriu seus contêineres da empresa TRANSAEX, a qual é especializada em atividades de comercialização internacional. Segundo consta em seu site (http://www.transaex. com.br/ogrupo.php), a instituição conta com unidades próprias no Brasil, Portugal, China e uma representação na Argentina e dispõe de uma versátil estrutura para práticas de exportação e importação. Entre os negócios anunciam amparo a exportadores, importadores e investidores em atividades diretamente relacionadas ao comércio exterior.

Os produtos anunciados pela empresa TRANSAEX foram adquiridos pela empresa TLE e possuem as capacidades conforme anunciado na Figura 1 a seguir.

Figura 1 - Tipos de contêineres, dimensões e capacidades

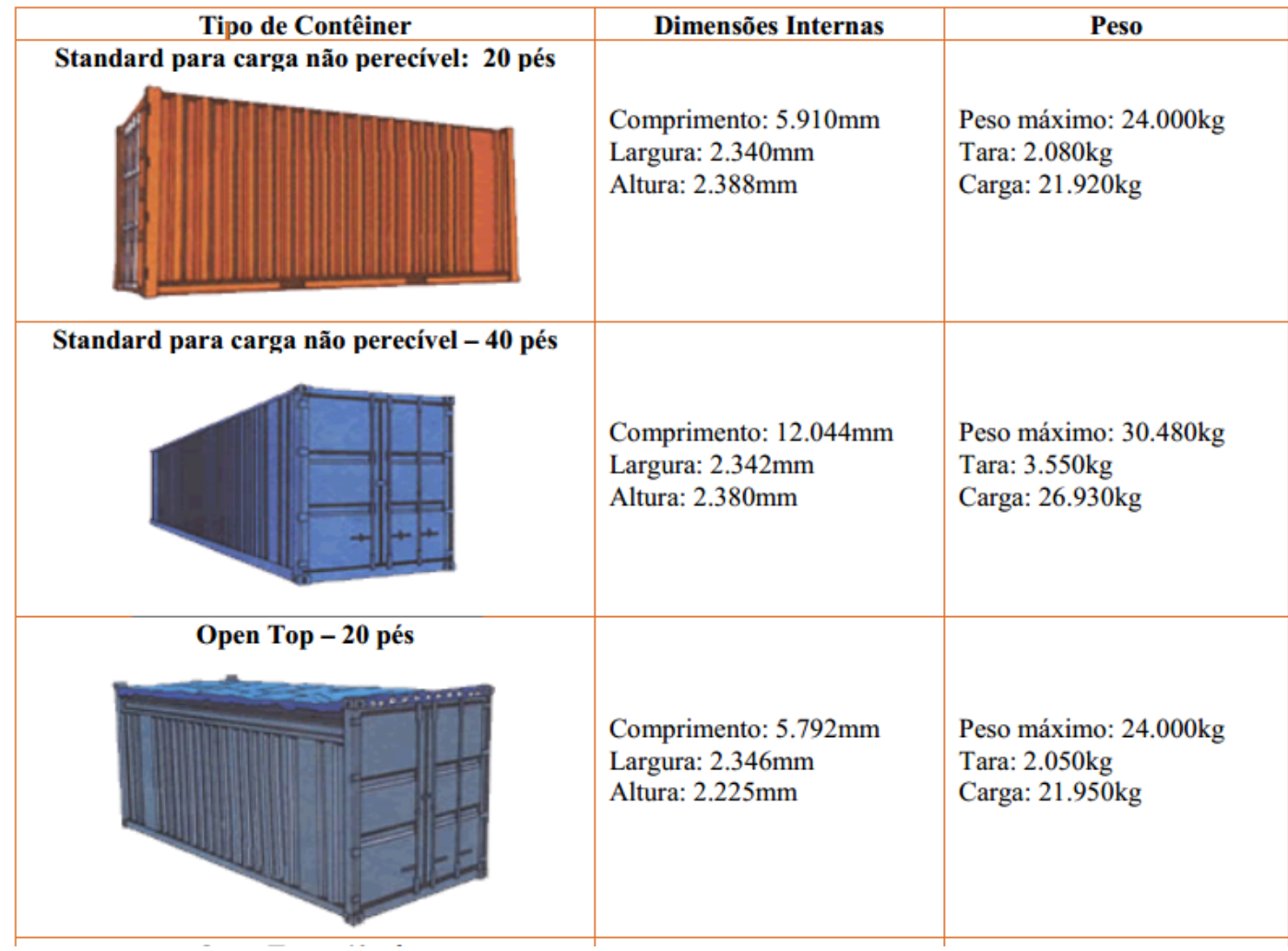




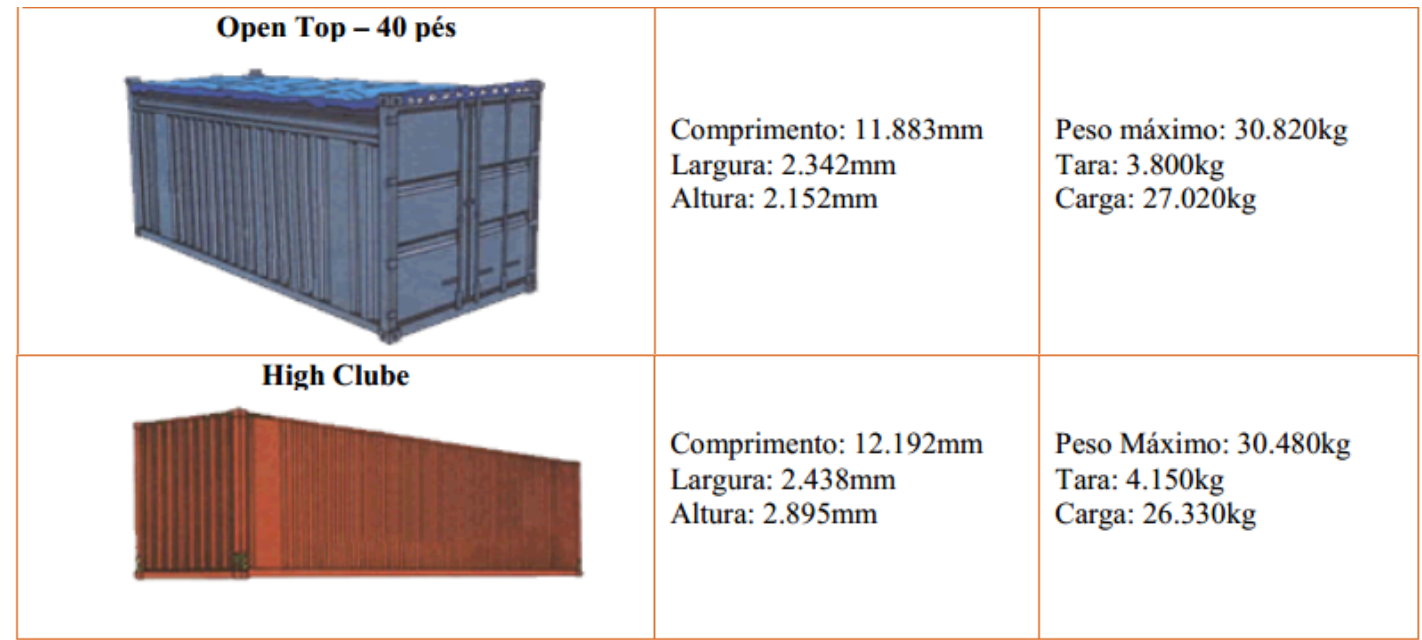

Fonte: Dos autores, 2015, com base no site http://www.transaex.com.br/dicas.php?acao=15

\section{DESCRIÇÃO DO PROBLEMA DA EMPRESA TLE}

Como já mencionado anteriormente, a empresa TLE vem constantemente perdendo licitações, pois seus custos de deslocamento para as mercadorias não são competitivos no mercado. Diante do levantamento de dados realizado por Carlos acerca da capacidade dos contêineres e ilustrado na Figura 1, seu gerente incumbiu-lhe de estudar uma nova situação: Transportar 5.500 caixas de base $50 \mathrm{~cm}$ por $40 \mathrm{~cm}$ e $30 \mathrm{~cm}$ de altura que não podem ser invertidas na sua altura pelo produto que contêm, conforme ilustrado na Figura 2.

Figura 2 - Caixa a ser transportada da cidade de Lajeado até o Porto de Rio Grande

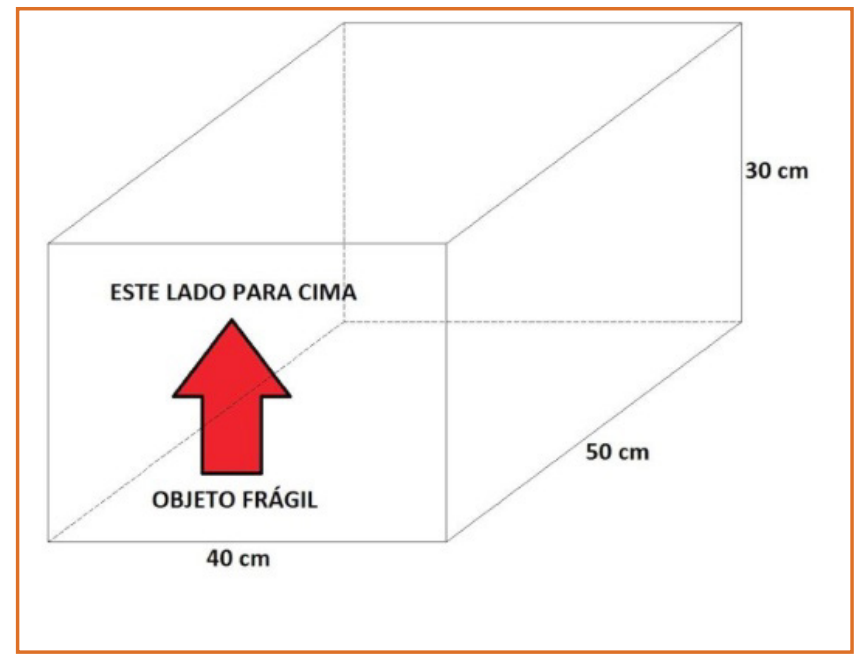

Fonte: Dos autores, 2015. contêineres para executar esta tarefa:

- Standard para carga não perecível - 20 pés

- Standard para carga não perecível - 40 pés

- Open Top - 20 pés

- Open Top - 40 pés

- Contêiner High Clube

A partir desta situação, Carlos verificou os custos de deslocamento de cada tipo de contêiner em função da distância, incluindo custos com óleo diesel, pedágios, taxas, entre outros, o total de contêineres disponíveis para a execução da tarefa e analisou em suas planilhas o tempo de carregamento de cada tipo de contêiner, conforme ilustra o Quadro 1 a seguir. Uma recomendação que recebeu de seu gerente é que teria somente 40 horas de trabalho disponíveis para realizar o carregamento do contêiner ou da combinação de contêineres. 
Quadro 1 - Tipos de contêiner, custos, disponibilidade e tempo de carregamento

\begin{tabular}{|c|c|c|c|c|}
\hline Tipo de contêiner & Custo até o destino & $\begin{array}{l}\text { Total de contêineres } \\
\text { disponiveis }\end{array}$ & $\begin{array}{l}\text { Total de caixas que podem ser } \\
\text { carregadas, dependo da posição }\end{array}$ & $\begin{array}{l}\text { Tempo para carregar } \\
\text { o contêiner }\end{array}$ \\
\hline $\begin{array}{c}\text { Standard para carga } \\
\text { não perecível - } 20 \text { pés }\end{array}$ & $\mathrm{R} \$ 4.000,00$ & 2 & $\begin{array}{l}\text { Opção 1: } 385 \\
\text { Opção 2: } 392\end{array}$ & $3 \mathrm{~h}$ \\
\hline $\begin{array}{c}\text { Standard para carga } \\
\text { não perecível - } 40 \text { pés }\end{array}$ & $\mathrm{R} \$ 4.500,00$ & 1 & $\begin{array}{l}\text { Opção 1: } 840 \\
\text { Opção 2: } 840\end{array}$ & $5 \mathrm{~h}$ \\
\hline Open Top - 20 pés & $\mathrm{R} \$ 3.800,00$ & 3 & $\begin{array}{l}\text { Opção 1: } 385 \\
\text { Opção 2: } 392\end{array}$ & $2,5 \mathrm{~h}$ \\
\hline Contêiner High Clube & $R \$ 5.100,00$ & 3 & $\begin{array}{l}\text { Opção 1: } 960 \\
\text { Opção 2: } 960\end{array}$ & $6 \mathrm{~h}$ \\
\hline Open Top - 40 pés & $R \$ 5.000,00$ & 2 & $\begin{array}{l}\text { Opção 1: } 805 \\
\text { Opção 2: } 812\end{array}$ & $4 \mathrm{~h}$ \\
\hline
\end{tabular}

Fonte: autores do caso de estudo, 2015.

Apresentado o contexto, a questão central deste case é: Qual é a melhor combinação/opção de contêineres para realizar o carregamento de produtos leves a um custo mínimo? Qual é este custo mínimo?

\section{SUGESTÕES DE ATIVIDADES E CONHECIMENTOS PRÉVIOS NECESSÁRIOS}

Esta atividade pode ser desenvolvida com alunos dos cursos de Logística, Administração de Empresas ou ainda Engenharia de Produção, em nível de graduação ou em cursos de especialização em Logística e Operações e em Gerência de Produção e Operações ou outros com enfoque similar. Recomenda-se que os alunos tenham algum conhecimento em técnicas de Pesquisa Operacional como a Programação linear.

Segundo Taha (2008), a programação linear é a técnica mais utilizada de Pesquisa Operacional e é aplicada a modelos cujas funções objetivo e restrições são lineares. De acordo com Moreira (2007), as características de um modelo de programação linear podem ser resumidas da seguinte forma:
1. Existe uma combinação de variáveis que deve ser maximizada ou minimizada. Essa combinação pode ser a expressão do custo de algumas operações industriais ou comerciais, do tempo gasto em certas atividades, do lucro atingido com a venda de alguns produtos, da rentabilidade média de uma composição de ações e títulos e assim por diante. Durante a formulação, a combinação de variáveis a que se chega é colocada na forma de expressão matemática, que recebe o nome de função objetivo [...]

2. A estrutura do problema é tal que existe, em geral, uma certa restrição de recursos, ou impossibilidade de economias, de forma que nunca é possível obter um lucro tão grande quanto se queira [...] Há de se buscar uma combinação ótima para se chegar ao melhor lucro possível, dadas as restrições práticas impostas pelo problema (MOREIRA, 2007, p. 1112). 
No caso deste problema, a função objetivo está relacionada com a minimização do custo de deslocamento, enquanto que as restrições estão relacionadas à disponibilidade de contêineres, à sua capacidade e ao tempo de carregamento.

Cabe ainda salientar que um estudo acerca das possibilidades de posicionamento das caixas necessita ser realizado, pois dependendo da posição dentro do contêiner, a capacidade de caixas em cada tipo de contêiner poderá variar. Essas informações poderão estar preenchidas ou não no Quadro 1. Para fins de apresentação deste case, optou-se por apresentar estas informações mas, à critério do professor, elas poderão ser ocultadas para que os alunos identifiquem estas possibilidades de estufamento.

Se utilizarmos o contêiner Standard para carga não perecível do modelo 20 pés e posicionarmos numa direção, conforme indica a Figura 3, caberão 392 caixas, mas invertendo o sentido (Figura 4) caberão 385 caixas. Vale ressaltar que em ambas as situações, a caixa não alterou a altura, respeitando a restrição imposta pelo problema.

Figura 3 - Possibilidade de estufamento 1

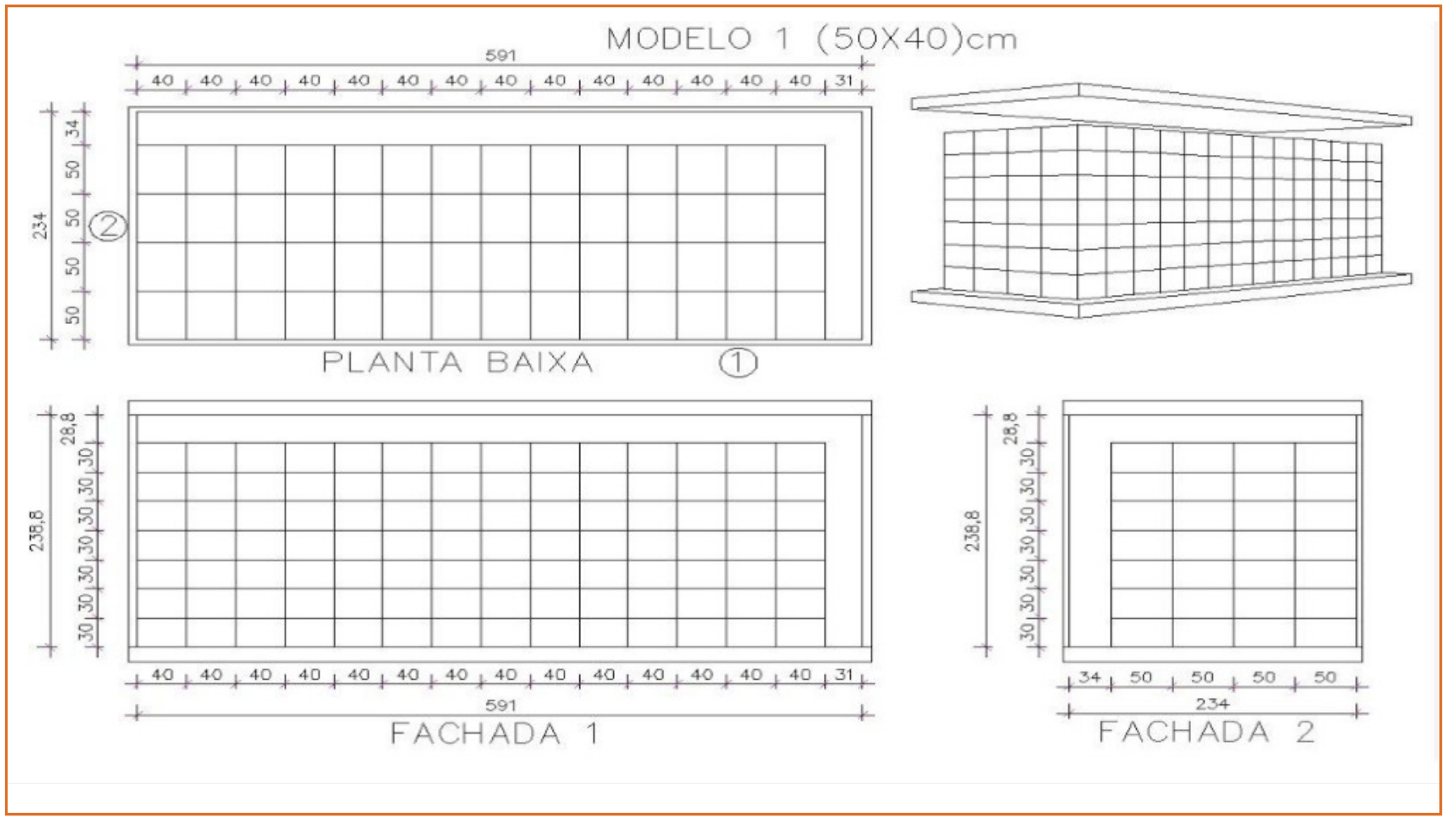

Fonte: autores do caso de estudo, 2015. 
Figura 4 - Possibilidade de estufamento 2

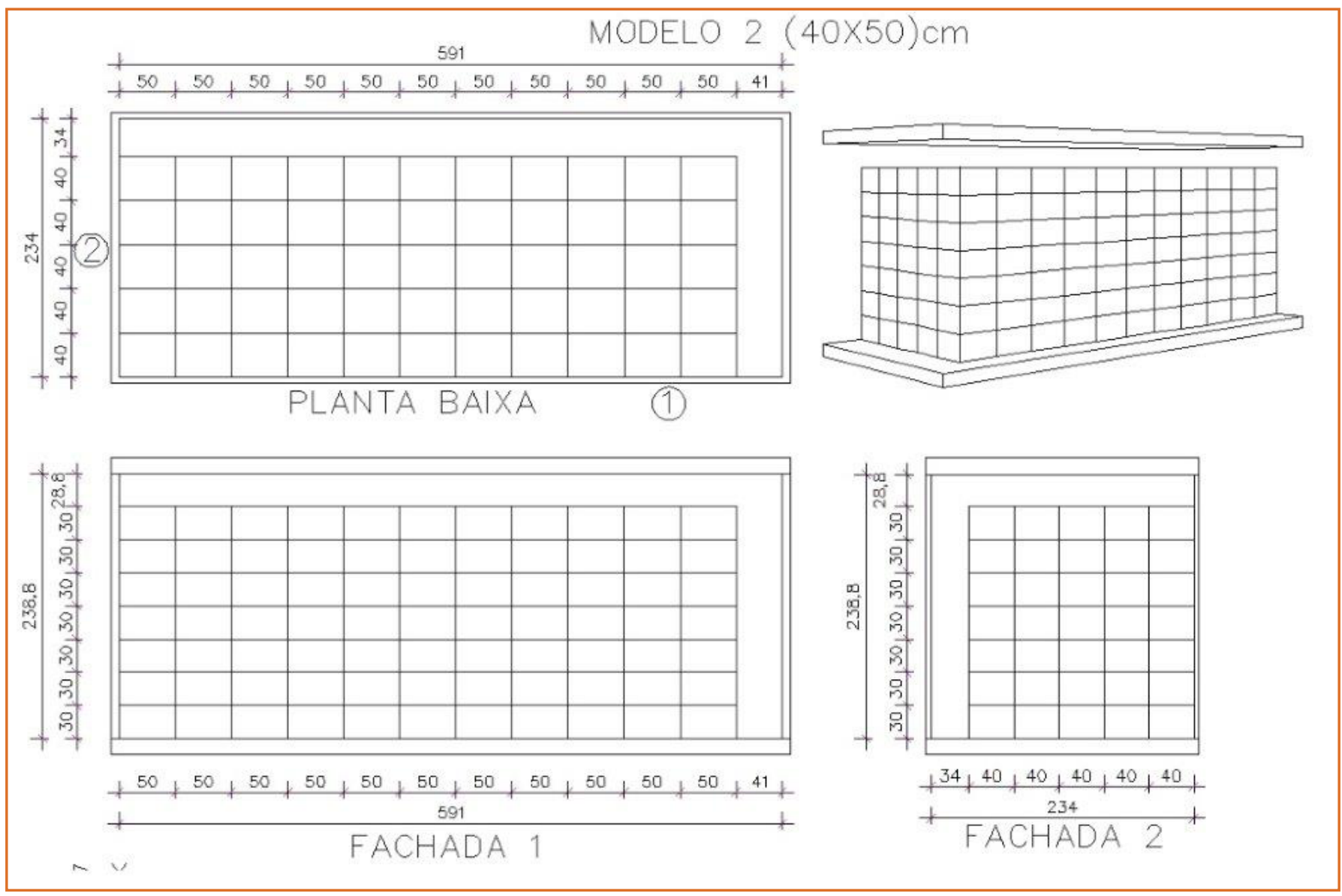

Fonte: autores do caso de estudo, 2015.

No que tange à resolução de um problema de pesquisa operacional, Arenales et al (2007) afirmam que ela envolve várias fases, a saber: (i) definição do problema, (ii) construção do modelo, (iii) solução do modelo, (iv) validação do modelo e (v) implementação da solução, conforme ilustrado na Figura 5.

Figura 5 - Fases para resolução de um problema em Pesquisa Operacional

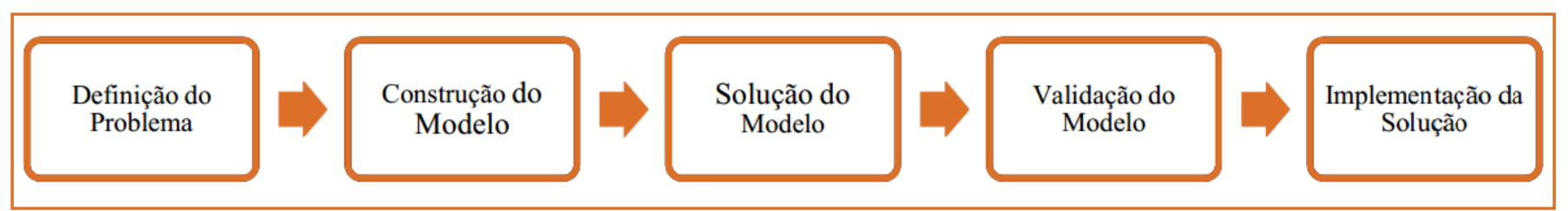

Fonte: elaborado pelos autores (2015), com base no método proposto por Arenales et al. (2007)

Conforme Arenales et al. (2007), na primeira fase, (i) definição do problema, deverá ser definido o escopo do problema, na qual devem ser coletados os dados e informações relevantes para a modelagem.

Na segunda fase, (ii) construção do modelo, os autores sugerem que o problema seja "traduzido" em relações lógicas de simulação, matemáticas ou uma combinação de ambas.

A terceira fase consiste na (iii) solução do modelo, enquanto que a quarta faseconsidera a (iv) validação do modelo, na qual se deve verificar se o modelo representa o problema de forma apropriada, ou seja, 
se prediz o comportamento do sistema de maneira adequada. Arenales et al. (2007) ainda acrescentam que a qualidade de uma solução depende da precisão com que o modelo representa a realidade, sendo que a qualidade dos dados de entrada neste modelo afeta diretamente na solução final do problema.

Por fim, a quinta fase preocupa-se com a implementação da solução obtida na prática, traduzindo os resultados em decisões (ARENALES et al., 2007).

A partir do esquema acima proposto por Arenales et al. (2007) e da discussão do modelo matemático que este caso de estudo gera, a solução pode ser obtida por meio de cálculos manuais usando, por exemplo, o método simplex (MOREIRA, 2007) ou por softwares como o solver do Excel (LACHTERMACHER, 2009; TAHA, 2008; LOESCH; HEIN, 1999); LINDO (Linear, Interactive and Discrete Optimizer), LINGO ou What's Best (LACHTERMACHER, 2009). O software Lindo tem sido considerado uma boa possibilidade e largamente utilizado por professores em suas disciplinas.

Segundo Rehfeldt (2009, p. 17),

Pivatto (2007) realizou um estudo acerca da minimização do custo da ração na granja de suínos de propriedade familiar com o auxílio do software LINDO. Utilizou os resultados para modificar a fórmula da ração, reduzindo, assim, os custos nas fases de desenvolvimento dos animais, o que possibilitou ao produtor maior lucratividade nos negócios. Da mesma forma, os trabalhos de conclusão do curso de Administração de Schneider (2008), Neuberger (2008), Jaeger (2008) e Schwarzer (2008) apontaram soluções e estratégias para as situações-problema encontradas nas respectivas empresas em que realizaram seu estágio curricular, todas apoiadas no software LINDO.

\section{RESULTADOS ENCONTRADOS E QUESTÕES PARA DISCUSSÃO}

Nesta situação-problema, o modelo matemático de programação linear seria o seguinte:

Min 4000C1P1+4000C1P2+4500C2+3800C3P1+3800

C3P2+5100C4+5000C5P1+5000C5P2 St

$\mathrm{C} 1 \mathrm{P} 1+\mathrm{C} 1 \mathrm{P} 2<=2$

$\mathrm{C} 2<=1$

$\mathrm{C} 3 \mathrm{P} 1+\mathrm{C} 3 \mathrm{P} 2<=3$

$\mathrm{C} 4<=3$

$\mathrm{C} 5 \mathrm{P} 1+\mathrm{C} 5 \mathrm{P} 2<=2$

$385 \mathrm{C} 1 \mathrm{P} 1+392 \mathrm{C} 1 \mathrm{P} 2+840 \mathrm{C} 2+385 \mathrm{C} 3 \mathrm{P} 1+392 \mathrm{C} 3 \mathrm{P} 2+96$

$0 \mathrm{C} 4+805 \mathrm{C} 5 \mathrm{P} 1+812 \mathrm{C} 5 \mathrm{P} 2>=5500$

$3 \mathrm{C} 1 \mathrm{P} 1+3 \mathrm{C} 1 \mathrm{P} 2+5 \mathrm{C} 2+2.5 \mathrm{C} 3 \mathrm{P} 1+2.5 \mathrm{C} 3 \mathrm{P} 2+6 \mathrm{C} 4+4 \mathrm{C} 5 \mathrm{P} 1$

$+4 \mathrm{C} 5 \mathrm{P} 2<=40$

End

Onde C1P1 significa o contêiner 1 na posição 1 e assim sucessivamente.

Ao ser executado no software LINDO gera a seguinte resposta:

- Custo mínimo: R\$33.600,00

- Contêineres que deverão ser utilizados: 1 do tipo Standard para carga não perecível - 40 pés, 1 do tipo Open Top - 20 pés, posicionado na posição 2, 3 contêineres do tipo Contêiner High Clube e, por fim, 2 contêineres Open Top - 40 pés na posição 2.

\section{QUESTÕES PARA DISCUSSÃO EM SALA DE AULA}

a. Qual seria o custo se tivéssemos usado somente contêineres do tipo Standard para carga não perecível - 20 pés? Qual seria esse acréscimo no custo?

b. O que aconteceria se a empresa tivesse 20 horas a mais para o carregamento dos contêineres?

c. A solução seria diferente se a empresa TLE disponibilizasse mais um contêiner do tipo Standard para carga não perecível - 40 pés? Qual seria o custo mínimo neste caso?

d. A empresa TLE teria contêineres suficientes caso não pudesse sobrepor as caixas por conterem produtos frágeis?

e. Quais as implicações do espaço não preenchido entre as linhas e colunas no contêiner, conforme 
ilustram as figuras 3 e 4? A mercadoria poderá ficar solta? Haverá algum dano à caixa ou ao produto? Caso haja alguma implicação do espaço não preenchido, qual material poderia suprir este espaço? Qual a implicação no custo?

f. O tempo gasto para estufar o contêiner tem alguma relação com a posição da caixa?

g. Todos os contêineres estão completos ou algum deles terá algum espaço a mais, além das folgas nas laterais?

h. Qual o número máximo de caixas que a empresa TLE poderá carregar com a quantidade de contêineres que tem?

i. Na atual circunstância, haverá alguma sobra no tempo disponibilizado para carregamento? Quantas horas?

j. Se o peso das caixas tivesse que ser levando em consideração, que tipo implicações isso traria no modelo matemático de programação linear?

\section{REFERÊNCIAS}

[1] ARENALES, Marcos et. al. Pesquisa operacional. Rio de Janeiro: Elsevier, 2007.

[2] LACHTERMACHER, Gerson. Pesquisa operacional na tomada de decisões. Rio Janeiro: Campus, 2009.

[3] LOESCH, Cláudio; HEIN, Nelson. Pesquisa operacional: fundamentos e modelos. Blumenau: FURB, 1999.

[4] MOREIRA, Daniel Augusto. Pesquisa operacional: curso introdutório. São Paulo: Thomson Learning, 2007.

[5] REHFELDT, Márcia Jussara Hepp. A aplicação de modelos matemáticos em situações problema-empresariais com o uso do software LINDO, 2009. 299 f. Tese (Doutorado). Programa de Pós-Graduação em Informática na Educação, Universidade Federal do Rio Grande do Sul, Porto Alegre, 2009.

[6] TAHA, Hamdy A. Pesquisa Operacional: uma visão geral. São Paulo: Pearson Prentice Hall, 2008. Site visitado: http://www.transaex.com.br/ogrupo.php. 


\title{
CAPÍTULO 19
}

\section{UM ESTUdO TEÓRICO SOBRE PLANEJAMENTO AGREGADO DE PRODUÇÃO (PAP)}

\author{
Denislaine Regina Cordeiro \\ Diullya Carolina Cordeiro \\ Edimar Nunes Dias \\ Márcia de Fátima Morais \\ Rony Peterson da Rocha
}

Resumo: As atividades envolvidas na área de Planejamento e Controle da Produção (PCP) são relevantes para muitas empresas, pois essas visam atender com a melhor coordenação e aplicação dos recursos produtivos os planos instituídos nos níveis estratégico, tático e operacional. Dentre as atividades presentes na área de PCP, destaca-se o Planejamento Agregado da Produção (PAP). No PAP é proposto um plano de produção com as informações sobre a quantidade e o momento para a realização da produção, utilizando dados e recursos da organização, tais como: capacidade de produção, quadro de pessoal, níveis de estoque, as horas extras, os índices de subcontratações e outras variáveis controláveis. Neste trabalho realizou-se uma revisão bibliográfica, a fim de levantar e estratificar o emprego do PAP em Pequenas Empresas (PE), Médias Empresas (ME) e Grandes Empresas (GE), o tipo de Sistema de Produção (SP) e Setor de Aplicação, os softwares/linguagens/solvers, modelos e/ou métodos e estratégias empregados nas pesquisas sobre o PAP. O estudo foi desenvolvido no âmbito nacional, no corte temporal de 2004 a 2015, na base de dados do Encontro Nacional de Engenharia de Produção (ENEGEP), Simpósio de Engenharia de Produção (SIMPEP), Congresso Brasileiro de Engenharia de Produção (CONBREPRO) e Encontro Mineiro de Engenharia de Produção (EMEPRO). Nota-se que o PAP desenvolve soluções rápidas e ótimas, para os problemas de produção, por meios de estratégias, softwares e modelos matemáticos para a representação do plano agregado da produção.

Palavras Chave: Planejamento Agregado, Plano de Produção, Revisão Bibliográfica. 


\section{INTRODUÇÃO}

Nos últimos anos, muitas empresas estão imersas em um ambiente empresarial altamente competitivo. Essa competitividade tem levado muitos gestores a buscar uma melhor coordenação da alocação dos recursos produtivos, contudo, devido à diversidade e complexidade dos sistemas de produção envolvidos nas empresas, recomenda-se a aplicação de técnicas de Planejamento e Controle da Produção (PCP).

O PCP é para Severo (2007) uma importante área dentro de uma empresa, responsável pelo gerenciamento da produção e impulsionadora do desempenho global desta. As atividades desenvolvidas no PCP envolvem segundo Fernandes e Filho (2010), diversas decisões sobre "o que, quanto e quando produzir, comprar e entregar, além de quem e/ou onde e/ou como produzir". Segundo Tubino (2007) essas atividades são desenvolvidas em três níveis hierárquicos (estratégico, tático e operacional) de planejamento e controle de um sistema de produção. Esses níveis são caracterizados conforme o horizonte de planejamento (HP) de: (a) longo; (b) médio e (c) curto prazo.

No HP de longo prazo, trabalha-se informações referentes ao plano de produção, envolvendo aspectos mais abrangentes relacionados à produção, tais como a definição da estratégia de produção a adotar, previsão de demanda, estabelecimento do planejamento agregado da produção em função do plano de vendas, definição prévia dos recursos produtivos necessários e capacidade de produção. No HP de médio prazo, desenvolvem-se planos mais detalhados, denominado de plano mestre de produção, estabelecendo os produtos que serão produzidos por período e a avaliação da capacidade de produção em relação à carga de trabalho que será exigida da máquina ou mão-de-obra para o cumprimento do plano de produção. No HP de curto prazo, preparase a programação e sequenciamento da produção, controla-se os estoques, emiti e libera as ordens de compras, fabricação e montagem, bem como executa o acompanhamento e controle da produção (TUBINO, 2007).

Neste artigo será retratada uma das atividades do PCP, denominada de Planejamento Agregado da Produção (PAP). O PAP é uma das atividades do PCP que visa monitorar diversos aspectos da produção com intuito de atender as necessidades dos clientes, casando taxa de produção e taxa de demanda. Este tipo de planejamento é a comunicação entre a alta gerência e a manufatura e é o pilar para o atendimento de objetivos estratégicos de uma empresa através da mobilização de recursos de produção (SIPPER e BULFIN, 1997; FERNANDES e FILHO, 2010).

Assim, o objetivo desse estudo é de apresentar uma revisão bibliográfica dos trabalhos publicados no Brasil sobre PAP. No presente estudo realizouse um levantamento e estratificação do emprego do PAP em Pequenas Empresas (PE), Médias Empresas (ME) e Grandes Empresas (GE), bem como, o tipo de Sistema de Produção (SP) e Setor de Aplicação, os softwares/linguagens/solvers, modelos e/ou métodos e estratégias empregados.

O artigo está dividido em cinco seções. Na primeira seção apresentam-se os objetivos e uma visão simplificada do que é o PAP. Na segunda seção é apresentada uma fundamentação teórica sobre o assunto. Na terceira seção é descrita a metodologia. $\mathrm{Na}$ quarta seção encontram-se os resultados e discussões do assunto abordado e, por fim, na quinta seção encontra-se a conclusão do estudo e as referências bibliograficas.

\section{FUNDAMENTAÇÃO TEÓRICA}

\subsection{PLANEJAMENTO AGREGADO DA PRODUÇÃO (PAP)}

O Planejamento Agregado da Produção (PAP) é um processo de balanceamento da produção com a demanda, em um horizonte de planejamento de seis a dezoito meses. Nesse horizonte devem-se definir as estratégias de produção e criar um plano agregado para atender a demanda e conseguir um custo mínimo de produção (MOREIRA, 2000).

Os problemas que envolvem o PAP apresentam um grande nível de agregação de dados com agrupamento de produtos similares em famílias de produtos e, por conveniência, também se agrega a capacidade de processamento de produção, isto é, agrupamento ou recursos (máquinas, equipamentos, 
mão de obra e etc.) no sistema de produção com capacidade previamente estabelecida para cada uma dessas famílias de produtos (MUNHOZ e MORABITO, 2010).

A partir das decisões tomadas no PAP é gerado um plano de produção que segundo Tubino (2007) procura servir como um referencial para os ajustes de longo prazo dos sistemas de produção, no sentido de maximizar os resultados das operações e minimizar os riscos nas tomadas de decisões. Para elaborar - plano agregado de produção, Moreira (2000) afirma que é necessário verificar as alternativas que influenciam a demanda e a produção, tais como: DEMANDA: Propaganda; Promoções e Preços Diferenciados; Reservas e Demoras na Liberação dos Produtos ou Serviços; Desenvolvimento de Produtos Complementares. PRODUÇÃO: Contratação/ Demissão; Subcontratação; Estocagem.

As alternativas que influenciam a demanda e a produção apresentadas acima levam a diferentes custos, que devem ser comparados entre si, à medida que diferentes combinações de alternativas são geradas para resolver o problema do PAP. Para Moreira (2000) os principais custos utilizados na modelagem do plano agregado de produção são: custos de contratação, custo de demitir, custo de horas extras, custo de deixar estoque, custo de subcontratações e custo de retardamento de entregas.

Existem formas simples para se minimizar os custos de produção e resolver os problemas de PAP. Essas formas podem ser por meio de estratégias para o PAP e métodos para solução de problemas. No Quadro 1 foram definidas a partir de Fernandes e Filho (2010) e Tubino (2000) oito tipos diferentes de estratégias ( $A, B, C, D, E, F, G$ e $H$ ), que podem ser escolhidas para a construção do PAP. Após o emprego de uma dessas estratégias, pode-se realizar a modelagem do problema e consequentemente resolvê-lo.

Quadro 1 - Tipos de estratégias

\begin{tabular}{|c|c|c|}
\hline ESTRATÉGIA & TIPO DE ESTRATÉGIA & DESCRIÇÃO DA ESTRATÉGIA \\
\hline A & Acompanhamento da Demanda & $\begin{array}{l}\text { Não há formação de estoque, produz a quantidade demandada. Os } \\
\text { principais métodos utilizados: Contratação, demissões, horas extras, banco } \\
\text { de dados. }\end{array}$ \\
\hline B & $\begin{array}{l}\text { Força de trabalho constante } \\
\text { permitindo Faltas }\end{array}$ & $\begin{array}{l}\text { Força de trabalho constante, estoques armazenados e utilizados em } \\
\text { períodos nos quais a demanda é maior que a capacidade produtiva. Faltas } \\
\text { (representadas por estoques negativos) são permitidas. }\end{array}$ \\
\hline C & $\begin{array}{l}\text { Força de trabalho constante não } \\
\text { permitindo faltas }\end{array}$ & $\begin{array}{l}\text { A estratégia é bastante parecida com a anterior, à diferença é que faltas } \\
\text { não são permitidas. }\end{array}$ \\
\hline D & $\begin{array}{l}\text { Força de trabalho constante } \\
\text { utilizando horas extras }\end{array}$ & $\begin{array}{l}\text { Utilizam-se um número constante de trabalhadores ao longo dos períodos } \\
\text { e quando essa produção irregular não é suficiente utilizam-se horas extras. }\end{array}$ \\
\hline E & $\begin{array}{l}\text { Força de trabalho constante } \\
\text { utilizando Subcontratação }\end{array}$ & $\begin{array}{l}\text { É bastante semelhante com a estratégia anterior, a diferença que ao invés } \\
\text { de utilizar horas extras é utilizado à subcontratação. }\end{array}$ \\
\hline $\mathrm{F}$ & Estratégia Mista & $\begin{array}{l}\text { É o mais utilizado na prática. Ela consiste na combinação inteligente das } \\
\text { estratégias puras. Atuando em ambas: na oferta de recursos (Admissão/ } \\
\text { demissão, horas-extras, subcontratação e estoques), e demanda (Preço } \\
\text { de venda, Promoção, atraso na entrega). Aproveitando suas vantagens e } \\
\text { descartando desvantagens intrínsecas e resultando no melhor custo. }\end{array}$ \\
\hline G & Redução Constante & $\begin{array}{l}\text { Em um determinado tempo é produzido e estocado, em seguida é } \\
\text { consumido os estoques previstos e novamente volta-se recompor o } \\
\text { estoque. }\end{array}$ \\
\hline $\mathrm{H}$ & Produção em Patamares & $\begin{array}{l}\text { Variação da taxa de produção em patamares, permitindo certo ritmo de } \\
\text { produção e reduzindo os níveis de estoque. }\end{array}$ \\
\hline
\end{tabular}

Fonte: Adaptado de Fernandes e Filho (2010) e Tubino (2000) 
Uma solução para o problema do PAP consiste em determinar, em cada período, a combinação de alternativas de produção, tal que atenda a demanda e o custo total de produção seja o menor valor possível. Neste sentido, Moreira (2000) descreve que os modelos para solução do problema de PAP, podem ser aqueles que assumem ou não a variação linear dos custos ou aqueles que levam ou não à solução ótima. Por "solução ótima" entende-se aquele que leva efetivamente ao custo total de produção mínimo, diante das alternativas de produção disponíveis.

Segundo Fernandes e Filho (2010), existem dois conjuntos de métodos para realizar o planejamento agregado. O primeiro método é chamado de "Método da Planilha" e o segundo é chamado de "Método Avançado". Uma descrição desses métodos é apresentada no Quadro 2.

Quadro 2 - Tipos de Métodos

\begin{tabular}{|ll|}
\hline $\begin{array}{l}\text { TIPOS DE } \\
\text { MÉTODOS }\end{array}$ & DESCRIçÃo \\
\hline & $\begin{array}{l}\text { Método simples que não utiliza ferramentas } \\
\text { matemáticas, exceto a aritmética elementar } \\
\text { para cálculo e comparação de custo. }\end{array}$ \\
- Método de & $\begin{array}{l}\text { Fornece uma solução heurística (isto é, } \\
\text { Planilha (MP): } \\
\text { ráda e geralmente não ótima) para o } \\
\text { problema. A geração de composição de } \\
\text { alternativas de produção pode ser feita com } \\
\text { o auxilio de tabelas ou gráficos. }\end{array}$ \\
\hline Método & $\begin{array}{l}\text { Método que permite considerar os custos } \\
\text { de contratação e demissão de pessoal e, } \\
\text { além disso, permite a montagem de modelos } \\
\text { diferenciados, conforme o objetivo e as } \\
\text { restrições envolvidas. Busca gerar uma } \\
\text { solução ótima para o problema utilizando a } \\
\text { pesquisa operacional. }\end{array}$ \\
\hline
\end{tabular}

Fonte: Adaptado de Fernandes e Filho (2010)

No Método Avançado (MA), apresentado no Quadro 2, é utilizada a programação matemática. Essa programação é subdividida segundo Lachtermacher (2004) em programação linear (PL); programação linear inteira mista (PLIM) e programação não linear inteira mista (PNLIM). Caixeta-Filho (2004) afirma que a PL é uma técnica aprimorada de resolução de sistemas de equações lineares por inversões sucessivas de matrizes. A PL, na visão de Prado (2003) é considerada como uma técnica de otimização, baseada em matemática e economia. Laesch e Hein (2009) complementam dizendo que esta procura resolver problemas de maximização ou minimização de um determinado objetivo.

Segundo Alves e Delgado (1997) um problema de Programação Linear Inteira (PLI) é um problema de Programação Linear ( $\mathrm{PL}$ ) onde a maioria das variáveis assumem valores inteiros. Afirmam ainda que "quando todas as variáveis estão sujeitas à condição de integralidade estamos perante um problema de Programação Linear Inteira Pura (PLIP) e se apenas algumas estiverem, enquadra-se como problema de Programação Linear Inteira Mista (PLIM)".

A Programação Linear Inteira (PLI) é considerada para Caixeta-Filho (2004), como uma variação da PL. Este tipo de programação é adequada tanto para problemas de Programação Linear Mista (PLM), que são aquelas de estrutura linear com características inteiras e não inteiras, como para problemas que envolvam variáveis binárias do tipo zero-um. Taha (2008) afirma que PLI são programações em que as variáveis estão restritas a valores inteiros, isto é, discretos. Quando apenas algumas variáveis, segundo Hillier e Lieberman (2010), apresentarem valores inteiros, esse modelo é caracterizado como Programação Linear Inteira Mista (PLIM). Existem decisões restritas apenas a dois valores, 0 e 1 , tais variáveis são chamadas de binárias, logo, problemas de PLI que apresentam apenas variáveis binárias são ditos como problemas de Programação Linear Inteira Binária (PLIB). Um problema de PLI, segundo Goldbarg e Luna (2005) é um tipo de modelo que não permite variáveis de decisão com valores contínuos, uma vez que neste modelo envolvem número de pessoas, configurações, objetos físicos etc, onde soluções fracionárias não apresentam sentido prático.

Ainda em relação ao MA, segundo Fernandes e Filho (2010), algumas técnicas podem ser utilizadas para a resolução do problema de PA, tais como: (i) Método Simplex (MS); (ii) Regra de decisão Linear (RDL); (iii) Abordagem dos Coeficientes Gerenciais (ACG); (iv) Método de Focalização (MF): (v) Método Heurístico de Busca Exaustiva (MHBE). Essas técnicas são 
apresentadas e descritas no Quadro 3.

Quadro 3 - Técnicas para resolução de MA

\begin{tabular}{|c|c|}
\hline TIPOS DE TÉCNICAS & DESCRIÇÃO \\
\hline - Método Simplex (MS) & $\begin{array}{l}\text { É uma técnica interativa que, utiliza um algoritmo, procurando maximizar ou minimizar (otimizar) } \\
\text { uma função objetiva de um modelo matemático (modelo linear), considerando-se algumas } \\
\text { restrições lineares. }\end{array}$ \\
\hline - Regra de decisão Linear (RDL) & $\begin{array}{l}\text { Essa técnica é usada através de programação matemática, assumindo os custos como uma série } \\
\text { de funções quadráticas. O modelo procura uma solução ótima. }\end{array}$ \\
\hline $\begin{array}{l}\text { - Abordagem dos Coeficientes } \\
\text { Gerenciais (ACG) }\end{array}$ & $\begin{array}{l}\text { É uma abordagem heurística que considera que as decisões passadas dos gerentes devem } \\
\text { ser incorporadas ao sistema, melhorando o processo de tomada de decisão atual. As decisões } \\
\text { tomadas no passado são analisadas estatisticamente e, em seguida, são determinados } \\
\text { coeficientes, que servirão de base para o planejamento futuro da produção. Não propõe uma } \\
\text { solução ótima. }\end{array}$ \\
\hline - Método de Focalização (MF) & $\begin{array}{l}\text { É um processo de focalização de etapas da produção, busca nortear as ações dos gestores e } \\
\text { desenvolve uma visão da organização como um sistema. Permite aos gestores focalizar seus } \\
\text { esforços nos recursos que implicam em maior impacto nos resultados da empresa. }\end{array}$ \\
\hline $\begin{array}{l}\text { - Método Heurístico de Busca } \\
\text { Exaustiva (MHBE) }\end{array}$ & $\begin{array}{l}\text { É um método de busca que podem ser modelados para encontrar uma boa solução viável para } \\
\text { o problema. É aquele procedimento que normalmente é um algoritmo iterativo completo em que } \\
\text { cada iteração envolve a condução de uma busca por uma nova solução que, eventualmente, } \\
\text { poderia ser melhor que a melhor solução encontrada previamente. }\end{array}$ \\
\hline
\end{tabular}

Fonte: Adaptado de Fernandes e Filho (2010)

\section{METODOLOGIA}

A presente pesquisa classifica-se, quanto aos fins, como descritiva e, quanto aos meios, como bibliográfica. O método de abordagem adotado foi o qualitativo-quantitativo. A busca por trabalhos foi realizada nos anais do ENEGEP (Encontro Nacional de Engenharia de Produção), SIMPEP (Simpósio de Engenharia de Produção), CONBREPRO (Congresso Brasileiro de Engenharia de Produção), EMEPRO (Encontro Mineiro de Engenharia de Produção) e na Biblioteca digital da UNESPAR (Universidade Estadual do Paraná). Realizou-se um levantamento de artigos, o qual foi pesquisado trabalhos com a palavra chave "Planejamento Agregado" entre os anos de 2004 a 2015.

\section{RESULTADOS E DISCUSSÕES}

Foram selecionados 29 trabalhos, pois apresentavam conteúdos relacionados aos objetivos da pesquisa sobre o PAP. Os trabalhos foram estruturados conforme o nível de atuação do PAP abordado na pesquisa, sendo eles: modeloes e/ou métodos, linguagens/ softwares/solvers, estratégias, tipos de sistemas de produção, setores de atividade e tamanho da empresa. Um esboço dos artigos levantados é apresentado no Quadro 4. 
Quadro 4 - Levantamento de Trabalhos para Análise do Estudo

\section{Ano de Publicação do Estudo Autor(es) e Descrição do Estudo}

\begin{tabular}{|c|c|}
\hline 2004 & $\begin{array}{l}\text { Proto e Mesquita (2004) implementaram um modelo de PAP para aplicação em empresas de produção } \\
\text { do tipo Make-to-Stock com múltiplas localidades. }\end{array}$ \\
\hline 2006 & $\begin{array}{l}\text { Palomino e Lanfredi (2006) elaboraram um plano de produção para maximizar a utilização dos recursos } \\
\text { produtivos numa empresa do setor metalúrgico, reduzindo a ociosidades e estoques e aumentando a } \\
\text { confiabilidade nos prazos de entrega dos pedidos. } \\
\text { Filho (2006) desenvolveu um planejamento da produção a partir de um modelo de programação linear } \\
\text { quadrático gaussiano, focado nas restrições de probabilidade nas variáveis de estoque e produção. } \\
\text { Salgado et al. (2006) estabeleceram o lote econômico de compra para os principais produtos } \\
\text { adquiridos por uma farmácia de manipulação de Itajubá, a partir do modelo (Não-Linear) foi possivel } \\
\text { reduzir os custos da empresa. }\end{array}$ \\
\hline 2007 & $\begin{array}{l}\text { Neto et al. (2007) apresentaram a aplicação da programação linear para definir o mix ideal de } \\
\text { produção de uma indústria de bebidas. } \\
\text { Vieira, Silva e Martins (2007) desenvolveram um sistema com planilha eletronica na modelagem do } \\
\text { modelo de Planejamento dos recursos Materias (MRP) para auxiliar o planejmanto da producao de uma } \\
\text { empresa de suplemnto alimentares. }\end{array}$ \\
\hline 2008 & $\begin{array}{l}\text { Donato, Mayerle e Figueiredo (2008) apresentaram uma aplicação ilustrativa de um modelo de } \\
\text { programação linear para PAP em múltiplos períodos, com o objetivo de maximizar a rentabilidade das } \\
\text { linhas de produtos de uma indústria metal mecânica. } \\
\text { Cezarino, Filho e Ratto (2008) desenvolveram um aplicativo de apoio a tomadas de decisão gerencial, } \\
\text { orientado à modelagem e solução de um problema de planejamento da produção, desenvolvido no } \\
\text { nível tático da produção para proporcionar agilidade, facilidade e soluções ótimas aos problemas de } \\
\text { PAP. } \\
\text { Silva et al (2008) propuseram o balanceamento de uma linha de remanufatura de cartuchos de uma } \\
\text { empresa através de dois diferentes modelos com o objetivo de compará-los do ponto de vista da } \\
\text { qualidade das soluções encontradas. } \\
\text { Vieira e Porto (2008) propõe um modelo matemático para planejamento de capacidade de um hospital, } \\
\text { de forma a minimizar os custos de operação e otimizar os recursos humanos para atendimento da } \\
\text { demanda (pacientes). }\end{array}$ \\
\hline 2009 & $\begin{array}{l}\text { Silva et al (2009) aplicaram um modelo de otimização multiobjectivo no planejamento agregado da } \\
\text { produção de uma usina sucroalcooleiro, estabelecendo planos de produção eficiente, uma ótima } \\
\text { alocação dos recursos, obtendo uma margem de contribuição global superior a margem obtida pela } \\
\text { usina para a safra e entressafra } 2007 / 2008 \text {. } \\
\text { Namba e Toso (2009) desenvolveram heurísticas para o dimensionamento de lotes e sequenciamento } \\
\text { da produção, obtendo resultados muito próximos à solução ótima em pouco tempo computacional. }\end{array}$ \\
\hline 2010 & $\begin{array}{l}\text { Rocha e Leonardi. (2010) apresentaram um estudo para a otimização do processamento em uma } \\
\text { célula gargalo, dentro de uma indústria têxtil. } \\
\text { Nichetti et al (2010) mostraram o problema de otimização na programação de horários de trabalho em } \\
\text { hospitais. }\end{array}$ \\
\hline 2011 & $\begin{array}{l}\text { Tanajura e Cabral (2011) analisaram o funcionamento do PAP numa indústria petroquímica, } \\
\text { relacionando-o com os aspectos dispostos na literatura, contribuindo para a construção de um } \\
\text { ambiente multidisciplinar na tomada de decisão, ampliando o envolvimento dos membros da empresa } \\
\text { na tentativa de seguir um único plano para a organização. } \\
\text { konagano et al (2011) trabalharam com a otimização de um plano de produção visando a minimização } \\
\text { dos custos, levando em consideração a utilização de recursos de mão-de-obra, de equipamentos e } \\
\text { estoque. } \\
\text { Marchi e Milnitz (2011) propuseram um modelo matemático para otimizar os recursos utilizados no } \\
\text { sistema produtivo, com o objetivo de reduzir o custo total de uma indústria gráfica. }\end{array}$ \\
\hline 2012 & $\begin{array}{l}\text { Lemos e Morais (2012) desenvolveram um modelo para manejo dos pastos e manejo nutricional, } \\
\text { testado com dados agropecuário de um caso real. } \\
\text { Lemos, Vale e Morais (2012) propuseram um modelo de PAP, considerando os produtos e subprodutos } \\
\text { de uma indústria sucroalcooleira, levando em consideração as decisões de produção e métodos } \\
\text { alternativos de colheita. }\end{array}$ \\
\hline
\end{tabular}




\begin{tabular}{|c|c|}
\hline Ano de Publicação do Estudo & Autor(es) e Descrição do Estudo \\
\hline 2013 & $\begin{array}{l}\text { Medeiros e Gerber (2013) desenvolveram um método para a elaboração de um PAP considerando o } \\
\text { gerenciamento de restrições (GR), para identificar recurso que restringe o processo. } \\
\text { Rodrigues e Santos (2013) aplicaram a programação linear na minimização dos custos de produção } \\
\text { em uma indústria de processamento de açaí, auxiliando no planejamento da produção e alocação de } \\
\text { recursos. } \\
\text { Fontes et al. (2014) utilizaram uma heurística baseada no algoritmo de busca exaustiva, para o } \\
\text { PAP (utilizando a quantidade de dias como variável de decisão) de uma empresa beneficiadora de } \\
\text { castanha do Pará, buscando o menor custo operacional. }\end{array}$ \\
\hline 2014 & $\begin{array}{l}\text { Melo et al. (2014) desenvolvem um modelo linear de PAP, visando à minimização dos custos e } \\
\text { considerando dados de demanda, mão de obra e produtividade em uma empresa siderúrgica. } \\
\text { Piovesan, Silva e Filho (2014) elaboraram um modelo de PAP para uma indústria metalúrgica, com o } \\
\text { intuito de reduzir os custos. } \\
\text { Brito et al. (2014) utilizaram a programação linear para desenvolver um modelo de PAP visando à } \\
\text { alocação otimizada dos recursos e à minimização dos custos em uma indústria de processamento de } \\
\text { fibras de coco. } \\
\text { Dias et al. (2014) desenvolveram um modelo baseado em programação linear para representar um } \\
\text { sistema de produção de uma indústria têxtil, incluindo decisões das fases de preparação, montagem, e } \\
\text { acabamento. } \\
\text { Santos et al. (2014) trabalharam com um problema de programação linear com o objetivo de maximizar } \\
\text { os lucros obtidos em uma cachaçaria regional. } \\
\text { Monteiro et al. (2014) desenvolveram um estudo aplicando um modelo matemático de programação } \\
\text { linear em uma indústria de sacos e plásticos, com o intuito de minimizar os custos, utilizando uma } \\
\text { estratégia de produção do tipo "Forca de trabalho constante utilizando horas extras". }\end{array}$ \\
\hline 2015 & $\begin{array}{l}\text { Amaral e Oliveira (2015) Trabalharam com um problema de Programação Linear para representar um } \\
\text { sistema de producao de uma industria têxtil de meias. Como resultado sugere-se que exclua-se o } \\
\text { terceiro turno, pois não é tão produtivo e apresenta muita rotatividade de funcionários. }\end{array}$ \\
\hline
\end{tabular}

Fonte: Autores (2015)

Com base nos 29 trabalhos encontrados sobre a temática relacionada ao PAP, verificou-se que 10,3\% abordaram o PAP em Pequenas Empresas (PE), 6,9\% em Médias Empresas (ME), 31,0\% em Grandes Empresas (GE) e, 51,7\% dos estudos levantados não especificaram o tamanho da empresa.

Referente ao tipo de Sistema de Produção (SP), apenas $6,9 \%$ dos trabalhos levantados mencionaram o tipo de SP Make-To-Stoke e 3,4\% do tipo Flow- Shop. 89,7\% dos trabalhos investigados não especificaram o tipo de SP adotado no caso do PAP.

Conforme observado na descrição dos trabalhos levantados sobre o PAP, os tipos de setores empregados para estudo da aplicação foram: 27,8\% Agroindústria (dois trabalhos no setor sucroalcooleiro, três em uma indústria têxtil, um na agropecuária, um em uma indústria de castanha-do-pará, um em uma indústria de fibras de coco); 10,3\% Metal Mecânico; 13,8\% Alimentos; 10,3\% Não Especificaram o Setor; 10,3\% Saúde (dois trabalhos em farmácia e um em hospital); 3,4\% Manufatura; 3,4\% Pecuária; 3,4\% Petroquímica; 3,4\% Gráfica; 3,4\% Eletrodomésticos; 3,4\% Siderúrgica; 3,4\% Bebidas e 3,4\% Plásticos.

No Gráfico 1, é apresentado os Tipos de Softwares/ linguagens/solvers encontrado nos trabalhos, sendo eles: Planilha Eletrônico do Excel (A), Planilha Excel \& Solver (B), Não Especificado (N.E), GAMS/CPLEX 12.3 (C), GAMS 22.6/SOLVER CPLEX 11.0 (D), Forecast Pro For Windows - versão 3.5 e LINDO/PC - versão 6.1 (E), MATLAB 2008 (F), LINGO 12.0 (G), GLPK Versão 4.9 e AMPL CPLEX Versão 9.1 (H), CPLEX, IBM, ILOG Optimization Studio (I). 
Gráfico 1- Porcentagem dos softwares/linguagens/solvers utilizados nos trabalhos pesquisados sobre PAP

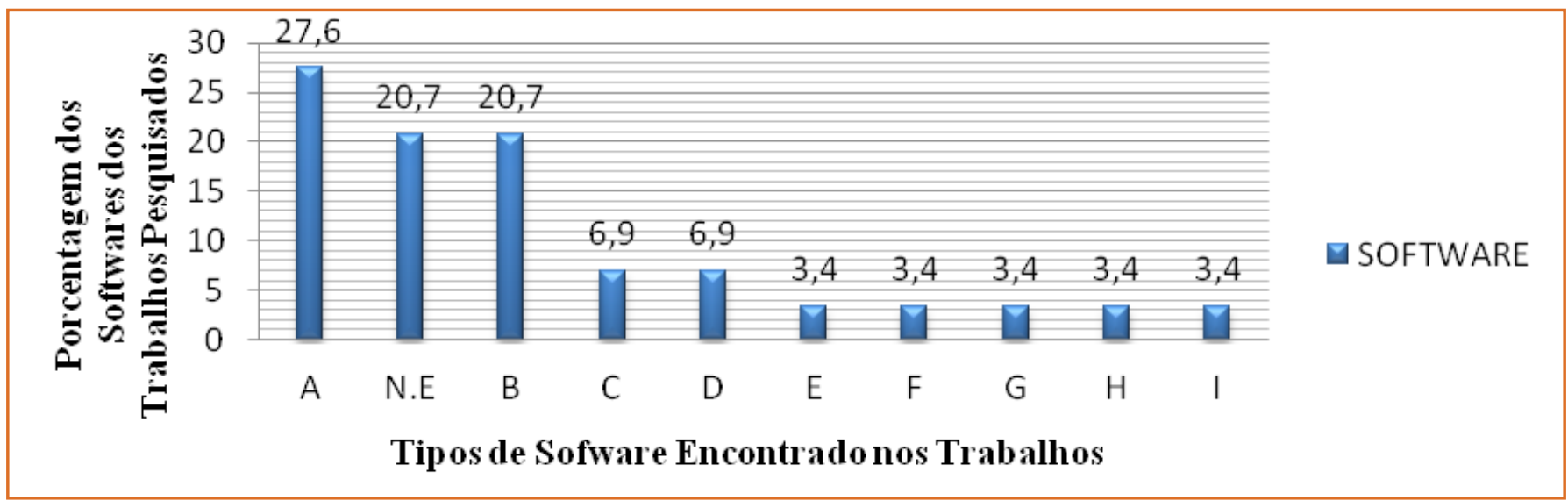

Dos nove diferentes softwares encontrados nos trabalhos, a A Planilha Eletrônico do Excel é considerada a mais utilizada, com um percentual de 27,6\%. 20,7\% dos trabalhos pesquisados não especificaram o software utilizado na pesquisa. A Planilha Excel com o emprego da ferramenta Solver apresentou um percentual de utilização de 20,7\%. O GAMS/CPLEX 12.3 e Planilha Eletrônica Excel e - GAMS 22.6/SOLVER CPLEX 11.0, apresentaram um percentual de 6,9\%, respectivamente. O CPLEX, IBM, ILOG Optimization Studio, GLPK Versão 4.9 e AMPL CPLEX Versão 9.1, LINGO 12.0, MATLAB 2008, Forecast Pro For Windows - versão 3.5 e LINDO/PC - versão 6.1, apresentaram um percentual de 3,4\%, respectivamente.
No gráfico 2, nota-se que 37,9\% dos trabalhos investigados não especificaram (NE) o tipo de estratégia utilizada no estudo. As estratégias B (Força de trabalho constante permitindo Faltas), C (Força de Trabalho Constante ) e H (Produção em Patamar), apresentaram um percentual de 3,4\%, respectivamente. As estratégias D (Força de Trabalho Constante utilizando horas extras) G (Redução Constante) apresentaram um percentual de 10,3\%, respectivamente. Já a estratégia A (Acompanhamento da Demanda) e H (Produção em Patamar), ambas teve um percentual de 37,9\%. E por fim, com 13,8 a F (Estratégia Mista).

Gráfico 2- Porcentagem das estratégias encontradas nos trabalhos pesquisados sobre PAP

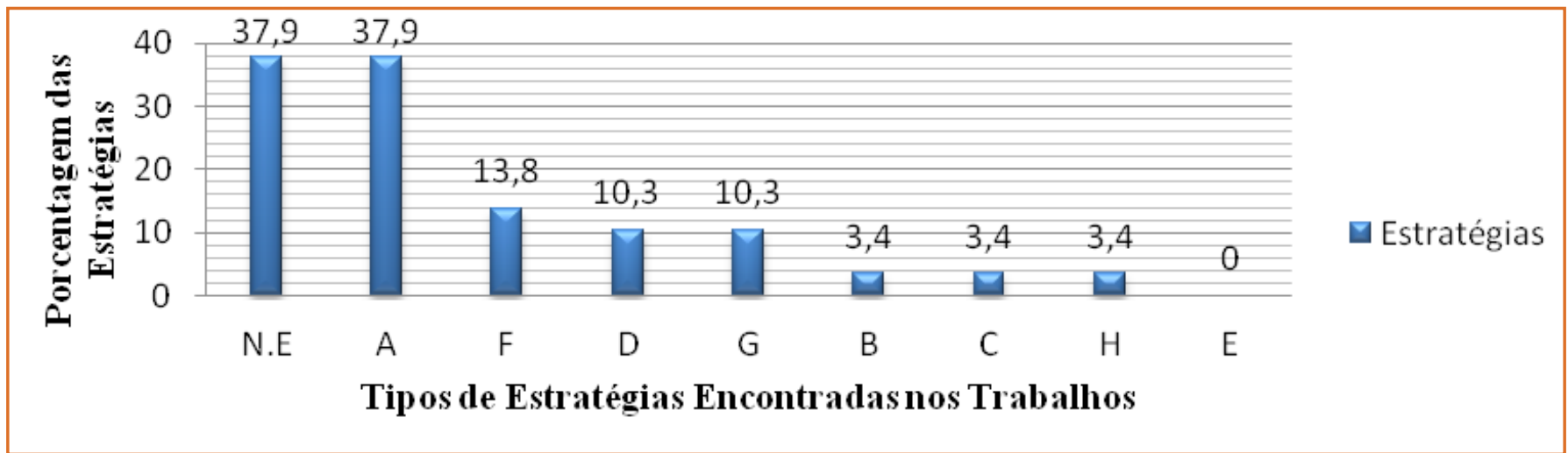

No gráfico 3 é visualizado o tipo de modelo empregado nos artigos levantados sobre o PAP. Pode-se observar que a Programação Linear (PL) é um dos modelos mais utilizados na resolução dos problemas de PAP, com um percentual de 55,2\%. Com 10,3\% classificouse a Programação Linear Inteira Mista (PLIM). Alguns trabalhos não especificaram o tipo de modelo, apenas demonstraram a utilização de Modelos Matemáticos (MM), quantificando-se em um percentual de 6,9\% dos trabalhos investigados, com o mesmo percentual se classificaram a Heurística $(H)$ e os trabalhos que Não Especificaram (N.E) os tipos de modelos empregados. 
Por fim, com um percentual de 3,4\% se classificaram os Método de Focalização (MF), Programação Inteira
Binária (PIB), Método Heurística de Busca Exaustiva (MHBE), e Programação Não Linear (PNL).

Gráfico 3 - Porcentagem dos tipos de modelos encontrados nos trabalhos pesquisados sobre PAP

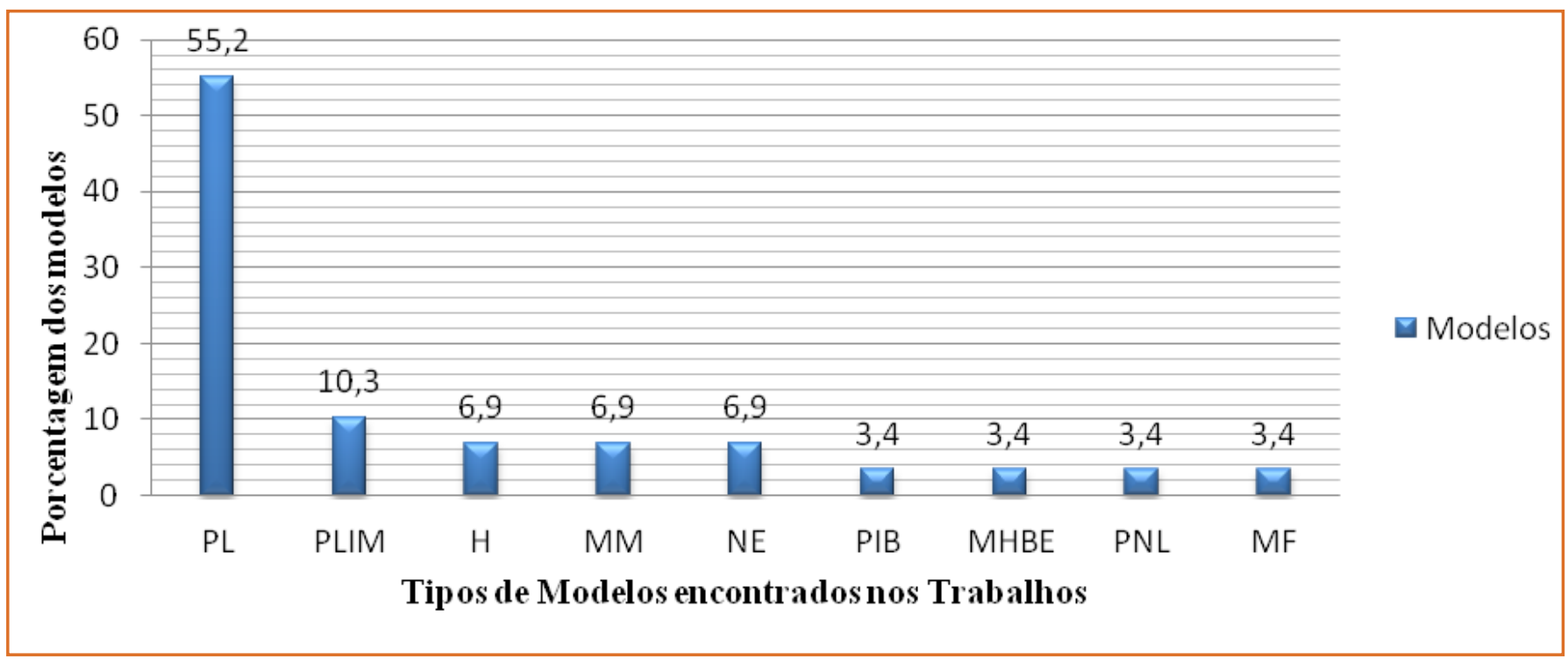

\section{CONSIDERAÇÕES FINAIS}

Diante dos artigos levantados sobre o PAP, foi possível identificar que as principais estratégias empregadas foram: A (Acompanhamento da Demanda) e $\mathrm{H}$ (Produção em Patamar), ambas com um percentual de 37,9\%. A Planilha Eletrônico do Excel foi utilizada com grande predominância, totalizando um percentual de $27,6 \%$ em relação aos demais Softwares. Nos artigos levantados e analisados, verificou-se um alto percentual de utilização de modelos de Programação Linear, totalizando um percentual de $53,8 \%$.

De acordo com a pesquisa desenvolvida e com os resultados encontrados, nota-se que o PAP desenvolve soluções rápidas e ótimas, para os problemas de produção, por meios de estratégias, softwares e modelos matemáticos para a representação do plano agregado da produção. Porém, muitas empresas tomam suas decisões baseadas na experiência dos seus gestores, portanto, sem auxilio de modelos matemáticos.

A abordagem proposta para o levantamento e análise de trabalhos sobre o PAP, servirá como norte para outra pesquisa, tal como a construção de uma interface amigável com utilização do Excel/VBA/GAMS-Solvers e emprego de modelos matemáticos baseados em Programação Linear, para diversas estratégias utilizadas na construção de um plano agregado da produção.

\section{REFERÊNCIAS}

[1] ALVES, R.; DELGADO, C. Programação Linear Inteira. In: Faculdade de Economia Universidade do Porto, 1997.

[2] AMARAL, L. S. R., OLIVEIRA, M. Elaboração de uma proposta de planejamento agregado da produção par uma indústria têxtil de Juiz de Fora - MG. ENCONTRO MINEIRO DE ENGENHARIA DE PRODUÇÃO, São João da Barra - RJ. Anais... XI EMEPRO, 2015.

[3] BARRA, R. B. M.; SOUZA, A. E. C.; MUTRAN, V. M.; SEPTIMIO, A. S.; MARTINS, V. W. B. M. Modelagem de um sistema de gerenciamento e planejamento agregado de uma usina de processamento de castanha do Pará utilizando um método heurístico de busca exaustiva. ENCONTRO NACIONAL DE ENGENHARIA DE PRODUÇÃO, Curitiba, PR, Brasil, 07 a 10 de Outubro de 2014. Anais... XXXIV ENEGEP, 2014.

[4] BRITO, T. O.; BEZERRA, D. S.; MOREIRA, C. R. M.; et al. Aplicação da programação linear para alocação otimizada de recursos em uma indústria de processamento de fibras de coco. ENCONTRO NACIONAL DE ENGENHARIA DE PRODUÇÃO, Curitiba, PR, Brasil, 07 a 10 de Outubro de 2014. Anais... XXXIV ENEGEP, 2014.

[5] CAIXETA-FILHO, José Vicente. Pesquisa Operacional: Técnicas de Otimização Aplicadas a Sistemas Agroindustriais. 2aㅡ. Ed. São Paulo: Atlas, 2004. 
[6] CEZARINO, W.; FILHO, O. S. S.; RATTO, J. R. Planejamento Agregado da Produção: modelagem e solução via planilha excel \& solver. ENCONTRO NACIONAL DE ENGENHARIA DE PRODUÇÃO, Rio de Janeiro, RJ, Brasil, 13 a 16 de Outubro de 2008. Anais... XXVIII ENEGEP, 2008.

[7] DIAS, I. F.; PAIVA, L. P. S. PAULA, J. F. R.; SILVA, G. Aplicação da programação linear para otimização do processo produtivo em uma empresa têxtil. ENCONTRO NACIONAL DE ENGENHARIA DE PRODUÇÃO, Curitiba, PR, Brasil, 07 a 10 de Outubro de 2014. Anais... XXXIV ENEGEP, 2014.

[8] DONATO, F. A. S.; MAYERLE, S. F.; FIGUEIREDO, J. N. Um modelo de Planejamento Agregado da Produção para otimizar o mix de produtos e clientes em uma indústria metalmecânica. ENCONTRO NACIONAL DE ENGENHARIA DE PRODUÇÃO, Rio de Janeiro, RJ, Brasil, 13 a 16 de Outubro de 2008. Anais... XXVIII ENEGEP, 2008.

[9] FERNANDES, Flávio C. F.; FILHO, Moacir, G. Planejamento e Controle da Produção: dos Fundamentos ao Essencial. São Paulo: Atlas, 2010.

[10] FILHO, O. S. S. Um modelo linear quadrático gaussiano com restrições de capacidade para planejamento agregado da produção. ENCONTRO NACIONAL DE ENGENHARIA DE PRODUÇÃO, Fortaleza, CE, Brasil, 09 a 11 de Outubro de 2006. Anais... XXVI ENEGEP, 2006.

[11] FONTES, R. B.; SOUZA, F. J. S. de.; CASTRO, C. H. C. de.; SIMPLICIO, C. C.; NETO, A. R. P. Balanceamento de linha de produção por meio de programação inteira binária: um estudo de caso em uma fábrica de eletrodomésticos. SIMPÓSIO DE ENGENHARIA DE PRODUÇÃO, 20, 2013, Bauru. Anais... XX SIMPEP, 2013.

[11] GOLDBARG, Marco Cesar.; LUNA, Henrrique P. L. Otimização Combinatória e Programação Linear: Modelos e Algoritmos. Rio de Janeiro: Elsevier, 2005.

[13] HILLER, Frederick S. Introdução a Pesquisa Operacional. 8 ed. Porto Alegre: AMGH, 2010.

[14] KONAGANO, K. S. H.; LIMA, R. do. N. P.; SANTOS, Y. B. I.; MORAES, M. de. S. O. Aplicação da programação linear para a utilização otimizada de recursos disponíveis em uma empresa de produção de camarão. SIMPÓSIO DE ENGENHARIA DE PRODUÇÃO, 18, 2011, Bauru. Anais... XVIII SIMPEP, 2011.

[15] LACHTERMACHER, Gerson. Pesquisa Operacional na Tomada de Decisões: Modelagem com Excel. 2. Ed. Rio de Janeiro: Elsevier, 2004.

[16] LAESCH, Cláudio; HEIN, Nelson. Pesquisa Operacional: Fundamentos e modelos. São Paulo: Saraiva, 2009.

[17] LEMOS, F. K.; Vale, M. P.; MORAIS, C. F. Planejamento agregado da produção no setor sucroalcooleiro considerando alternativas de colheita sob perspectiva da cogeração. ENCONTRO NACIONAL DE ENGENHARIA DE PRODUÇÃO, Bento Gonçalves, RS, Brasil, 15 a 18 de Outubro de 2012. Anais... XXXII ENEGEP, 2012.
[18] LEMOS, K. F.; MORAIS, B. L. Modelo linear inteiro misto para planejamento agregado da produção em bovinocultura de corte. ENCONTRO NACIONAL DE ENGENHARIA DE PRODUÇÃO, Bento Gonçalves, RS, Brasil, 15 a 18 de Outubro de 2012. Anais... XXXII ENEGEP, 2012.

[19] MARCHI, J. J.; MILNITZ, D. Modelo de otimização da produção através de programação linear: uma aplicação inicial em uma indústria do setor gráfico. SIMPÓSIO DE ENGENHARIA DE PRODUÇÃO, 18, 2011, Bauru. Anais... XVIII SIMPEP, 2011.

[20] MARQUESINI, A. G.; SANCHES, R. B. Modelo matemáticos para otimizar a roteirização mensal das frentes de colheita de cana-de-açúcar em usinas sucroalcooleiras. SIMPÓSIO DE ENGENHARIA DE PRODUÇÃO, 13, 2006, Bauru. Anais... XII SIMPEP, 2006.

[21] MARTINS, A. X.; SOUZA, M. J. F.; CARVALHO, R.; SILVA, T. C. B. Modelo de otimização do processo de lavra de curto prazo baseado em programação linear por metas aplicado à uma empresa. SIMPÓSIO DE ENGENHARIA DE PRODUÇÃO, 14, 2007, Bauru. Anais... XII SIMPEP, 2007.

[22] MEDEIROS, S. S.; GERBER, J. Z. Desenvolvimento de um método para auxiliar na elaboração do planejamento agregado da produção. ENCONTRO NACIONAL DE ENGENHARIA DE PRODUÇÃO, Salvador, BA, Brasil, 08 a 11 de Outubro de 2013. Anais... XXXIII ENEGEP, 2013.

[23] MELO, I. M.; BARBOSA, H. S.; MIRANDA, C. C.; SANTOS, Y. B. I.; OLIVEIRA, R. G. D. Minimização de custos em uma empresa siderúrgica pelo uso da programação linear. ENCONTRO NACIONAL DE ENGENHARIA DE PRODUÇÃO, Curitiba, PR, Brasil, 07 a 10 de Outubro de 2014. Anais... XXXIV ENEGEP, 2014.

[24] MONTEIRO, A. S.; JUNIOR, A. P. R.; JUNIOR, C. H. de. L. S.; CUSTODIO, K. C.; SANTOS, Y. B. I. Modelo de planejamento agregado da produção: um estudo de caso na indústria de sacos e plásticos. SIMPÓSIO DE ENGENHARIA DE PRODUÇÃO, 21, 2014, Bauru. Anais... XXI SIMPEP, 2014.

[25] MUNHOZ, José R.; MORABITO, Reinaldo. Otimização no planejamento agregado de produção em indústrias de processamento de suco concentrado congelado de laranja. Gest. Prod., São Carlos, v. 17, n. 3, p. 465-481, 2010.

[26] NETO, A. R.; TOSATI, M.; DEIMLING, M. F. Aplicação da programação linear no planejamento e controle da produção: definição do mix de produção de uma indústria de bebidas. SIMPÓSIO DE ENGENHARIA DE PRODUÇÃO, 14, 2007, Bauru. Anais... XII SIMPEP, 2007.

[27] NICHETTI, D. V.; TIBURCIO, D. M.; GUEDES, G. B.; BARBOZA, A. O.; STEINER, M. T. A. S. otimização na programação de horários de trabalho de funcionários aplicada em hospitais. SIMPÓSIO DE ENGENHARIA DE PRODUÇÃO, 17, 2010, Bauru. Anais... XVI SIMPEP, 2010. 
[28] PALOMINO, R. C.; LANFRED, A. A. Planejamento agregado da produção em uma empresa de pequeno porte: um estudo caso. ENCONTRO NACIONAL DE ENGENHARIA DE PRODUÇÃO, Fortaleza, CE, Brasil, 09 a 11 de Outubro de 2006. Anais... XXVI ENEGEP, 2006.

[29] PIOVESAN, J.; SILVA, L. G. O.; FILHO, A. T. A. Modelo de planejamento agregado multiproduto em uma indústria metalúrgica. ENCONTRO NACIONAL DE ENGENHARIA DE PRODUÇÃO, Curitiba, PR, Brasil, 07 a 10 de Outubro de 2014. Anais... XXXIV ENEGEP, 2014.

[30] PROTO, L. O. Z.; MESQUITA, M. A. Desenvolvimento de um modelo de planejamento agregado da produção e da distribuição para aplicação em empresas de produção maketo-stock com múltiplas localidades. ENCONTRO NACIONAL DE ENGENHARIA DE PRODUÇÃO, Florianopolis, SC, Brasil, 03 a 05 de Novembro de 2004. Anais... XXIV ENEGEP, 2004.

[31] ROCHA, J. A.; LEONARDI, F. Aplicação de heurísticas em confecção têxtil de médio porte. SIMPÓsIO DE ENGENHARIA DE PRODUÇÃO, 17, 2010, Bauru. Anais... XVI SIMPEP, 2010.

[32] RODRIGUES, E. C. N.; SANTOS, Y. B. I. Aplicação da programação linear na minimização dos custos de produção em uma indústria de processamento de açaí de pequeno porte no município de Belém. SIMPÓSIO DE ENGENHARIA DE PRODUÇÃO, 20, 2013, Bauru. Anais... XX SIMPEP, 2013.

[33] SALGADO, E. G.; NEVES, T. I. P. da C.; MONTEVECHI, J. A. B. D. A utilização da Programação Não-Linear para redução dos custos através da determinação do Lote Econômico de Compras: estudo de caso em uma farmácia de manipulação. SIMPÓSIO DE ENGENHARIA DE PRODUÇÃO, 13, 2006, Bauru. Anais... XII SIMPEP, 2006.

[34] SANTOS, F. A.; RODRIGUES, M. T. Modelo computacional para formulação de rações de mínimo custo para pequenos ruminantes utilizando programação linear. SIMPÓSIO DE ENGENHARIA DE PRODUÇÃO, 13, 2006, Bauru. Anais... XII SIMPEP, 2006.

[35] SANTOS, Y. B. I.; RODRIGUES, A. F. B.; CARVALHO, L. M.; QUEIROZ, L. P. M.; FERREIRA, L. P. Aplicação da programação linear na maximização dos lucros de produção em uma cachaçaria regional. SIMPÓSIO DE ENGENHARIA DE PRODUÇÃO, 21, 2014, Bauru. Anais... XXI SIMPEP, 2014. SEVERO, Larissa S. Aplicação de Modelo de Programação da Produção na Indústria de Couros. 107 f. Dissertação (Mestrado em Engenharia Química) - PEQ, Programa de Pós Graduação em Engenharia Química - UFRGS, Universidade Federal do Rio Grande do Sul, 2007.
[36] SILVA, A. F da.; MONTEVECHI, J. A. B.; MARINS, F. A. S.; NEVES, S. M.; DUARTE, R. N. Modelagem e otimização do planejamento agregado da Produção de uma usina sucroalcooleira. SIMPÓSIO DE ENGENHARIA DE PRODUÇÃO, 16, 2009, Bauru. Anais... XVI SIMPEP, 2009.

[37] SILVA, M. C.; ALMEIDA, J. F. de. F.; CONCEIÇAO, S. $\checkmark$. Modelos de balanceamento em uma linha multi-produto de uma empresa do segmento E.M.S. SIMPÓSIO DE ENGENHARIA DE PRODUÇÃO, 15, 2008, Bauru. Anais... XV SIMPEP, 2008

[38] SIPPER, D.; BULFIN JR, R. L. Production Planning, Control, and Integration. New York: McGraw-Hill, 1997.

[39] TAHA, Hamdy A. Pesquisa Operacional: Uma Visão Geral. 8 ed. São Paulo: Pearson Prentice Hall, 2008.

[40] TUBINO, D. F. Planejamento e Controle da Produção: Teoria e Prática. 2a ${ }^{a}$. Ed. São Paulo: Atlas, 2009.

[41] TANAJURA, A. P. M.; CABRAL, S. Planejamento de vendas e operações (s\&op): um estudo de caso numa petroquímica. ENCONTRO NACIONAL DE ENGENHARIA DE PRODUÇÃO, Belo Horizonte, MG, Brasil, 04 a 07 de Outubro de 2011. Anais... XXXI ENEGEP, 2011.

[42] VIEIRA, K. G.; SILVA, R. A. C da.; MARTINS D. D. S. Desenvolvimento de um sistema em planilhas eletrônicas para o planejamento da produção em pequenas empresas de suplementos alimentares: um estudo de caso. ENCONTRO MINEIRO DE ENGENHARIA DE PRODUÇÃO, Belo Horizonte, MG, Brasil, 07 a 09 de Junho de 2007. Anais... III EMEPRO, 2007

[43] VIEIRA, J. G. V.; PORTO, R. N. Planejamento de capacidade: um estudo de caso em um hospital. ENCONTRO MINEIRO DE ENGENHARIA DE PRODUÇÃO, Ouro Preto, MG, Brasil, 01 a 03 de Maio de 2008. Anais... IV EMEPRO, 2008. 


$$
\text { Alutary }
$$




\section{Marcelo Ruy (Organizador)}

Possui graduação em Engenharia de Produção Mecânica - USP - Escola de Engenharia de São Carlos (1997), mestrado em Engenharia de Produção pela Universidade Federal de São Carlos (2002) e doutorado em Engenharia de Produção pela Universidade Federal de São Carlos (2011). Tem experiência na área de Engenharia de Produção, com ênfase nos seguintes temas: Estatística, Qualidade e Desenvolvimento de Produtos.

\section{Ademar Alves de Meira}

Graduado em Tecnologia em Eletrônica - Modalidade Automação de Processos Industriais, e especialização em Engenharia de Produção, ambos pela UTFPR. Possui conhecimentos teóricos e realiza atividades de instalação, programação e manutenção nos seguintes equipamentos: Centrais Telefônicas ( analógicas e digitais); Equipamentos telefônicos em geral; Monocanais; Centrais de Alarmes; CFTV; Vídeo Porteiro e Interfone (residencial e coletivo); Parabólicas (residencial e coletiva); Portões Eletrônicos; Impressoras Fiscais. Possui conhecimento CLP; Sensores; Micro Processadores e outros componentes similares.

\section{Alessandra Lopes Carvalho}

Possui graduação em Engenharia Elétrica ( PUC Minas 1996), mestrado em Engenharia Elétrica com ênfase em Automação ( UFMG 1998) e doutorado em Engenharia Elétrica, linha de pesquisa Confiabilidade de Sistemas (UFMG, 2008). Integra o corpo docente da PUC MG ah dezessete anos. É membro do Núcleo Docente Estruturante do curso de Engenharia de Produção da PUC-MG onde leciona Engenharia da Qualidade, Controle Estatístico e Confiabilidade de Produtos e Processos. É também consultora associada da empresa ReliaSoft Brasil. Sua área de atuação em pesquisa é Confiabilidade de Produtos e Processos.

\section{Ana Carolina de Almeida Alvarenga}

Consultora na KPMG do Brasil, atua atualmente no setor de Tecnologia, Mídia e Telecomunicações. Possui graduação em Engenharia de Produção pela pela Universidade Tecnológica Federal do Paraná (2017). Participou do programa de trainee na KMPG do Brasil na área de Suppy Chain por 8 meses (2016). Realizou a graduação sanduíche na Dublin Business School (2014) no curso de Business and Managment. Ainda na graduação, participou de estudos na área de Comportamento Organizacional (2015) e pesquisas envoltas na técnica de Avaliação do Ciclo de Vida - ACV (2013).

\section{Ana Paula de Carli Bertaioli}

Possui MBA em Gestão Estratégica e Financeira pela Universidade do Oeste de Santa Catarina (2015) e graduação em Administração - Habilitação em Comércio Exterior pela Universidade do Oeste de Santa Catarina (2003). Tem experiência na Área de Gestão Administrativa, na qual atuou por mais de dez anos. Atualmente é servidora pública federal na Universidade Federal da Fronteira Sul atuando como Chefe do Setor de Assessoria de Comunicação. 


\section{Andre de Mendonça Santos}

Professor Assistente na Universidade Federal do Oeste da Bahia no curso de Engenharia Mecânica, área Materiais/Processos de Fabricação. Possui graduação em Engenharia de Produção pela Universidade Estadual de Santa Cruz (UESC). Mestre em Ciências, Inovação e Modelagem em Materiais pela UESC.

\section{Andréia Gura}

Mestranda em Engenharia de Produção pela Universidade Tecnológica Federal do Paraná (UTFPR). Possui graduação em Ciências Contábeis pela Universidade Estadual do CentroOeste (2008) e Especialização em Gestão Financeira de Negócios pela Universidade Estadual do Centro Oeste (2014). Foi professora substituta do Instituto Federal do Paraná nos anos de 2015 e 2016. Tem experiência na área de Administração, com ênfase em Ciências Contábeis. Possui experiência como Auditora Interna do Sistema de Gestão Integrado - ISO 9001 e 14001.

\section{Antonio Cecilio Silvério}

Possui graduação em Ciências Contábeis pelo Centro Pastoral Educacional e Assistência Dom Carlos (1991), Especilalização em Gerência Contábil (1994) e mestrado em Ciências Sociais Aplicadas, área de concentração Contabilidade, pelo Centro Pastoral Educacional e Assistência Dom Carlos (1999). Atualmente é professor ebtt do Instituto Federal do Paraná. Tem experiência na área de Administração, com ênfase em Ciências Contábeis, atuando principalmente nos seguintes disciplinas: Contabilidade Geral; Contabilidade de Custos; Análise de Custos; Perícia Contábil; Análise Demonstrações Contábeis; Controladoria. Foi Professor de Ensino Superior no UNICS por 13, anos, Coordenador de Curso de Ciências Contábeis do UNICS por 4 anos. Professor Ensino Superior e Coordenador do Curso de Ciências Contábeis na UTFPR, por 4 anos. Atuou como Profissional Liberal/Contador em empresas privadas por 15 anos.

\section{Antônio Suerlilton Barbosa da Silva}

Pós-doutorando em Administração, pela Universidade Federal de Itajubá (UNIFEI). Doutor em Gestão, pela Universidade de Trás-os-Montes e Alto Douro (2013), com revalidação de diploma pela Universidade Federal do Rio de Janeiro - UFRJ (portaria 1077/12). Mestre em Economia, pela Universidade Federal do Estado do Ceará (2006). Especialista em Gerenciamento de Projetos. Graduado em Ciências Econômicas, pela Universidade do Estado do Rio Grande do Norte (2002). Professor e Coordenador do Programa de Bolsas de Iniciação Científica - PROBIC, da Faculdade de Ciências Sociais Aplicadas do Sul de Minas (FACESM). Professor e Coordenador do Núcleo de Inovação Tecnológica - NIT, do Centro Universitário de Itajubá (FEPI). 


\section{Ariel Orlei Michaloski}

Possui experiência em construção civil, indústria e academia. Atualmente é Professor do Departamento de Engenharia de Produção -UTFPR PG onde atua como professor dos cursos de graduação em engenharia de produção, engenharia elétrica, engenharia mecânica e engenharia química. É coordenador e professor dos cursos Lato Sensu (Especialização) em Engenharia de Segurança do Trabalho e Engenharia de Produção ambos da UTFPR PG. É professor do Programa de Mestrado/Doutorado em Engenharia de Produção da UTFPR - PG. É professor do Mestrado Profissional em Administração Pública a nível nacional PROFIAP/UTFPR- PR. Possui mais de 15 anos de experiência em obras públicas atuando como engenheiro de projetos, relações humanas, licitações, gerenciamento de obra pública e fiscal de contrato de obras públicas na UTFPR Ponta Grossa. É Técnico em Edificações pela Universidade Tecnológica Federal do Paraná (1985); Graduado em Engenharia Civil Universidade Estadual de Ponta Grossa - UEPG PR (1996); Especialização em Gerenciamento de Obras pela Universidade Tecnológica Federal do Paraná (1997); Engenheiro de Segurança do Trabalho - Universidade Tecnológica Federal do Paraná (1999); Coordenador da Qualidade e Auditor Interno pela Deutsche Gesellschaft Für Qualität e V, DGQ, Alemanha e Universidade Tecnológica Federal do Paraná (2000); Gerenciamento Ambiental Empresarial pela Carl Duisberg Gesellschaft e V, CDG, Alemanha e Universidade Tecnológica Federal do Paraná (2001); Mestrado em Tecnologia e Desenvolvimento pela Universidade Tecnológica Federal do Paraná - UTFPR (2002); Doutorado em Engenharia de Produção pela Universidade Federal de Pernambuco - UFPE (2011). Atua no grupo de pesquisa do Laboratório de Ergonomia - LabErgo do Programa de Pós Graduação em Engenharia de Produção da UTFPR, Campus de Ponta Grossa, Ergonomia em Processos Produtivos - Segurança do Trabalho, devidamente cadastrado junto ao CNPQ. Atua na Diretoria de Pesquisa e Pós Graduação da UTFPR-PR Ponta Grossa na assessoria Lato Sensu. Desenvolve trabalhos como perito judicial na área de segurança do trabalho. É consultor e instrutor na área de engenharia de segurança do trabalho. Tem interesse em pesquisas para as seguintes áreas: Segurança do trabalho,Higiene ocupacional, Administração pública, Técnicas e processos de execução de obras civis.

\section{Bismarck Soares Matos Santos}

Possui graduação em ENGENHARIA DE AGRIMENSURA E CARTOGRÁFICA pela Universidade Federal de Viçosa (2015). Pós graduado em Engenharia de Segurança do Trabalho na FACISA/UNIVIÇOSA (2016). Tem experiência na área de Geociências, com ênfase em Geoprocessamento e Sensoriamento Remoto, e na área de Engenharia de Produção, com ênfase em ENGENHARIA DE SEGURANÇA DO TRABALHO, atuando principalmente nos seguintes temas: Land Change Modeler, Desastre Ambiental e Sistemas de Informações Geográficas.

\section{Bruna Zuccolotto Guedes}

Graduanda em Engenharia de Produção pela Universidade Tecnológica Federal do Paraná (UTFPR). Atua como Assistente de Customer Facing na Nestlé Brasil. Possui experiência nas áreas de Engenharia de Produção, Análise de Dados e Customer Facing/Customer Service. 


\section{Bruno Alexandre Oliveira}

Bacharel em Engenharia de Produção pela Universidade Tecnológica Federal do Paraná (UTFPR). Pós Graduando no MBA em Gestão de Projetos pela Universidade de São Paulo (USP). Analista de Processos Indústriais (BRF - OneFoods), com atuação em projetos de automação industrial, eficiência global, gestão e produtividade industrial.

\section{Celise Roder}

Especialista em Gestão Empresarial pela Faculdade Integrado de Campo Mourão (2014), graduada em Engenharia de Produção Agroindustrial pela Faculdade Estadual de Ciências e Letras de Campo Mourão (2011) Docente da Faculdade Integrado de Campo Mourão lotada no colegiado de Engenharia Civil

\section{Dalila Giovana Pagnoncelli Laperuta}

Mestre em Engenharia de Produção e Sistemas (UTFPR, 2016), Especialista em Recursos de Tecnologia da Informação (UTFPR, 2009), Especialista em Redes de Computadores (UTFPR, 2011), Graduada em Tecnologia em Sistemas de Informação (UTFPR, 2008). Área de Pesquisa: Ergonomia (Métodos e Ferramentas de Avaliação Ergonômica), Usabilidade (IHC), e suas relações com a Engenharia de Software e Produtos.

\section{Denise Ransolin Soranso}

Mestre em Ciências Florestais pela Universidade Federal do Espírito Santo (2015), pós graduada em Engenharia de Segurança do Trabalho pela Universidade de Cuiabá - UNIC (2013) e graduada em Engenharia Florestal pela Universidade do Estado de Mato Grosso (2010) . Tem experiência na área de Recursos Florestais e Engenharia Florestal, com ênfase em Tecnologia de Produtos Florestais e Segurança no Trabalho Florestal.

\section{Denislaine Regina Cordeiro}

Pesquisadora no Grupo de Estudos e Pesquisas em Processos e Gestão de Operações (GEPPGO) e Graduanda em Engenharia de Produção Agroindustrial pela UNESPAR Universidade Estadual do Paraná Campus de Campo Mourão.

\section{Diego Ricardo Krohl}

Mestre em Engenharia de Processos pela Universidade da Região de Joinville (UNIVILLE 2014), pós-graduado em Gestão da Tecnologia da Informação (UDESC - 2010) e graduado em Tecnologia em Sistemas de Informação (TSI) pela Universidade do Estado de Santa Catarina (UDESC - 2008). Tem experiência na área de Sistemas de Informação, com ênfase na área de Gestão da Tecnologia da Informação, onde atuou na coordenação de implantação de Sistemas de Informação (ERP), para o setor industrial. Atuou como facilitador do programa DOT (Digital Opportunity Trust) no treinamento de docentes com recursos tecnológicos educacionais. Atualmente é professor do ensino básico técnico e tecnológico do Instituto Federal Catarinense - Campus Videira. 


\section{Diullya Carolina Cordeiro}

Pesquisadora em projeto de Iniciação Científica Júnior desenvolvido no Grupo de Estudos e Pesquisas em Processos e Gestão de Operações (GEPPGO) do Curso de Engenharia de Produção Agroindustrial da UNESPAR - Universidade Estadual do paraná Campus de Campo Mourão.

\section{Edimar Nunes Dias}

Engenheiro de Produção Agroindustrial pela UNESPAR - Universidade Estadual do Paraná Campus de Campo Mourão (2016). Atuou como consultor Júnior na OTIMIZA EJ no período de 2014-2016. Formação em Green Belt - 6 Sigmas e Lean Manufacturing pela RL Associados. Atualmente é analista técnico no setor de produção de um abatedouro de aves.

\section{Everaldo Veres Zahaikevitch}

Doutorando em Engenharia da Produção pela UTFPR - Campus de Ponta Grossa - PR. (2017), Mestrado em Engenharia da Produção pela UTFPR - Campus de Ponta Grossa - PR. (2014) Especialização em Gestão Industrial na UTFPR - Ponta Grossa - PR (2011). Especialização em MBA em GERÊNCIA CONTÁBIL, PERÍCIA, AUDITORIA E CONTROLADORIA, pela Faculdade Internacional de Curitiba, Facinter, Curitiba, Brasil (2008), Graduação em CIÊNCIAS CONTÁBEIS pela Universidade Estadual do Centro-Oeste (2005). Atualmente sou Professor EBTT do curso de Ciências Contábeis - no Instituto Federal do Paraná - IFPR, Campus Palmas -PR. Com experiência na área de Administração, com ênfase em Ciências Contábeis nas seguintes áreas: Contabilidade Geral, Contabilidade Empresarial, Contabilidade Gerencial, Análise das Demonstrações Contábeis, Contabilidade Aplicada ao terceiro setor, Contabilidade Avançada, Contabilidade Aplicada ao Agronegócio, Pericia, Sistemas Contábeis e Teoria da Contabilidade.

\section{Fabrício Alves de Almeida}

Mestre em Engenharia de Produção pela Universidade Federal de Itajubá na área de otimização e controle. Graduado em Ciências Econômicas pela Faculdade de Ciências Sociais Aplicadas do Sul de Minas com ênfase em Economia Industrial e atuação em ecommerce. Atualmente é membro do grupo de pesquisa do Núcleo de Otimização da Manufatura e Tecnologia da Inovação (NOMATI) na Universidade Federal de Itajubá, atuando principalmente nos temas: Análise Multivariada de dados; otimização multiobjetivo; economia industrial; projeto e planejamento de experimentos e engenharia da qualidade.

\section{Fernanda Gomes de Andrade}

Bacharel em Engenharia de Produção, graduada pela Universidade Tecnológica Federal do Paraná (UTFPR) - câmpus Ponta Grossa. Possui experiência na área de Planejamento e Controle da Produção e Gestão de Operações. Possui atuação nos temas de Tomada de Decisão e Gestão Industrial. 


\section{Flavio Fuhr}

Possui graduação em Ciências Contábeis pela Universidade Tecnológica Federal do Paraná (1999). Especialista em Contabilidade e Finanças pela Universidade Federal do Paraná / Especialização em Auditoria e Perícia Contábil (2007). MBA em Gestão Empresarial (2010) FAE. Esteve como professor e Coordenador Adjunto de Ciências Contábeis da Universidade Comunitária Regional de Chapecó. Cursando Mestrado por meio do Programa de PósGraduação em Engenharia de Produção e Sistemas pela UTFPR, Campus Pato Branco-PR. Atuou como Professor na Instituição FADEP - Faculdade de Pato Branco. Atualmente Professor do Curso de Ciências Contábeis do IFPR - Campus Palmas - PR Experiência na área de Administração/Contabilidade, com ênfase em Finanças, Contabilidade Básica e Aplicada.

\section{Gabriel Machado Braido}

Graduado em Administração (Habilitação em Análise de Sistemas), com especialização em Finanças e Controladoria, e Mestrado em Administração. Atualmente é Doutorando em Administração e Professor Assistente do Centro Universitário UNIVATES.

\section{Guilherme Constantini}

Cursando Bacharelado em Ciências da Computação (IFC-2017) pelo Instituto Federal Catarinense - Campus Videira. Tem experiência na área de gestão de $\mathrm{TI}$, com o gerenciamento de redes e sistemas Windows Server e Mikrotik. Atualmente trabalha como gerente de TI.

\section{Horrany Leite de Carvalho}

Graduanda de Engenharia de Produção no Centro Universitário Christus (Unichristus) tendo participado como bolsista no Programa de Iniciação Científica da referida instituição, possuindo publicação em eventos da área como o CONBEPRO (Congresso Brasileiro de Engenharia de Produção) e na Revista Interagir (ISSN 1809-5771). Foi membro fundadora e diretora presidente da gestão 2016 da Planep Consultoria Júnior - Empresa Junior do Curso de Eng. de Produção da Unichristus. É Palestrante sobre empreendedorismo e Movimento Empresa Junior e atualmente trabalha com Desenvolvimento de Produtos na empresa Mil Plastic - Indústria e Comércio de Plásticos.

\section{Ibaldo Gonçalves Pedra Júnior}

Possui graduação em Administração pela Universidade do Extremo Sul Catarinense. Tem experiência na área de Administração, atuando principalmente em logística internacional e comércio exterior.

\section{Indara Santos de Souza}

Graduada em Engenharia de Produção pela Universidade Estadual de Santa Cruz (2015). 


\section{Jaciara Dias Trzaskos}

Engenheira Civil e Engenheira de Segurança do Trabalho

\section{Jean Carlos B. de Almeida}

Graduado em Engenharia Ambiental pela Faculdade Dinâmica das Cataratas (2013), licenciado em Química pela Universidade Tecnológica Federal do Paraná, mestre em Engenharia Química na Universidade Estadual do Oeste do Parana (linha de pesquisa: Controle e Monitoria Ambiental) e cursando doutorado no Programa de Pós-Graduação em Engenharia de Recursos Hídricos e Ambiental- UFPR.

\section{Jordana Dorca dos Santos}

Graduada em Engenharia Ambiental pela Universidade Tecnológica Federal do Paraná. Especialista em Engenharia de Segurança do Trabalho pela Universidade Estadual de Maringá. Mestre pelo programa de pós-graduação em Engenharia Química pela UNIOESTEToledo. Tem experiência na área de tratamento de efluentes industriais, Gestão Ambiental e de qualidade. Atualmente é professora colaboradora no Departamento de Engenharia de Produção-UNESPAR.

\section{Joseane Pontes}

Doutora em Engenharia de Produção (2007) e Mestre em Engenharia de Produção (2003) pela Universidade Federal de Santa Catarina, graduação em Administração (1998) e Ciências Econômicas (1999) pela Universidade Estadual do Centro-Oeste. Atualmente é professora da Universidade Tecnológica Federal do Paraná (UTFPR /Ponta Grossa), atuando nas áreas: Engenharia da Qualidade, Engenharia Organizacional e Redes de Empresa e líder do grupo de pesquisa em Engenharia da Qualidade em Processos de Produtos e Serviços.

\section{Kazuo Hatakeyama}

Ph.D., "Design of Manufacturing Processes", UK. M.Sc., "Planning of Engineering Courses", USA e PG Dipl., "Management and Manufacturing Technology", Scotland. PosDoc. "Management of Higher Education"; "Innovation Policy", England e "Information, Production and Systems, Japan. Coordenou o Colegiado de EMEC da UFBA; o Mestrado em EP da UTFPR; projetos de intercâmbio de graduação na Alemanha, PQI e Pro-engenharia para a formação de doutores e mestres. Orientou alunos dos cursos de graduação, de especialização, de mestrado e co-orientou os de doutorado em tecnologia e engenharia. Publicou artigos em eventos nacionais e internacionais em assuntos relacionados a engenharia e formação de recursos humanos nas áreas tecnológicas. 


\section{Lays Costa Faria}

Co-fundadora da Etruska CNC, uma empresa de democratização do ensino maker com fresadoras CNC especialmente desenvolvidas para a necessidade do artesanato brasileiro, aluna especial do programa de pós-graduação em Engenharia de Produção e de Manufatura (EPM) na Unicamp. Formada em Engenharia de Produção pela Universidade Tecnológica Federal do Paraná (2017), fez graduação sanduíche na University of Southern Indiana nos EUA (2014), onde realizou projetos na área de logística e arranjo de fábrica em empresas locais. Ainda na graduação, participou de estudos na área de Comportamento Organizacional (2015) e pesquisas na área de sustentabilidade em green marketing e green supply chain (2013).

\section{Letícia Pavan Silva}

Bacharel em Engenharia de Produção pela Universidade Tecnológica Federal do Paraná (UTFPR) - Campus Ponta Grossa. Realizou pesquisas na área de Lean Healthcare e possui experiência profissional com aplicação de ferramentas Lean no setor industrial.

\section{Livia Pinto Neri}

Graduada em Engenharia de Produção pela Universidade Estadual de Santa Cruz- UESC (2014). Especialista de Engenharia de Segurança do Trabalho pela Faculdade de Tecnologia e Ciência - FTC (2016). Mestre em Ciências, Inovação e Modelagem em Materiais pela UESC (2017). Atualmente, é coordenadora e professora dos cursos de engenharia civil, mecânica e produção na Faculdade Pitágoras.

\section{Luani Back}

Doutorado em andamento em Engenharia de Produção, pela Universidade Tecnológica Federal do Paraná, Campus Ponta Grossa. Mestre em Engenharia de Produção - Stricto Sensu, pela Universidade Tecnológica Federal do Paraná (UTFPR), Campus Ponta Grossa, na área de concentração de Gestão Industrial e linha de pesquisa Transferência de Tecnologia. Bacharel em Engenharia de Produção pela Universidade Tecnológica Federal do Paraná (UTFPR), Campus Medianeira. Atualmente é professora na UDC Medianeira, nos cursos de Administração e Tecnologia em Gestão Comercial.

\section{Luci Mercedes De Mori}

Possui graduação em Engenharia Civil pela Universidade Estadual de Maringá (1989), mestrado em Engenharia de Produção pela Universidade Federal de Santa Catarina (1998), doutorado em Programa de Pós-Graduação em Engenharia Civil pela Universidade Federal de Santa Catarina (2008) e Especialização em Engenharia de Segurança do Trabalho pela Universidade Estadual de Maringá (2012). Atualmente é professor associado da Universidade Estadual de Maringá. Tem experiência na área de Engenharia Civil, com ênfase em Processos Construtivos, atuando principalmente nos seguintes temas: planejamento, orçamento, produtividade, construção civil, alvenaria, argamassas e segurança do trabalho" 


\section{Luciano José Minette}

Possui graduação em Engenharia Florestal pela Universidade Federal de Viçosa (1984), mestrado em Ciência Florestal pela Universidade Federal de Viçosa (1987) e doutorado em Ciência Florestal pela Universidade Federal de Viçosa (1995). Possui especialização em Engenharia de Segurança do Trabalho - FUMEC (2002). Atualmente, é professor associado IV da Universidade Federal de Viçosa, integrante da Universidade Federal do Espírito Santo. Coordenador do curso de Especialização, Lato Sensu, em Engenharia de Segurança do Trabalho, da Universidade Federal de Viçosa. Tem experiência na área de Engenharia de Produção, com ênfase em Segurança do Trabalho e Ergonomia, atuando principalmente nos seguintes temas: ergonomia, colheita florestal, transporte florestal e segurança do trabalho.

\section{Luis Felipe Cândido}

Eng. Civil e Mestre em Eng. Civil pela UFC. Atualmente é professor dos cursos de Eng. Civil e Eng. de Produção na Unichristus, atuando no ensino, pesquisa e extensão em cursos de curta duração, orientação de trabalhos de iniciação científica, Grupo de Estudos e Pesquisa em Gestão e Tecnologia da Construção e tutoria da Empresa Jr de Eng. de Produção (PLANEP). É membro do GERCON atuando como pesquisador e coordenador técnico em projetos diversos. Atua como avaliador de artigos científicos no CONBREPRO e no Encontro de Iniciação à Pesquisa da Unichristus. Por fim atua como consultor na indústria da construção civil.

\section{Maikon Bridi}

Bacharel em Ciência da Computação (IFC-2017) pelo Instituto Federal Catarinense - Campus Videira, Técnico em soluções de impressão (Reis Office - 2016) com Certificado em Liderança, Inteligência Interpessoal e comunicação Eficaz (MASTER MIND LINCE - 2015). Possui experiência em manutenção de multifuncionais, softwares para gerenciamento de impressão e automação, configuração de redes e servidores. Atualmente trabalha como técnico na empresa MaqSistem.

\section{Marcelo Souza Nery}

Possui graduação em Ciência da Computação pela Pontifícia Universidade Católica de Minas Gerais (PUC Minas 2001), mestrado em Ciência da Computação pela Universidade Federal de Minas Gerais (UFMG 2004) e é doutorando em Ciência da Computação pela UFMG (2012 atual) na área de Inteligência Artificial (Jogos Digitais). Foi coordenador do curso de Sistemas de Informação da PUC Minas em Guanhães (2005 - 2008) e atualmente é coordenador da Graduação Tecnológica em Jogos Digitais da PUC Minas (2009 - atual). Sua área de atuação em pesquisa é em Jogos Digitais, Visão Computacional, Processamento de Imagens e Computação Gráfica. 


\section{Márcia de Fátima Morais}

Engenheira de Produção Agroindustrial pela Faculdade Estadual de Ciências e Letras de Campo Mourão (2002). Mestre em Engenharia (Engenharia de Produção) pela Universidade de São Paulo (2008). Doutoranda em Engenharia de Produção e Sistemas pela Universidade Pontifícia Católica do Paraná. Desenvolve pesquisas na linha Modelos de Apoio à Tomada de Decisão da área de concentração Gerência de Produção e Logística. Atualmente é professora assistente da Universidade Estadual do Paraná, Campus de Campo Mourão. Tem experiência na área de Engenharia de Produção, com ênfase em Pesquisa Operacional.

\section{Márcia Jussara Hepp Rehfeldt}

Professora graduada em Matemática, Mestrado em Administração e Doutorado em Informática pela Educação. Atua no Centro Universitário UNIVATES nos Mestrados em Ensino e Ensino de Ciências Exatas e em disciplinas na área da Matemática.

\section{Maria Helena Souza dos Santos}

Possui graduação em Administração pela Universidade do Extremo Sul Catarinense (2005); pós graduação em gestão da cadeia logística; mestranda em Desenvolvimento Socioeconômico -PPGDS- UNESC. Professora da Universidade do Extremo Sul Catarinense. Tem experiência na área de Administração e comércio exterior, atuando principalmente nos temas: termos internacionais, exportação, importação, logística internacional, logística reversa.

\section{Mario Eugenio de Paula Alves Bezerra}

Mestrando pelo Programa de Pós-Graduação em Trabalho, Saúde e Ambiente pela Fundacentro/SP. Realizou estágio nos Laboratório de Microscopia, Gravimetria e Difratometria de Raios-x e Instrumentação. Graduado em Engenharia de Produção pela Universidade Federal de Ouro Preto. Foi aluno do curso de Engenharia Industrial e Gestão na Faculdade de Engenharia da Universidade do Porto/Portugal no primeiro semestre de 2015, pelo programa de mobilidade acadêmica da CAINT/UFOP. Realizou estágio curricular em Gestão da Qualidade na Santa Casa de Misericórdia de Ouro Preto, no período de 05/03/2012 a 21/12/2012. Participou de treinamentos da consultora IAG Saúde, com ênfase implementação da norma ISO 9001.

\section{Mauricio João Atamanczuk}

Graduado em Administração pela Universidade Estadual do Centro-Oeste (2004), mestre em Engenharia de Produção pela Universidade Tecnológica Federal do Paraná (2009) e doutor em Administração pela Universidade Positivo (2016). Possui experiência profissional nas áreas de administração comercial e logística. Professor da Universidade Estadual do Centro-Oeste desde julho de 2005 atuando principalmente nas disciplinas de Administração da Produção e Logística. 


\section{Mehran Misaghi}

Bacharel em Informática pela Universidade do Vale do Rio dos Sinos (1995), mestre em Ciências da Computação pela Universidade Federal de Santa Catarina (2001) e doutor em Engenharia Elétrica pela Universidade de São Paulo (2008). Atualmente é professor de graduação e mestrado na Centro Universitário UNISOCIESC. Consultor e auditor de segurança da Moore Stephens Brasil. Pesquisador associado do Instituto de Pesquisa em Tecnologia e Inovação (IPTI-SP). Líder de Grupo de pesquisa em Segurança e Criptografia (GruSeC). Atua nas áreas relacionadas com a segurança da informação, especialmente em gestão e auditoria de sistemas, sistemas criptográficos baseado em identidade e sistemas de reputação em redes sociais.

\section{Natalia Luisa Felicio Macedo}

Doutoranda em Administração de Empresas pela Fundação Getúlio Vargas em São Paulo. Mestrado em Engenharia de Produção pela Universidade Federal de São Carlos e Graduada em Engenharia de Produção pela Universidade Federal de Ouro Preto. Atua como professora efetiva do curso de Engenharia de Produção na Universidade Federal de Ouro Preto.

\section{Natália Martins Gonçalves}

Doutora na Eberhard Karls Universität Tübingen, Alemanha, Faculdade de Ciências, área de Planejamento de transportes e desenvolvimento. Possui mestrado em Engenharia de Produção pela Universidade Federal de Santa Catarina (UFSC) e graduação em Ciências Econômicas pela Universidade Federal de Uberlândia (UFU). Tem experiência na área acadêmica como professora e pesquisadora; cooperação internacional; networking; desenvolvimento de negócios e projetos internacionais; MKT Internacional; transportes; logística; gestão pública e privada. É professora e pesquisadora na Universidade do Extremo Sul Catarinense e consultora em projetos da área pública e gestão empresarial.

\section{Nilton Fabiano Ribeiro}

É graduado em Engenharia de Produção pelo Centro Universitário de Itajubá - FEPI, e possui formação técnica em Telecomunicações pelo Centro de Educação Profissional de Itajubá CEP e Informática Industrial pelo SENAI, sendo neste último congratulado em 2009 pela FIEMG (Federação das Indústrias do Estado de Minas Gerais) como um dos destaques do curso no estado de Minas Gerais. Já atuou como coordenador de materiais em indústria de eletrônicos e fez parte de implementação do sistema de gestão da qualidade e preparação para certificação ISO 9001, também em empresa do mesmo ramo. Atualmente, atua como analista de planejamento de materiais e procurement e no PCP (Planejamento e Controle da Produção) em uma empresa do ramo de energia. 


\section{Paulo Rotela Junior}

Possui graduação em Computação pelo Centro Universitário de Itajubá (2007), graduação em Engenharia de Produção pelo Centro Universitário de Itajubá (2012), e pós-graduação MBA Executivo pela Universidade Federal de Itajubá (2010). Mestre em Engenharia de Produção pela Universidade Federal de Itajubá (2012) na linha de pesquisa Modelagem, Otimização e Controle. Doutor em Engenharia de Produção pela Universidade Federal de Itajubá (2015) na linha de pesquisa Modelagem e Otimização, tendo trabalhado com Otimização Robusta de Portfólios. Atualmente é professor na Universidade Federal da Paraíba, atuando principalmente nos seguintes temas: Finanças, Contabilidade Gerencial, Engenharia Econômica e Pesquisa Operacional.

\section{Priscila Pereira Suzart de Carvalho}

Engenheira de Produção formada pela Universidade Estadual de Santa Cruz (2009), mestra em Engenharia Industrial pela Universidade Federal da Bahia (2013) e doutoranda em Engenharia Industrial pela Universidade Federal da Bahia. Atualmente é professora e coordenadora do Curso de Engenharia de Produção da Universidade Estadual de Santa Cruz (UESC). Desenvolve trabalhos nas áreas de logística, gestão da cadeia de suprimentos, ergonomia, higiene e segurança do trabalho.

\section{Rodrigo Randow de Freitas}

Doutor em Ciências Agrárias pela Universidade Federal do Rio Grande (FURG), Bacharel em Administração: Ênfase em análises de sistemas pela Faculdade Ciências Humanas de Vitória (HUMANAS). Tem experiência como Professor de ensino superior desde 2006. Atualmente leciona no curso de graduação em Engenharia de Produção e pós-graduação em Gestão Pública, na Universidade Federal do Espírito Santo (UFES).

\section{Rodrigo Salvador}

Graduando em Engenharia de Produção pela Universidade Tecnológica Federal do Paraná (UTFPR). Instrutor de língua inglesa. Pesquisador nos temas Sustentabilidade, Avaliação do Ciclo de Vida (ACV) e Pesquisa Operacional (Laboratório de Estudos em Sistemas Produtivos Sustentáveis (LESP-UTFPR)). Participou da realização de projetos de pesquisa nas áreas de ACV, Inovação Tecnológica e Viabilidade Econômico-financeira. Possui experiência profissional nas áreas de engenharia de produção, gestão de processos, análise de dados e ensino de língua inglesa.

\section{Roger Poglia da Luz}

Mestre em Engenharia de Produção e Sistemas - UTFPR - 2014. Especialista - Gestão de Negócios e Logística - UTFPR - 2008. Graduado em Administração - UTFPR - 2007. Atua na área de Administração, com ênfase em Organizações Públicas, Gestão de Negócios, Logística, Administração de Materiais e Compras Públicas. Atua na Universidade Tecnológica Federal do Paraná - Campus Pato Branco, no cargo de Administrador, desde 2008. Pesquisa nas seguintes áreas: Engenharia de Produção, Ergonomia, Organização do Trabalho, Gestão Estratégica de Operações e Gestão de Operações Sustentáveis. 


\section{Rogério Martins de Azevedo}

Possui graduação em Engenharia de Produção pelo Centro Universitário de Itajubá - FEPI. Tem experiência em Gestão de Pessoas adquirida no período em que ocupou o cargo de Líder no setor de Refrigeração Industrial em uma Indústria do ramo alimentício localizada no Sul de Minas Gerais. Também aplicou treinamentos para colaboradores do setor sobre Fenômenos de Transporte, Termodinâmica e Elementos de Máquinas. Atualmente atua como Analista de PCP nessa mesma empresa.

\section{Rommel Souza da Silva}

Bacharel em Engenharia Civil pela Universidade Federal do Rio Grande do Norte (2008), especializado em Gestão e Tecnologia da Construção Civil pela Universidade Potiguar (2010) e Mestrando em Engenharia de Produção pela UNISOCIESC. Atualmente é Técnicoadministrativo em Educação (TAE) na Instituição Federal Catarinense - IFC. Atua nas áreas relacionadas com a Engenharia Civil; Leciona em órgãos público e privado; Desenvolve projetos da construção civil e gestão estratégica no IFC.

\section{Rony Peterson da Rocha}

Engenheiro de Produção Agroindustrial, pela Universidade Estadual do Paraná - Campus de Campo Mourão (2004). Doutor e Mestre em Engenharia Química - Modelagem e Otimização de Processos, pelo Programa de Pós Graduação em Engenharia de Química, Universidade Estadual de Maringá (UEM). Especialista em MBA em Gestão Empresarial e Especialista em Gestão Ambiental pela FECILCAM - Faculdade Estadual de Ciências e Letras de Campo Mourão. Professor Adjunto do Colegiado de Engenharia de Produção, Universidade Estadual do Paraná - Campus de Campo Mourão, Campo Mourão/PR. Pesquisador do Grupo de Estudos e Pesquisas em Processos e Gestão de Operações (GEPPGO). Coordenador do Curso de Engenharia de Produção Agroindustrial (2016-2017).

\section{Sergio Luiz Ribas Pessa}

Engenheiro Mecânico (UNISINOS - 1988). Mestre - Eng. e Ciência dos Materiais (UEPG 2005). Doutor em Eng. de Produção (UFRGS- 2010). Professor (UTFPR) nos cursos de Graduação: Tecnologia de Manutenção Industrial, Eng. Mecânica; Especializações: Eng. de Segurança do Trabalho, Eng. de Produção; Mestrado em Eng. de Produção e Sistemas. Pesquisa/atuação áreas: Manutenção industrial, Manutenção/Gestão e Avaliação de Frotas, Desenvolvimento de Materiais Compósitos Funcionais e Estruturais, Ergonomia e Segurança do Trabalho (Ageing e ICT), Ergonomia Ocupacional (Métodos e Gestão).

\section{Tassiana Cristina Dala Costa}

Fisioterapeuta, especialista em Fisioterapia do Trabalho e Ergonomia pela Esab, atuando na área de Fisioterapia do Trabalho, realizando atividades como Consultoria e Acessoria em Ergonomia, Ginástica Laboral, Palestras, Avaliações admissionais/demissionais e periódicas, Análise Ergonômica do Trabalho e Reabilitação nas diversas áreas da Fisioterapia. 


\section{Thiago Crestani}

Bacharel em Ciência da Computação (IFC-2015) e Técnico em Informática (IFC-2012) pelo e Instituto Federal Catarinense - Campus Videira com Pós-graduação em Tecnologias para Aplicações Web (UNOPAR-2017) pela Universidade Norte do Paraná. Tem experiência em desenvolvimento de sistemas e gerenciamento de banco de dados. Atualmente trabalha desenvolvedor de softwares jurídicos no setor privado.

\section{Thiago Francisco de Souza}

Possui graduação em Engenharia de Produção e Sistemas e mestrado em Ciência, Inovação e Modelagem em Materiais, pela Universidade Estadual de Santa Cruz (UESC/ILhéus-BA). Atualmente professor assistente (dedicação exclusiva) do curso de Engenharia de Produção na Universidade Estadual de Santa Cruz - UESC

\section{Wellington Gonçalves}

Doutor em Engenharia de Produção pela Universidade Metodista de Piracicaba (UNIMEP), Bacharel em Administração pela Faculdade de Nova Venécia (UNIVEN). Tem experiência como Professor de ensino médio/técnico. Professor do ensino superior desde 2000. Atualmente leciona no curso de Engenharia de Produção da Universidade Federal do Espírito Santo (UFES). 
Agência Brasileira do ISBN

ISBN 978-85-93729-21-8

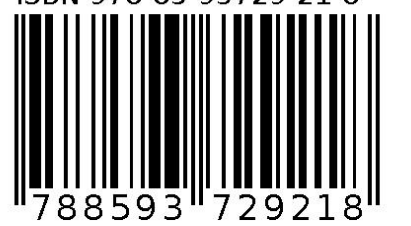

